\title{
Individual optimisation of contrast media application and radiation dose in computed tomographic angiography
}

Citation for published version (APA):

Kok, M. (2016). Individual optimisation of contrast media application and radiation dose in computed tomographic angiography: from phantom to patient. [Doctoral Thesis, Maastricht University]. Maastricht University. https://doi.org/10.26481/dis.20161118mk

Document status and date:

Published: 01/01/2016

DOI:

10.26481/dis.20161118mk

Document Version:

Publisher's PDF, also known as Version of record

\section{Please check the document version of this publication:}

- A submitted manuscript is the version of the article upon submission and before peer-review. There can be important differences between the submitted version and the official published version of record.

People interested in the research are advised to contact the author for the final version of the publication, or visit the DOI to the publisher's website.

- The final author version and the galley proof are versions of the publication after peer review.

- The final published version features the final layout of the paper including the volume, issue and page numbers.

Link to publication

\footnotetext{
General rights rights.

- You may freely distribute the URL identifying the publication in the public portal. please follow below link for the End User Agreement:

www.umlib.nl/taverne-license

Take down policy

If you believe that this document breaches copyright please contact us at:

repository@maastrichtuniversity.nl

providing details and we will investigate your claim.
}

Copyright and moral rights for the publications made accessible in the public portal are retained by the authors and/or other copyright owners and it is a condition of accessing publications that users recognise and abide by the legal requirements associated with these

- Users may download and print one copy of any publication from the public portal for the purpose of private study or research.

- You may not further distribute the material or use it for any profit-making activity or commercial gain

If the publication is distributed under the terms of Article 25fa of the Dutch Copyright Act, indicated by the "Taverne" license above, 
Individual Optimisation of Contrast Media Application and Radiation dose in Computed Tomographic Angiography From Phantom to Patient

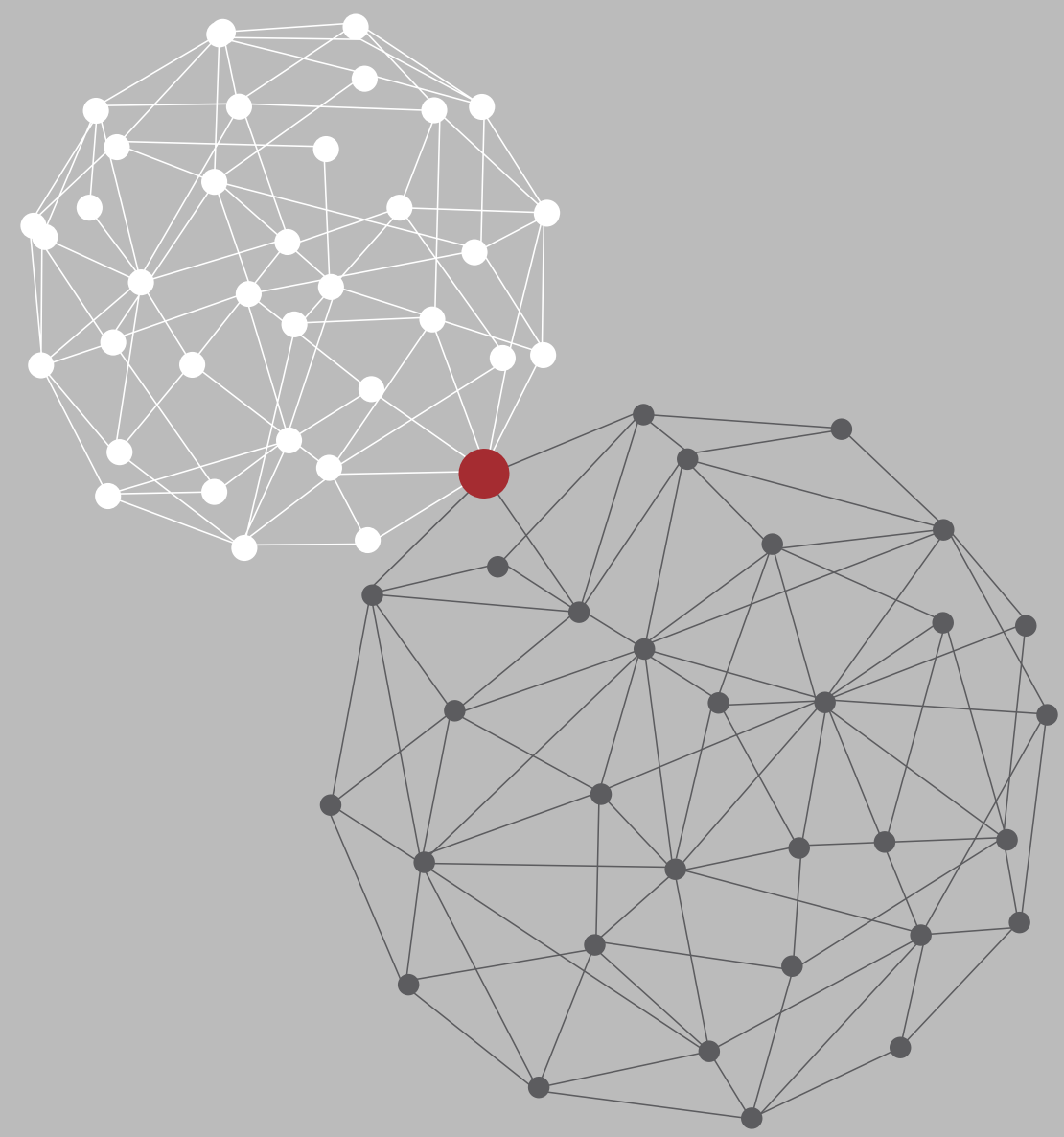

MADELEINE KOK 



\title{
Individual Optimisation of Contrast Media Application and Radiation Dose in Computed Tomographic Angiography;
}

\section{From Phantom to Patient}

\author{
PROEFSCHRIFT \\ Ter verkrijging van de graad van doctor \\ aan de Universiteit Maastricht, \\ op gezag van de Rector Magnificus, Prof. dr. Rianne M. Letschert, \\ volgens het besluit van het College van Decanen, \\ in het openbaar te verdedigen op \\ vrijdag 18 november 2016 om 12.00 uur \\ door \\ Madeleine Kok \\ Geboren op 30 april 1988 te Amsterdam
}




\section{Promotor}

Prof. dr. J.E. Wildberger

\section{Copromotoren}

Dr. M. Das

Dr. B.L.J.H. Kietselaer

\section{Beoordelingscommissie}

Prof. dr. H.J.G.M Crijns, voorzitter

Dr. C.R. Jeukens

Prof. dr. T. Leiner (Universitair Medisch Centrum Utrecht)

Prof. dr. F.W. Prinzen

Prof. dr. R. Vliegenthart (Universitair Medisch Centrum Groningen) 


\section{CONTENTS}

CHAPTER 2 Influence of contrast media on viscosity and temperature on injection pressure in computed tomographic angiography: a phantom study.

CHAPTER 3 Automated kVp selection for radiation dose reduction in CTA - is it independent from contrast media concentration?

CHAPTER 4 Optimising contrast media application in coronary CT angiography at lower tube voltage: evaluation in a circulation phantom and sixty patients

CHAPTER 5 Individually tailored contrast enhancement in CT pulmonary angiography

CHAPTER 6 Low contrast media volume in pre-TAVI CT examinations

CHAPTER 7 Individualised CT angiography protocols for the evaluation of the aorta: A feasibility study

CHAPTER 8 General Discussion

CHAPTER 9

9.2 Valorisation 159

9.3 Dankwoord 163

9.4 Curriculum vitae 169

9.5 List of publications 



\section{CHAPTER 1}

General introduction 


\section{COMPUTED TOMOGRAPHIC ANGIOGRAPHY}

Computed tomographic angiography (CTA) is an imaging method which is widely used as a diagnostic tool for the visualisation and evaluation of vascular structures such as carotid arteries, the circle of Willis, pulmonary arteries, coronary arteries, the thoracic and abdominal aorta as well as peripheral arteries.

CTA technology has undergone many changes in the past two decades; especially the advent of multidetector-row CT (MDCT) with high spatial and temporal resolution, wider detector coverage, increased rotation speed and iterative reconstruction (IR) improved image quality, resulting in improved visualisation of these various vascular structures. $^{1-10}$

\section{IMAGE QUALITY}

Reasonable image quality is the prerequisite for optimal diagnostic accuracy. Image quality of a CTA depends on a combination of the degree of intravascular enhancement, image noise and the presence of artefacts. Even with technical advances of $\mathrm{MDCT}$, image quality is still subject to changes by aforementioned factors since they are influenced by different parameters: contrast media (CM) characteristics, injection parameters, scan technique and patient related factors. ${ }^{11-14}$ Figure $\mathbf{1 . 1}$ shows the different factors influencing image quality in CTA. 


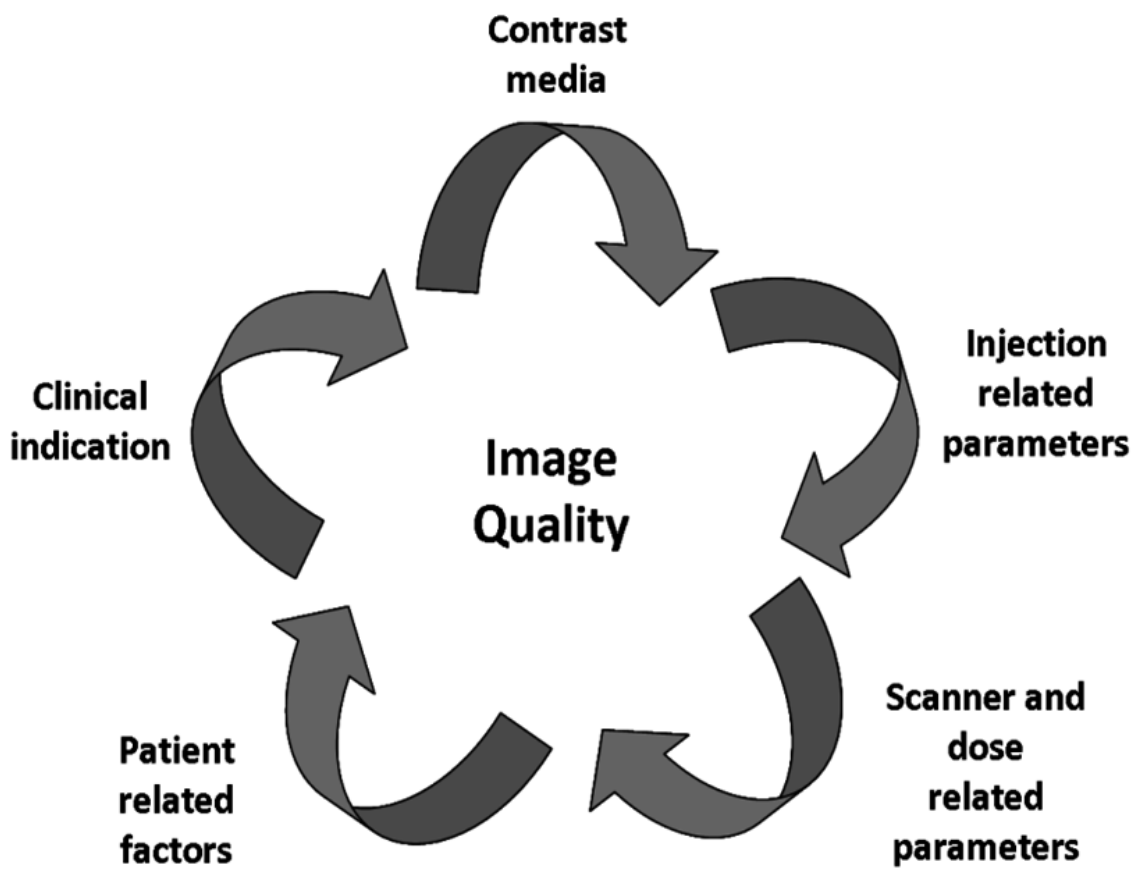

Figure 1.1 influencing factors on image quality for CTA

\section{AND INJECTION RELATED FACTORS}

Previous studies have already investigated the influence of iodine concentration, injection rates and iodine delivery rate (IDR) on diagnostic intravascular enhancement. ${ }^{15-22}$ The influence of the iodine concentration on arterial enhancement has led to contradictory statements in the literature. In coronary arteries, publications have mainly stated that the use of higher concentrated CM significantly increases arterial attenuation compared to the use of lower CM concentrations. ${ }^{21,23}$ However, the IDR and total iodine load (TIL) in those studies were variable. In turn, other studies showed that the use of low and high CM concentrations will result in comparable arterial enhancement, when using an identical IDR and TIL. ${ }^{20,22}$

Another important $\mathrm{CM}$ characteristic is viscosity - as the viscosity of $\mathrm{CM}$ is relatively high and consequently increases the viscosity of blood plasma. ${ }^{24}$

Viscosity plays an important role in $\mathrm{CM}$ delivery, as viscosity is directly influenced by temperature, meaning viscosity decreases with increasing temperature. ${ }^{16,25-27}$ On the other hand, viscosity increases with higher iodine concentration of CM. Low viscosity 
could be beneficial in terms of lower injection pressure and therefore higher injection rates might be accepted.

Higher injection rates, in turn, might be advantageous in CTA if high intravascular enhancement is required. This can be achieved by higher IDR - defined as the factor of flow rate and $\mathrm{CM}$ concentration $[\mathrm{gl} / \mathrm{s}] .{ }^{12,22} \mathrm{~A}$ high IDR can be achieved by using either a standard concentrated $\mathrm{CM}$ at a relatively high injection rate or a highly concentrated $\mathrm{CM}$ at a lower injection rate.

\section{SCAN RELATED FACTORS}

The scan protocol also has an influence on image quality; scan parameters influence intravascular enhancement, image noise and the presence of artefacts. For example, lowering tube voltage $[\mathrm{kVp}]$ in CTA increases the degree of vascular contrast enhancement. ${ }^{28-30}$ This is explained by the fact that lower tube voltage translates into lower effective photon energy (effective photon energy being approximately half the $k V p$ ), bringing the latter closer to the K-edge of lodine $(33.2 \mathrm{keV}) .{ }^{31,}{ }^{32}$ Higher intravascular enhancement may increase the signal-to-noise ratio (SNR) since image noise remains constant at normalised dose settings. However, if lower tube voltages are used without concordantly increasing tube-current-time product settings [mAs], the reduced radiation dose exposure will result in increased image noise and invariably the SNR will decrease. Therefore, selecting scan parameters such as tube voltage and tube-currenttime product can be very complex and must be adjusted to the clinical indication as well as to the patient's anatomy.

In addition, new reconstruction technologies such as IR reduce image noise and improve image quality in comparison to routinely used filtered back projection (FBP) ${ }^{33-36}$, which may help to maintain diagnostic image quality whilst using reduced radiation dose.

\section{PATIENT RELATED FACTORS}

With respect to patient's anatomy, the level of intravascular enhancement decreases with increased body weight due to increased circulating blood volume and cardiac output. This correlation was found to be clinically significant, as well as the correlation between intravascular enhancement and body mass index (BMI). ${ }^{12}{ }^{37}$ Higher body weight also significantly decreases SNR compared to lower body weight, due to the fact that there is more absorbing tissue in the scan range. ${ }^{30}$ In obese patients, body surface area $\left[\mathrm{kg}^{0.65}\right]^{38}$ and lean body weight (weight other than fat) should also be considered, as these patients have a high proportion of body fat and a relatively small blood volume and proportionally a small well-perfused extracellular compartment. ${ }^{12}$ 
Furthermore, the presence of prosthesis materials or stent-grafts in patients will more frequently result in artefacts when lower kVp settings are used.

\section{CLINICAL INDICATION}

Several above described factors are determined by the clinical indication for CTA. For example, different vascular structures will be imaged using a particular scan acquisition protocol resulting in specific scan duration. Logically, the scan duration may influence the injection time and injection parameters need to be adapted accordingly. Nowadays it is possible to perform a coronary CTA (CCTA) or CT pulmonary angiography (CTPA) in $1-2$ seconds only. This requires sharp bolus timing and a smaller CM bolus might be feasible. On the other hand, performing CTA of the entire aorta or even combined CTA acquisitions (e.g. coronary arteries + entire aorta) will increase the scan duration making optimal bolus timing at each level more challenging; a longer injection duration is required to ensure that the $\mathrm{CM}$ bolus will not run out during the scan.

A different minimum degree of intravascular enhancement is required for each vascular structure. For example, the required enhancement for pulmonary arteries is about 180 Hounsfield Units $[\mathrm{HU}]^{39}$, whereas the required degree for the aorta and coronary arteries is $200-250 \mathrm{HU}^{40,41}$ and $325 \mathrm{HU}$, respectively. ${ }^{42}$ Thus, the optimal intravascular enhancement degree is related to the particular vascular structure and the underlying clinical indication.

Furthermore, various clinical indications also include diversity in differential diagnosis within the same vascular structure. For example, in patients referred for transcatheter aortic valve implantation (TAVI), a CTA aorta will be performed and optimal image quality - meaning high enhancement and low image noise - is required at the level of the ascending aorta only, in order to ensure adequate assessment of aortic root dimensions for different time points within the cardiac cycle. For the evaluation of peripheral access higher noise levels are acceptable as treatment requires information regarding vessel diameters and extent of calcifications. For other indications of CTA aorta; bleeding, dissection or stenosis of the smaller branches such as the renal arteries, low image noise levels are recommended.

\section{DRAWBACKS FOR CTA}

Although CTA has some advantages over other image modalities, there are also potential drawbacks for CTA. These potential drawbacks include the administration of iodinated CM - which may cause allergic reactions or contrast induced nephropathy (CIN). Previous investigation found that CIN occurs in $>10 \%$ of patients who undergo contrast enhanced $\mathrm{CT}$ in the outpatient setting and is associated with a significant risk 
for severe renal failure and death. ${ }^{44}$ In this respect, contrast volume has been identified as most important risk factor on $\mathrm{CIN}^{43,44}$

Furthermore, the use of ionising radiation dose can lead to induction of point mutations, chromosomal translocations, and gene fusions, which are all linked to the induction of cancer. Although the individual risk estimates are small, the concern about the risks from CT is mostly related to the rapid increase in its use. On the basis of risk on CT use from 1991 through 1996, it has been estimated that about $0.4 \%$ of all cancers in the United States may be attributable to the radiation from CT studies. By adjusting the estimate ten years later, this estimate was increased four to five times already. ${ }^{46}$ Therefore, the reduction of radiation exposure to the patient during $C T$ is one of the most important requirements of the as low as reasonably achievable (ALARA) principle. $^{45-48}$

\section{OUTLINE OF THE THESIS}

CTA is widely used as a diagnostic tool for different vascular diseases. With the advances in knowledge on all above stated self-contained factors influencing image quality of CTA, the most challenging part is to efficiently combine these factors in order to ensure optimal image quality while providing the opportunity to reduce radiation dose and $\mathrm{CM}$ volume. Therefore, we attempted to individually adapt injection and scan parameters in CTA for different clinical indications.

Chapter 2 provides insight in the relationship between different CM characteristics, namely $\mathrm{CM}$ concentration and viscosity. In addition, the influence of viscosity on injection parameters - and especially injection pressure - during coronary CTA was investigated using a circulation phantom.

Chapter 3 explores the relationship between CM characteristics, injection parameters, radiation dose and image quality in general CTA using a circulation phantom. The potential for automated $\mathrm{kVp}$-selection to reduce the radiation dose during CTA using different concentrated CM - normalised to an identical IDR - was evaluated.

Chapter 4 investigates how scan parameters - especially kVp settings - influence the intravascular enhancement in CTA. A circulation phantom was used to systematically investigate how IDR and CM volume can be adapted to a particular kVp setting in order to obtain optimal enhancement levels. Based on these primary results, the concept was clinically tested in sixty patients referred for CCTA. 
Chapter 5 studies the effect on image quality when using body weight adapted injections in patients referred for CTPA. The benefits of individualised CM protocols for patients of different body sizes were investigated. We hypothesised that the use of a standard CM protocol with fixed parameters could more often result in enhancement levels below diagnostic level for heavier patients, whereas these enhancement levels may be higher than required for smaller patients.

Chapter 6 elaborates on the role of individual adaptation of both injection and scan protocols in patients referred for pre-TAVI CT examination. These patients frequently suffer from an impaired renal function, which enhances the importance of CM reduction. However, in order to ensure technical success and optimal valve-prosthesis sizing, dedicated scan technique including reliable CM injection protocols are of utmost importance providing optimal filling at the level of the aortic root as well as the peripheral arteries. Our purpose was to evaluate the possibility of reducing CM volumes while using lower kVp settings in combination with IR.

Chapter 7 studies the possibility of reducing radiation dose exposure and $\mathrm{CM}$ volume in patients referred for the standard evaluation of the aorta, without compromising image quality. Aortic CTA is associated with frequent follow-up over time, which implies high cumulative radiation dose and iodinated $\mathrm{CM}$ volumes for these patients. Therefore, we investigated the effect on radiation dose exposure and $\mathrm{CM}$ volume of individualised scan and injection protocols and compared these to current protocols using fixed parameters.

Chapter 8 contains the general discussion on the relationship between all factors influencing image quality in CTA as mentioned by all above stated manuscripts, as well as future perspectives on this topic. 


\section{REFERENCES}

1. Meyer M, Haubenreisser H, Schoepf UJ, Vliegenthart R, Leidecker C, Allmendinger T, Lehmann R, Sudarski S, Borggrefe $M$, Schoenberg SO and Henzler T. Closing in on the $\mathrm{K}$ edge: coronary $\mathrm{CT}$ angiography at 100,80 , and $70 \mathrm{kV}$-initial comparison of a second- versus a third-generation dualsource CT system. Radiology. 2014;273:373-82.

2. Alexander SA and Rubin GD. Imaging the thoracic aorta: anatomy, technical considerations, and trauma. Seminars in roentgenology. 2009;44:8-15.

3. Einstein AJ. Effects of radiation exposure from cardiac imaging: how good are the data? Journal of the American College of Cardiology. 2012;59:553-65.

4. Stolzmann P, Leschka S, Scheffel H, Krauss T, Desbiolles L, Plass A, Genoni M, Flohr TG, Wildermuth S, Marincek B and Alkadhi H. Dual-source CT in step-and-shoot mode: noninvasive coronary angiography with low radiation dose. Radiology. 2008;249:71-80.

5. Achenbach S, Goroll T, Seltmann M, Pflederer T, Anders K, Ropers D, Daniel WG, Uder M, Lell M and Marwan M. Detection of coronary artery stenoses by low-dose, prospectively ECG-triggered, high-pitch spiral coronary CT angiography. JACC Cardiovascular imaging. 2011;4:328-37.

6. Lell M, Marwan M, Schepis T, Pflederer T, Anders K, Flohr T, Allmendinger T, Kalender W, Ertel D, Thierfelder C, Kuettner A, Ropers D, Daniel WG and Achenbach S. Prospectively ECG-triggered high-pitch spiral acquisition for coronary CT angiography using dual source CT: technique and initial experience. European radiology. 2009;19:2576-83.

7. Yin WH, Lu B, Li N, Han L, Hou ZH, Wu RZ, Wu YJ, Niu HX, Jiang SL, Krazinski AW, Ebersberger U, Meinel FG and Schoepf UJ. Iterative reconstruction to preserve image quality and diagnostic accuracy at reduced radiation dose in coronary CT angiography: an intraindividual comparison. JACC Cardiovascular imaging. 2013;6:1239-49.

8. Ghaye B, Szapiro D, Mastora I, Delannoy V, Duhamel A, Remy J and Remy-Jardin M. Peripheral pulmonary arteries: how far in the lung does multi-detector row spiral CT allow analysis? Radiology. 2001;219:629-36.

9. Patel S, Kazerooni EA and Cascade PN. Pulmonary embolism: optimization of small pulmonary artery visualization at multi-detector row CT. Radiology. 2003;227:455-60.

10. Remy-Jardin M, Remy J, Wattinne L and Giraud F. Central pulmonary thromboembolism: diagnosis with spiral volumetric CT with the single-breath-hold technique--comparison with pulmonary angiography. Radiology. 1992;185:381-7.

11. Bae KT, Tran HQ and Heiken JP. Uniform vascular contrast enhancement and reduced contrast medium volume achieved by using exponentially decelerated contrast material injection method. Radiology. 2004;231:732-6.

12. Bae KT. Intravenous contrast medium administration and scan timing at CT: considerations and approaches. Radiology. 2010;256:32-61.

13. Johnson PT, Pannu HK and Fishman EK. IV contrast infusion for coronary artery CT angiography: literature review and results of a nationwide survey. AJR Am J Roentgenol. 2009;192:W214-21.

14. Awai $\mathrm{K}$, Hiraishi $\mathrm{K}$ and Hori S. Effect of contrast material injection duration and rate on aortic peak time and peak enhancement at dynamic CT involving injection protocol with dose tailored to patient weight. Radiology. 2004;230:142-50.

15. Behrendt FF, Bruners P, Keil S, Plumhans C, Mahnken AH, Stanzel S, Das M, Gunther RW and Muhlenbruch G. Impact of different vein catheter sizes for mechanical power injection in CT: in vitro evaluation with use of a circulation phantom. Cardiovasc Intervent Radiol. 2009;32:25-31.

16. Cademartiri F, Mollet NR, van der Lugt A, McFadden EP, Stijnen T, de Feyter PJ and Krestin GP. Intravenous contrast material administration at helical 16-detector row CT coronary angiography: effect of iodine concentration on vascular attenuation. Radiology. 2005;236:661-5.

17. Nance JW, Jr., Henzler T, Meyer M, Apfaltrer P, Braunagel M, Krissak R, Schoepf UJ, Schoenberg SO and Fink C. Optimization of contrast material delivery for dual-energy computed tomography 
pulmonary angiography in patients with suspected pulmonary embolism. Invest Radiol. 2012;47:78-84.

18. Rist C, Nikolaou K, Kirchin MA, van Gessel R, Bae KT, von Ziegler F, Knez A, Wintersperger BJ, Reiser MF and Becker CR. Contrast bolus optimization for cardiac 16-slice computed tomography: comparison of contrast medium formulations containing 300 and 400 milligrams of iodine per milliliter. Invest Radiol. 2006;41:460-7.

19. Behrendt FF, Pietsch H, Jost G, Palmowski M, Gunther RW and Mahnken AH. Identification of the iodine concentration that yields the highest intravascular enhancement in MDCT angiography. AJR Am J Roentgenol. 2013;200:1151-6.

20. Muhlenbruch G, Behrendt FF, Eddahabi MA, Knackstedt C, Stanzel S, Das M, Seidensticker P, Gunther RW, Wildberger JE and Mahnken AH. Which lodine concentration in chest CT?--a prospective study in 300 patients. European radiology. 2008;18:2826-32.

21. Cademartiri F, de Monye C, Pugliese F, Mollet NR, Runza G, van der Lugt A, Midiri M, de Feyter PJ, Lagalla R and Krestin GP. High iodine concentration contrast material for noninvasive multislice computed tomography coronary angiography: iopromide 370 versus iomeprol 400 . Investigative radiology. 2006;41:349-53.

22. Mihl C, Wildberger JE, Jurencak T, Yanniello MJ, Nijssen EC, Kalafut JF, Nalbantov G, Muhlenbruch G, Behrendt FF and Das M. Intravascular enhancement with identical iodine delivery rate using different iodine contrast media in a circulation phantom. Investigative radiology. 2013;48:813-8.

23. Cademartiri F, Mollet NR, Lemos PA, Saia F, Midiri M, de Feyter PJ and Krestin GP. Higher intracoronary attenuation improves diagnostic accuracy in MDCT coronary angiography. AJR American journal of roentgenology. 2006;187:W430-3.

24. Reinhart WH, Pleisch B, Harris LG and Lutolf $M$. Influence of contrast media (iopromide, ioxaglate, gadolinium-DOTA) on blood viscosity, erythrocyte morphology and platelet function. Clinical hemorheology and microcirculation. 2005;32:227-39.

25. Halsell RD. Heating contrast media in a microwave oven. Radiology. 1987;163:279-80.

26. Schwab SA, Kuefner MA, Anders K, Adamietz B, Heinrich MC, Baigger JF, Janka R, Uder M and Kramer M. Peripheral intravenous power injection of iodinated contrast media: the impact of temperature on maximum injection pressures at different cannula sizes. Acad Radiol. 2009;16:1502-8.

27. Schwab SA, Uder M, Anders K, Heinrich MC and Kuefner MA. Peripheral intravenous power injection of iodinated contrast media through $22 \mathrm{G}$ and $20 \mathrm{G}$ cannulas: can high flow rates be achieved safely? A clinical feasibility study. Rofo. 2009;181:355-61.

28. Funama Y, Awai K, Nakayama Y, Kakei K, Nagasue N, Shimamura M, Sato N, Sultana S, Morishita S and Yamashita $Y$. Radiation dose reduction without degradation of low-contrast detectability at abdominal multisection CT with a low-tube voltage technique: phantom study. Radiology. 2005;237:905-10.

29. Huda W, Scalzetti EM and Levin G. Technique factors and image quality as functions of patient weight at abdominal CT. Radiology. 2000;217:430-5.

30. Nakayama Y, Awai K, Funama Y, Hatemura M, Imuta M, Nakaura T, Ryu D, Morishita S, Sultana S, Sato $\mathrm{N}$ and Yamashita $\mathrm{Y}$. Abdominal $\mathrm{CT}$ with low tube voltage: preliminary observations about radiation dose, contrast enhancement, image quality, and noise. Radiology. 2005;237:945-51.

31. Mahesh M. MDCT physics: the basics: technology, image quality and radiation dose. 1st ed. ed. Philadelphia: Lippincott Williams and Wilkins; 2009.

32. Brooks RA. A quantitative theory of the Hounsfield unit and its application to dual energy scanning. Journal of computer assisted tomography. 1977;1:487-93.

33. Pontana F, Pagniez J, Duhamel A, Flohr T, Faivre JB, Murphy C, Remy J and Remy-Jardin M. Reduced-dose low-voltage chest CT angiography with Sinogram-affirmed iterative reconstruction versus standard-dose filtered back projection. Radiology. 2013;267:609-18.

34. Wang R, Schoepf UJ, Wu R, Reddy RP, Zhang C, Yu W, Liu Y and Zhang Z. Image quality and radiation dose of low dose coronary $\mathrm{CT}$ angiography in obese patients: sinogram affirmed 
iterative reconstruction versus filtered back projection. European journal of radiology. 2012;81:3141-5.

35. Korn A, Bender B, Fenchel M, Spira D, Schabel C, Thomas C, Flohr T, Claussen CD, Bhadelia R, Ernemann $U$ and Brodoefel $H$. Sinogram affirmed iterative reconstruction in head $C T$ : improvement of objective and subjective image quality with concomitant radiation dose reduction. European journal of radiology. 2013;82:1431-5.

36. Baker ME, Dong F, Primak A, Obuchowski NA, Einstein D, Gandhi N, Herts BR, Purysko A, Remer E and Vachhani N. Contrast-to-noise ratio and low-contrast object resolution on full- and low-dose MDCT: SAFIRE versus filtered back projection in a low-contrast object phantom and in the liver. AJR American journal of roentgenology. 2012;199:8-18.

37. Schoellnast $H$, Deutschmann HA, Berghold A, Fritz GA, Schaffler GJ and Tillich M. MDCT angiography of the pulmonary arteries: influence of body weight, body mass index, and scan length on arterial enhancement at different iodine flow rates. AJR American journal of roentgenology. 2006;187:1074-8.

38. Livingston EH and Lee S. Body surface area prediction in normal-weight and obese patients. American journal of physiology Endocrinology and metabolism. 2001;281:E586-91.

39. Delesalle MA, Pontana F, Duhamel A, Faivre JB, Flohr T, Tacelli N, Remy J and Remy-Jardin M. Spectral optimization of chest CT angiography with reduced iodine load: experience in 80 patients evaluated with dual-source, dual-energy CT. Radiology. 2013;267:256-66.

40. Bae KT. Optimization of contrast enhancement in thoracic MDCT. Radiologic clinics of North America. 2010;48:9-29.

41. Weininger M, Barraza JM, Kemper CA, Kalafut JF, Costello P and Schoepf UJ. Cardiothoracic CT angiography: current contrast medium delivery strategies. AJR American journal of roentgenology. 2011;196:W260-72.

42. Isogai T, Jinzaki M, Tanami Y, Kusuzaki H, Yamada M and Kuribayashi S. Body weight-tailored contrast material injection protocol for 64-detector row computed tomography coronary angiography. Japanese journal of radiology. 2011;29:33-8.

43. Mehran R and Nikolsky E. Contrast-induced nephropathy: definition, epidemiology, and patients at risk. Kidney international Supplement. 2006:S11-5.

44. Mitchell AM, Jones AE, Tumlin JA, Kline JA. Incidence of contrast-induced nephropathy after contrast-enhanced computed tomography in the outpatient setting. Clinical journal of the American Society of Nephrology : CJASN. 2010;5:4-9.

45. Brody AS, Frush DP, Huda W, Brent RL and American Academy of Pediatrics Section on R. Radiation risk to children from computed tomography. Pediatrics. 2007;120:677-82.

46. Brenner DJ and Hall EJ. Computed tomography--an increasing source of radiation exposure. The New England journal of medicine. 2007;357:2277-84.

47. Keil S, Behrendt FF, Stanzel S, Suhling M, Koch A, Bubenzer J, Muhlenbruch G, Mahnken AH, Gunther RW and Das M. Semi-automated measurement of hyperdense, hypodense and heterogeneous hepatic metastasis on standard MDCT slices. Comparison of semi-automated and manual measurement of RECIST and WHO criteria. European radiology. 2008;18:2456-65.

48. Schenzle JC, Sommer WH, Neumaier K, Michalski G, Lechel U, Nikolaou K, Becker CR, Reiser MF and Johnson TR. Dual energy CT of the chest: how about the dose? Investigative radiology. 2010;45:347-53. 




\section{CHAPTER 2}

\section{Influence of contrast media on viscosity and}

temperature on injection pressure in computed tomographic angiography: a phantom study.

Kok M, Mihl C, Mingels AM, Kietselaer BLJH, Mühlenbruch G, Seehofnerova A, Wildberger JE, Das M.

Investigative Radiology 2014 Apr; 49(4):217-23. 


\begin{abstract}
Purpose

lodinated contrast media (CM) in CT angiography (CTA) is characterised by its concentration and consecutively by its viscosity. Viscosity itself is directly influenced by temperature, which will furthermore have an impact on injection pressure. Therefore, the purpose of this study was to systematically evaluate the viscosity of different $\mathrm{CM}$ at different temperatures and to assess their impact on injection pressure in a circulation phantom.
\end{abstract}

\title{
Methods and materials
}

Initially viscosity of different contrast media concentrations $(240,300,370$ and $400 \mathrm{mgl} / \mathrm{ml})$ was measured at different temperatures $\left(20^{\circ} \mathrm{C}-40^{\circ} \mathrm{C}\right)$ with a commercially available viscosimeter. In the next step a circulation phantom with physical conditions was used. Contrast media was prepared at different temperatures $\left(20^{\circ} \mathrm{C}, 30^{\circ} \mathrm{C}, 37^{\circ} \mathrm{C}\right)$ and injected through a standard $18 \mathrm{G}$ needle. All other relevant parameters were kept constant (iodine delivery rate IDR=1.9gl/s: total amount of iodine=15gl). Peak flow rate $[\mathrm{ml} / \mathrm{s}]$ and injection pressure [psi] were monitored. Significance differences were tested by the Kruskal-Wallis test (SPSS).

\section{Results}

Viscosities for iodinated $\mathrm{CM}$ of $240,300,370$ and $400 \mathrm{mgl} / \mathrm{ml}$ at $20^{\circ} \mathrm{C}$ were $5.1,9.1$, 21.2 , and $28.8 \mathrm{mPa}$.s, respectively, while at $40^{\circ} \mathrm{C}$ these were substantially lower (2.8, $4.4,8.7$, and $11.2 \mathrm{mPa} . \mathrm{s}$ ). In the circulation phantom, peak pressures (mean $\pm \mathrm{SD}$ ) for $\mathrm{CM}$ $240 \mathrm{mgl} / \mathrm{ml}$ at $20^{\circ} \mathrm{C}, 30^{\circ} \mathrm{C}$, and $37^{\circ} \mathrm{C}$ were $107 \pm 1.5,95 \pm 0.6,92 \pm 2.1 \mathrm{psi} ; \mathrm{CM} 300 \mathrm{mgl} / \mathrm{ml}$ : $119 \pm 1.5,104 \pm 0.6,100 \pm 3.6 \mathrm{psi} ; \mathrm{CM} 370 \mathrm{mgl} / \mathrm{ml} 150 \pm 0.6,133 \pm 4.4,120 \pm 3.5 \mathrm{psi}$; and CM $400 \mathrm{mgl} / \mathrm{ml} 169 \pm 1.0,140 \pm 2.1,135 \pm 2.9$ psi respectively, with all $p$-values $<0.05$.

\section{Conclusion}

Low concentration, low viscosity and high temperatures of CM are beneficial in terms of injection pressure. This should also be considered for individual tailored contrast protocols in daily routine scanning. 


\section{INTRODUCTION}

The quality of computed tomography angiography (CTA) and especially coronary computed tomography angiography (CCTA) depends utmost on the degree of intravascular enhancement. Sufficient vessel attenuation is crucial for proper evaluation of vascular pathology, especially with respect to smaller vessels. ${ }^{1}$ Enhancement characteristics are influenced by scan technique, patient related factors, contrast media (CM) characteristics as well as injection parameters. ${ }^{2-5}$ Previous studies already investigated the influence of iodine concentration, injection rates and iodine delivery rate (IDR) on diagnostic intravascular attenuation. ${ }^{1,6-12}$

Another factor that plays an important role in CM delivery and thus enhancement is viscosity. Viscosity is directly influenced by temperature, which means viscosity decreases with increasing temperature. ${ }^{7,13-16}$

On the other hand, viscosity of $\mathrm{CM}$ increases with higher iodine concentrations. Low viscosity will be advantageous in several ways: Injection pressure is lower and CM distribution in the blood might be facilitated. This can potentially be advantageous for the visualisation of distal vessel segments. ${ }^{2,6}$ However, this comes at the expenditure of higher flow rates when an identical IDR has to be maintained. Only few studies investigated differences in injection pressure with different injection protocols. ${ }^{1,17}$

Literature about $\mathrm{CM}$ characteristics and injection parameters remains heterogeneous and controversial. Intravascular attenuation will not significantly change with iodine concentration in a standardised setting. ${ }^{11}$ Thus, the purpose of this study was to evaluate different $\mathrm{CM}$ with different iodine concentrations in a standardised manner at different temperatures and to further investigate its influence on injection parameters, with special regard to injection pressure.

\section{METHODS AND MATERIALS}

\section{Viscosity analysis}

Viscosity was measured in a standard lab environment as depicted in figure 2.1, using a commercially available viscosimeter (Ostwald viscosimeter; Julabo $\mathrm{GmbH}$, Seelbach, Germany). Monomeric non-ionic and low-osmolar CM were used (iopromide 240, 300, 370 [Ultravist; Bayer Healthcare, Berlin, Germany] and iomeprol 400 [Iomeron; Bracco Imaging, Milan, Italy]) containing 240, 300, 370, and 400 mgl/ml, respectively. CM was warmed up in a standardised and controllable fashion in a water bath, which was immediately followed by loading the u-tube of the viscosimeter with $2 \mathrm{ml} \mathrm{CM}$. The measurements were performed between $20^{\circ} \mathrm{C}$ and $40^{\circ} \mathrm{C}$ with steps of two degrees centigrade. All measurements were repeated two times to determine reproducibility. 
Kinematic viscosity $\left[\mathrm{mm}^{2} / \mathrm{s}\right]$ was defined by multiplying the constant of the u-tube with the exact time that was required for each $\mathrm{CM}$ to run through the u-tube. Dynamic viscosity [mPa.s] was defined by multiplying the kinematic viscosity $\left[\mathrm{mm}^{2} / \mathrm{s}\right]$ with the corresponding density of $\mathrm{CM}[\mathrm{gl} / \mathrm{ml}$. Density of $\mathrm{CM}[\mathrm{gl} / \mathrm{ml}]$ was measured using a commercially available density instrument (Mettler Toledo Densito 30PX, Columbus, $\mathrm{OH}$, USA).

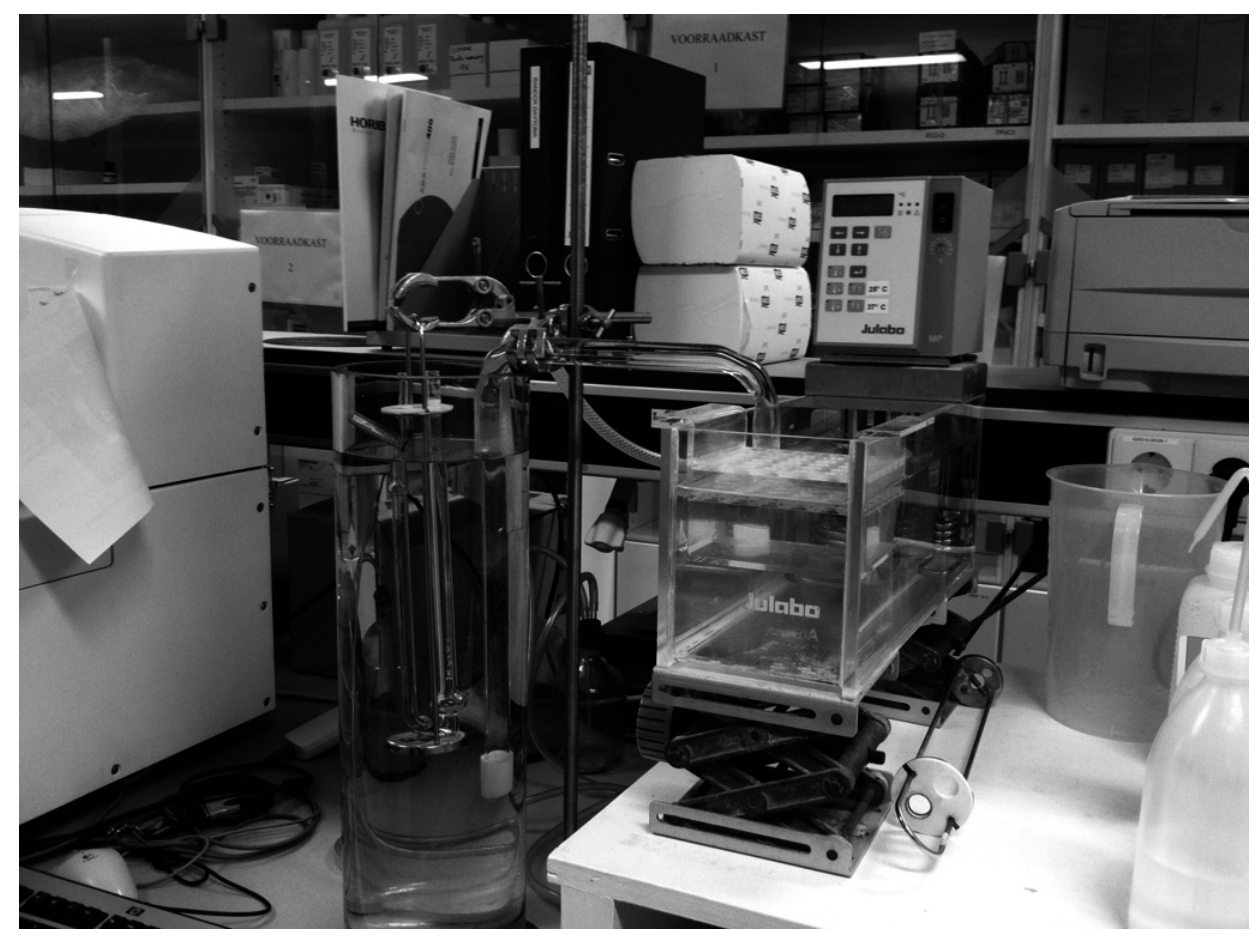

Figure 2.1 The U-tube of the viscosimeter

Left: $U$-tube hanging in the water bath, which is connected with a tube to the main water bath with temperature control (right)

\section{Circulation phantom}

A modified circulation phantom with physiological circulation parameters was used as first described by Behrendt et al. ${ }^{18}$ This phantom consists of a low-pressure lung and a high-pressure body circulation system, with accurate replicas of the entire aorta, as well as the coronary arteries (figure 2.2). In addition, the phantom consists of connecting tubes, a water filled acrylic container, two pressure meters and a pressure relieve valve for modulation of arterial and venous pressure. The phantom was filled with water at body temperature $\left(37^{\circ} \mathrm{C}\right)$, and subsequently circulation was driven by a pulsa- 
tile Harvard medical heart pump (BS4, Harvard Apparatus, Holliston, MA). All values were set within physiological limits: heart rate 60 beats per minute [bpm]; stroke volume $60 \mathrm{ml}$; diastole/systole ratio $60: 40$ and blood pressure $120 / 80 \mathrm{mmHg}$. Both aortic and coronary elements of the phantom were encased in a water-filled acrylic container, mimicking CT-attenuation characteristics of the mediastinum. The phantom was connected to the scanner's electrocardiogram (ECG) lead inputs, in order to provide a synchronised ECG waveform based on the phantom's parameters.

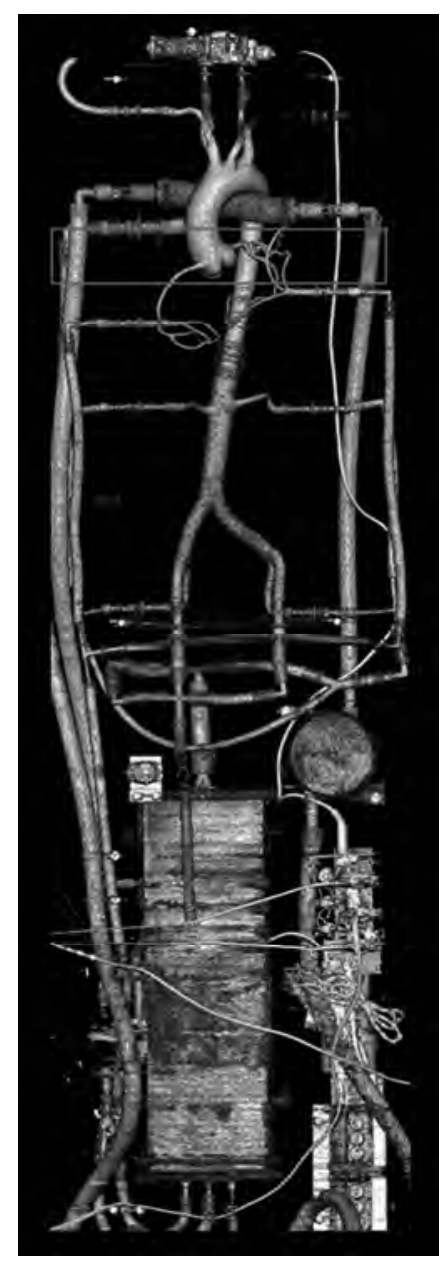

Figure 2.2 Three-dimensional reconstruction of the circulation phantom with scan range outlined 


\begin{tabular}{|c|c|c|c|c|c|}
\hline $\begin{array}{l}\text { CM concentration } \\
{[\mathrm{mgl} / \mathrm{ml}]}\end{array}$ & $\begin{array}{l}\text { CM Volume } \\
\text { [ml] }\end{array}$ & $\begin{array}{c}\text { CM flow rate } \\
{[\mathrm{ml} / \mathrm{s}]}\end{array}$ & $\begin{array}{l}\text { IDR } \\
{[\mathrm{g} \mid / \mathrm{s}]}\end{array}$ & $\begin{array}{l}\text { Total amount of } \\
\text { iodine } \\
\text { [gl] }\end{array}$ & $\begin{array}{c}\text { Injection time } \\
{[s]}\end{array}$ \\
\hline 240 & 62.5 & 7.9 & 1.9 & 15.0 & 7.9 \\
\hline 300 & 50 & 6.3 & 1.9 & 15.0 & 7.9 \\
\hline 370 & 40.5 & 5.1 & 1.9 & 15.0 & 7.9 \\
\hline 400 & 38 & 4.8 & 1.9 & 15.0 & 7.9 \\
\hline
\end{tabular}

Table 2.1 Injection parameters for all CM protocols

\section{Injection and scan protocol}

$\mathrm{CM}$ with consecutive iodine concentrations of $240 \mathrm{mgl} / \mathrm{ml}, 300 \mathrm{mgl} / \mathrm{ml}, 370 \mathrm{mgl} / \mathrm{ml}$ and $400 \mathrm{mgl} / \mathrm{ml}$ was injected with different pre-heated temperatures $\left(20^{\circ} \mathrm{C}, 30^{\circ} \mathrm{C}\right.$ and $\left.37^{\circ} \mathrm{C}\right)$. IDR and total amount of iodine in all groups were kept identical $(1.9 \mathrm{gl} / \mathrm{s}$ and $15 \mathrm{gl}$, respectively). Flow rates and applied contrast media injection protocols used are listed in table 2.1. After every scan, the phantom was flushed with water from the container. CM was injected into the phantom using a standard CT power injector (Stellant, MEDRAD, Pittsburgh, USA), through a three-way stopcock extension tube and a standard $18 \mathrm{G}$ needle (Sterican, Braun, Melsungen, Germany), into the injection port (figure 2.3). Injection time was set to 7.9s for all injections throughout the experiment, no saline chaser was used.

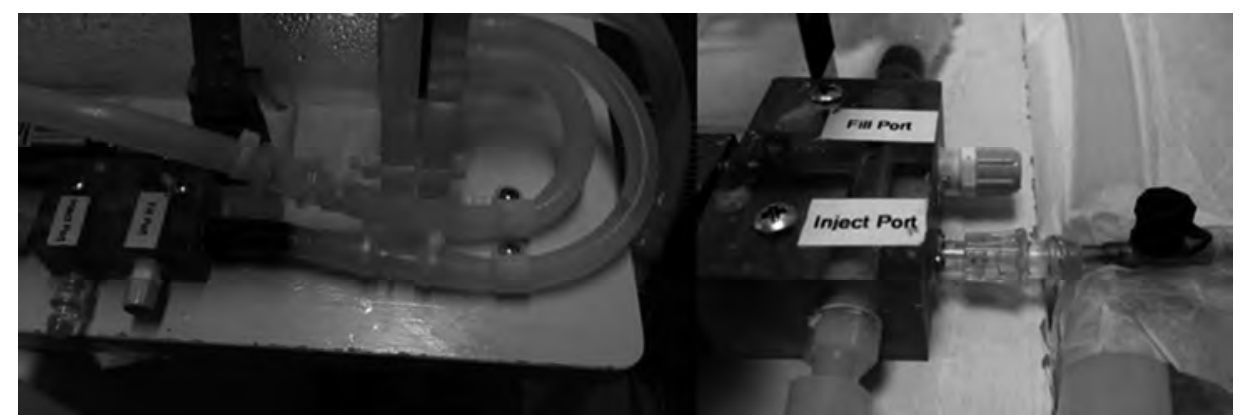

Figure 2.3 Injection port of the circulation phantom

Left: injection port connected to a tube that enters the circulation phantom. Right, close-up: 18G needle connected to the CM injector and inserted in the injection port of the phantom 
Temperature of the pre-heated CM was measured prior to scanning. All relevant injection related parameters as total amount of $\mathrm{CM}$ used, flow rate, peak flow rate and peak pressure were closely monitored using the Certegra ${ }^{\mathrm{TM}}$ Informatics Platform (Bayer-Medrad, Indianola, PA). In addition, an independent data acquisition system (National Instruments Corporation, Austin, TX) was used to monitor the physiological parameters of the phantom throughout the experiments.

Serial CT-scans were performed at the level of the ascending aorta (AA), descending aorta (DA) and the coronary arteries (at the level of the left main coronary artery [LM]), using a $2^{\text {nd }}$ generation DSCT scanner (Definition Flash, Siemens Healthcare, Forchheim, Germany) with a sequential examination protocol $(2 \times 64 \times 0.6 \mathrm{~mm}$ slice collimation, tube voltage of $120 \mathrm{kVp}, 150 \mathrm{mAs}$ eff, at a gantry rotation time of $500 \mathrm{~ms}$, a cycle time of $1000 \mathrm{~ms}$ ). Reconstruction was performed with an adapted field of view (FOV) at $5 \mathrm{~mm}$ thick sections using a soft reconstruction kernel (Siemens B30f). All protocols were repeated three times each to determine reproducibility.

\section{Quantitative analysis}

All injection related parameters were read out after each injection.

Peak attenuation was measured on all serial CT-scan images by delineating a circular region of interest (ROI) in the $A A, D A$ and $L M$ (figure 2.4). A constant maximum size of intra-luminal ROI was set and maintained at all anatomic sites. Resulting average attenuation values for each CM protocol were compared graphically using timeenhancement curves for all vessels. All measurements were independently analysed by two experienced observers, blinded to each other's results. Peak enhancement and time to peak (TTP) were determined for all vessels. 


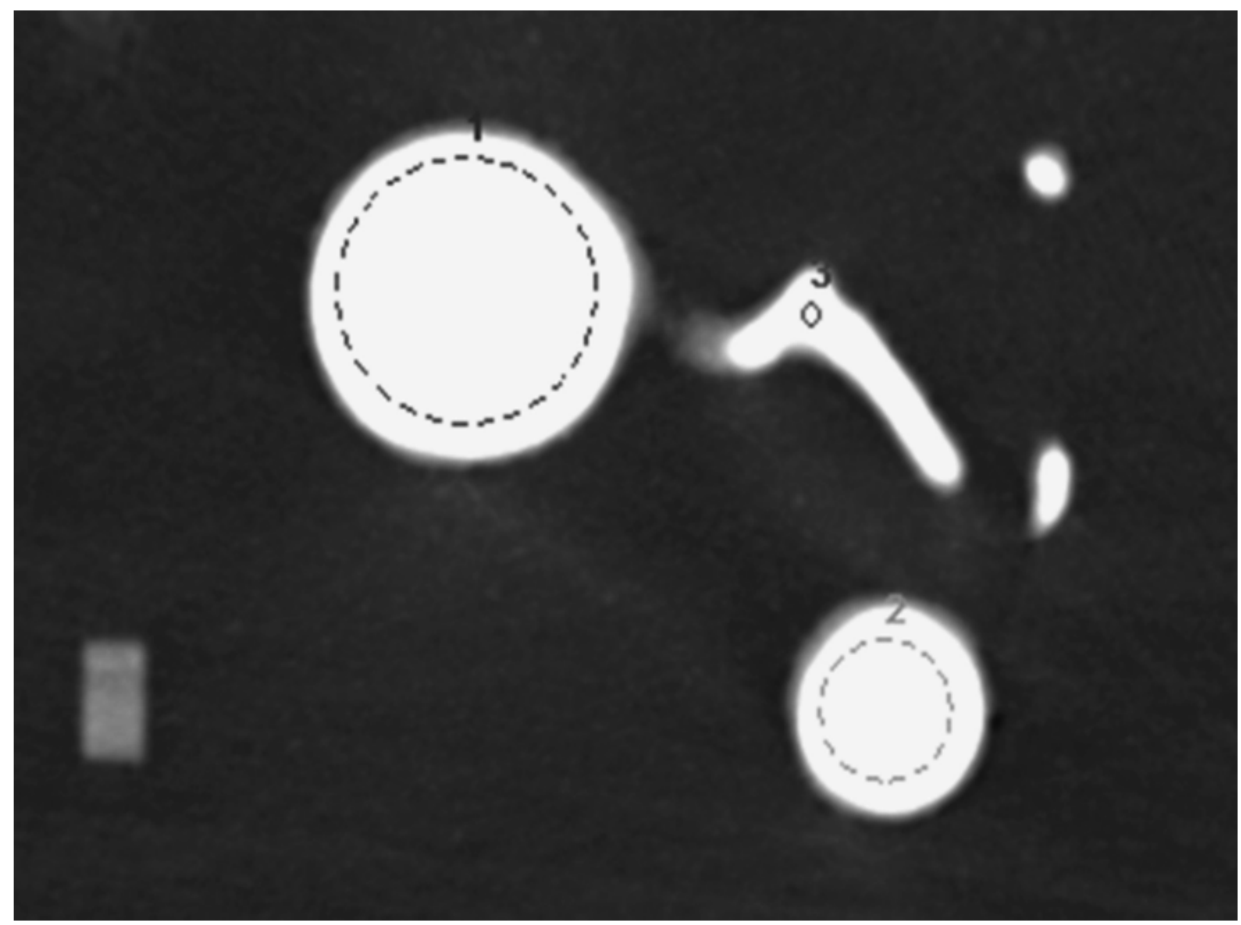

Figure 2.4 Measurement performances on images of the serial CT scans

Mean attenuation was measured by placing a circular ROI in the AA (1), DA (2), and the LM (3)

\section{Statistical analysis}

Peak pressures in different concentrations $\mathrm{CM}$ and different temperatures were compared using the non-parametric Kruskal-Wallis one-way analysis of variance by ranks. Also TTP and attenuation values in both AA and DA as well as the LM were compared using the non-parametric Kruskal-Wallis one-way analysis of variance by ranks. In addition, attenuation values of $A A, D A$ and $L M$ in all contrast media groups were compared individually by means of independent samples T-test. The values are expressed as the mean \pm standard deviation (SD). Interobserver agreement was calculated using the intraclass correlation coefficient in a two-way mixed effects model. Data analysis was conducted with SPSS version 20.0 (SPSS Inc, Chicago, IL). All p-values are 2-sided, and a p-value below 0.05 was considered statistically significant. 


\section{RESULTS}

The exact time required for each $\mathrm{CM}$ to run through the u-tube was measured twice and varied between $213 \mathrm{~s}$ (for $240 \mathrm{mg} / \mathrm{ml}$ in $40^{\circ} \mathrm{C}$ ) and $1740 \mathrm{~s}$ (for $400 \mathrm{mg} / \mathrm{ml}$ in $20^{\circ} \mathrm{C}$ ). The average of two measurements was used to calculate the viscosity, because of the high reproducibility of the experiments (difference between times was max. 1s). The viscosity values for iodinated $\mathrm{CM}$ of $240,300,370$, and $400 \mathrm{mgl} / \mathrm{ml}$ as measured with the viscosimeter between $20^{\circ} \mathrm{C}$ and $40^{\circ} \mathrm{C}$ in the laboratory are given in table $\mathbf{2 . 2}$ and figure 2.5. The lowest viscosity was found for the lowest concentrated $\mathrm{CM}$ of $240 \mathrm{mgl} / \mathrm{ml}$ at the highest temperature $\left(2.8 \mathrm{mPa}\right.$.s at $\left.40^{\circ} \mathrm{C}\right)$. The highest viscosity was found at room temperature for the highest concentrated CM of $400 \mathrm{mgl} / \mathrm{ml}(28.8 \mathrm{mPa} . \mathrm{s}$ at $\left.20^{\circ} \mathrm{C}\right)$. At body temperature, the viscosity of highest concentrated CM $(400 \mathrm{mgl} / \mathrm{ml}$; $12.6 \mathrm{mPa} . \mathrm{s}$ at $37^{\circ} \mathrm{C}$ ) is still higher than $\mathrm{CM}$ of $300 \mathrm{mgl} / \mathrm{ml}$ at room temperature (9.1mPa.s at $\left.20^{\circ} \mathrm{C}\right)$.

\begin{tabular}{|c|c|c|c|c|}
\hline $\begin{array}{c}\text { Temperature } \\
{\left[{ }^{\circ} \mathrm{C}\right]}\end{array}$ & $\begin{array}{l}\text { lopromide } \\
{[240 \mathrm{mgl} / \mathrm{ml}]}\end{array}$ & $\begin{array}{c}\text { lopromide } \\
{[300 \mathrm{mg} \mathrm{l} / \mathrm{ml}]}\end{array}$ & $\begin{array}{l}\text { lopromide } \\
{[370 \mathrm{mg} \mathrm{l} / \mathrm{ml}]}\end{array}$ & $\begin{array}{c}\text { lomeprol } \\
{[400 \mathrm{mg} \mathrm{I} / \mathrm{ml}]}\end{array}$ \\
\hline 20 & 5.1 & 9.1 & 21.2 & 28.8 \\
\hline 21 & 4.9 & 8.7 & 19.7 & 27.2 \\
\hline 23 & 4.6 & 8.0 & 17.8 & 24.1 \\
\hline 25 & 4.3 & 7.3 & 16.0 & 22.2 \\
\hline 27 & 4.0 & 6.8 & 14.2 & 20.1 \\
\hline 29 & 3.7 & 6.3 & 13.0 & 18.3 \\
\hline 31 & 3.5 & 6.0 & 12.0 & 16.4 \\
\hline 33 & 3.4 & 5.6 & 11.1 & 15.0 \\
\hline 35 & 3.2 & 5.2 & 10.2 & 13.7 \\
\hline 37 & 3.1 & 4.9 & 9.8 & 12.6 \\
\hline 38 & 3.0 & 4.7 & 9.4 & 12.1 \\
\hline 39 & 2.9 & 4.6 & 9.0 & 11.6 \\
\hline 40 & 2.8 & 4.4 & 8.7 & 11.2 \\
\hline
\end{tabular}

Table 2.2 Viscosity levels of different iodine concentrations at different temperatures Viscosity levels are expressed in mPa.s 


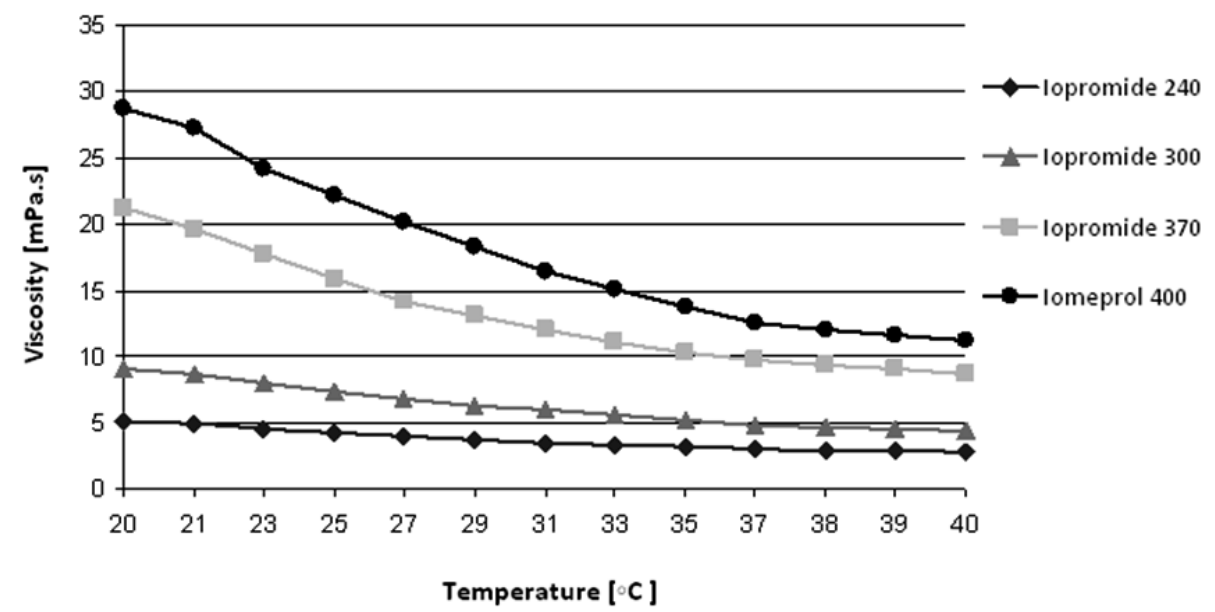

Figure 2.5 Graph lines showing the effect of different temperatures on the viscosity of iodinated CM with different iodine concentrations

The effect of temperature and iodine concentration was further validated in the circulation phantom. No pressure or circulation related problems were encountered throughout the experiments.

Table 2.3 shows that significant differences in peak pressure [psi] were found at $20^{\circ} \mathrm{C}$,

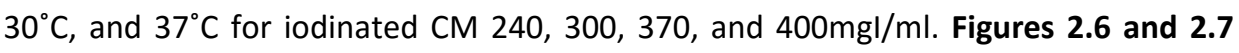
furthermore show that significant differences in peak pressure [psi] were found between all different $\mathrm{CM}$. Overall, the lowest peak pressure was found for the lowest concentrated $\mathrm{CM}$ of $240 \mathrm{mgl} / \mathrm{ml}$ at body temperature $\left(92 \mathrm{psi}\right.$ at $\left.37^{\circ} \mathrm{C}\right)$.

\begin{tabular}{|c|c|c|c|c|}
\hline $\mathrm{CM}[\mathrm{mg} / \mathrm{ml}]$ & $\begin{array}{c}\text { Mean peak pressure [psi] } \\
20^{\circ} \mathrm{C}\end{array}$ & $\begin{array}{c}\text { Mean peak pressure [psi] } \\
30^{\circ} \mathrm{C}\end{array}$ & $\begin{array}{c}\text { Mean peak pressure [psi] } \\
37^{\circ} \mathrm{C}\end{array}$ & $p$-value \\
\hline 240 & $107 \pm 1.5$ & $95 \pm 0.6$ & $92 \pm 2.1$ & 0.027 \\
\hline 300 & $119 \pm 1.5$ & $104 \pm 0.6$ & $100 \pm 3.6$ & 0.027 \\
\hline 370 & $150 \pm 0.6$ & $133 \pm 4.4$ & $120 \pm 3.5$ & 0.026 \\
\hline 400 & $169 \pm 1.0$ & $140 \pm 2.1$ & $135 \pm 2.9$ & 0.027 \\
\hline$p$-value & 0.015 & 0.017 & 0.015 & \\
\hline
\end{tabular}

Table 2.3 Mean peak pressure in different iodine concentrations of CM and temperatures P-values $<0.05$ were considered to be statistically significant 


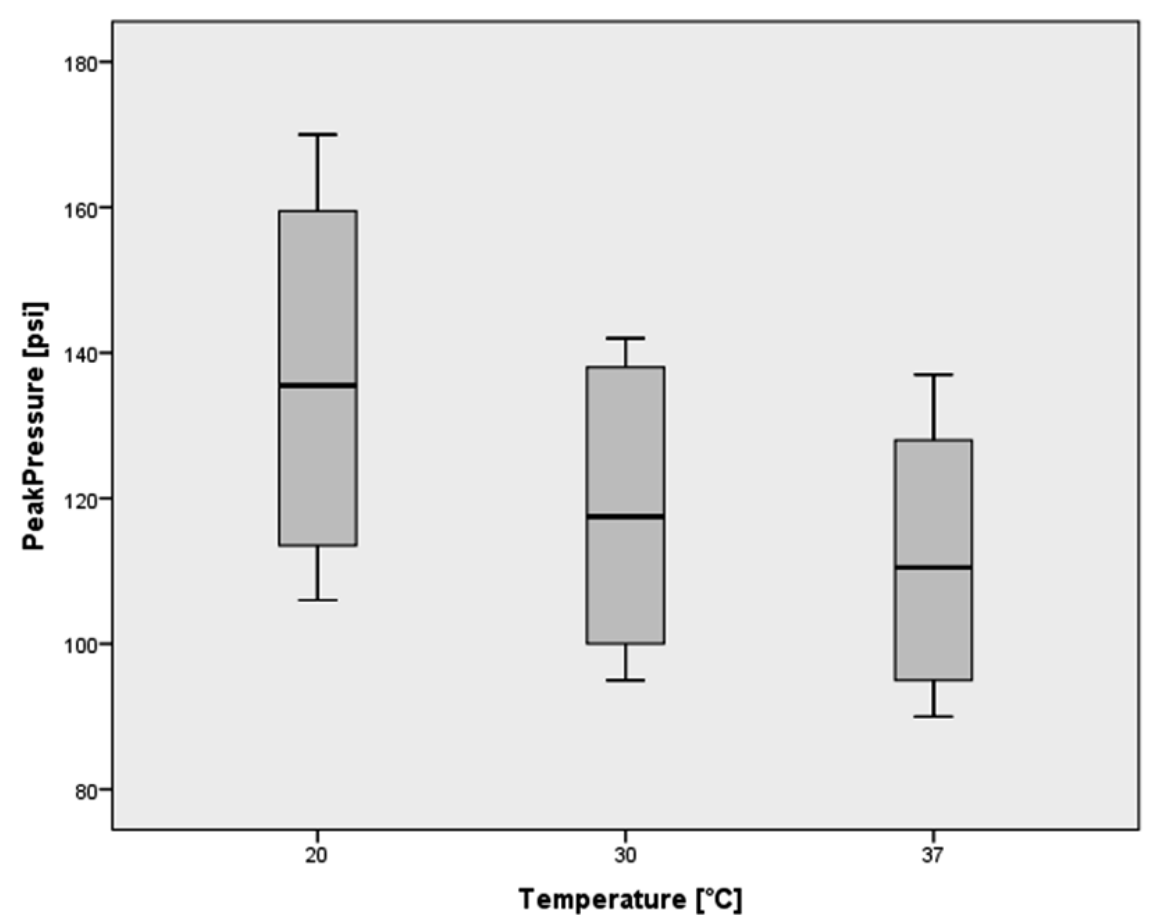

Figure 2.6 Pooled box plots showing different temperatures on the $x$ axis and peak pressure values for the tested $\mathrm{CM}$ concentrations on the $\mathrm{y}$ axis

The horizontal line is the median, the ends of the box are the upper and lower quartiles, and the vertical lines are the full range of values in the data 


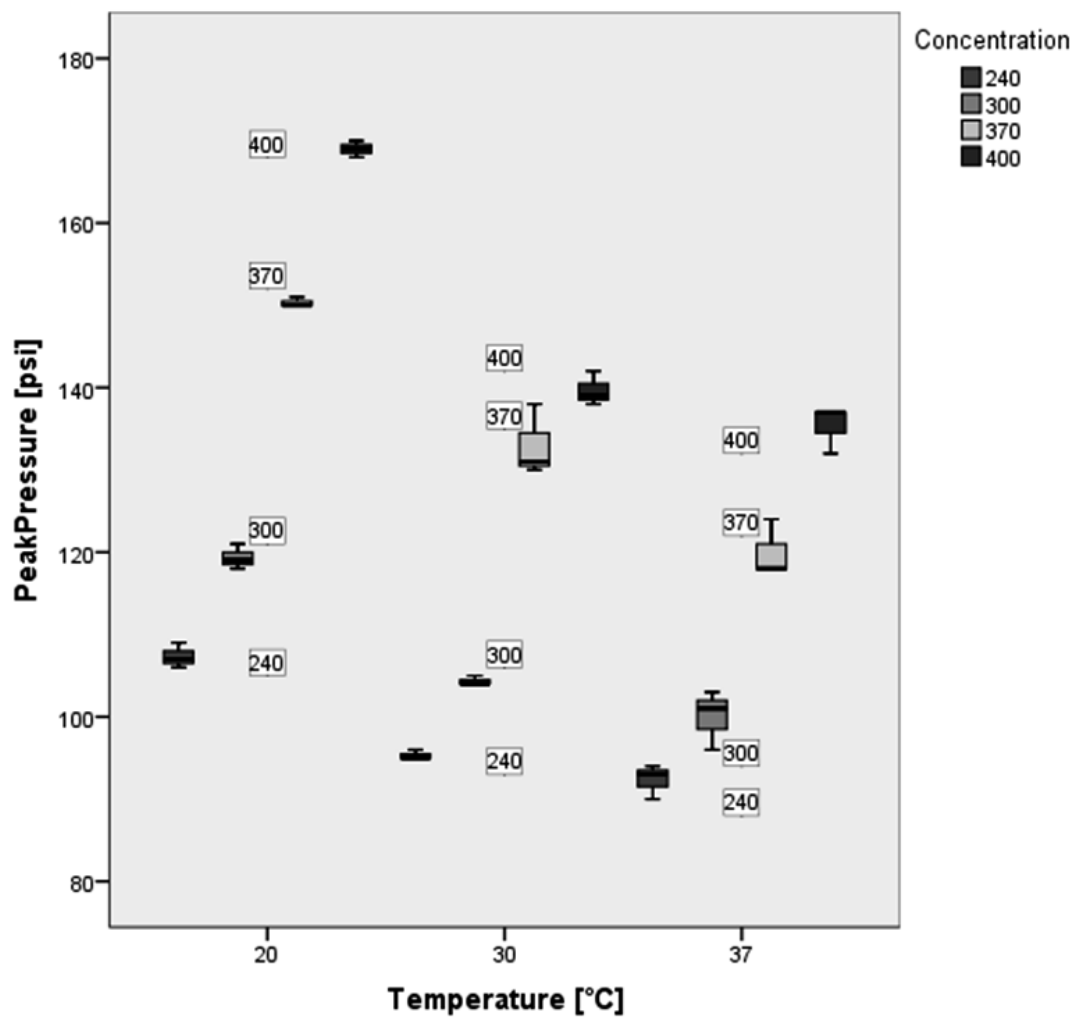

Figure 2.7 Detailed box plots showing different temperatures on the $x$ axis and peak pressure values in different concentrations $\mathrm{CM}$ on the $\mathrm{y}$ axis

These box plots are clustered by the concentration of $\mathrm{CM}$

No significant differences could be detected in TTP [s] for AA, DA and LM, respectively as can be seen in table 2.4. Consecutively mean peak attenuation values were comparable and not statistically different for all protocols at different temperatures and with different iodine concentrations (table 2.5). The reproducibility of the attenuation values proved to be very good: inter-observer correlation was high (>0.910). 


\begin{tabular}{|c|c|c|c|c|c|c|c|c|c|}
\hline $\begin{array}{c}\mathrm{CM} \\
{[\mathrm{mgl} / \mathrm{ml}]}\end{array}$ & \multicolumn{3}{|c|}{$\begin{array}{c}\text { TTP AA } \\
{[\mathrm{s}]}\end{array}$} & \multicolumn{3}{|c|}{$\begin{array}{c}\text { TTP DA } \\
\text { [s] }\end{array}$} & \multicolumn{3}{|c|}{$\begin{array}{c}\text { TTP LM } \\
\text { [s] }\end{array}$} \\
\hline & $20^{\circ} \mathrm{C}$ & $30 \cdot \mathrm{C}$ & $37^{\circ} \mathrm{C}$ & $20^{\circ} \mathrm{C}$ & $30^{\circ} \mathrm{C}$ & $37^{\circ} \mathrm{C}$ & $20^{\circ} \mathrm{C}$ & $30^{\circ} \mathrm{C}$ & $37^{\circ} \mathrm{C}$ \\
\hline 240 & $10.4 \pm 0.5$ & $11.0 \pm 0.0$ & $10.0 \pm 0.0$ & $12.1 \pm 0.1$ & $12.7 \pm 0.6$ & $12.1 \pm 1.1$ & $10.7 \pm 0.5$ & $11.0 \pm 0.0$ & $10.7 \pm 0.6$ \\
\hline 300 & $10.1 \pm 0.9$ & $10.3 \pm 0.6$ & $10.7 \pm 0.6$ & $11.7 \pm 0.5$ & $12.0 \pm 0.0$ & $12.1 \pm 0.1$ & $10.1 \pm 0.9$ & $10.3 \pm 0.6$ & $11.1 \pm 0.1$ \\
\hline 370 & $10.7 \pm 0.6$ & $11.8 \pm 0.7$ & $11.1 \pm 0.1$ & $12.4 \pm 0.5$ & $13.8 \pm 0.7$ & $13.1 \pm 0.1$ & $11.1 \pm 1.1$ & $11.8 \pm 0.5$ & $10.7 \pm 1.1$ \\
\hline 400 & $11.3 \pm 0.6$ & $12.0 \pm 0.0$ & $11.5 \pm 0.5$ & $13.4 \pm 0.5$ & $13.7 \pm 0.6$ & $13.1 \pm 0.1$ & $11.4 \pm 1.2$ & $11.7 \pm 0.6$ & $12.5 \pm 1.1$ \\
\hline$\rho$-value & 0.595 & 0.445 & 0.155 & 0.179 & 0.216 & 0.287 & 0.577 & 0.167 & 0.120 \\
\hline
\end{tabular}

Table 2.4 Mean time to peak in the ascending aorta (AA), the descending aorta (DA) and the left main coronary artery (LM)

P-values $<0.05$ were considered to be statistically significant

\begin{tabular}{|l|c|c|c|c|c|c|c|c|c|}
\hline $\begin{array}{c}\text { CM } \\
\text { [mgl/ml] }\end{array}$ & \multicolumn{3}{|c|}{$\begin{array}{c}\text { AA } \\
\text { [HU] }\end{array}$} & \multicolumn{3}{c|}{$\begin{array}{c}\text { DA } \\
\text { [HU] }\end{array}$} \\
\hline & $20 \circ \mathrm{C}$ & $30 \circ \mathrm{C}$ & $37 \circ \mathrm{C}$ & $20 \circ \mathrm{C}$ & $30 \circ \mathrm{C}$ & $37 \circ \mathrm{C}$ & $20 \circ \mathrm{C}$ & $30 \circ \mathrm{C}$ & $37 \circ \mathrm{C}$ \\
\hline 240 & $424 \pm 10$ & $419 \pm 2$ & $418 \pm 6$ & $418 \pm 3$ & $412 \pm 5$ & $414 \pm 4$ & $418 \pm 2$ & $419 \pm 6$ & $417 \pm 2$ \\
\hline 300 & $429 \pm 8$ & $420 \pm 6$ & $420 \pm 5$ & $427 \pm 4$ & $413 \pm 4$ & $416 \pm 5$ & $414 \pm 6$ & $410 \pm 6$ & $407 \pm 2$ \\
\hline 370 & $424 \pm 5$ & $420 \pm 8$ & $430 \pm 7$ & $417 \pm 5$ & $416 \pm 4$ & $423 \pm 9$ & $417 \pm 10$ & $412 \pm 10$ & $422 \pm 10$ \\
\hline 400 & $433 \pm 27$ & $426 \pm 4$ & $432 \pm 8$ & $417 \pm 27$ & $422 \pm 17$ & $425 \pm 5$ & $417 \pm 20$ & $427 \pm 10$ & $417 \pm 14$ \\
\hline$p$-value & 0.680 & 0.275 & 0.172 & 0.259 & 0.742 & 0.170 & 0.889 & 0.141 & 0.213 \\
\hline
\end{tabular}

Table 2.5 Mean peak attenuation values in the ascending aorta (AA), the descending aorta (DA) and the left main coronary artery (LM)

Values are expressed as mean \pm SD. P-values $<0.05$ were considered to be statistically significant 


\section{DISCUSSION}

Different CM have different characteristics mainly due to their amount of iodine. Viscosity is directly correlated to the amount of iodine per milliliter. This was confirmed with our experiments as it was shown that highest concentrated $\mathrm{CM}(400 \mathrm{mgl} / \mathrm{ml})$ was associated with the highest viscosity of the CMs studied. Interestingly, even under optimal conditions (at body temperature of $37^{\circ} \mathrm{C}$ ), highest concentrated $\mathrm{CM}$ had a higher viscosity as e.g. $300 \mathrm{mgl} / \mathrm{ml}$ at room temperature.

Viscosity itself plays an important role in $\mathrm{CM}$ delivery and enhancement. ${ }^{3,19,20}$ Cademartiri et $\mathrm{al}^{7}$ stated that preheating $\mathrm{CM}(400 \mathrm{mgl} / \mathrm{ml})$ from $20^{\circ} \mathrm{C}$ to $37^{\circ} \mathrm{C}$ decreases the viscosity by more than $50 \%$ ( 27.5 to $12.6 \mathrm{mPa} . \mathrm{s}$ ), as confirmed in our study.

Knollmann et $a l^{17}$ showed that high iodinated $\mathrm{CM}(370 \mathrm{mgl} / \mathrm{ml}$ and $400 \mathrm{mgl} / \mathrm{ml})$ reached the pressure limit at certain high injection rates and concluded that these were problematic due to their high viscosity.

Low viscosity should reduce injection pressure and may accelerate CM distribution within the blood. ${ }^{3,6}$ Until now, several studies focused on optimisation of intravascular contrast enhancement and in particular on the influence of injection rate, iodine concentration and IDR, respectively. 2, 8, 9, 21-25 But none of these studies systematically investigated the effect of pre-heated $\mathrm{CM}$ on intravascular enhancement or on these injection parameters. Schwab et $a l^{15,16}$ concluded that heating CM $(300 \mathrm{mgl} / \mathrm{ml})$ effectively reduces injection pressure, when tested with injection cannulas of different sizes.

Significant differences in peak pressure were found for all concentrations at different temperatures. The other way around, significant differences in peak pressure were found for all temperatures in the different concentration groups. Highest efficacy of reduced viscosity by preheating $\mathrm{CM}$ (from $20^{\circ} \mathrm{C}$ to $37^{\circ} \mathrm{C}$ ) was found for highest concentrated $\mathrm{CM}(400 \mathrm{mgl} / \mathrm{ml}): 56 \%$ reduced viscosity compared to $41 \%$ reduced viscosity in $240 \mathrm{mgl} / \mathrm{ml}$, the peak pressure for the highest concentrated CM $(400 \mathrm{mgl} / \mathrm{ml})$ was even higher at body temperature $\left(135 \mathrm{psi}\right.$ at $\left.37^{\circ} \mathrm{C}\right)$ when compared to $\mathrm{CM}$ with 240 at room temperature $\left(107 \mathrm{psi}\right.$ at $\left.20^{\circ} \mathrm{C}\right)$. Given the statistical significance of these findings, the positive effect of preheating $\mathrm{CM}$ in order to reduce viscosity and therefore, to reduce injection pressure, is stressed.

Furthermore, low viscosity should allow an accelerated distribution within the blood and thus potentially better visualisation of small sized vessels and for advanced perfusion protocols. This could potentially be helpful in the assessment of tumor patients as dedicated workup on blood flow, time to peak and blood volume as a marker of angiogenesis. $^{26}$

Last but not least, attenuation levels were comparable for all $\mathrm{CM}$, which again underlines the fact, that IDR is the most important parameter when different $\mathrm{CM}$ are compared. The results of our study will have major implications for the logistical work-up 
within a CT suite. For instance, incubators and heating cabinets will allow standardised pre-heating of $\mathrm{CM}$ to the desired temperature Furthermore, if not single vials and disposables are used for a single patient, CM temperature has to be maintained after the CM bottles are taken out and are opened up. This can be guaranteed by using dedicated injection power injectors or other preheating devices at the scanner site (figure 2.8).

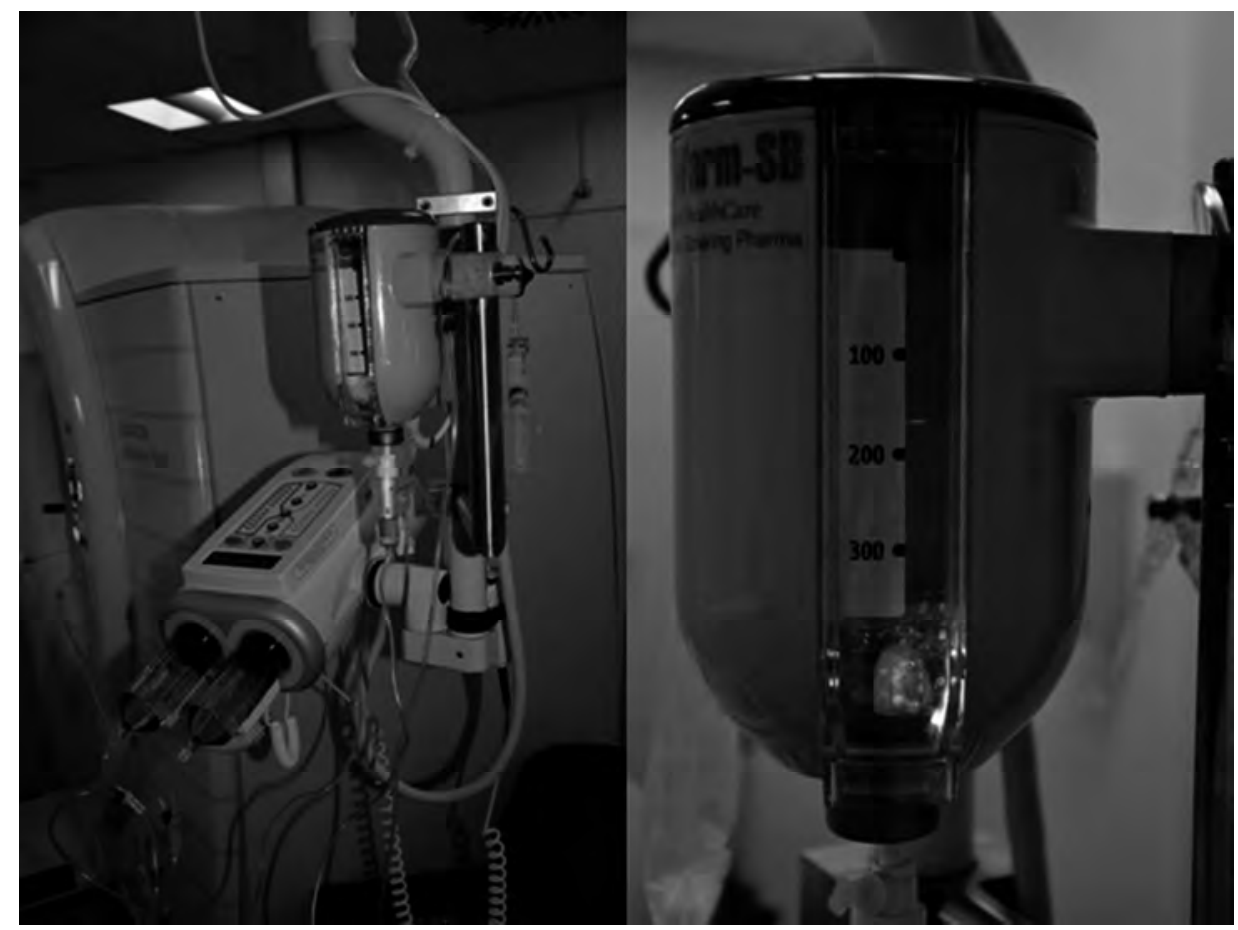

Figure 2.8 Photograph of the pre-heating device next to the CT scanner

WARM-SB (Nemoto International, Herent, Belgium) facilititates constant temperature, even if the bottle is opened up. The maximum bottle volume for this setup is $500 \mathrm{ml}$

\section{Limitations}

Pre-heating CM and precise registering of temperature before injection is mandatory in this phantom study to evaluate the influence of viscosity on these parameters. In this experiment, pre-heated CM in bottles of $100 \mathrm{ml}$ was used. Scanning was commenced, directly after measurement of the temperature, in order to keep temperatures constant. However, the preheated CM was used in two or three repetitive scans. The possibility exists that temperature will decrease within small margins and with that viscosity could have increased after several minutes. However, injection parameters such as peak flow rate and peak pressure did not differ significantly from each other. 


\section{CONCLUSION}

The results of these experiments show in a standardised way that high temperature, low concentration iodine and low viscosity decrease injection pressure. This impacts individual tailored contrast protocols in daily routine scanning. Standardised preheating should be a prerequisite for clinical CM administration. 


\section{REFERENCES}

1. Behrendt FF, Bruners P, Keil S, Plumhans C, Mahnken AH, Stanzel S, Das M, Gunther RW and Muhlenbruch $\mathrm{G}$. Impact of different vein catheter sizes for mechanical power injection in CT: in vitro evaluation with use of a circulation phantom. Cardiovascular and interventional radiology. 2009;32:25-31.

2. Bae KT, Tran HQ and Heiken JP. Uniform vascular contrast enhancement and reduced contrast medium volume achieved by using exponentially decelerated contrast material injection method. Radiology. 2004;231:732-6.

3. Bae KT. Intravenous contrast medium administration and scan timing at CT: considerations and approaches. Radiology. 2010;256:32-61.

4. Johnson PT, Pannu HK and Fishman EK. IV contrast infusion for coronary artery CT angiography: literature review and results of a nationwide survey. AJR American journal of roentgenology. 2009;192:W214-21.

5. Awai K, Hiraishi K and Hori S. Effect of contrast material injection duration and rate on aortic peak time and peak enhancement at dynamic CT involving injection protocol with dose tailored to patient weight. Radiology. 2004;230:142-50.

6. Muhlenbruch G, Behrendt FF, Eddahabi MA, Knackstedt C, Stanzel S, Das M, Seidensticker P, Gunther RW, Wildberger JE and Mahnken AH. Which lodine concentration in chest CT?--a prospective study in 300 patients. European radiology. 2008;18:2826-32.

7. Cademartiri F, Mollet NR, van der Lugt A, McFadden EP, Stijnen T, de Feyter PJ and Krestin GP. Intravenous contrast material administration at helical 16-detector row CT coronary angiography: effect of iodine concentration on vascular attenuation. Radiology. 2005;236:661-5.

8. Cademartiri F, de Monye C, Pugliese F, Mollet NR, Runza G, van der Lugt A, Midiri M, de Feyter PJ, Lagalla $R$ and Krestin GP. High iodine concentration contrast material for noninvasive multislice computed tomography coronary angiography: iopromide 370 versus iomeprol 400 . Investigative radiology. 2006;41:349-53.

9. Nance JW, Jr., Henzler T, Meyer M, Apfaltrer P, Braunagel M, Krissak R, Schoepf UJ, Schoenberg SO and Fink C. Optimization of contrast material delivery for dual-energy computed tomography pulmonary angiography in patients with suspected pulmonary embolism. Investigative radiology. 2012;47:78-84.

10. Rist C, Nikolaou K, Kirchin MA, van Gessel R, Bae KT, von Ziegler F, Knez A, Wintersperger BJ, Reiser MF and Becker CR. Contrast bolus optimization for cardiac 16-slice computed tomography: comparison of contrast medium formulations containing 300 and 400 milligrams of iodine per milliliter. Investigative radiology. 2006;41:460-7.

11. Mihl C, Wildberger JE, Jurencak T, Yanniello MJ, Nijssen EC, Kalafut JF, Nalbantov G, Muhlenbruch G, Behrendt FF and Das M. Intravascular Enhancement With Identical lodine Delivery Rate Using Different lodine Contrast Media in a Circulation Phantom. Investigative radiology. 2013.

12. Behrendt FF, Pietsch H, Jost G, Palmowski M, Gunther RW and Mahnken AH. Identification of the iodine concentration that yields the highest intravascular enhancement in MDCT angiography. AJR American journal of roentgenology. 2013;200:1151-6.

13. Halsell RD. Heating contrast media: role in contemporary angiography. Radiology. 1987;164:2768.

14. Halsell RD. Heating contrast media in a microwave oven. Radiology. 1987;163:279-80.

15. Schwab SA, Kuefner MA, Anders K, Adamietz B, Heinrich MC, Baigger JF, Janka R, Uder M and Kramer M. Peripheral intravenous power injection of iodinated contrast media: the impact of temperature on maximum injection pressures at different cannula sizes. Academic radiology. 2009;16:1502-8.

16. Schwab SA, Uder M, Anders K, Heinrich MC and Kuefner MA. Peripheral intravenous power injection of iodinated contrast media through $22 \mathrm{G}$ and $20 \mathrm{G}$ cannulas: can high flow rates be 
achieved safely? A clinical feasibility study. RoFo : Fortschritte auf dem Gebiete der Rontgenstrahlen und der Nuklearmedizin. 2009;181:355-61.

17. Knollmann F, Schimpf $\mathrm{K}$ and Felix R. [lodine delivery rate of different concentrations of iodinecontaining contrast agents with rapid injection]. RoFo : Fortschritte auf dem Gebiete der Rontgenstrahlen und der Nuklearmedizin. 2004;176:880-4.

18. Behrendt FF, Bruners P, Kalafut J, Mahnken AH, Keil S, Plumhans C, Das M, Stanzel S, Wildberger JE, Pfeffer J, Gunther RW and Muhlenbruch G. Introduction of a dedicated circulation phantom for comprehensive in vitro analysis of intravascular contrast material application. Investigative radiology. 2008;43:729-36.

19. Behrendt FF, Bruners P, Keil S, Plumhans C, Mahnken AH, Stanzel S, Das M, Gunther RW and Muhlenbruch G. Impact of different vein catheter sizes for mechanical power injection in CT: in vitro evaluation with use of a circulation phantom. Cardiovascular and interventional radiology. 2009;32:25-31.

20. Brunette J, Mongrain R, Laurier J, Galaz R and Tardif JC. 3D flow study in a mildly stenotic coronary artery phantom using a whole volume PIV method. Medical engineering \& physics. 2008;30:1193-200.

21. Becker CR, Vanzulli A, Fink C, de Faveri D, Fedeli S, Dore R, Biondetti P, Kuettner A, Krix M and Ascenti G. Multicenter comparison of high concentration contrast agent iomeprol-400 with isoosmolar iodixanol-320: contrast enhancement and heart rate variation in coronary dual-source computed tomographic angiography. Investigative radiology. 2011;46:457-64.

22. Cademartiri F, Mollet NR, Runza G, Bruining N, Hamers R, Somers P, Knaapen M, Verheye S, Midiri $\mathrm{M}$, Krestin GP and de Feyter PJ. Influence of intracoronary attenuation on coronary plaque measurements using multislice computed tomography: observations in an ex vivo model of coronary computed tomography angiography. European radiology. 2005;15:1426-31.

23. Christensen JD, Meyer LT, Hurwitz LM and Boll DT. Effects of iopamidol-370 versus iodixanol-320 on coronary contrast, branch depiction, and heart rate variability in dual-source coronary MDCT angiography. AJR American journal of roentgenology. 2011;197:W445-51.

24. Tsai IC, Lee T, Tsai WL, Chen MC, Wu MJ, Lee WL and Ting HJ. Contrast enhancement in cardiac MDCT: comparison of iodixanol 320 versus iohexol 350. AJR American journal of roentgenology. 2008;190:W47-53.

25. Yamamuro M, Tadamura E, Kanao S, Wu YW, Tambara K, Komeda M, Toma M, Kimura T, Kita T and Togashi K. Coronary angiography by 64-detector row computed tomography using low dose of contrast material with saline chaser: influence of total injection volume on vessel attenuation. Journal of computer assisted tomography. 2007;31:272-80.

26. Garcia-Figueiras R, Goh VJ, Padhani AR, Baleato-Gonzalez S, Garrido M, Leon L and GomezCaamano A. CT perfusion in oncologic imaging: a useful tool? AJR American journal of roentgenology. 2013;200:8-19. 




\section{CHAPTER 3}

Automated $\mathrm{kVp}$ selection for radiation dose reduction in CTA - is it independent from contrast media concentration?

Kok M, Mihl C, Seehofnerova A, Turek J, Jost G, Haberland U, Wildberger JE, Das M. AJR Am J Roentgenol. 2015 Dec;205(6):1332-8. 


\section{ABSTRACT}

\section{Purpose}

The purpose was to systematically investigate radiation dose reduction using automated tube voltage $[\mathrm{kVp}$ ] selection during CTA and to evaluate the impact of contrast media (CM) injection protocols on dose reduction.

\section{Materials and methods}

A circulation phantom containing the thoracic-abdominal vasculature was used. Four different $\mathrm{CM}$ concentrations (iopromide 300 and $370 \mathrm{mgl} / \mathrm{ml}$ and iomeprol 350 and $400 \mathrm{mgl} / \mathrm{ml}$ ) were administered, maintaining an identical iodine delivery rate $(1.8 \mathrm{gl} / \mathrm{s})$ and total iodine load $(20 \mathrm{gl})$. Three different scan protocols for CTA of the thoracoabdominal aorta were used: A: no dose modulation; B: automated tube current modulation (CAREDose4D ${ }^{\mathrm{TM}}$ ); and $\mathrm{C}$ : automated tube voltage selection (CAREkV ${ }^{\mathrm{TM}}$ ). The dose-length product was recorded to calculate the effective dose. Attenuation values [HU], image noise levels and signal-to-noise ratios in six predefined intravascular sites ( 3 thoracic and 3 abdominal) were measured by two readers. All values were analysed using the Kruskal-Wallis test and two-way ANOVA.

\section{Results}

There was a significant reduction in the effective dose [mSv] for protocols $B$ $(2.03 \pm 0.1 \mathrm{mSv})$ and $C(1.00 \pm 0.0 \mathrm{mSv})$ compared to protocol $A(4.34 \pm 0.0 \mathrm{mSv})$. The dose was reduced by $53 \%$ for protocol $B$ and by $77 \%$ for protocol $C$. No significant differences were found in the effective dose between the different $\mathrm{CM}$ injection protocols within the scan protocols; all $p$-values $>0.05$. The attenuation values and signal-tonoise ratios were comparable between all different $\mathrm{CM}$ injection protocols; all $p$-values $>0.05$.

\section{Conclusion}

A large radiation dose reduction (77\%) can be achieved using automated tube voltage selection, independent of the $\mathrm{CM}$ injection protocols. 


\section{INTRODUCTION}

The reduction of radiation exposure to the patient during computed tomography (CT) studies is one of the most important requirements of the as low as reasonably achievable (ALARA) principle. ${ }^{1-4}$ Different methods of reducing the radiation dose have been developed in recent years. Aside from low-dose protocols using a reduced tube current that is adjusted to the patient's size, automated attenuation-based tube current modulation and $\mathrm{kVp}$ selection ${ }^{2,}$ 5-9, high-pitch scanning ${ }^{10-12}$ and iterative reconstruction ${ }^{13}$ have been evaluated in several studies.

Automated tube current [mAs] modulation is widely used in clinical settings and is based on the principle that $\mathrm{X}$-ray attenuation and quantum image noise are determined by the size of the object and its tissue density. ${ }^{14}$

Furthermore, the tube voltage $[\mathrm{kVp}]$ displays a strong potential for radiation dose reduction due to the use of lower tube voltages (dose reduced by approximately the square root of the tube voltage) ${ }^{15-19}$ In contrast enhanced CT angiography (CTA), the potential for a reduction of the radiation dose is particularly high. The $x$-ray attenuation of iodine is significantly higher at lower tube voltages (low-energy $x$-rays are better absorbed by iodine). ${ }^{20}$ However, the use of a lower kVp affects not only the radiation dose and contrast but also the image noise. ${ }^{21}$ Therefore, the tube current must be adjusted to the tube voltage, the diagnostic task and the patient's anatomy. Automated $\mathrm{kVp}$-selection is performed using a software tool that uses information gathered by the topogram and user-defined reference values to optimise the tube current and voltage for the diagnostic objective. Thus, the algorithm calculates the $x$-ray tube settings using the lowest radiation dose required for the user-defined image quality. The full potential of this method can be achieved using the latest technology, high-power $\mathrm{x}$-ray tubes, enabling the effective use of lower tube voltages, even for larger objects. ${ }^{22}$ The use of lower tube voltages leads to an obviously higher contrast media (CM) signal enhancement and in turn allows an increase of image noise and hence reducing the radiation dose while maintaining the signal-to noise ratio (SNR). This effect is especially effective in CTA, in which the attenuation is primarily based on the vessel CM opacification. However, the intravascular SNR does not exclusively depend on the technical imaging parameters. The basis of the attenuation, i.e., the intravascular iodine concentration, primarily depends on the contrast injection protocol. For CTA, the key contrast parameters are the $\mathrm{CM}$ concentration, the injection rate and, consequently, the iodine delivery rate (IDR; [gl/s]). A high IDR that is required for CTA can be achieved by using a standard concentrated $\mathrm{CM}$ at a relatively high injection rate or a highly concentrated $\mathrm{CM}$ at a relatively low injection rate.

Aside from the iodine concentration, different $\mathrm{CM}$ also display distinct physicochemical properties, such as the increase in the osmolarity and the viscosity with increasing iodine concentration. In particular, increased viscosity affects the vascular flow, which, in turn, may alter the shape of the bolus profile ${ }^{23}$ and the intravascular enhancement. ${ }^{24}$ 
The purpose of the present study was to systematically evaluate radiation dose reduction and image quality by using automated kVp-selection in CTA and, in addition, to evaluate if different $\mathrm{CM}$ injection protocols have an impact on radiation dose reduction and/or image quality. Therefore, fixed reference values of the kVp-selection algorithm, a normalised IDR and identical total iodine load (TIL; [gl]) were used. This study was performed in-vitro using a circulation phantom, ensuring high reproducibility and excluding patient-related variability, such as differences in the cardiovascular parameters or the patient size.

\section{MATERIALS AND METHODS}

\section{Circulation phantom}

A circulation phantom exhibiting physiological circulation parameters (heart rate 60 beats per minute [bpm] and blood pressure $120 / 80 \mathrm{mmHg}$ ), as first described by Behrendt et $a l^{25}$, was used. A modified version of this phantom was described in previous studies $^{26,27}$ (figure 3.1). 


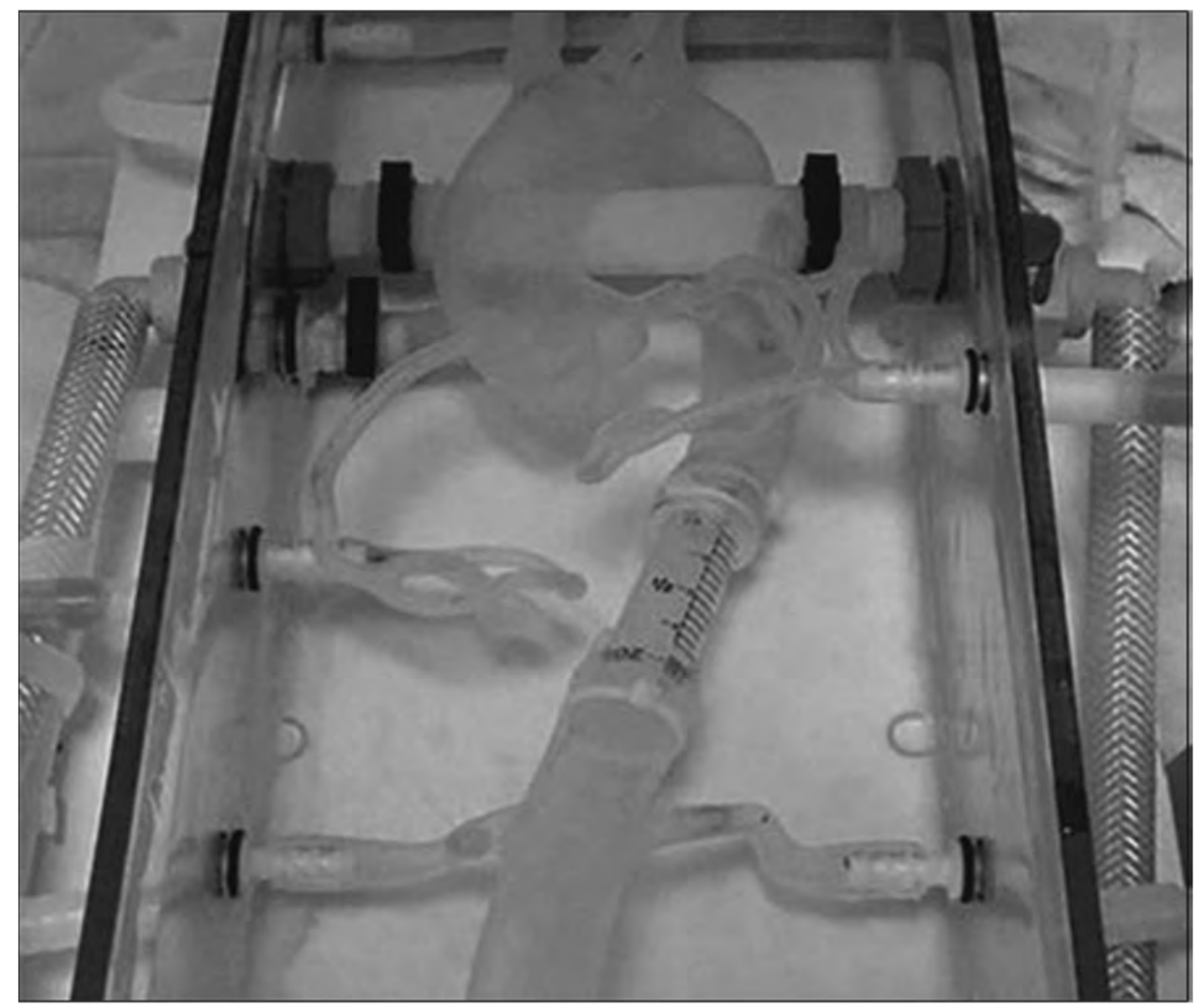

Figure 3.1 Acrylic container consisting of the circulation phantom, including replicas of the ascending and descending aorta, as well as the coronary and renal arteries

\section{Injection and scan protocols}

Non-ionic and low-osmolar CM were used (iopromide $300 \mathrm{mgl} / \mathrm{ml}$ and $370 \mathrm{mgl} / \mathrm{ml}$ [UItravist; Bayer Healthcare, Berlin, Germany] and iomeprol $350 \mathrm{mgl} / \mathrm{ml}$ and $400 \mathrm{mgl} / \mathrm{ml}$ [lomeron; Bracco Imaging, Milan, Italy]). The IDR and TIL in all groups were held constant $(1.8 \mathrm{gl} / \mathrm{s}$ and $20 \mathrm{gl}$, respectively). The CM injection protocols are listed in table 3.1. $\mathrm{CM}$ was injected into the phantom using a standard CT power injector (MEDRAD Stellant, Bayer Healthcare, Indianola, PA, USA) via a three-way stopcock extension tube and a standard $18 \mathrm{G}$ needle (Sterican, Braun, Melsungen, Germany) into the injection port. The injection time was set to $11 \mathrm{~s}$ for all injections throughout the experiment; a saline chaser at the same flow rate (injection time of $5 \mathrm{~s}$ ) was administered after every scan. 
The $\mathrm{CM}$ was pre-heated to $37^{\circ} \mathrm{C}$. All relevant injection-related parameters (e.g. total amount of $\mathrm{CM}$, flow rate, peak flow rate and peak pressure) were closely monitored using the Certegra ${ }^{\mathrm{TM}}$ Informatics Platform (Bayer Healthcare, Indianola, PA, USA). In addition, an independent data acquisition system (National Instruments Corporation, Austin, TX, USA) was used to monitor the physiological circulation parameters (e.g. blood pressure and heart rate) of the phantom throughout the experiments. After every scan, the vasculature of the phantom was flushed with water. Monitoring was needed for manual regulation of the preset $(120 / 80 \mathrm{mmHg})$ blood pressure during flushing.

\begin{tabular}{|l|l|l|l|l|l|}
\hline \multicolumn{1}{|c|}{$\begin{array}{c}\text { CM concentration } \\
{[\mathrm{mgl} / \mathrm{ml}]}\end{array}$} & $\begin{array}{c}\text { CM Volume } \\
{[\mathrm{ml}]}\end{array}$ & $\begin{array}{c}\text { Flow rate } \\
{[\mathrm{ml} / \mathrm{s}]}\end{array}$ & \multicolumn{1}{|c|}{$\begin{array}{c}\text { IDR } \\
{[\mathrm{g} / \mathrm{s}]}\end{array}$} & $\begin{array}{c}\text { Total iodine load } \\
[\mathrm{g}] \mathrm{l}]\end{array}$ & \multicolumn{1}{|c|}{$\begin{array}{c}\text { Injection time } \\
{[\mathrm{s}]}\end{array}$} \\
\hline 300 (lopromide) & 67 & 6.0 & 1.8 & 20.0 & 11.1 \\
\hline 350 (lomeprol) & 57 & 5.1 & 1.8 & 20.0 & 11.1 \\
\hline 370 (lopromide) & 54 & 4.9 & 1.8 & 20.0 & 11.1 \\
\hline 400 (lomeprol) & 50 & 4.5 & 1.8 & 20.0 & \\
\hline
\end{tabular}

Table 3.1 Injection parameters for all CM protocols

A dynamic CT scan without table feed (120kVp, 210mAs), using a $2^{\text {nd }}$ generation DSCT scanner (SOMATOM Definition Flash, Siemens Healthcare, Forchheim, Germany), was performed at the level of the heart. Based on the ROI signal measurement in the ascending aorta, the time to peak (TTP) for each CM concentration was determined. Then, helical CT scans of the thoraco-abdominal aorta were performed using a standard spiral examination protocol $(128 \times 0.6 \mathrm{~mm}$ slice collimation, pitch 0.9 , reference tube voltage $120 \mathrm{kVp}$, qual. reference tube current $210 \mathrm{mAs}$ and gantry rotation time $500 \mathrm{~ms}$ ), which was separated into the following three protocols: (A) no dose modulation; (B) 3D tube current modulation (CAREDose $4 \mathrm{D}^{\mathrm{TM}}$; and (C) automated tube voltage selection with $3 \mathrm{D}$ tube current modulation $\left(C A R E k V^{\mathrm{TM}}\right.$ ). For the latter, the dose optimisation setting 11 (vessels) was used. The strength setting parameter in the CAREkV ${ }^{\mathrm{TM}}$ tool can vary between 1 and 12 , where 12 is matching iodine CNR ${ }^{19}$. When selecting higher strength, the chance of lower tube voltage selection by the tool is higher and therefore as well the chance on reduced radiation dose. This study simulated dose reduction in CTA and therefore primary interest was iodine CNR, thus vessel setting (11) was selected. Furthermore, the dose reduction was predicted on the scan interface (see also figure $1 \mathrm{in}^{15}$ ), a noise level prediction was not available. 
Reconstruction was performed using an adapted field of view (FOV) of $2 \mathrm{~mm}$ thick sections at increments of $1.4 \mathrm{~mm}$ using a soft reconstruction kernel (Siemens B31f). All protocols were performed for each $\mathrm{CM}$ concentration $(300,350,370$ and $400 \mathrm{mgl} / \mathrm{ml}$ ) using the determined TTP in the ascending aorta (AA), including the initial scan delay (10s) as the delay time. All measurements were repeated three times.

\section{Quantitative analysis}

The dose-length product (DLP) was recorded for each protocol to calculate the effective dose [mSv]. The effective dose (E) was quantified by multiplying the DLP value and the conversion factor for the thorax ( $k=0.014 \mathrm{mSv} /[\mathrm{mGy} . \mathrm{cm}])$ and the abdomen $(\mathrm{k}=$ $0.015 \mathrm{mSv} /[\mathrm{mGy} . \mathrm{cm}]) .^{28}$ Because of the thoraco-abdominal scan range, an average conversion factor $(\mathrm{k}=0.0145 \mathrm{mSv} /[\mathrm{mGy} . \mathrm{cm}])$ was used. The attenuation [HU] was measured on all spiral CT-scan images by delineating a circular region of interest (ROI) in the lumen of the $A A$, coronary arteries (left main coronary artery [LM]), the descending aorta (DA), the abdominal aorta ( $A A O)$, the left renal artery (LRA) and the right renal artery (RRA). ROI were made as large as possible and placed centrally, in order to avoid the wall. Image noise was defined as a standard deviation (SD) of the attenuation. Signal-to-noise ratio (SNR) was calculated as vessel attenuation divided by image noise. In addition, the SNR per unit dose of radiation was calculated according to the following equation: SNR/(effective dose). Two experienced observers (MK, JT) who were blinded to each other's results independently analysed all ROI measurements. All dose-related parameters, such as the tube current, the tube voltage, the computed tomography dose index $\left(\mathrm{CTDI}_{\text {vol }}\right)$ and the DLP were reported directly from the scanner console after each scan.

\section{Statistical analysis}

All values are expressed as the means $\pm S D$. DLP, CTDI ${ }_{\text {vol }}$ and effective dose for the various $\mathrm{CM}$ injection protocols and scan protocols was compared using the nonparametric Kruskal-Wallis one-way analysis of variance test by ranks. For post-hoc comparisons between scan protocols the Mann-Whitney $U$ test was used. The mean attenuation values and the SNR in the AA, LM, DA, AAo, LRA and RRA, as well as for the different $\mathrm{CM}$ injection protocols, using the three scan protocols were compared via two-way ANOVA followed by the three-way Tukey test for post-hoc comparisons between the scan protocols, the CM injection protocols and the vascular segments. Intra-observer variability was assessed by calculating the intra-class correlation coefficients (ICC) using a two-way mixed model. The data analysis was performed using SPSS version 20.0 software (SPSS, Inc., Chicago, IL). All p-values are 2-sided, and a p-value of less than 0.05 was considered to be statistically significant. 


\section{RESULTS}

All dose-related scan parameters are listed in table 3.2. Automated tube-current modulation (protocol B) caused the averaged tube-current time product to be reduced from $210 \mathrm{mAs}_{\text {ref }}$ (protocol A) to $97 \pm 0.4 \mathrm{mAs}_{\text {eff }}$ and, therefore, a significant reduction in the mean effective dose from $4.34 \pm 0.0 \mathrm{mSv}$ to $2.03 \pm 0.1 \mathrm{mSv}$, with $p$-value $<0.001$. The use of automated $\mathrm{kVp}$-selection (protocol C) caused the tube voltage to be reduced from $120 \mathrm{kVp}$ to $80 \mathrm{kVp}$ and $166 \pm 0.9 \mathrm{mAs}_{\text {eff }}$, resulting in a significantly lower effective dose of $1.00 \pm 0.0 \mathrm{mSv}$ compared to protocols $A$ and $B$ with both $p$-values $<0.001$. Thus, the use of automated $\mathrm{kVp}$-selection resulted in a $77 \%$ reduction in the radiation dose compared to the standard setting without dose modulation and a $51 \%$ reduction compared to tube current modulation alone.

\begin{tabular}{|c|c|c|c|c|}
\hline Scan parameter & Protocol A* & Protocol B* & Protocol C* & P-value \\
\hline $\mathrm{kVp}_{\text {ref }} / \mathrm{mAs}_{\text {ref }}$ & $120 / 210$ & $120 / 210$ & $120 / 210$ & \\
\hline$k V p$ & 120 & 120 & 80 & \\
\hline $\mathrm{mAs}_{\text {eff }}$ & $210 \pm 0.0$ & $97 \pm 0.4$ & $166 \pm 0.9$ & \\
\hline $\mathrm{CTDI}_{\text {vol }}[\mathrm{mGy}]$ & $14.1 \pm 0.0$ & $6.6 \pm 0.03$ & $3.2 \pm 0.02$ & $<0.001$ \\
\hline $\mathrm{DLP}$ [mGy.cm] & $299 \pm 0.04$ & $140 \pm 0.6$ & $69 \pm 0.4$ & $<0.001$ \\
\hline Effective Dose [mSv] & $4.34 \pm 0.0$ & $2.03 \pm 0.1$ & $1.00 \pm 0.0$ & $<0.001$ \\
\hline
\end{tabular}

Table 3.2 Dose related scan parameters for all three scan protocols in all CM concentrations Values are expressed as mean $\pm S D$. The significant $p$-value involves differences between protocols $A-B, A-C$ and B-C (results of post-hoc group comparison).

* Protocol $A=$ no dose modulation; Protocol $B=C A R E D o s e 4 D^{T M}$ and Protocol $C=C A R E k V^{T M}$ 


\begin{tabular}{|l|l|l|l|}
\hline \multicolumn{1}{|c|}{ CM concentration [mgl/ml] } & \multicolumn{1}{|c|}{$\begin{array}{c}\text { Effective Dose [mSv] } \\
\text { Protocol A* }\end{array}$} & \multicolumn{1}{c|}{$\begin{array}{c}\text { Effective Dose [mSv] } \\
\text { Protocol B* }\end{array}$} & \\
\hline 300 (lopromide) & & & \\
\hline 350 (lomeprol) & $4.34 \pm 0.0$ & $2.03 \pm 0.1$ & $1.00 \pm 0.0$ \\
\hline 370 (lopromide) & $4.34 \pm 0.0$ & $2.03 \pm 0.1$ & $1.00 \pm 0.0$ \\
\hline 400 (lomeprol) & $4.34 \pm 0.0$ & $2.03 \pm 0.1$ & $1.00 \pm 0.0$ \\
\hline p-value & & & $1.00 \pm 0.0$ \\
\hline
\end{tabular}

Table 3.3 Effective dose for protocols $A, B$ and $C$ and for the different $C M$ concentrations Values are expressed as mean $\pm S D$. Protocol $A=$ no dose modulation; ${ }^{*}$ Protocol $B=C A R E D o s e 4 D^{T M}$ and Protocol $\mathrm{C}=\mathrm{CAREkV} \mathrm{TM}^{\mathrm{T}}$

The effective dose for each scan protocol and CM injection protocol are presented in table 3.3. The comparison between different $\mathrm{CM}$ injection protocols within the three scan protocols revealed no differences in the effective dose (table 3.3).

The mean attenuation values for protocols $A(442.2 \pm 16.3 \mathrm{HU})$ and $B(428.2 \pm 14.5 \mathrm{HU})$ were nearly identical, whereas significantly higher attenuation values were observed for protocol $\mathrm{C}(747.0 \pm 25.6 \mathrm{HU})$, with $p<0.001$ for all vascular segments (between protocol A-C and B-C) (figure 3.2).

No significant differences were detected in the attenuation values between the different $\mathrm{CM}$ injection protocols $(300,350,370$ and $400 \mathrm{mgl} / \mathrm{ml})$ for any of the three scan protocols or any of the vascular segments; all $p$-values $\geq 0.78$ (figure 3.2 ).

The mean SNR was higher for protocol A $(54.7 \pm 10.9)$ than for protocols B $(43.4 \pm 7.1)$ and $C(42.9 \pm 5.1)$. This difference was significant in four of the six vascular segments: $A A, D A, A A o$ and RRA. The corresponding eight $p$-values for all four segments and between protocols $A-B$ and $A-C$ were all $<0.001$. No statistically significant differences in the SNR were found between the different $\mathrm{CM}$ injection protocols for any of the three scan protocols or any of the vascular segments; all $p$-values $\geq 0.59$ (figure 3.3). 

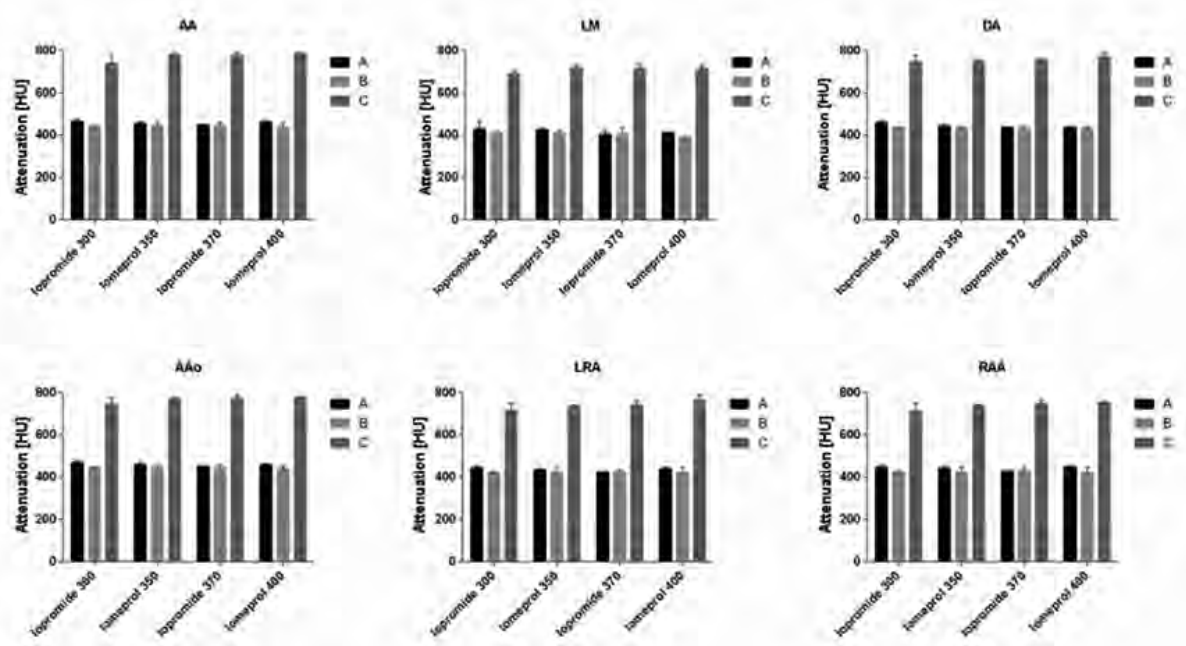

Figure 3.2 Bar graphs displaying the difference in the attenuation values between the scan protocols (A, B, and $\mathrm{C}$ ) and the $\mathrm{CM}$ injection protocols for each vascular segment

There were significantly higher attenuation values for protocol $\mathrm{C}$ compared to the other two protocols $(p<0.001)$ in each vascular segment. No significant differences were found in the attenuation values between the different $\mathrm{CM}$
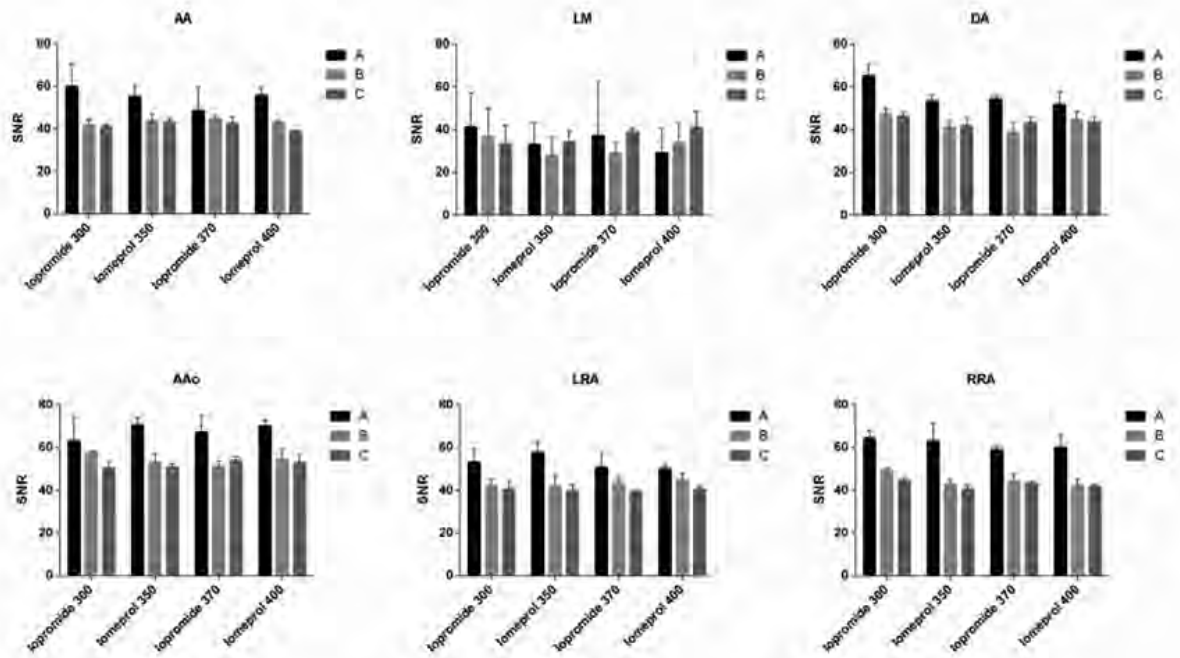

Figure 3.3 Bar graphs displaying the difference in the SNR between the scan protocols (A, B and C) and the $\mathrm{CM}$ injection protocols for each vascular segment

There were significantly higher SNR values for protocol A compared to the other two protocols in the AA, DA, $A A o$ and RRA $(p<0.001)$. No significant differences were found in the SNR between the different CM 
The mean SNR per unit radiation dose, a measure of the dose effectiveness, was higher in protocol C $\left(41.6 \pm 4.9 \mathrm{mSv}^{-1}\right)$ than in protocols $B\left(20.6 \pm 3.4 \mathrm{mSv}^{-1}\right)$ and $\mathrm{A}\left(12.2 \pm 2.4 \mathrm{mSv}^{-}\right.$ $\left.{ }^{1}\right)$. The corresponding eighteen $p$-values for all six segments between protocols $C-B ; C$ $A$ and $A-B$ were all $<0.001$. This difference was independent of the $C M$ injection protocol, all $p>0.421$ (figure 3.4). The reproducibility of the attenuation measurements was very high, with an intra-observer correlation of 0.997.

The TTP did not differ between the dynamic scans and was determined to be $14 \mathrm{~s}$ for each CM concentration and protocol. The analysis of the injection parameters revealed only minor, negligible differences between the planned and applied CM volumes and flow rates (table 3.4). However, the injection pressure differed significantly between the $\mathrm{CM}$ injection protocols, except from the difference between 300 and $370 \mathrm{mgl} / \mathrm{ml}$ (table 3.4). The highest peak pressure $(104 \pm 2.5 \mathrm{psi})$ was recorded for the protocol using highest concentration of $\mathrm{CM}$, whereas the lowest pressure $(82 \pm 2.1 \mathrm{psi})$ was detected for the $350 \mathrm{mgl} / \mathrm{ml}$ concentration protocol. The monitoring of heart-rate and blood pressure reveals no deviation from the defined values.
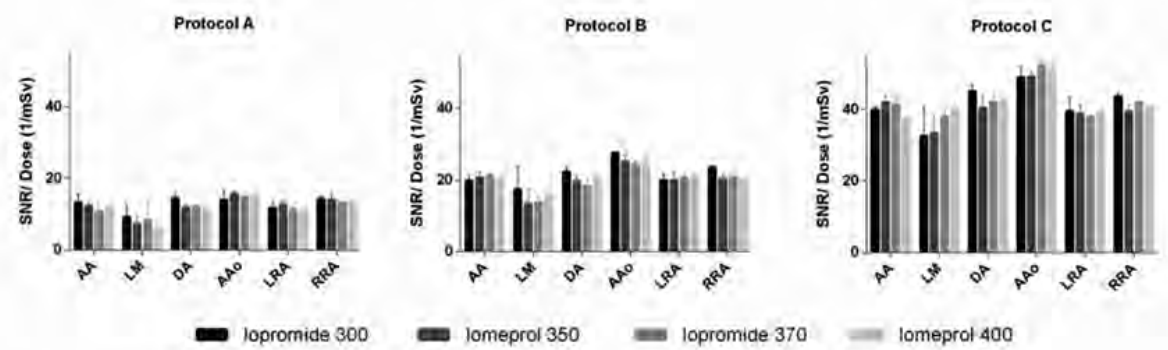

Figure 3.4 Bar graphs displaying the difference in the SNR normalised to the effective radiation dose (Dose) between the four different CM injection protocols in all vascular segments for each scan protocol The SNR/Dose ratio was significantly higher $(p<0.001)$ for protocol $C$ compared to the other two protocols. No significant differences in the SNR/dose ratio were found between the different CM 


\begin{tabular}{|l|c|c|c|c|}
\hline $\begin{array}{c}\text { CM Concentration } \\
{[\mathrm{mgl} / \mathrm{ml}]}\end{array}$ & $\begin{array}{c}\text { Time to peak, TTP } \\
{[\mathrm{s}]}\end{array}$ & $\begin{array}{c}\text { Applied volume } \\
{[\mathrm{ml}]}\end{array}$ & $\begin{array}{c}\text { Applied flow rate } \\
{[\mathrm{ml} / \mathrm{s}]}\end{array}$ & $\begin{array}{c}\text { Peak pressure } \\
\text { [psi] }\end{array}$ \\
\hline 300 (lopromide) & 14 & $67.0 \pm 0.1$ & $5.6 \pm 0.1$ & $95 \pm 1.5$ \\
\hline 350 (lomeprol) & 14 & $56.9 \pm 0.1$ & $4.8 \pm 0.1$ & $82 \pm 2.1$ \\
\hline 370 (lopromide) & 14 & $54.0 \pm 0.1$ & & $92 \pm 2.7$ \\
\hline 400 (lomeprol) & 14 & $49.9 \pm 0.1$ & $4.7 \pm 0.1$ & \\
\hline
\end{tabular}

Table 3.4 Time-to-peak analysis and injection parameters recorded using the Certegra ${ }^{\text {TM }}$ Informatics Platform

Values are expressed as mean $\pm \mathrm{SD}$

\section{DISCUSSION}

In this phantom study, the potential for automated $\mathrm{kVp}$-selection to reduce the radiation dose during CTA using different concentrated CM normalised to an identical IDR was evaluated. Therefore, automated $k V p$-selection (CAREkV ${ }^{T M}$ ) was compared to the well-established automated tube current modulation alone (CAREDose $4 D^{T M}$ ) and referenced to the standard CT settings without dose modulation.

In contrast to clinical studies, our measurement setup allows for the repeated injection of CM under highly standardised conditions, thus enabling an evaluation of different $\mathrm{CM}$ injection protocols to explore radiation dose reduction and signal enhancement. The phantom resembles the human condition with respect to the vascular architecture, the circulation parameters (heart rate, stroke volume and blood pressure) and the applied injection parameters (IDR, total amount of iodine and power injection via an $18 \mathrm{G}$ i.v. line). ${ }^{27}$ Additionally, the reference settings of the CT-scan ( $\left.k V p_{\text {ref }}, m A s_{\text {ref }}\right)$ are equivalent to the settings for human thoracic abdominal CTA. Thus, the measurement setup and procedures are comparable to the clinical condition.

Although both dose modulation techniques significantly reduced the radiation dose, automated kVp-selection was much more effective than automated tube current modulation alone, both being independent of the $\mathrm{CM}$ injection protocol. Using protocol $\mathrm{C}$, the tube voltage was automatically reduced from 120 to $80 \mathrm{kVp}$. Consequently, the vascular attenuation for protocol $\mathrm{C}$ is higher than for protocols $\mathrm{A}$ and $\mathrm{B}$. On the other hand, the highest SNR was observed for protocol A However, a SNR greater than 30, which was found in each scan protocol $\left(A, B\right.$, and $C$ ) ensures appropriate image quality. ${ }^{29}$ 
As we could show, automated $\mathrm{kVp}$-selection has a higher dose reducing potential compared to tube current modulation, as both $\mathrm{kVp}$ and tube current could be reduced at the same time. ${ }^{15}$ However, switching to lower kVp settings using automated kVpselection is only feasible over the whole scan length, while tube current modulation gives the opportunity to reduce tube current [mAs] per slice. ${ }^{30,31}$ For example, in patients with increased BMI, weight or abdominal diameter, the possibility arises that the scanner won't be able to reduce tube voltage, as x-ray tube power is limited and image noise may increase. ${ }^{9}$ Then, both algorithms may result in identical radiation doses as automated kVp-selection includes also automatic tube current modulation. If maximum $\mathrm{kVp}$ switching is desired with regards to optimise radiation dose, only the relatively thin patients will benefit from the current results. In patients with a normal to higher $\mathrm{BMI}$, the maximum radiation dose reduction will be limited as the scanner will not switch to $80 \mathrm{kVp}$. However, the recently introduced high power $\mathrm{x}$-ray tubes have the potential to overcome this limitation and the number of patients who will benefit from such a maximum radiation dose reduction can only be expected to increase in the future. $^{22}$

Automated $k V p$-selection requires an important user input; settings as $k V p$ and $m A s$ reference values must be defined. These parameters determine the noise level and directly impact the calculation of the required scan parameters for automated tube current modulation and automated kVp-selection. In our study, the standard settings for abdominal scans (120kVp and $210 \mathrm{mAs}$ ) used in protocol A were used as reference values for protocols $B$ and $C$ to ensure a meaningful comparison of the two dose modulation algorithms. The impact of the reference settings on the automated tube voltage selection was investigated in a study by Schwarz et al. ${ }^{32}$ They found that a reduction in the reference tube-current time product from 330 to $250 \mathrm{mAs}$ results in an increased use of lower tube voltages and therefore a reduction in the radiation dose. However, this reduction was accompanied by a significant increase in the image noise. In contrast to our study, Schwarz et $a f^{32}$ increased the IDR and the TIL by administering $400 \mathrm{mgl} / \mathrm{ml} \mathrm{CM}$ applied at the same flow rate and volume as $300 \mathrm{mgl} / \mathrm{ml} \mathrm{CM}$. This significant increase in the TIL compensated for the higher noise and maintained the SNR.

For the evaluation of automated dose modulation algorithms for CTA, the radiation dose and the SNR must be considered. Therefore, the SNR-to-dose ratio was introduced, which takes both parameters into account. Considering protocol $A$ as a reference, the SNR-to-dose ratio was increased by a factor of 2 for protocol B and a factor of 3.4 for protocol $\mathrm{C}$ independent of the $\mathrm{CM}$ concentration that were administered at normalised IDR.

For CTA, in which the attenuation primarily depends on the intravascular iodine concentration, the greatest reduction in the radiation dose can be achieved. Consequently, the contrast injection protocol plays a major role. In clinical practice, different CM concentrations, ranging between 300 and $400 \mathrm{mgl} / \mathrm{ml}$, are routinely used during CTA. 
The key parameters that determine the vascular signal enhancement are the IDR and the TIL. ${ }^{33,34}$ Therefore, the injection rate and volume in our study were adapted to the CM concentration, whereas the IDR, the TIL and the injection time were held constant. The resulting intravascular attenuation did not differ between the CM concentrations for either the reference measurement (protocol A) or the dose modulation protocols (protocol B / C). Consequently, we conclude that the vascular attenuation, the automated tube voltage selection-mediated dose reduction and the image quality are independent of the CM concentration when a normalised IDR is used. This finding is quantitatively described by the nearly identical SNR-to-dose ratios for the different CM concentrations.

The different physicochemical properties of different concentrated $\mathrm{CM}$, in particular the increasing viscosity for higher iodine concentrations may have an impact of the bolus profile ${ }^{23}$ and enhancement. ${ }^{24}$ In our phantom study, no differences in time-topeak or vascular attenuation between the different concentrations of CM were detected. However, the injection pressure differed between the $\mathrm{CM}$ concentrations; the highest peak pressure was found for $400 \mathrm{mgl} / \mathrm{ml}$, which could be explained by its highest viscosity. ${ }^{27}$

\section{Limitations}

In this experiment, all scans were performed on a circulation phantom. This phantom, which contains controllable and consistent physiological parameters, does not provide the physiological and anatomical heterogeneity of a standard population. Therefore, the effects of different BMIs on dose reduction were not evaluated.

\section{CONCLUSION}

These results show that automated tube current modulation can result in radiation dose reduction up to $53 \%$ and automated tube voltage selection up to $77 \%$, if human subjects approximate the dimensions and therefore the attenuation values of the phantom used in this experiment. Dose reduction was - as expected - independent of the CM concentration applied at normalised IDR. 


\section{REFERENCES}

1. Brody AS, Frush DP, Huda W, Brent RL and American Academy of Pediatrics Section on R. Radiation risk to children from computed tomography. Pediatrics. 2007;120:677-82.

2. Brenner DJ and Hall EJ. Computed tomography--an increasing source of radiation exposure. The New England journal of medicine. 2007;357:2277-84.

3. Keil S, Behrendt FF, Stanzel S, Suhling M, Koch A, Bubenzer J, Muhlenbruch G, Mahnken AH, Gunther RW and Das M. Semi-automated measurement of hyperdense, hypodense and heterogeneous hepatic metastasis on standard MDCT slices. Comparison of semi-automated and manual measurement of RECIST and WHO criteria. European radiology. 2008;18:2456-65.

4. Schenzle JC, Sommer WH, Neumaier K, Michalski G, Lechel U, Nikolaou K, Becker CR, Reiser MF and Johnson TR. Dual energy CT of the chest: how about the dose? Investigative radiology. 2010;45:347-53.

5. Kalra MK, Maher MM, Toth TL, Hamberg LM, Blake MA, Shepard JA and Saini S. Strategies for CT radiation dose optimization. Radiology. 2004;230:619-28.

6. McCollough $\mathrm{CH}$, Bruesewitz MR and Kofler JM, Jr. CT dose reduction and dose management tools: overview of available options. Radiographics : a review publication of the Radiological Society of North America, Inc. 2006;26:503-12.

7. McNitt-Gray MF. AAPM/RSNA Physics Tutorial for Residents: Topics in CT. Radiation dose in CT. Radiographics : a review publication of the Radiological Society of North America, Inc. 2002;22:1541-53.

8. Huda W, Scalzetti EM and Levin G. Technique factors and image quality as functions of patient weight at abdominal CT. Radiology. 2000;217:430-5.

9. Winklehner A, Goetti R, Baumueller S, Karlo C, Schmidt B, Raupach R, Flohr T, Frauenfelder T and Alkadhi H. Automated attenuation-based tube potential selection for thoracoabdominal computed tomography angiography: improved dose effectiveness. Investigative radiology. 2011;46:767-73.

10. Baumueller S, Alkadhi H, Stolzmann P, Frauenfelder T, Goetti R, Schertler T, Plass A, Falk V, Feuchtner G, Scheffel H, Desbiolles $L$ and Leschka S. Computed tomography of the lung in the high-pitch mode: is breath holding still required? Investigative radiology. 2011;46:240-5.

11. Lell MM, May M, Deak P, Alibek S, Kuefner M, Kuettner A, Kohler H, Achenbach S, Uder M and Radkow T. High-pitch spiral computed tomography: effect on image quality and radiation dose in pediatric chest computed tomography. Investigative radiology. 2011;46:116-23.

12. Sommer WH, Schenzle JC, Becker CR, Nikolaou K, Graser A, Michalski G, Neumaier K, Reiser MF and Johnson TR. Saving dose in triple-rule-out computed tomography examination using a highpitch dual spiral technique. Investigative radiology. 2010;45:64-71.

13. Prakash P, Kalra MK, Kambadakone AK, Pien H, Hsieh J, Blake MA and Sahani DV. Reducing abdominal CT radiation dose with adaptive statistical iterative reconstruction technique. Investigative radiology. 2010;45:202-10.

14. Kalra MK, Maher MM, Toth TL, Schmidt B, Westerman BL, Morgan HT and Saini S. Techniques and applications of automatic tube current modulation for CT. Radiology. 2004;233:649-57.

15. Katharine Grant PaBS, PhD. CAREkV Automated dose-optimized selection of X-ray tube voltage. 2011.

16. Heyer CM, Mohr PS, Lemburg SP, Peters SA and Nicolas V. Image quality and radiation exposure at pulmonary CT angiography with 100 - or $120-\mathrm{kVp}$ protocol: prospective randomized study. Radiology. 2007;245:577-83.

17. Bischoff B, Hein F, Meyer T, Hadamitzky M, Martinoff S, Schomig A and Hausleiter J. Impact of a reduced tube voltage on $\mathrm{CT}$ angiography and radiation dose: results of the PROTECTION I study. JACC Cardiovascular imaging. 2009;2:940-6. 
18. Siegel MJ, Schmidt B, Bradley D, Suess C and Hildebolt C. Radiation dose and image quality in pediatric CT: effect of technical factors and phantom size and shape. Radiology. 2004;233:515-22.

19. Yu L, Fletcher JG, Grant KL, Carter RE, Hough DM, Barlow JM, Vrtiska TJ, Williamson EE, Young PM, Goss BC, Shiung M, Leng S, Raupach R, Schmidt B, Flohr T and McCollough CH. Automatic selection of tube potential for radiation dose reduction in vascular and contrast-enhanced abdominopelvic CT. AJR American journal of roentgenology. 2013;201:W297-306.

20. Kalender WA, Deak P, Kellermeier M, van Straten M and Vollmar SV. Application- and patient sizedependent optimization of x-ray spectra for CT. Medical physics. 2009;36:993-1007.

21. McCollough $\mathrm{CH}$, Primak AN, Braun N, Kofler J, Yu L and Christner J. Strategies for reducing radiation dose in CT. Radiologic clinics of North America. 2009;47:27-40.

22. Meinel FG, Canstein C, Schoepf UJ, Sedlmaier M, Schmidt B, Harris BS, Flohr TG and De Cecco CN. Image quality and radiation dose of low tube voltage 3(rd) generation dual-source coronary CT angiography in obese patients: a phantom study. European radiology. 2014;24:1643-50.

23. Mahnken $\mathrm{AH}$, Jost $\mathrm{G}$, Seidensticker $\mathrm{P}$, Kuhl $\mathrm{C}$ and Pietsch $\mathrm{H}$. Contrast timing in computed tomography: effect of different contrast media concentrations on bolus geometry. European journal of radiology. 2012;81:e629-32.

24. Behrendt FF, Pietsch H, Jost G, Sieber MA, Keil S, Plumhans C, Seidensticker P, Gunther RW and Mahnken $\mathrm{AH}$. Intra-individual comparison of different contrast media concentrations (300 mg, $370 \mathrm{mg}$ and $400 \mathrm{mg}$ iodine) in MDCT. European radiology. 2010;20:1644-50.

25. Behrendt FF, Bruners P, Kalafut J, Mahnken AH, Keil S, Plumhans C, Das M, Stanzel S, Wildberger JE, Pfeffer J, Gunther RW and Muhlenbruch G. Introduction of a dedicated circulation phantom for comprehensive in vitro analysis of intravascular contrast material application. Investigative radiology. 2008;43:729-36.

26. Mihl C, Wildberger JE, Jurencak T, Yanniello MJ, Nijssen EC, Kalafut JF, Nalbantov G, Muhlenbruch G, Behrendt FF and Das M. Intravascular enhancement with identical iodine delivery rate using different iodine contrast media in a circulation phantom. Investigative radiology. 2013;48:813-8.

27. Kok M, Mihl C, Mingels AA, Kietselaer BL, Muhlenbruch G, Seehofnerova A, Wildberger JE and Das M. Influence of Contrast Media Viscosity and Temperature on Injection Pressure in Computed Tomographic Angiography: A Phantom Study. Investigative radiology. 2014.

28. Deak PD, Smal Y and Kalender WA. Multisection CT protocols: sex- and age-specific conversion factors used to determine effective dose from dose-length product. Radiology. 2010;257:158-66.

29. Lee SM, Lee W, Chung JW, Park EA and Park JH. Effect of kVp on image quality and accuracy in coronary $\mathrm{CT}$ angiography according to patient body size: a phantom study. The international journal of cardiovascular imaging. 2013;29 Suppl 2:83-91.

30. Angel E, Yaghmai N, Jude CM, DeMarco JJ, Cagnon CH, Goldin JG, McCollough CH, Primak AN, Cody DD, Stevens DM and McNitt-Gray MF. Dose to radiosensitive organs during routine chest CT: effects of tube current modulation. AJR American journal of roentgenology. 2009;193:1340-5.

31. Graser A, Wintersperger BJ, Suess C, Reiser MF and Becker CR. Dose reduction and image quality in MDCT colonography using tube current modulation. AJR American journal of roentgenology. 2006;187:695-701.

32. Schwarz F, Grandl K, Arnoldi A, Kirchin MA, Bamberg F, Reiser MF and Becker CR. Lowering radiation exposure in $C T$ angiography using automated tube potential selection and optimized iodine delivery rate. AJR American journal of roentgenology. 2013;200:W628-34.

33. Awai K, Hiraishi $\mathrm{K}$ and Hori S. Effect of contrast material injection duration and rate on aortic peak time and peak enhancement at dynamic CT involving injection protocol with dose tailored to patient weight. Radiology. 2004;230:142-50.

34. Bae KT. Intravenous contrast medium administration and scan timing at CT: considerations and approaches. Radiology. 2010;256:32-61. 




\section{CHAPTER 4}

Optimising contrast media application in coronary CT angiography at lower tube voltage: evaluation in a circulation phantom and sixty patients

Kok M, Mihl C, Hendriks BMF, Altintas S, Kietselaer BLH, Wildberger JE, Das M. Eur J Radiol. 2016 Jun;85(6):1068-74. 


\section{ABSTRACT}

\section{Purpose}

The purpose was to investigate optimal contrast media (CM) injection parameters for lower kVp settings, whilst maintaining diagnostic attenuation levels.

\section{Methods and materials}

First, a circulation phantom with physiological parameters (BP 120/80mmHg, HR $60 \mathrm{bpm}$ ) was used. A fixed $\mathrm{CM}$ injection protocol was used for each $\mathrm{kVp}$ setting $(300 \mathrm{mgl} / \mathrm{ml}$ [lopromide], volume $=45 \mathrm{ml}$, flow rate $=6.0 \mathrm{ml} / \mathrm{s}$, iodine delivery rate $(I D R)=1.8 \mathrm{gl} / \mathrm{s}$, iodine load=13.5gl; at 120,100, 80 and $70 \mathrm{kVp})$. Then, IDR was decreased by steps of $0.2 \mathrm{gl} / \mathrm{s}$ for each $\mathrm{kVp}$ setting, until diagnostically insufficient attenuation values were reached $(<325 \mathrm{HU})$. In order to keep injection time constant $(7.5 \mathrm{~s})$, total iodine load (TIL) was reduced accordingly.

Second, clinical applicability at 120 and $100 \mathrm{kVp}$ was evaluated in patients $(n=60)$ referred for coronary CT angiography. A standard and reduced ( $12 \%$ less) CM protocol was used based on weight classes and scan duration ('high-pitch': 1s; 'adaptive sequence' and 'helical': 7s). Attenuation levels of the coronary arteries were measured and compared between protocols.

\section{Results}

Using a fixed $\mathrm{CM}$ injection at each $\mathrm{kVp}$ level resulted in the following values (HU $\pm S D$ ):

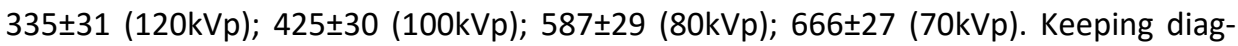
nostic enhancement levels ( $353 \pm 28$ ) CM could be reduced as follows: $12 \%$ for $100 \mathrm{kVp}$; $45 \%$ for $80 \mathrm{kVp}$ and $56 \%$ for $70 \mathrm{kVp}$. Diagnostic enhancement levels could be reproduced with concurrent $\mathrm{CM}$ reduction $(-12 \%$ at $100 \mathrm{kVp})$ in the clinical setting $(382 \pm 35)$.

\section{Conclusion}

$\mathrm{CM}$ injection parameters can be substantially reduced at low kVp settings (up to $56 \%$ at $70 \mathrm{kVp}$ ), whilst maintaining diagnostic attenuation levels. This may play an important role in CT imaging of the coronary arteries as well as cerebral and peripheral circulations in the future. 


\section{INTRODUCTION}

Lowering tube voltage $[\mathrm{kVp}]$ in $\mathrm{CT}$ angiography (CTA) increases the degree of vascular contrast enhancement. ${ }^{1-3}$ This is explained by the fact that lower $\mathrm{kVp}$ translates into lower effective photon energy (effective photon energy being approximately half the $\mathrm{kVp})$, bringing the latter closer to the K-edge of lodine $(33.2 \mathrm{keV}){ }^{4,5}$ Thus, at lower kVp settings comparable attenuation values can theoretically be reached using less contrast media. Reducing the amount of CM whilst maintaining optimal diagnostic enhancement values is desirable as it may increase patient safety, reducing the risk of contrast-induced nephropathy $(\mathrm{CIN})^{6}$, and reduce variable costs.

Theoretically, there are different ways in which $\mathrm{CM}$ injection protocols may be adapted for CTA. Important parameters are CM volume [ml], total iodine load (TIL = total iodine in $\mathrm{gI})$, and iodine delivery rate (IDR= the amount of iodine injected per second $[\mathrm{gl} / \mathrm{s}]=$ concentration of $\mathrm{CM}^{*}$ flow rate in $\mathrm{ml} / \mathrm{s}$ ). In this respect, multiple studies indicated that the IDR can be considered as the most decisive parameter in attenuation of the vascular structures. ${ }^{71}$ IDR can be adapted solely or in a combined fashion with TIL. If adapted separately, however, overall injection time is influenced as well. This is undesirable, injection time being a decisive injection protocol parameter, optimised for the target organ in combination with the scan protocol chosen. Adapting TIL and IDR simultaneously, however, will allow injection time to remain constant. Furthermore, using a combination of TIL and IDR in study design ensures uniformity even when different CM types are used.

The use of lower kVp settings in CTA has become more popular, however, image noise increases at lower kVp settings, mainly due to higher absorption of low-energy photons by the patient. ${ }^{12}$ Nowadays, new reconstruction technologies such as iterative reconstruction (IR) improve image quality in comparison to routinely used filtered back projection (FBP), as IR reduces image noise. ${ }^{13-16}$ This may help in maintaining diagnostic image quality whilst using reduced radiation dose.

The purpose of this study was to systematically investigate how to optimise CM injection parameters at lower kVp settings. First, a circulation phantom was used, ensuring high reproducibility, standardisation, and, therefore, excluding patient-related variability. Second, based on the results of the in vitro study, the clinical applicability was evaluated in a patient population at $120 \mathrm{kVp}$ and $100 \mathrm{kVp}$ in combination with IR. 


\section{METHODS AND MATERIALS}

\section{Study design}

The systematic approach of optimising CM injection parameters to lower kVp settings was assessed in vitro with a circulation phantom. Reproducibility of optimised CM injections was evaluated in vivo.

\section{In vitro setup}

\section{Circulation phantom}

A circulation phantom with physiological circulation parameters was used (heart rate 60 beats per minute [bpm], blood pressure $120 / 80 \mathrm{mmHg}$ ) as first described by Behrendt et $a l^{17}$ In recent years this phantom has been modified and validated in several experiments. ${ }^{8,9}$ The vasculature of the phantom consists of replicas of the ascending and descending aorta, the coronary arteries including left main coronary artery (LM); left anterior descending artery (LAD); circumflex artery (Cx) and right coronary artery (RCA), renal arteries and common iliac arteries.

\section{Scan and CM injection protocol}

Spiral CT scans of the coronary arteries were performed using a $2^{\text {nd }}$ generation dual source CT (DSCT) scanner (SOMATOM Definition Flash, Siemens Healthcare, Forchheim, Germany). A 3D reconstruction of the phantom aortic root and coronary elements is shown in figure 4.1.

A tissue equivalent ring was placed around the area of the coronary elements to simulate body surface. A clinically used examination protocol was applied with the following scan parameters: $128 \times 0.6 \mathrm{~mm}$ slice collimation; gantry rotation time $0.28 \mathrm{~s}$ and pitch value 0.23 . An automated tube current modulation (CareDose4D, Siemens) was switched off in the phantom experiments and the chosen effective tube-currenttime product varied for the different $k V p$ settings between $284-370 m A s_{\text {eff }}: 320 m A s_{\text {eff }}$ for 120 and $100 \mathrm{kVp}$ settings, reference tube-current-time product [mAs $\mathrm{s}_{\text {ref }}$ ] being 320 in clinical routine. For 80 and $70 \mathrm{kVp}$ settings, 370 and $284 \mathrm{mAs}_{\text {eff }}$ were chosen respectively, these values being the highest technically feasible tube-current-time product at these low $\mathrm{kVp}$ settings using this dedicated scanner. Image reconstruction was carried out using $0.75 \mathrm{~mm}$ slice thickness and an increment of $0.5 \mathrm{~mm}$ using an raw-data based iterative reconstruction mode (kernel: I26f SAFIRE iterative reconstruction strength 2 ). 


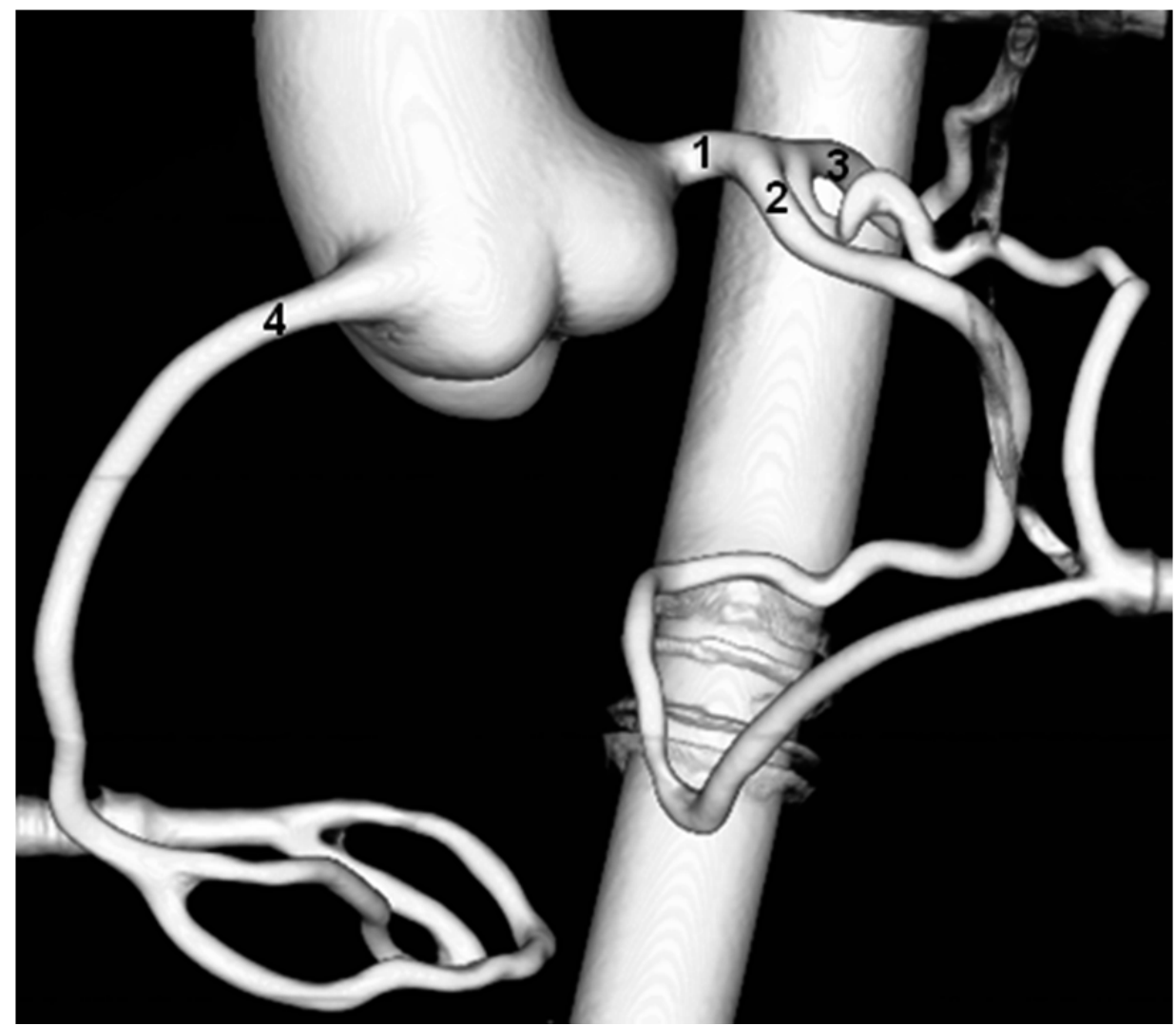

Figure 4.1 $A$ 3D reconstruction of the circulation phantom used $1=\mathrm{LM} ; 2=\mathrm{LAD} ; 3=\mathrm{Cx}$ and $4=\mathrm{RCA}$

$\mathrm{CM}$ with an iodine concentration of $300 \mathrm{mgl} / \mathrm{ml}$ (lopromide, Ultravist, Bayer Healthcare, Berlin, Germany) was applied at different kVp settings (120, 100, 80 and $70 \mathrm{kVp})$. After being warmed to body temperature $\left(37^{\circ} \mathrm{C} / 99^{\circ} \mathrm{F}\right), \mathrm{CM}$ was injected into the circulation phantom using a standard CT power injector (Stellant, MEDRAD, Pittsburgh, PA, USA), a three-way stopcock extension tube and a standard $18 \mathrm{G}$ needle (Sterican, Braun, Melsungen, Germany), under the following standardised conditions: First, one and the same $\mathrm{CM}$ injection protocol was used at each $\mathrm{kVp}$ setting (CM volume: $45 \mathrm{ml}$, flow rate: $6.0 \mathrm{ml} / \mathrm{s}$, IDR: $1.8 \mathrm{gl} / \mathrm{s}$ and TIL: $13.5 \mathrm{gl}$, at $120,100,80$ and $70 \mathrm{kVp})$. Second, based on the differences in attenuation values for these first scans, a specific starting point for IDR and TIL was chosen for the lower kVp settings (100, 80 and $70 \mathrm{kVp}$ ): $1.8 \mathrm{gl} / \mathrm{s}$ and $13.5 \mathrm{gl}$ for $100 \mathrm{kVp} ; 1.2 \mathrm{gl} / \mathrm{s}$ and $9 \mathrm{gl}$ for $80 \mathrm{kVp}$; and $1.0 \mathrm{gl} / \mathrm{s}$ and $7.5 \mathrm{gl}$ for $70 \mathrm{kVp}$. IDR was then decreased by steps of $0.2 \mathrm{gl} / \mathrm{s}$ for each $\mathrm{kVp}$ setting, until diagnostically insufficient attenuation values were reached $(<325 \mathrm{HU})^{18-20}$; TIL was reduced accordingly in order to keep injection time constant (7.5s). Before each injection pro- 
tocol, test bolus technique was used to determine the particular scan delay for each flow rate using $10 \mathrm{ml}$ of $\mathrm{CM}$. After each scan, a saline chaser was injected the same flow rate, injection time $3 \mathrm{~s}$. All flow rates and $\mathrm{CM}$ injection protocols used are listed in table 4.1 and were closely monitored during the experiments by using the Certegra ${ }^{\mathrm{TM}}$ Informatics Platform (Bayer). All protocols were repeated five times in order to determine reproducibility.

\begin{tabular}{|c|c|c|c|c|c|c|c|}
\hline $\begin{array}{l}\text { Tube } \\
\text { Voltage } \\
{[\mathrm{kVp}]}\end{array}$ & $\begin{array}{l}\text { Injection } \\
\text { Parameter } \\
\text { Reduction } \\
\text { [\%] }\end{array}$ & $\begin{array}{l}\mathrm{CM} \\
\text { Volume } \\
\text { [ml] }\end{array}$ & $\begin{array}{l}\text { Flow rate } \\
{[\mathrm{ml} / \mathrm{s}]}\end{array}$ & $\begin{array}{l}\text { IDR } \\
{[\mathrm{g} \mid / \mathrm{s}]}\end{array}$ & $\begin{array}{l}\text { TIL } \\
\text { [gl] }\end{array}$ & $\begin{array}{l}\text { Delay } \\
\text { [s] }\end{array}$ & $\begin{array}{l}\text { Injection } \\
\text { Time } \\
{[s]}\end{array}$ \\
\hline 120 & 0 & 45 & 6.0 & 1.8 & 13.5 & 16 & 7.5 \\
\hline \multirow[t]{3}{*}{100} & 0 & 45 & 6.0 & 1.8 & 13.5 & 16 & 7.5 \\
\hline & 12 & 40 & 5.3 & 1.6 & 12 & 17 & 7.5 \\
\hline & 23 & 35 & 4.7 & 1.4 & 10.5 & 17 & 7.5 \\
\hline \multirow[t]{3}{*}{80} & 34 & 30 & 4.0 & 1.2 & 9 & 18 & 7.5 \\
\hline & 45 & 25 & 3.3 & 1.0 & 7.5 & 19 & 7.5 \\
\hline & 56 & 20 & 2.7 & 0.8 & 6 & 20 & 7.5 \\
\hline \multirow[t]{3}{*}{70} & 45 & 25 & 3.3 & 1.0 & 7.5 & 19 & 7.5 \\
\hline & 56 & 20 & 2.7 & 0.8 & 6 & 20 & 7.5 \\
\hline & 67 & 15 & 2.0 & 0.6 & 4.5 & 24 & 7.5 \\
\hline
\end{tabular}

Table 4.1 Injection parameters used at the different kVp settings in the phantom experiments

\section{Data processing}

Dose related parameters such as computed tomography dose index (CTDI $\mathrm{vol}_{\text {ol }}$ ) and dose length product (DLP) for 120,100, 80 and 70kVp settings were recorded directly from the scanner console after each scan; injection related parameters were read out after each scan. Attenuation values (HU士SD) of CT-scan images were measured by delineating circular regions of interest (ROI) placed in the centers of the LM, LAD, Cx and RCA, using the source images on a dedicated post processing workstation (SyngoVia ${ }^{\mathrm{TM}}$, Siemens). SNR was calculated by dividing attenuation values by their standard deviations. In addition, background attenuation values $\left(\mathrm{HU}_{\text {water }}\right)$ and image noise $\left(\mathrm{SD}_{\text {water }}\right)$ were measured by delineating a circular region of interest (ROI) in the water-filled container. CNR was defined as the attenuation value of the enhanced vessel ( $\left.H U_{\text {vessel }}\right)$, minus the background attenuation value, divided by background image noise ( $\left.S D_{\text {water }}\right)$. 
Phantom images were independently analysed by two blinded experienced observers (MK, BH).

\section{Statistical analysis}

All continuous variables are reported as mean \pm standard deviation (SD). Intraobserver variability was evaluated by calculating intraclass correlation coefficients (ICC), using a two-way mixed model (SPSS version 20.0, SPSS Inc, Chicago, IL, USA).

Validation of the reproducibility of optimised CM injections: an in vivo setup

\section{Patients}

Clinical applicability was evaluated in a patient population $(n=60)$. Patients referred for coronary CTA (CCTA) with stable symptoms of chest discomfort and suspected coronary artery disease (CAD), were included. Baseline characteristics such as age, weight and heart rate were recorded for each patient.

Ethical approval was given and informed consent for the use of (coded) images was waived by the local ethical committee, as the data was analysed anonymously in accordance with the Institutional Review Board guidelines (METC 14-4-049).

\section{Scan and CM injection protocol}

For the assessment of the coronary arteries, scans were performed using the same scanner as was used in the phantom experiments. Scan parameters were as follows: $128 \times 0.6 \mathrm{~mm}$ slice collimation; $320 \mathrm{mAs}_{\text {ref; }}$ gantry rotation time $0.28 \mathrm{~s}$; pitch value 0.23 ("helical") or 3.4 ("high-pitch"); and a variable scan delay according to the test bolus method. An automated tube current modulation (CareDose4D, Siemens) was switched on. Image reconstruction was carried out with individually adapted FOV at $0.75 \mathrm{~mm}$ slice thickness and an increment of $0.5 \mathrm{~mm}$ using an raw-data based iterative reconstruction mode (kernel: I26f SAFIRE iterative reconstruction strength 2).

In patients with a stable heart rate of $<60$ beats per minute [bpm], a prospectively ECG-triggered "high pitch" spiral protocol was used. In patients with a stable heart rate of 60-90bpm, a prospectively triggered "adaptive sequence" protocol was used (prospective sequential data acquisition). In patients with an irregular heart rate, or with a stable heart rate of $>90 \mathrm{bpm}$, a retrospectively gated "helical" protocol was used. All patients received an oral dose of $50 \mathrm{mg}$ metoprolol tartrate (Selokeen; AstraZeneca, Zoetermeer, The Netherlands), two hours before CCTA. When indicated, an additional dose of 5-20mg metoprolol tartrate was administered intavenously with the aim to lower the heart rate to $<60 \mathrm{bpm}$, if possible. A maximum dose of $0.8 \mathrm{mg}$ nitroglycerine (Isordil ${ }^{\circledR}$, Pohl-Boskamp, Hohenlockstedt, Germany) was given sublingually just prior to CCTA. Heart rate and ECG were monitored during CCTA. 
Prewarmed $\mathrm{CM}\left(300 \mathrm{mgl} / \mathrm{ml}\right.$ at $\left.37^{\circ} \mathrm{C}\left[99^{\circ} \mathrm{F}\right]\right)$ was injected with a standard $\mathrm{CT}$ power injector, a three-way stopcock extension tube, and a standard $18 \mathrm{G}$ needle. Patients were divided into three groups ( $n=20$ for each group). Group 1 (120kVp) and group 2 $(100 \mathrm{kVp})$ received our standard clinical injection protocol for CCTA, which is based on the weight of the patient and duration of the CT data acquisition (P3T Cardiac ${ }^{\mathrm{TM}}$, Bayer). Group $3(100 \mathrm{kVp})$ received a reduction protocol, in which the standard injection protocol parameters CM volume, IDR and TIL were reduced by the percentage found in the experimental setup for $100 \mathrm{kVp}$. The clinical applicability of the $80 \mathrm{kVp}$ and $70 \mathrm{kVp}$ protocols was not tested due to technical limitations of the current used scanner in the experiments: it is not feasible for the current scanner to apply the necessary tube-current-time products for all patients in order to maintain diagnostic image quality in lower kVp settings.

The details of each protocol are given in table 4.2. Scan delay was determined by using test bolus technique $(20 \mathrm{ml}$ of $\mathrm{CM}$ in combination with the calculated flow rate). All injection parameters were closely monitored using a dedicated informatics platform (Certegra ${ }^{\mathrm{TM}}$, Bayer).

\section{Data processing}

Injection related parameters were read out after each scan. Images were analysed by using the source images on a dedicated post processing workstation (SyngoVia ${ }^{\mathrm{TM}}$, Siemens).

Subjective image quality of the images was determined by rating the presence of artefacts using a 4-point grading-scale: 1 = non diagnostic image quality; 2 = reduced image quality due to major artefacts, but still diagnostic; 3 = good image quality with minor artefacts and 4 = excellent image quality without artefacts. Image quality was rated in consensus by an experienced radiologist and cardiologist. Objective image quality was determined by measuring intravascular enhancement of the coronary arteries using manually placed ROIs at the levels of the LM, LAD, Cx and RCA. Measurements were performed by placing ROls in the center of each vessel - using the maximum possible diameter and while avoiding the vessel wall (see also figure 4.2). Background attenuation levels and image noise - required for the calculation of CNR - were measured by delineating a circular region of interest (ROI) in pectoral muscle. Diagnostic image quality was considered sufficient at attenuation values $>325 \mathrm{HU}^{18-20}$ and $\mathrm{CNR}>10 .^{21}$ Objective image quality was independently analysed by two blinded experienced observers (MK, BH). 
OPTIMISING CONTRAST MEDIA APPLICATION IN CORONARY CTA

\begin{tabular}{|c|c|c|c|c|c|c|c|}
\hline Injection protocol & $\begin{array}{c}\mathrm{CM} \text { bolus } \\
\text { [ml] }\end{array}$ & $\begin{array}{c}\text { Mixed bolus } \\
(20 \% \mathrm{CM}) \\
{[\mathrm{ml}]}\end{array}$ & $\begin{array}{c}\text { Total volume } \\
\text { (CM) } \\
\text { [ml] }\end{array}$ & $\begin{array}{r}\text { Saline } \\
\text { flush } \\
{[\mathrm{ml}]}\end{array}$ & $\begin{array}{c}\text { Flow rate } \\
{[\mathrm{ml} / \mathrm{s}]}\end{array}$ & $\begin{array}{c}\text { IDR } \\
{[\mathrm{g} \mid / \mathrm{s}]}\end{array}$ & $\begin{array}{l}\text { TIL } \\
{[g \mid]}\end{array}$ \\
\hline \multicolumn{8}{|l|}{$\begin{array}{l}\text { Standard } \\
\text { (Groups } 1 \text { and } 2 \text { ) }\end{array}$} \\
\hline \multicolumn{8}{|l|}{$60-74 \mathrm{~kg}$} \\
\hline 'adaptive/helix' & 56 & $67(13.4)$ & $123(69.4)$ & 40 & 5.6 & 1.7 & 22 \\
\hline 'flash' & 45 & $67(13.4)$ & $112(58.4)$ & 40 & 5.6 & 1.7 & 20 \\
\hline \multicolumn{8}{|l|}{$75-94 \mathrm{~kg}$} \\
\hline 'adaptive/helix' & 66 & $84(16.8)$ & $150(82.8)$ & 40 & 6.6 & 2.0 & 23 \\
\hline 'flash' & 53 & $84(16.8)$ & $137(69.8)$ & 40 & 6.6 & 2.0 & 21 \\
\hline \multicolumn{8}{|l|}{$\underline{12 \% \text { reduction }}$} \\
\hline \multicolumn{8}{|l|}{ (Group 3) } \\
\hline \multicolumn{8}{|l|}{$60-74 \mathrm{~kg}$} \\
\hline 'adaptive/helix' & 49 & $59(11.8)$ & $108(60.8)$ & 40 & 4.9 & 1.5 & 22 \\
\hline 'flash' & 40 & $59(11.8)$ & $99(51.8)$ & 40 & 4.9 & 1.5 & 20 \\
\hline \multicolumn{8}{|l|}{$75-94 \mathrm{~kg}$} \\
\hline 'adaptive/helix' & 58 & $74(14.8)$ & $132(72.8)$ & 40 & 5.8 & 1.7 & 23 \\
\hline 'flash' & 46 & $74(14.8)$ & $120(60.8)$ & 40 & 5.8 & 1.7 & 21 \\
\hline
\end{tabular}

Table 4.2 Injection protocol parameters according to patient body weight 

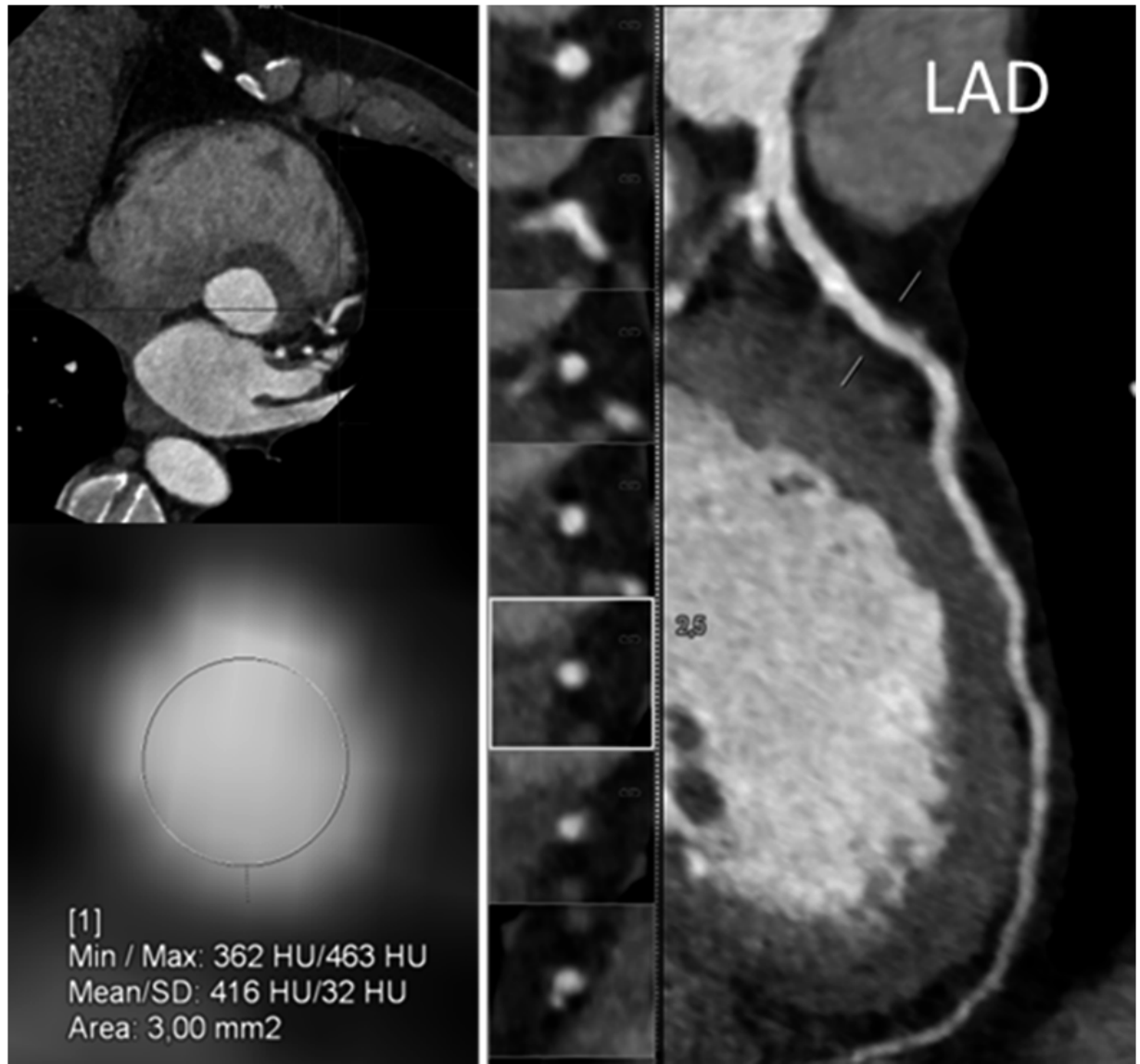

Figure 4.2 Images as reconstructed by Syngo-Via ${ }^{\mathrm{TM}}$ software

An axial multiplanar reconstruction (MPR) at the level of the LAD (left, top image); a straightened-MPR of the LAD with a given landmark (right image) and an orientated cross-section of the landmark including the ROI measurement (left, bottom image)

\section{Statistical analysis}

All continuous variables are reported as mean \pm standard deviation (SD). Objective image quality measurements and baseline characteristics (e.g. weight, age and heart rate) were compared between groups using one-way ANOVA followed by Tukey test for post hoc comparisons between groups. Differences in the division of scan protocols and subjective image quality were compared between groups using a Chi-Square test. Intra-observer variability was evaluated by calculating intraclass correlation coefficients (ICC), using a two-way mixed model (SPSS version 20.0, SPSS Inc, Chicago, IL, USA). 


\section{RESULTS}

In vitro setup

Radiation dose decreased with $83 \%$ when lowering $k V p$ settings from $120 \mathrm{kVp}$ to $70 \mathrm{kVp}$. Corresponding CTDIvol and DLP (mean \pm SD) were as follows: $71 \pm 1$ and $1088 \pm 18$ (120kVp); $43 \pm 2$ and $658 \pm 24$ (100kVp); $24 \pm 2$ and $363 \pm 37$ (80kVp); $12 \pm 1$ and $181 \pm 18$ (70kVp).

Using identical injection parameters, attenuation values (HU士SD) were as follows: $335 \pm 31$ (120kVp); $425 \pm 30$ (100kVp); 587 \pm 29 (80kVp); 666 \pm 27 (70kVp) (see figure 4.3). After stepwise reduction of IDR for lower kV settings, the minimum IDR and TIL values yielding diagnostically sufficient attenuation values were estimated to be as follows (see table 4.1 , bold): $1.6 \mathrm{gl} / \mathrm{s}$ and $12 \mathrm{gl}$ for $100 \mathrm{kVp} ; 1.0 \mathrm{gl} / \mathrm{s}$ and $7.5 \mathrm{gl}$ for $80 \mathrm{kVp} ; 0.8 \mathrm{gl} / \mathrm{s}$ and $6.0 \mathrm{gl}$ for $70 \mathrm{kVp}$. Corresponding attenuation values were in the range of $360 \pm 27$ and $382 \pm 35 \mathrm{HU}$ for all vascular segments. (see table 4.3 , bold). After post hoc comparisons, significant lower attenuation values were found in the LAD and $C x$ of $120 \mathrm{kVp}$ compared the other $k V p$ settings, with $p$-values $\leq 0.01$. TIL and IDR could be decreased at lower $\mathrm{kV}$ settings as compared to at $120 \mathrm{kVp}$, yielding diagnostically sufficient attenuation values: $12 \%$ at $100 \mathrm{kVp}, 45 \%$ at $80 \mathrm{kVp}$, and $56 \%$ at $70 \mathrm{kVp}$. 


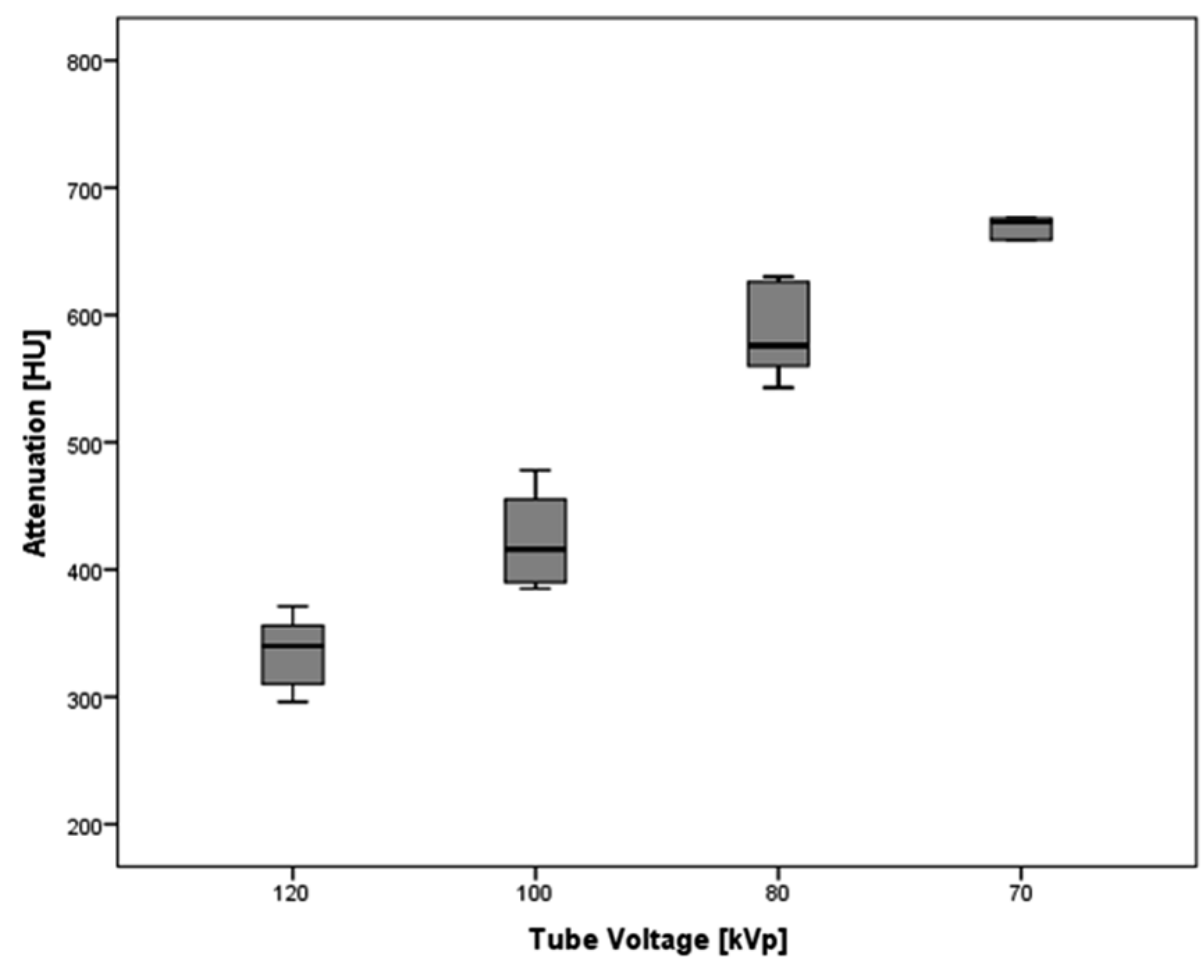

Figure 4.3 Mean attenuation values at different kVp settings

Identical injection parameters were used (CM volume: $45 \mathrm{ml}$, flow rate: $6.0 \mathrm{ml} / \mathrm{s}$, IDR: $1.8 \mathrm{gl} / \mathrm{s}$ and TIL: $13.5 \mathrm{gI})$ in phantom

SNR and CNR decreased with lowering kVp: $17 \pm 3$ and $21 \pm 2$ (120kVp); $13 \pm 3$ and $16 \pm 4$ $(100 \mathrm{kVp}) ; 10 \pm 2$ and $11 \pm 2(80 \mathrm{kVp})$ and $5 \pm 1$ and $8 \pm 1(70 \mathrm{kVp})$, with $p$-values <.001 (see table 4.3, bold). Reproducibility of image quality measurements proved to be very good: intraclass correlation was high (0.993). 


\begin{tabular}{|l|l|l|l|l|l|l|l|}
\hline $\begin{array}{l}\text { Tube Voltage } \\
{[\mathrm{kVp}]}\end{array}$ & $\begin{array}{l}\text { Injection parameter } \\
\text { reduction } \\
{[\%]}\end{array}$ & $\begin{array}{l}\text { LM } \\
{[\mathrm{HU}]}\end{array}$ & $\begin{array}{l}\text { LAD } \\
{[\mathrm{HU}]}\end{array}$ & $\begin{array}{l}\mathrm{CX} \\
{[\mathrm{HU}]}\end{array}$ & $\begin{array}{l}\text { RCA } \\
{[\mathrm{HU}]}\end{array}$ & SNR & CNR \\
\hline \multirow{2}{*}{120} & 0 & $335 \pm 31$ & $337 \pm 29$ & $327 \pm 20$ & $354 \pm 27$ & $17 \pm 3$ & $21 \pm 2$ \\
\hline \multirow{3}{*}{100} & 0 & $425 \pm 30$ & $422 \pm 23$ & $419 \pm 29$ & $463 \pm 23$ & $16 \pm 3$ & $18 \pm 4$ \\
\cline { 2 - 8 } & 12 & $377 \pm 22$ & $360 \pm 30$ & $362 \pm 16$ & $365 \pm 27$ & $13 \pm 3$ & $16 \pm 4$ \\
\cline { 2 - 8 } & 23 & $319 \pm 27$ & $315 \pm 17$ & $323 \pm 34$ & $320 \pm 18$ & $13 \pm 4$ & $14 \pm 1$ \\
\hline 80 & 34 & $434 \pm 26$ & $436 \pm 28$ & $408 \pm 36$ & $430 \pm 23$ & $10 \pm 1$ & $13 \pm 2$ \\
\cline { 2 - 8 } & 45 & $375 \pm 28$ & $360 \pm 30$ & $381 \pm 25$ & $382 \pm 35$ & $10 \pm 2$ & $11 \pm 2$ \\
\cline { 2 - 8 } & 56 & $290 \pm 29$ & $272 \pm 33$ & $294 \pm 30$ & $288 \pm 11$ & $6 \pm 1$ & $9 \pm 1$ \\
\hline 70 & 45 & $446 \pm 29$ & $443 \pm 29$ & $438 \pm 30$ & $470 \pm 17$ & $6 \pm 1$ & $10 \pm 1$ \\
\cline { 2 - 8 } & 56 & $379 \pm 14$ & $375 \pm 30$ & $376 \pm 19$ & $377 \pm 29$ & $5 \pm 1$ & $8 \pm 1$ \\
\cline { 2 - 8 } & 67 & $284 \pm 31$ & $274 \pm 30$ & $280 \pm 24$ & $284 \pm 31$ & $4 \pm 1$ & $5 \pm 2$ \\
\hline
\end{tabular}

Table 4.3 Attenuation values of vascular segments at 70, 80, 100 and $120 \mathrm{kVp}$

Values are expressed as mean \pm SD. According the injection parameters of table 4.1.

* P-values were based on the differences between attenuation values of different $k V p$ settings - provided in the middle row of each $\mathrm{kVp}$ setting (bold)

^ Significant differences were only found between $120 \mathrm{kVp}$ and 100, 80 and 70kVp

\section{In vivo setup}

Mean body weight of groups 1, 2 and 3 was: $84 \pm 6 \mathrm{~kg}$ (range: $75-90) ; 83 \pm 5 \mathrm{~kg}$ (range: 75-90) and 79 $\pm 4 \mathrm{~kg}$ (range: $73-87$ ) respectively. All baseline characteristics are listed in table 4.4. Significant lower weight was found for group 3 compared to the other two groups $(p=0.04)$.

Mean CTDIvol and DLP (mean \pm SD) for $120 \mathrm{kVp}$ (group 1) and 100kVp (group 2 and 3) were as follows: group 1: $11 \pm 1$ and $121 \pm 16$ ('high-pitch'), $52 \pm 6$ and $467 \pm 103$ ('adaptive'); group 2 and 3: $6 \pm 1$ and 59 \pm 7 ('high-pitch') and $33 \pm 11$ and 270 \pm 97 ('adaptive'/'helical'). 


\begin{tabular}{|c|c|c|c|c|}
\hline \multicolumn{5}{|c|}{ Baseline characteristics } \\
\hline & $\begin{array}{l}\text { Group } 1 \\
(n=20)\end{array}$ & $\begin{array}{l}\text { Group } 2 \\
(n=20)\end{array}$ & $\begin{array}{l}\text { Group } 3 \\
(n=20)\end{array}$ & $\mathrm{p}$-value \\
\hline Age $[y]$ & $57 \pm 10$ & $55 \pm 11$ & $55 \pm 9$ & 0.81 \\
\hline Weight [kg] & $84 \pm 6$ & $83 \pm 5$ & $79 \pm 4$ & 0.04 \\
\hline Heart rate [bpm] & $60 \pm 6$ & $58 \pm 6$ & $61 \pm 8$ & 0.29 \\
\hline \multicolumn{5}{|c|}{ Scan protocol applied } \\
\hline & $\begin{array}{lr}\text { Flash } & 16(80 \%) \\
\text { Adaptive } & 4(20 \%)\end{array}$ & $\begin{array}{lr}\text { Flash } & 16(80 \%) \\
\text { Adaptive } & 4(20 \%)\end{array}$ & $\begin{array}{lr}\text { Flash } & 14(70 \%) \\
\text { Adaptive } & 4(20 \%) \\
\text { Helix } & 2(10 \%)\end{array}$ & 0.38 \\
\hline
\end{tabular}

Table 4.4 Baseline characteristics of study patient groups and applied scan protocols Values are expressed as mean \pm SD or $n$; (percentage)

Subjective image quality is shown in figure 4.4 and all datasets were diagnostic, no significant difference was found in image quality between groups ( $p=0.94)$. Figure 4.5 shows mean attenuation values for all three groups. Using identical injection parameters, attenuation values (HU \pm SD) were: Group 1: $328 \pm 21$ (LM), $320 \pm 29$ (LAD), $322 \pm 24$ (CX), and 330 \pm 31 (RCA); Group 2: $421 \pm 29$ (LM), 426 \pm 37 (LAD), $420 \pm 45$ (Cx), and 434 \pm 14 (RCA). Applying a $12 \%$ reduction in TIL and IDR at $100 \mathrm{kVp}$, provided attenuation values as follows: $369 \pm 38$ (LM); $353 \pm 28$ (LAD); $354 \pm 29$ (CX); and $355 \pm 39$ (RCA). Significant differences in attenuation values were found between al groups, with $p$-values <.001. Figure 4.6 shows mean SNR and CNR for all three groups. Mean SNR and CNR were as follows: $17 \pm 7$ and $23 \pm 6$ (group 1); $18 \pm 7$ and $19 \pm 7$ (group 2) and $18 \pm 11$ and $15 \pm 4$ (group $3)$. Significant differences were found in CNR between all groups, with $p$-values <.001. No significant differences were found in SNR between the three groups, with $p$-values $\geq 0.58$.

Reproducibility of objective image quality measurements proved to be very good: intraclass correlation was high (0.986). 


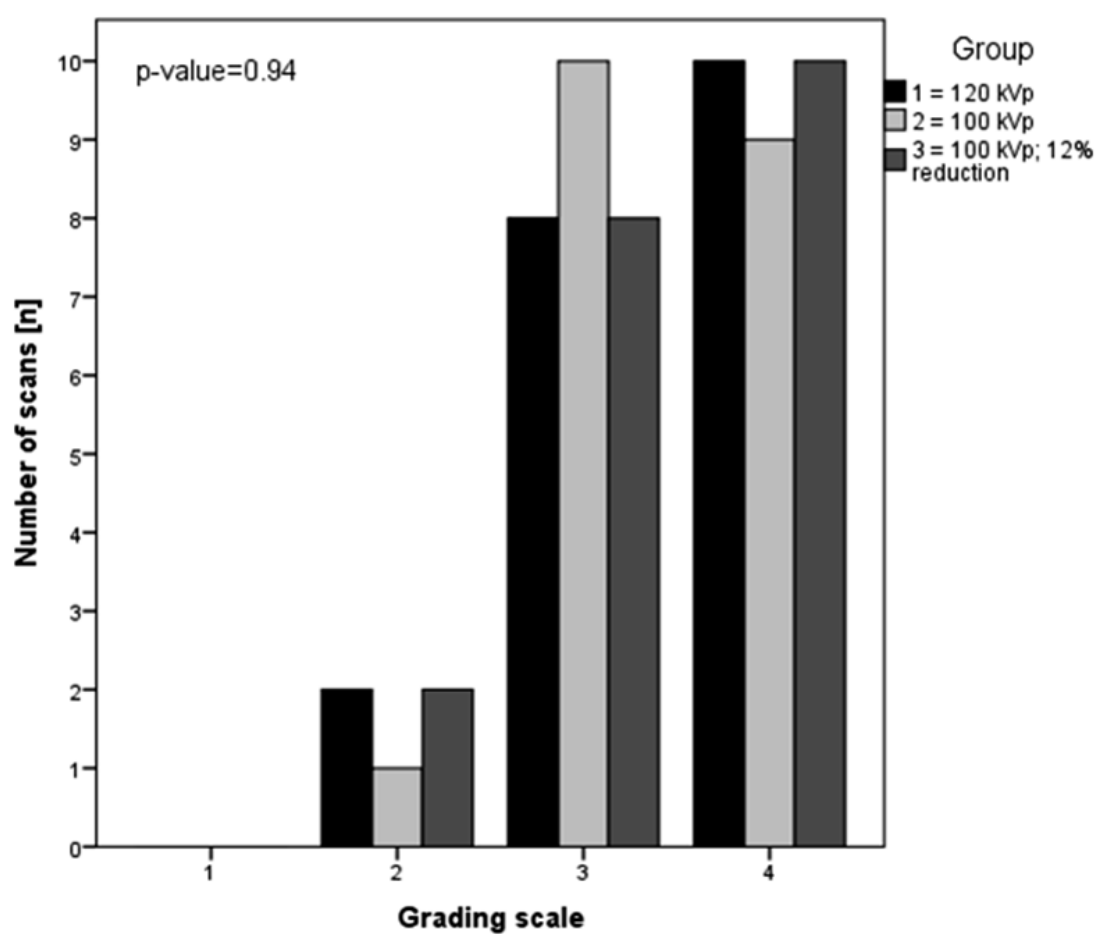

Figure 4.4 Subjective image qualities for group 1, 2 and 3

No significant differences were found between groups, with $p=0.94$ using Chi-square test. Grading scale: 1=non-diagnostic; 2=diagnostic with major artefacts; 3=good with minor artefacts and 4=excellent 


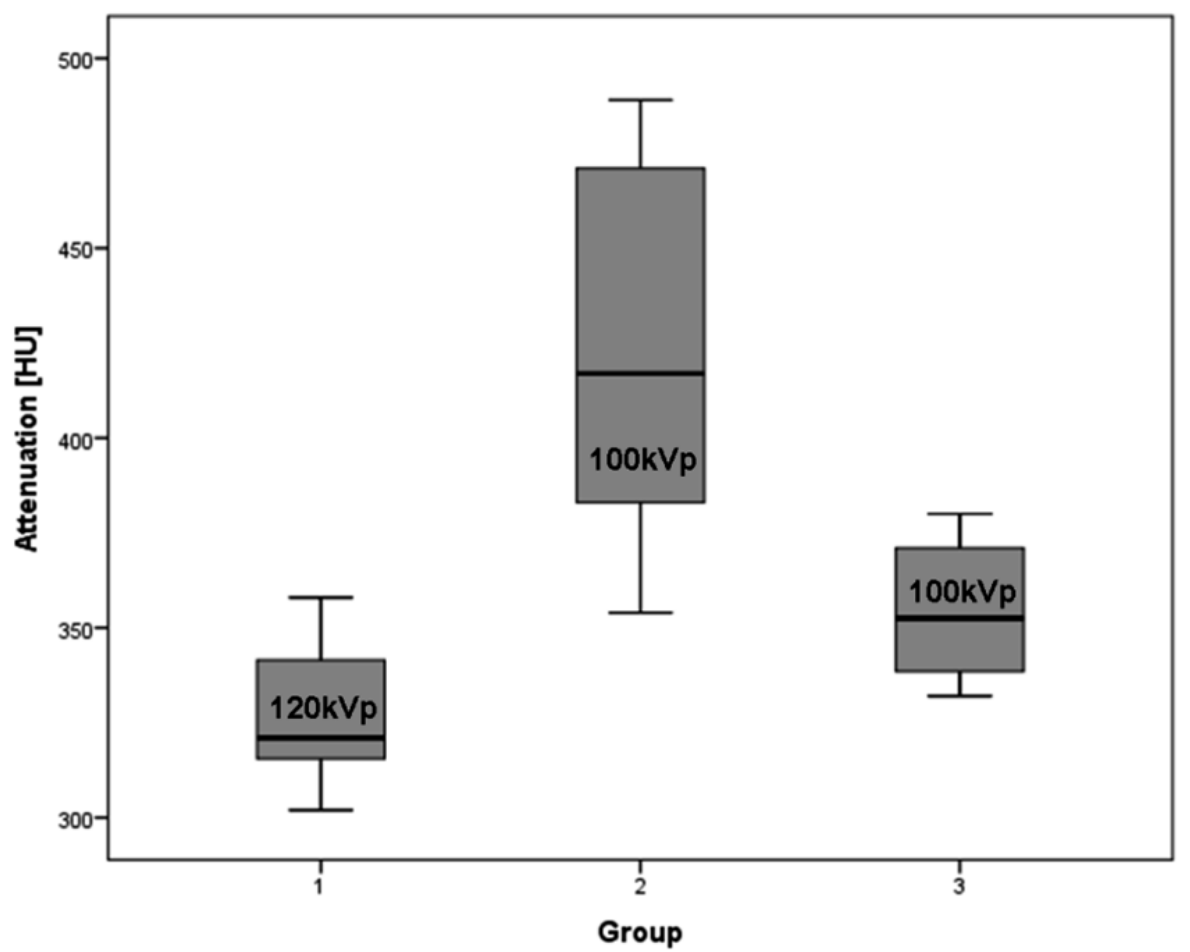

Figure 4.5 Box plots show mean enhancement levels in clinical setting for group 1, 2 and 3 $12 \%$ reduction of injection parameters was used in group 3 


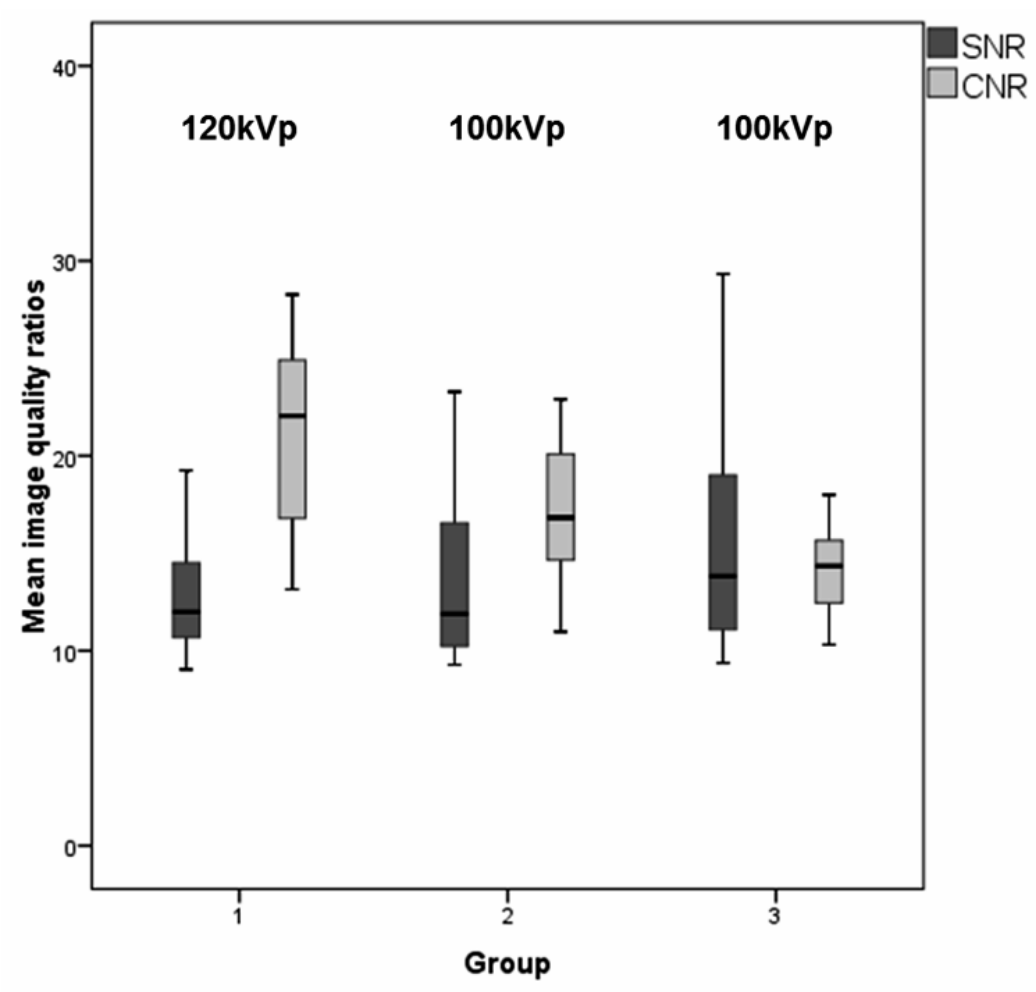

Figure 4.6 Box plots show the matching SNR and CNR in clinical setting for group 1, 2 and 3 $12 \%$ reduction of injection parameters was used for group 3

\section{DISCUSSION}

The current study presents a systematic approach on how to optimise CM injection for CTA at lower kVp settings, with a target enhancement level of $>325 \mathrm{HU}$. The systematic approach was successfully applied in phantom settings and confirmed in a patient setup.

In the systematic approach CM could be reduced by $12-56 \%$ for different $k V p$ settings and this is in line with other recent publications. For example, Lell et $a l^{22}$ investigated $k V p$ adjusted $\mathrm{CM}$ delivery in a systematic way for the thoraco-abdominal aorta with special regards to injection duration and IDR, using a porcine model. They also concluded that arterial enhancement could be maintained by adjusting the IDR to the specific $\mathrm{kVp}$ setting. They used a reduction percentage of $49 \%$ for $70 \mathrm{kVp}$ which is almost in line with our results; however, they did not describe any results from a clinical setting.

Thor et $a l^{23}$ investigated $\mathrm{kVp}$ adjusted $\mathrm{CM}$ volume reduction in various abdominal phantom sizes. They concluded that $44-53 \%$ CM volume could be saved using DSCT 
with $80 \mathrm{kVp}$ and $70 \mathrm{kVp}$, respectively. However, this was at the cost of radiation dose reduction: tube current was increased according to the $\mathrm{kVp}$ setting in order to maintain CNR. Namely, the challenge of reducing CM is to keep diagnostic image quality not only in terms of enhancement level but also in terms of CNR, as lower kVp settings result in higher image noise unless tube current could be adjusted sufficiently. Thus, the target level of $325 \mathrm{HU}$ would be sufficient only if image noise levels remained equal at all kVp settings. Unfortunately this is not possible for all type of CT scanners, hindering the use of lower kVp settings in a broad range of patients. Anyhow, modern CT scanners have higher tube current potential and better detector technology, allowing the use of lower kVp settings in a broader spectrum of patients and not only in pediatric patients and thinner patients.

In our clinical setting, we were able to apply $120 \mathrm{kVp}$ and $100 \mathrm{kVp}$ settings to patients weighing 73 - $90 \mathrm{~kg}$ while diagnostic image quality was maintained. The reduction to $100 \mathrm{kVp}$, including a CM volume reduction of $12 \%$, was validated: attenuation values were diagnostic and comparable to those achieved in phantom, even with higher attenuation values for $100 \mathrm{kVp}$ settings compared to $120 \mathrm{kVp}$, which was probably due to a lower overall patient weight in group 3. This indicates that even higher $\mathrm{CM}$ reduction can be feasible in lower weight patients.

Adaptation of CM to lower kV settings has been investigated by other groups as well, even though mostly not in a systematic approach and lower kV settings had to be restricted to a certain weight group. Zhang et $a l^{24}$ found that a reduction of CM and IDR by $10-20 \%$ in CCTA at $100 \mathrm{kVp}$ as compared to $120 \mathrm{kVp}$ yielded adequate diagnostic image quality in patients with mean body mass index $(B M I)<25 \mathrm{~kg} / \mathrm{m}^{2}$. LaBounty et $a l^{25}$ used an $80 \mathrm{kVp}$ protocol in patients with a $\mathrm{BMI}<25 \mathrm{~kg} / \mathrm{m}^{2}$ undergoing CCTA, and found it to be feasible. However, CM parameters were not adapted, resulting in higher contrast enhancement with lower $\mathrm{kVp}$, as well as overall attenuation values above 700 $\mathrm{HU}$. These results emphasise the need for CM optimisation at different $\mathrm{kVp}$ settings in order to achieve the required enhancement level.

Kidoh et $\left.a\right|^{26}$ used an $80 \mathrm{kVp}$ protocol for CTA in triple-rule out patients, achieving a $30 \%$ reduction of $\mathrm{CM}$ as compared to their standard protocol. Mean body weight was around $60 \mathrm{~kg}$, however, which is not representative of the general patient population. Cao et $a l^{27}$ used an $80 \mathrm{kVp}$ protocol in patients undergoing CCTA, but only in patients with a $\mathrm{BMI}<23 \mathrm{~kg} / \mathrm{m}^{2}$ and low calcium load. They also achieved a $30 \%$ reduction of $\mathrm{CM}$ volume but again only in a patient population not representative for the general population in terms of body weight (mean $=58 \mathrm{~kg}$ ).

Practically, the use of lower kVp settings allow for the reduction of $\mathrm{CM}$. However, as aforementioned, lower kVp settings without sufficient adjustment of tube current will result in higher image noise levels and therefore diagnostic image quality can be compromised. In most recent literature, several approaches of image reconstruction have 
been explored to reduce image noise in low-dose CT while maintaining diagnostic image quality. ${ }^{28-30}$ For example, Song et $\left.a\right|^{28}$ achieved a significant reduction of image noise and radiation dose by using IR (SAFIRE) in comparison to the use of FBP in contrast-enhanced CT examination of the liver. And Berlin et al ${ }^{30}$ achieved comparable results by using hybrid IR compared to the use of FPB in contrast-enhanced pediatric abdominal CT.

Leng et $a l^{29}$ used virtual monoenergetic dual energy (DE) CT images in combination with an energy domain noise reduction technique in water phantoms. An advantage of virtual monoenergetic images is that iodine attenuation increases at lower monoenergetic energy. From this study, they concluded that the use of the energy domain noise reduction algorithm substantially decreased image noise with lower monoenergetic settings.

The current study gives insight into the underlying principles of a standardised approach reducing the most important injection parameters at lower kVp settings (IDR and TIL). The results may promote understanding of how to apply lower kVp settings on an individual basis, how to directly link contrast parameters such as IDR and TIL to tube voltage, and how to subsequently optimise contrast and dose settings. In view of ongoing advancements in detector technology, especially in adaptation of tubecurrent-time product, the number of patients who will benefit from such an individualised approach can only be expected to increase in the future. ${ }^{31-33}$

Furthermore, the presented reduction percentages might be generalised to the imaging of other circulations - for example cerebral and peripheral CTA - as the reductions were adapted to the $\mathrm{kVp}$ setting and applied in relation to the standard injection protocol for the specific vasculature.

\section{Limitations}

Although the clinical applicability of the systematic approach in a circulation phantom was tested in patients, the number of patients was limited and clinical applicability of the $80 \mathrm{kVp}$ and $70 \mathrm{kVp}$ protocols was not tested due to technical limitations of the current scanner.

\section{CONCLUSION}

This study provides a unique description of a systemic approach to CM injection optimisation at different kVp settings. In a circulation phantom, lower kVp settings allowed a substantial reduction in $\mathrm{CM}$ volume - up to $56 \%$ at $70 \mathrm{kVp}$ - whilst maintaining diagnostically sufficient attenuation within the target vessels. Initial results in patients 
confirmed this finding at $100 \mathrm{kVp}$ using $12 \%$ reduction of $\mathrm{CM}$ volume in CCTA. Attaining diagnostic attenuation values using reduced $\mathrm{CM}$ volumes may play an important role in the future - especially due to the ongoing advancements in detector technologies. Therefore, future prospective studies may help to define the clinical use of this technique in different circulations. 


\section{REFERENCES}

1. Funama Y, Awai K, Nakayama Y, Kakei K, Nagasue N, Shimamura M, et al. Radiation dose reduction without degradation of low-contrast detectability at abdominal multisection CT with a low-tube voltage technique: phantom study. Radiology. 2005;237:905-10.

2. Huda W, Scalzetti EM, Levin G. Technique factors and image quality as functions of patient weight at abdominal CT. Radiology. 2000;217:430-5.

3. Nakayama $Y$, Awai $K$, Funama $Y$, Hatemura M, Imuta M, Nakaura T, et al. Abdominal CT with low tube voltage: preliminary observations about radiation dose, contrast enhancement, image quality, and noise. Radiology. 2005;237:945-51.

4. Mahesh M. MDCT physics: the basics: technology, image quality and radiation dose. 1st ed. ed. Philadelphia: Lippincott Williams and Wilkins; 2009.

5. Brooks RA. A quantitative theory of the Hounsfield unit and its application to dual energy scanning. Journal of computer assisted tomography. 1977;1:487-93.

6. Mitchell AM, Jones AE, Tumlin JA, Kline JA. Incidence of contrast-induced nephropathy after contrastenhanced computed tomography in the outpatient setting. Clinical journal of the American Society of Nephrology : CJASN. 2010;5:4-9.

7. Muhlenbruch G, Behrendt FF, Eddahabi MA, Knackstedt C, Stanzel S, Das M, et al. Which lodine concentration in chest CT?--a prospective study in 300 patients. European radiology. 2008;18:2826-32.

8. Mihl C, Wildberger JE, Jurencak T, Yanniello MJ, Nijssen EC, Kalafut JF, et al. Intravascular enhancement with identical iodine delivery rate using different iodine contrast media in a circulation phantom. Investigative radiology. 2013;48:813-8.

9. Kok M, Mihl C, Mingels AA, Kietselaer BL, Muhlenbruch G, Seehofnerova A, et al. Influence of contrast media viscosity and temperature on injection pressure in computed tomographic angiography: a phantom study. Investigative radiology. 2014;49:217-23.

10. Nance JW, Jr., Henzler T, Meyer M, Apfaltrer P, Braunagel M, Krissak R, et al. Optimization of contrast material delivery for dual-energy computed tomography pulmonary angiography in patients with suspected pulmonary embolism. Investigative radiology. 2012;47:78-84.

11. Rist C, Nikolaou K, Kirchin MA, van Gessel R, Bae KT, von Ziegler F, et al. Contrast bolus optimization for cardiac 16-slice computed tomography: comparison of contrast medium formulations containing 300 and 400 milligrams of iodine per milliliter. Investigative radiology. 2006;41:460-7.

12. McCollough $\mathrm{CH}$, Primak AN, Braun N, Kofler J, Yu L, Christner J. Strategies for reducing radiation dose in CT. Radiologic clinics of North America. 2009;47:27-40.

13. Pontana F, Pagniez J, Duhamel A, Flohr T, Faivre JB, Murphy C, et al. Reduced-dose low-voltage chest CT angiography with Sinogram-affirmed iterative reconstruction versus standard-dose filtered back projection. Radiology. 2013;267:609-18.

14. Wang R, Schoepf UJ, Wu R, Reddy RP, Zhang C, Yu W, et al. Image quality and radiation dose of low dose coronary $\mathrm{CT}$ angiography in obese patients: sinogram affirmed iterative reconstruction versus filtered back projection. European journal of radiology. 2012;81:3141-5.

15. Korn A, Bender B, Fenchel M, Spira D, Schabel C, Thomas C, et al. Sinogram affirmed iterative reconstruction in head $\mathrm{CT}$ : improvement of objective and subjective image quality with concomitant radiation dose reduction. European journal of radiology. 2013;82:1431-5.

16. Baker ME, Dong F, Primak A, Obuchowski NA, Einstein D, Gandhi N, et al. Contrast-to-noise ratio and low-contrast object resolution on full- and low-dose MDCT: SAFIRE versus filtered back projection in a low-contrast object phantom and in the liver. AJR American journal of roentgenology. 2012;199:8-18.

17. Behrendt FF, Bruners $P$, Kalafut J, Mahnken AH, Keil S, Plumhans $\mathrm{C}$, et al. Introduction of a dedicated circulation phantom for comprehensive in vitro analysis of intravascular contrast material application. Investigative radiology. 2008;43:729-36. 
18. Cademartiri F, Maffei E, Palumbo AA, Malago R, La Grutta L, Meiijboom WB, et al. Influence of intracoronary enhancement on diagnostic accuracy with 64-slice CT coronary angiography. European radiology. 2008;18:576-83.

19. Cademartiri F, Mollet NR, Lemos PA, Saia F, Midiri M, de Feyter PJ, et al. Higher intracoronary attenuation improves diagnostic accuracy in MDCT coronary angiography. AJR American journal of roentgenology. 2006;187:W430-3.

20. Isogai T, Jinzaki M, Tanami Y, Kusuzaki H, Yamada M, Kuribayashi S. Body weight-tailored contrast material injection protocol for 64-detector row computed tomography coronary angiography. Japanese journal of radiology. 2011;29:33-8.

21. Leber AW, Knez A, Becker C, Becker A, White C, Thilo C, et al. Non-invasive intravenous coronary angiography using electron beam tomography and multislice computed tomography. Heart (British Cardiac Society). 2003;89:633-9.

22. Lell MM, Jost G, Korporaal JG, Mahnken AH, Flohr TG, Uder M, et al. Optimizing contrast media injection protocols in state-of-the art computed tomographic angiography. Investigative radiology. 2015;50:161-7.

23. Thor D, Brismar TB, Fischer MA. Low tube voltage dual source computed tomography to reduce contrast media doses in adult abdomen examinations: A phantom study. Medical physics. 2015;42:5100-9.

24. Zhang C, Zhang Z, Yan Z, Xu L, Yu W, Wang R. 320-row CT coronary angiography: effect of 100-kV tube voltages on image quality, contrast volume, and radiation dose. The international journal of cardiovascular imaging. 2011;27:1059-68.

25. LaBounty TM, Leipsic J, Poulter R, Wood D, Johnson M, Srichai MB, et al. Coronary CT angiography of patients with a normal body mass index using $80 \mathrm{kVp}$ versus $100 \mathrm{kVp}$ : a prospective, multicenter, multivendor randomized trial. AJR American journal of roentgenology. 2011;197:W860-7.

26. Kidoh M, Nakaura T, Nakamura S, Namimoto T, Nozaki T, Sakaino N, et al. Contrast material and radiation dose reduction strategy for triple-rule-out cardiac $\mathrm{CT}$ angiography: feasibility study of nonECG-gated low kVp scan of the whole chest following coronary CT angiography. Acta radiologica. 2013.

27. Cao JX, Wang YM, Lu JG, Zhang Y, Wang P, Yang C. Radiation and contrast agent doses reductions by using $80-\mathrm{kV}$ tube voltage in coronary computed tomographic angiography: a comparative study. European journal of radiology. 2014;83:309-14.

28. Song JS, Choi EJ, Kim EY, Kwak HS, Han YM. Attenuation-based automatic kilovoltage selection and sinogram-affirmed iterative reconstruction: effects on radiation exposure and image quality of portalphase liver CT. Korean journal of radiology. 2015;16:69-79.

29. Leng S, Yu L, Fletcher JG, McCollough CH. Maximizing lodine Contrast-to-Noise Ratios in Abdominal CT Imaging through Use of Energy Domain Noise Reduction and Virtual Monoenergetic Dual-Energy CT. Radiology. 2015;276:562-70.

30. Berlin SC, Weinert DM, Vasavada PS, Martinez-Rios C, Parikh RA, Wien MA, et al. Successful Dose Reduction Using Reduced Tube Voltage With Hybrid Iterative Reconstruction in Pediatric Abdominal CT. AJR American journal of roentgenology. 2015;205:392-9.

31. Meinel FG, Canstein C, Schoepf UJ, Sedlmaier M, Schmidt B, Harris BS, et al. Image quality and radiation dose of low tube voltage $3(\mathrm{rd})$ generation dual-source coronary CT angiography in obese patients: a phantom study. European radiology. 2014;24:1643-50.

32. Meyer M, Haubenreisser H, Schoepf UJ, Vliegenthart R, Leidecker C, Allmendinger $T$, et al. Closing in on the $\mathrm{K}$ edge: coronary $\mathrm{CT}$ angiography at 100,80 , and $70 \mathrm{kV}$-initial comparison of a second-versus a thirdgeneration dual-source CT system. Radiology. 2014;273:373-82.

33. Hell MM, Bittner D, Schuhbaeck A, Muschiol G, Brand M, Lell M, et al. Prospectively ECG-triggered highpitch coronary angiography with third-generation dual-source CT at $70 \mathrm{kVp}$ tube voltage: feasibility, image quality, radiation dose, and effect of iterative reconstruction. Journal of cardiovascular computed tomography. 2014;8:418-25. 




\section{CHAPTER 5}

\section{Individually tailored contrast enhancement in CT pulmonary angiography}

Hendriks BMF, Kok M, Mihl C, Bekkers SC, Wildberger JE, Das M.

Br J Radiol. 2016 May;89(1061):20150850. 


\section{ABSTRACT}

\section{Purpose}

The purpose was to evaluate individually shaped contrast media (CM) delivery in CT pulmonary angiography (CTPA) for suspected pulmonary embolism.

\section{Materials and methods}

100 consecutive emergency patients with clinical suspicion for pulmonary embolism were evaluated. High-pitch CTPA was performed on a $2^{\text {nd }}$ generation dual-source CT using the following parameters: $100 \mathrm{kVp}, 200-250 \mathrm{mAs}_{\text {ref, }}$ rot.time $0.28 \mathrm{~s}, 128 \times 0.6 \mathrm{~mm}$ col., image reconstruction 1.0/0.8mm (B30f). Group $1(n=50)$ then received a fixed CM bolus $(300 \mathrm{mgl} / \mathrm{ml}$, volume $=90 \mathrm{ml}$, flow rate $=6 \mathrm{ml} / \mathrm{s})$; group $2(n=50)$ received a body weight adapted $\mathrm{CM}$ bolus determined by dedicated contrast injection software. For analysis, groups were further subdivided into low $(40-75 \mathrm{~kg})$ and high $(76-117 \mathrm{~kg}$ ) weight groups. Technical image quality was graded using a four-point Likert scale (1=non-diagnostic; 2 =diagnostic; 3=good and 4=excellent image quality) at the level of the pulmonary trunk and pulmonary arteries. Objective image quality analysis was done measuring contrast enhancement in Hounsfield units [HU] at the same levels. Attenuation levels $>180 \mathrm{HU}$ were considered diagnostic.

\section{Results}

All examinations were graded diagnostic at each level. The individual minimum pulmonary attenuation was $184 \mathrm{HU}$ and $270 \mathrm{HU}$ for group 1 and 2, respectively. Mean attenuation was as follows: group 1: $475 \pm 105 \mathrm{HU}(40-75 \mathrm{~kg})$ and $402 \pm 115 \mathrm{HU}$ (76$117 \mathrm{~kg}), \mathrm{p}<0.03$. Group 2: $424 \pm 76 \mathrm{HU}(40-75 \mathrm{~kg})$ and $418 \pm 100 \mathrm{HU}(76-117 \mathrm{~kg}), \mathrm{p}=0.8$. For group 2, CM volumes were: $55 \pm 5 \mathrm{ml}(40-75 \mathrm{~kg})$ and $66 \pm 5 \mathrm{ml}(76-117 \mathrm{~kg})$, leading to a 16 $51 \% \mathrm{CM}$ reduction.

\section{Conclusion}

Even under emergency conditions, individualised $\mathrm{CM}$ protocols can provide diagnostic and robust image quality in CTPA for pulmonary embolism with a substantial reduction of $\mathrm{CM}$ volume for lower weight patients, compared to a fixed CM protocol. 


\section{INTRODUCTION}

Pulmonary embolism (PE) is a major cause of morbidity and mortality with acute PE being the most severe clinical presentation. ${ }^{1}$ Computed tomographic pulmonary angiography (CTPA) is widely used to rule out or confirm the presence of PE and is considered the reference standard for this emergency indication. ${ }^{2,3}$ The improvement of scanning techniques with the invention of the multidetector-row CT has led to high spatial and temporal resolution, better delineation of peripheral arteries and an increased detection rate of (sub-)segmental PE., ${ }^{3,4}$ Additionally, CTPA has been shown to provide an alternative diagnosis in up to $70 \%$ of patients where PE is not confirmed. ${ }^{5}$ The diagnostic and clinical value of CTPA has already been firmly substantiated ${ }^{5-8}$, thus future research should focus on optimising scan protocols and improving workflow. 9,10 A considerable obstacle in current clinical practice is a substantial number of nondiagnostic scans, with reported rates ranging between $3.3 \%$ and $7.3 \% .{ }^{11,}{ }^{12}$ However, for an emergency indication such as PE, the scan protocol should be expected to deliver robust and reliable results twenty four hours a day, seven days a week. According to current literature, a diagnostically enhanced CTPA requires an intra-arterial attenuation of at least $180 \mathrm{HU}$, which allows for visualisation of pulmonary pathology in at least $90 \%$ of the patient population. ${ }^{11,13}$ The enhancement of pulmonary arteries depends on multiple factors: scan technique including tube settings (voltage [kVp]; current [mAs]), scan duration, patient related factors such as breathing (Valsalva) and body weight as well as contrast media (CM) administration parameters. ${ }^{11,14,15}$ Regarding the latter, both the amount of iodine injected per second (iodine delivery rate; [IDR]) and the total amount of iodine (total iodine load; [TIL]) are important factors in the enhancement of the pulmonary arteries. ${ }^{5,14-16}$ One of the most influential patient related factors is body weight; arterial enhancement and body weight have been found to correlate significantly, as well as enhancement and body mass index (BMI). ${ }^{14,15}$ Therefore, fixed CM protocols may result in attenuation values below diagnostic level for heavier patients, whereas for skinny patients attenuation may exceed required levels. Therefore, a solution could possibly be found in individualising contrast application for each patient. This study aimed to prospectively evaluate individually shaped CM delivery in emergency CTPA for suspected PE.

\section{MATERIALS AND METHODS}

\section{Ethics}

A waiver of written informed consent was obtained from the local ethical committee (METC, ref. 14-4-198). 


\section{Study population}

Inclusion criteria were: referral for CTPA for suspected PE; $\geq 18$ years of age and a glomerular filtration rate $\geq 60 \mathrm{ml} / \mathrm{min} / 1.73 \mathrm{~m}^{2}$. All patients were weighed by radiological technicians directly before CTPA; in case of immobile patients weighing was sometimes obstructed and the last known weight was recorded from the electronic patient files, when available. Patients were excluded when an alternative scan protocol (e.g. higher kilovoltage; $[k V p])$ had to be used $(n=11)$ or when body weight/injection data was incomplete $(n=25)$. A total of 100 consecutive patients were included for data analysis.

\section{Imaging protocol}

All scans were performed on a $2^{\text {nd }}$ generation dual-source multidetector-row CT scanner (Somatom Definition Flash, Siemens Healthcare, Forchheim, Germany) using a high-pitch CTA protocol ("Flash") with a tube voltage of $100 \mathrm{kVp}$, a tube current of 200 $250 \mathrm{mAs}_{\text {ref }}$ (CareDose $4 \mathrm{D}^{\mathrm{TM}}$, Siemens) and a pitch value of 2.6. A gantry rotation time of $0.28 \mathrm{~s}$ and a slice collimation of $128 \times 0.6 \mathrm{~mm}$ were applied. Image reconstruction was performed using a medium-smooth soft tissue kernel (Siemens B30f) at a slice thickness of $1 \mathrm{~mm}$ with an overlapping increment of $0.8 \mathrm{~mm}$.

\section{CM injection protocol}

Pre-warmed $\left(37^{\circ} \mathrm{C}\left[99^{\circ} \mathrm{F}\right]\right) \mathrm{CM}$ (Ultravist; lopromide $300 \mathrm{mgl} / \mathrm{ml}$, Bayer Healthcare, Berlin, Germany) was used for all patients. CM was administered using a programmable dual-head CT injector (Stellant, Bayer), via an 18-20G intravenous injection catheter in the left or right antecubital vein.

The first fifty patients (group 1) received $\mathrm{CM}$ injection according to our clinical standard PE protocol consisting of a $\mathrm{CM}$ phase of $75 \mathrm{ml}$, as well as a mixed phase with total $30 \mathrm{ml}$ of $50 \% \mathrm{CM}$ and $50 \% \mathrm{NaCl}$ (TIL: $27 \mathrm{gl}$ ). Flow rate was $6 \mathrm{ml} / \mathrm{s}$ (IDR: $1.8 \mathrm{gl} / \mathrm{s}$ ). All CM injections were followed by a saline chaser of $30 \mathrm{ml}$ at the same flow rate.

The second fifty patients (group 2) received individual CM injection protocols adjusted to body weight $[\mathrm{kg}$ ] and scan duration [s], calculated by a dedicated contrast injection software (Certegra ${ }^{\text {TM }}$ P3T, Bayer). This injection software is able to calculate CM volume and flow rate based upon a nonlinear relationship between patient weight and duration of the CT data acquisition. ${ }^{17,18}$ After the body weight of the patient and average scan duration for the specific acquisition are provided by the user, $\mathrm{CM}$ volume and flow rate will be adapted simultaneously in order to provide similar injection duration for each patient. All injections were followed by a saline chaser of $30 \mathrm{ml}$ at the same calculated flow rates. 
For both groups, individual bolus timing in order to generate an individual start delay was performed using test bolus technique at the level of the pulmonary trunk: $20 \mathrm{ml}$ of $\mathrm{CM}$ were followed by $40 \mathrm{ml}$ of saline using the flow rates pre-calculated for the diagnostic scan. An overview of all injection parameters is listed in table 5.1.

\begin{tabular}{|l|c|c|c|c|c|c|}
\hline Injection parameters & $\begin{array}{c}\text { CM Bolus } \\
{[\mathrm{ml}]}\end{array}$ & $\begin{array}{c}\text { Mixed phase* } \\
{[\mathrm{ml}]}\end{array}$ & $\begin{array}{c}\text { Saline Chaser } \\
{[\mathrm{ml}]}\end{array}$ & $\begin{array}{c}\text { Flowrate } \\
{[\mathrm{ml} / \mathrm{s}]}\end{array}$ & $\begin{array}{c}\text { TIL } \\
{[\mathrm{g}]}\end{array}$ & $\begin{array}{c}\text { IDR } \\
{[\mathrm{g} / \mathrm{s}]}\end{array}$ \\
\hline Group 1 & 75 & 30 & 30 & 6.0 & 27 & 1.8 \\
\hline Group 2 & & & & & & \\
\hline $40-75 \mathrm{~kg}$ & $42-60$ & - & 30 & $4.2-6.0$ & $13-18$ & $1.3-1.8$ \\
$76-117 \mathrm{~kg}$ & $61-76$ & - & 30 & $6.1-7.6$ & $18-23$ & $1.8-2.3$ \\
\hline
\end{tabular}

Table 5.1 Injection protocols as used in this study

For group 1 the injection protocol was fixed for all patients $(n=50)$. In group 2 the injection protocol was adapted according to the patient weight in $\mathrm{kg}$; this table shows the ranges of parameters that were used.

*The mixed phase consisted of $50 \% \mathrm{CM}$ and $50 \% \mathrm{NaCl}$

\section{Clinical outcome}

All images were immediately clinically evaluated by experienced radiologists. Information about the presence and location of PE was collected from the clinical reports.

\section{Data processing}

Acquired data was analysed on a dedicated medical workstation (SyngoVia ${ }^{\mathrm{TM}}$, Siemens) using $1 \mathrm{~mm}$ transverse sections. Technical image quality of all scans was graded by an experienced research fellow (MK) who was blinded to the injection protocols, using a four-point Likert scale (1= non-diagnostic; $2=$ diagnostic; 3=good and 4=excellent image quality) at the level of the left and right pulmonary artery as well as at the level of lobular, segmental and sub-segmental arteries. Technical image quality was determined as a combination of contrast enhancement, image noise and the presence of artefacts. 

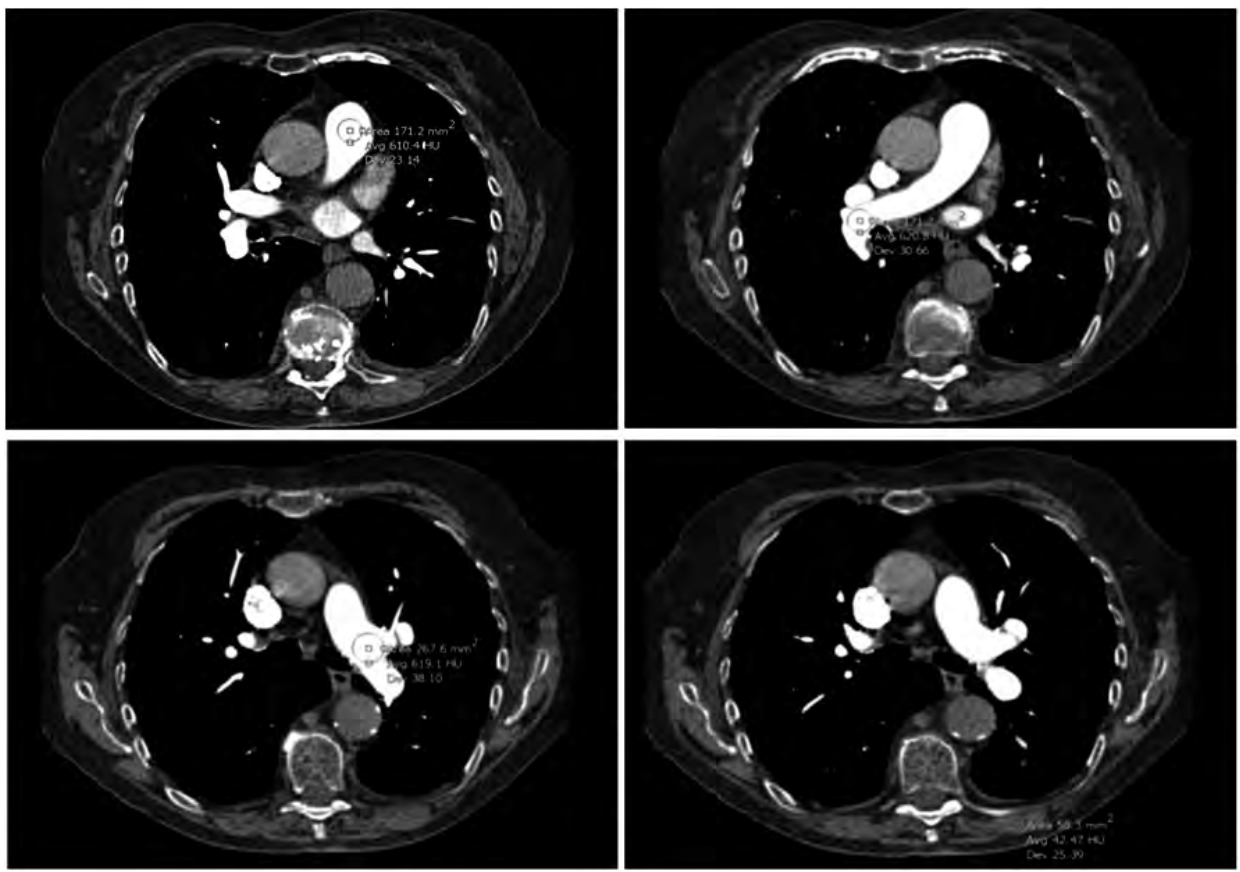

Figure 5.1 Images show the regions of interest (ROI) for attenuation measurements at level of the pulmonary trunk (left top, 610HU), right pulmonary artery (right top, 620HU), left pulmonary artery (left bottom $62 \mathrm{HU}$ ) and paraspinal muscle (right bottom, 42HU)

Objective image quality including contrast enhancement in Hounsfield units [HU], contrast-to-noise ratio (CNR) and signal-to-noise ratio (SNR) was measured by a research fellow $(\mathrm{BH})$ who was blinded to the injection protocols. Regions of interest (ROIs) were manually delineated on the axial thin slices at the level of the origin of the pulmonary trunk just cranial to the pulmonary valve and in both left and right pulmonary artery (see figure 5.1). Sufficient image quality was defined as attenuation values $>180 \mathrm{HU}$ and CNR values $\geq 10$. $^{19}$ SNR and CNR were defined according to the following equations ${ }^{13}: S N R=$ mean pulmonary enhancement $\left(\mathrm{HU}_{\text {vessel }}\right)$ divided by mean pulmonary enhancement standard deviation $\left(S_{\text {vessel }}\right)$. $C N R=$ mean pulmonary enhancement $\left(\mathrm{HU}_{\text {vessel }}\right)$ minus mean muscle enhancement $\left(\mathrm{HU}_{\text {muscle }}\right)$ divided by mean muscle SD.

All injection parameters (volume, flow rate, peak flow rate and peak pressure) were continuously monitored by a data acquisition program (Certegra ${ }^{\mathrm{TM}}$ Informatics Platform, Bayer) and read out after each injection. 


\section{Statistical analysis}

S Statistical analysis was performed using Statistical Package for Social Sciences version 22.0 (SPSS Inc, Chicago, IL, USA). For comparison between different body weights, patients were divided into two groups: 40-75kg (low weight) and $76-117 \mathrm{~kg}$ (high weight). Groups were checked for normal distribution using the Kolmorov-Smirnov test. Continuous variables were reported as the mean \pm standard deviation (SD) and differences between groups were calculated using one-way ANOVA with a Tukey test for post hoc comparisons. Categorical variables were reported as percentages and the chi-square test was used to measure differences between groups. All $p$-values are 2sided, and a $p$-value below 0.05 was considered statistically significant.

\section{RESULTS}

\section{Baseline characteristics}

Baseline characteristics of the study population are summarised in table 5.2, no significant differences in baseline characteristics were found. For group 1 mean age $[y]$, body weight $[\mathrm{kg}]$ and $\mathrm{BMI}\left[\mathrm{kg} / \mathrm{m}^{2}\right]$ were; $64 \pm 15$ (range: 16-91), $75 \pm 17$ (range: 49-109) and $26 \pm 5$ (range: 18-39). For group 2 these values were $63 \pm 16$ (range: 21-92), $71 \pm 15$ (range: 43-117) and 25 \pm 5 (range: 15-39), with associated $p$-values of $0.79,0.26$ and 0.25 , respectively.

\section{Injection parameters}

Mean flow rates in group 2 were $5.2 \pm 0.4 \mathrm{ml} / \mathrm{s}$ for patients between $40-75 \mathrm{~kg}$ and $6.1 \pm 0.4 \mathrm{ml} / \mathrm{s}$ for patients between $76-117 \mathrm{~kg}$, ranging from 4.2 to $7.6 \mathrm{ml} / \mathrm{s}$. CM volumes were calculated as between $42 \mathrm{ml}(40 \mathrm{~kg})$ and $76 \mathrm{ml}(117 \mathrm{~kg})$, IDR ranged from 1.26 to $2.28 \mathrm{gl} / \mathrm{s}$, TIL from 12.6 to $22.8 \mathrm{gl}$, respectively. Peak pressures for both groups ranged between $99 \pm 17$ psi and $122 \pm 33$ psi and did not differ significantly between group 1 and 2 , with $p>0.3$ (see table 5.3). Maximal injection pressure of 325psi was never reached in any patient or for any flow rate. 


\begin{tabular}{|l|c|c|c|c|c|}
\hline & $\begin{array}{c}\text { Age } \\
{[\mathrm{y}]}\end{array}$ & $\begin{array}{c}\text { Sex } \\
(\text { Male; [\%]) }\end{array}$ & $\begin{array}{c}\text { Body weight } \\
{[\mathrm{kg}]}\end{array}$ & $\begin{array}{c}\text { Height } \\
{[\mathrm{cm}]}\end{array}$ & $\begin{array}{c}\text { BMI } \\
{\left[\mathrm{kg} / \mathrm{m}^{2}\right]}\end{array}$ \\
\hline Group 1 & $64 \pm 15$ & 54 & $75 \pm 17$ & $169 \pm 9$ & $26 \pm 5$ \\
\hline Group 2 & $63 \pm 16$ & 46 & $71 \pm 15$ & $170 \pm 8$ & $25 \pm 5$ \\
\hline p-value & 0.79 & 0.42 & 0.26 & 0.82 & 0.25 \\
\hline
\end{tabular}

Table 5.2 Baseline characteristics

This table shows baseline characteristics of the two main groups; no significant differences were found

\begin{tabular}{|c|c|c|c|c|c|c|c|c|}
\hline & & $\begin{array}{c}\text { Flow rate } \\
{[\mathrm{ml} / \mathrm{s}]}\end{array}$ & $\begin{array}{l}\text { Peak Flow } \\
\text { rate } \\
{[\mathrm{ml} / \mathrm{s}]}\end{array}$ & $\begin{array}{c}\text { IDR } \\
{[\mathrm{g} \mid / \mathrm{s}]}\end{array}$ & $\begin{array}{l}\text { Main bolus } \\
\text { volume } \\
{[\mathrm{ml}]}\end{array}$ & $\begin{array}{l}\text { TIL } \\
[g] 1]\end{array}$ & $\begin{array}{c}\text { lodine per } \\
\mathrm{kg} \\
{[\mathrm{g} \mid]}\end{array}$ & $\begin{array}{c}\text { Peak } \\
\text { Pressure } \\
\text { [psi] }\end{array}$ \\
\hline \multirow[t]{2}{*}{ Group 1} & $\begin{array}{l}\text { Low weight } \\
40-75 \mathrm{~kg}\end{array}$ & $5.8 \pm 0.3$ & $6.3 \pm 0.0$ & $1.8 \pm 0.0$ & $89.5+1.1$ & $26.8 \pm 0.3$ & $0.43 \pm 0.05$ & $103 \pm 18$ \\
\hline & $\begin{array}{l}\text { High weight } \\
76-117 \mathrm{~kg}\end{array}$ & $5.7 \pm 0.1$ & $6.3 \pm 0.0$ & $1.8 \pm 0.0$ & $90.0 \pm 0.3$ & $26.9 \pm 0.1$ & $0.30 \pm 0.03$ & $106 \pm 26$ \\
\hline \multirow[t]{2}{*}{ Group 2} & $\begin{array}{l}\text { Low weight } \\
40-75 \mathrm{~kg}\end{array}$ & $5.2 \pm 0.4$ & $5.8 \pm 0.5$ & $1.6 \pm 0.1$ & $54.6 \pm 4.5$ & $16.4 \pm 1.4$ & $0.26 \pm 0.05$ & $99 \pm 17$ \\
\hline & $\begin{array}{l}\text { High weight } \\
76-117 \mathrm{~kg}\end{array}$ & $6.1 \pm 0.4$ & $7.0 \pm 0.5$ & $2.0 \pm 0.1$ & $65.6 \pm 4.7$ & $19.7 \pm 1.4$ & $0.20 \pm 0.00$ & $122 \pm 33$ \\
\hline $\mathrm{p}$-value & & $<0.01$ & $<0.01$ & $<0.01$ & $<0.01$ & $<0.01$ & $<0.01$ & 0.33 \\
\hline
\end{tabular}

Table 5.3 Injection parameters for both groups

A significant decrease is seen for total iodine load (TIL), main bolus volume and iodine per $\mathrm{kg}$ for the individualised protocol versus standard protocol, in both low and high weight group

TIL was $27 \mathrm{gl}$ for group 1 and ranged from $12.6 \mathrm{gl}$ to $22.8 \mathrm{gl}$ in group 2 . The mean TIL for group 2 was $16 \pm 1.4 \mathrm{gl}(40-75 \mathrm{~kg})$ and $20 \pm 1.4 \mathrm{gl}(76-117 \mathrm{~kg})$, showing a significant $\mathrm{CM}$ dose reduction for all patients compared to group 1, with $p<0.01$ (see table $\mathbf{5 . 3}$ and figure 5.2). In patients who received an individualised bolus, $\mathrm{CM}$ volume could be reduced by $51 \%, 33 \%$ and $16 \%$ for the lightest patient of group $2(44 \mathrm{ml}$ at $42 \mathrm{~kg})$, an average patient $(60 \mathrm{ml}$ at $75 \mathrm{~kg})$ and the heaviest patient of group $2(76 \mathrm{ml}$ at $117 \mathrm{~kg})$, respectively. 
For both weight groups the iodine per kg body weight was significantly lower in group 2 , with $p<0.01$. lodine per $\mathrm{kg}$ body weight in group 1 was: $0.4 \mathrm{gl} / \mathrm{kg}$ for $40-75 \mathrm{~kg}$ and $0.3 \mathrm{gl} / \mathrm{kg}$ for $76-117 \mathrm{~kg}$ patients. For the same weight groups values in group 2 were $0.3 \mathrm{gl} / \mathrm{kg}$ and $0.2 \mathrm{gl} / \mathrm{kg}$ respectively (see table 5.3 and figure $\mathbf{5 . 3}$ ).

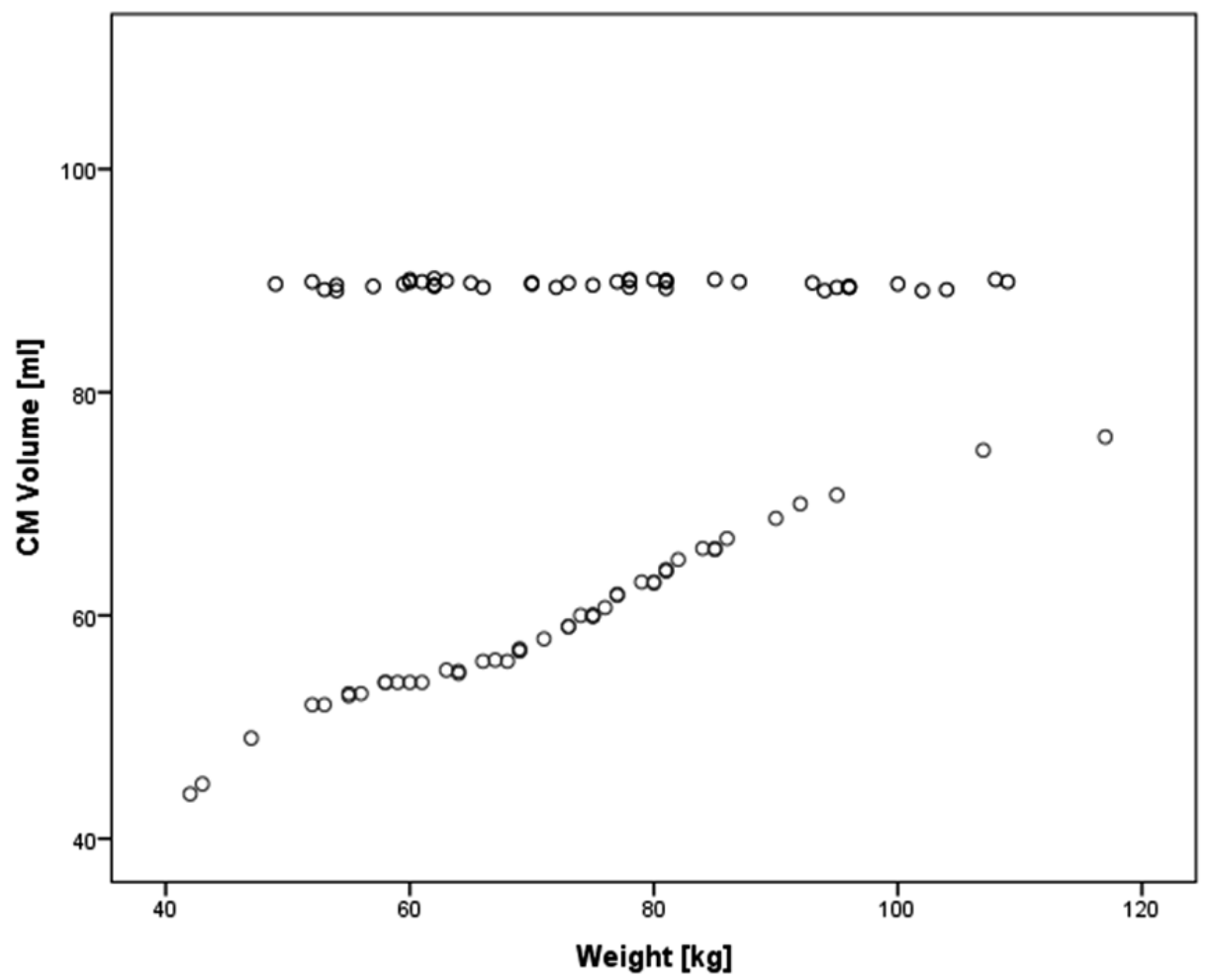

Figure 5.2 Scatter-dot shows all patients by weight in kilograms with their corresponding received CM volume

All group 1 patients received $90 \mathrm{ml} \mathrm{CM}$. All patients in group 2 received less CM (range: $44-76 \mathrm{ml}$ ) and for low weight patients the $\mathrm{CM}$ dose reduction was most pronounced 


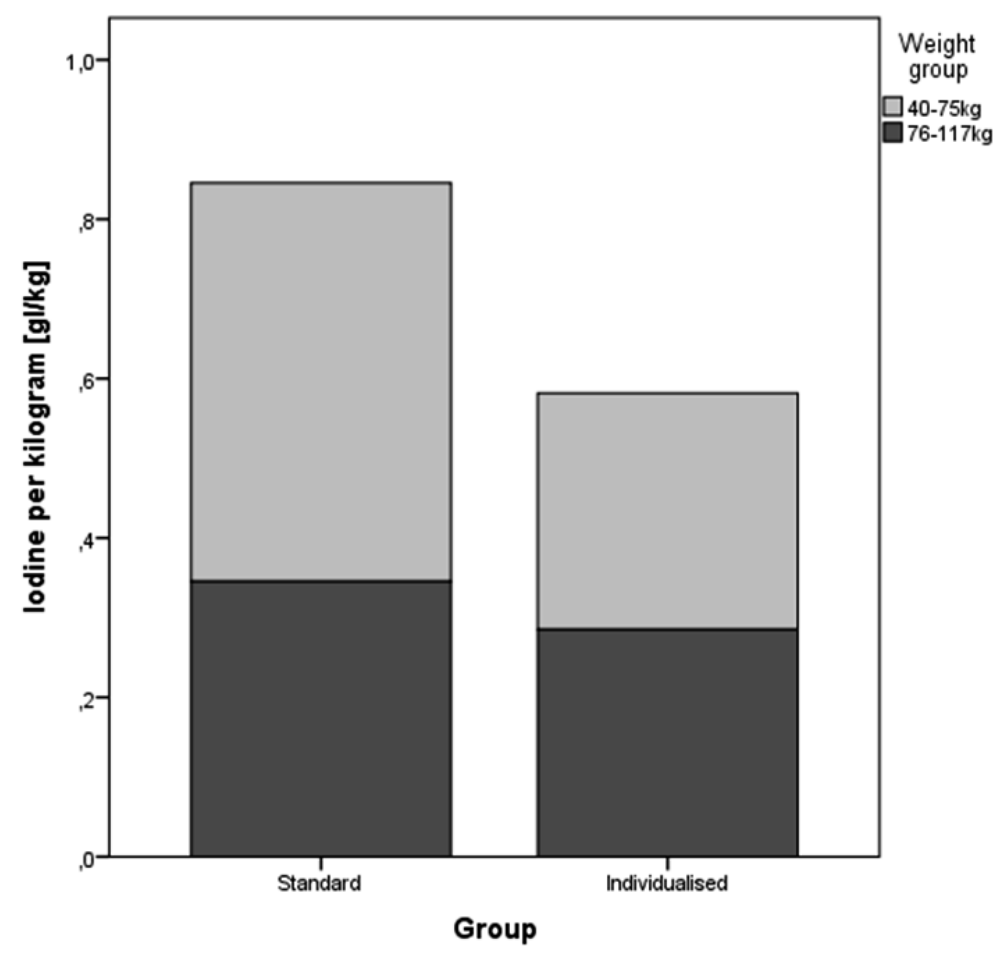

Figure 5.3 This bar graph shows the mean iodine per kg load for the low weight and the high weight patients in group 1 (left) and group 2 (right)

The iodine per kg is reduced for group 2 both in low and high weight categories

\section{Clinical Outcome}

The total incidence of PE in this study population was $18 \%$. In group 1 a total of 10 patients was diagnosed with PE, including 2 central, 3 lobar and 5 segmental emboli. Group 2 showed 8 patients with PE; 2 patients had lobar PE, 3 had segmental and 3 had sub-segmental PE. These are the most proximal points of the emboli, for an overview of the extent of disease in each patient see table 5.4.

\section{Technical image quality}

For both groups, all scans were graded as diagnostic image quality at each anatomic level. Lowest grade was 2 and this grade was found in one patient of each group, only. All other scans were graded as 'good' or 'excellent' at each anatomic level. 


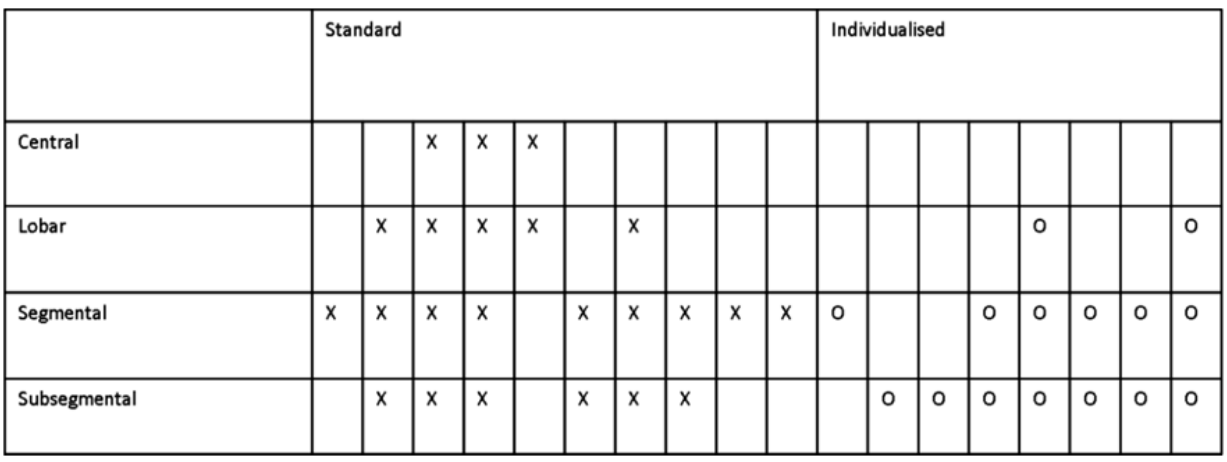

Table 5.4 Extension of PE in each group

Each column represents one patient and the extent of disease found. 18 patients showed $P E$, with $n=10$ in group 1 and $n=8$ in group 2

\section{Objective image quality}

For group 1, mean attenuation values in the pulmonary trunk (PT) and in the right and left pulmonary artery (RPA/LPA) were as follows (40-75kg vs. $76-117 \mathrm{~kg}): 475 \pm 105 \mathrm{HU}$ vs. $402 \pm 115 \mathrm{HU}$ (PT); $435 \pm 94 \mathrm{HU}$ vs. $369 \pm 104 \mathrm{HU}$ (RPA) and $426 \pm 101 \mathrm{HU}$ vs. $360 \pm 102 \mathrm{HU}$ (LPA). There was a significant difference in attenuation values between weight groups for PT, LPA and RPA, with $p$-values of 0.03 (see table 5.5). For group 2, these attenuation values were as follows (40-75kg vs. $76-117 \mathrm{~kg}$ ): $424 \pm 76 \mathrm{HU}$ vs. $418 \pm 100 \mathrm{HU}$ (PT); $418 \pm 84 \mathrm{HU}$ vs. $408 \pm 90 \mathrm{HU}$ (RPA) and $413 \pm 81 \mathrm{HU}$ vs. $403 \pm 92 \mathrm{HU}$ (LPA). Within group 2 , no significant differences were found in attenuation values between both weight groups, all $p$-values $>0.6$ (see table 5.5 ). 


\begin{tabular}{|c|c|c|c|c|c|c|}
\hline & & $\begin{array}{l}\text { PT } \\
{[\mathrm{HU}]}\end{array}$ & $\begin{array}{l}\text { RPA } \\
{[\mathrm{HU}]}\end{array}$ & $\begin{array}{l}\text { LPA } \\
\text { [HU] }\end{array}$ & CNR & SNR \\
\hline \multirow[t]{2}{*}{ Group 1} & $\begin{array}{l}\text { Low weight } \\
40-75 \mathrm{~kg}\end{array}$ & $475 \pm 105$ & $435 \pm 94$ & $426 \pm 101$ & $15 \pm 5$ & $14 \pm 4$ \\
\hline & $\begin{array}{l}\text { High weight } \\
76-117 \mathrm{~kg}\end{array}$ & $402 \pm 115$ & $369 \pm 104$ & $360 \pm 102$ & $11 \pm 5$ & $11 \pm 3$ \\
\hline p-value & & 0.03 & 0.03 & 0.03 & $>0.01$ & $>0.01$ \\
\hline \multirow[t]{2}{*}{ Group 2} & $\begin{array}{l}\text { Low weight } \\
40-75 \mathrm{~kg}\end{array}$ & $424 \pm 76$ & $418 \pm 84$ & $413 \pm 81$ & $16 \pm 6$ & $15 \pm 5$ \\
\hline & $\begin{array}{l}\text { High weight } \\
76-117 \mathrm{~kg}\end{array}$ & $418 \pm 100$ & $408 \pm 90$ & $403 \pm 92$ & $15 \pm 5$ & $13 \pm 3$ \\
\hline $\mathrm{p}$-value & & 0.80 & 0.67 & 0.70 & 0.24 & $>0.01$ \\
\hline
\end{tabular}

Table 5.5 Mean pulmonary artery attenuation values

Mean attenuation values for low and height weight groups per injection protocol and per artery, comparing a low weight and a high weight group

On a group level, no significant differences in attenuation values were found between group 1 and 2. However, attenuation values for group 2 show a much smaller range (see figure $\mathbf{5 . 4}$ and 5.5). Both groups showed no non-diagnostic scans with a minimum mean pulmonary attenuation of $184 \mathrm{HU}$ for group 1 and $270 \mathrm{HU}$ for group 2 .

CNR was acceptable for both groups, but better for group 2, with values (low weight high weight) of $16 \pm 6$ and $15 \pm 5$ vs. $15 \pm 5$ and $11 \pm 5$. SNR values for group 1 were $14 \pm 4$ (low weight) and $11 \pm 3$ (high weight), for group 2 these values were $15 \pm 5$ and $13 \pm 3$, respectively (see table $\mathbf{5 . 5}$ ). 


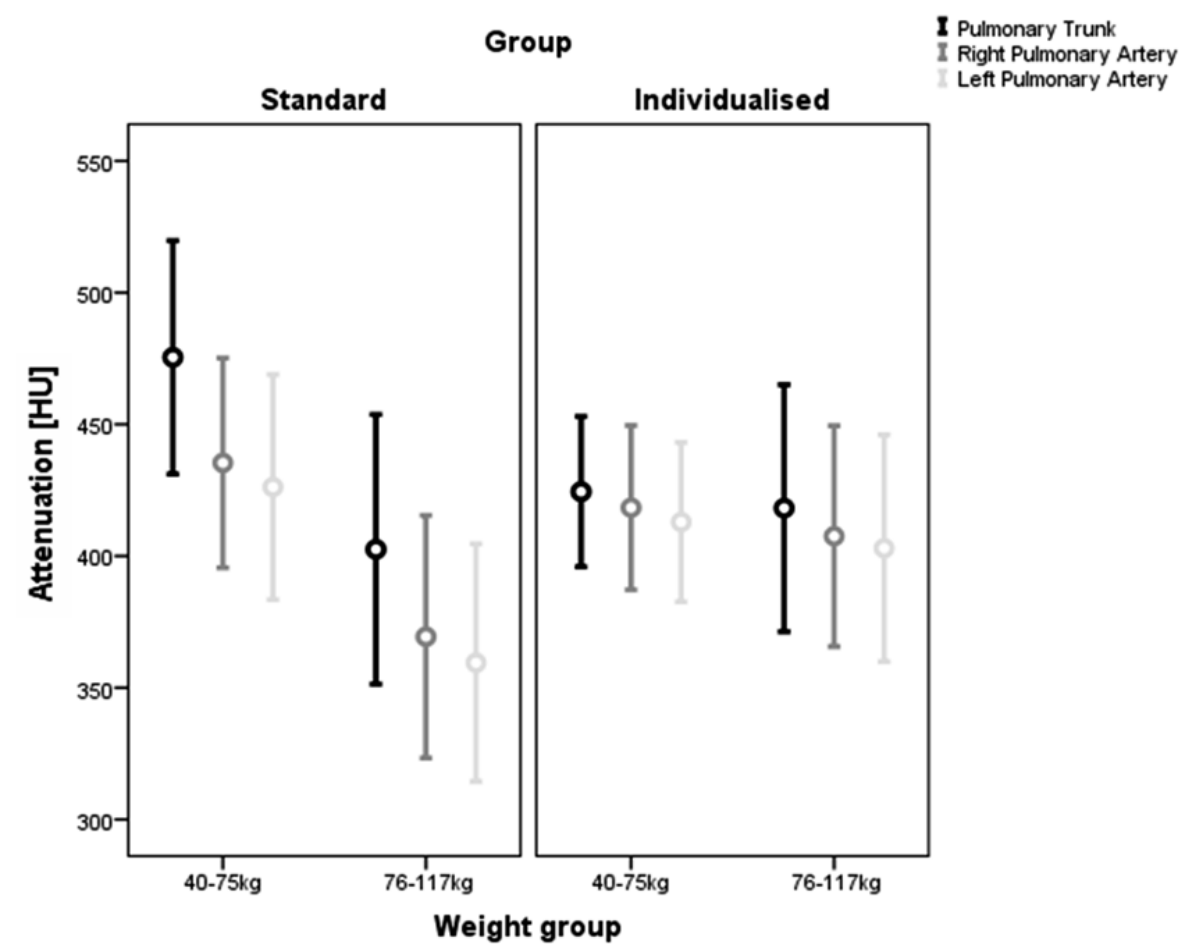

Figure 5.4 Error bars show the mean attenuation and 95\% confidence intervals for both injection protocols and weight groups

The intervals define the values that are most plausible for the mean of a greater population. A decreased mean attenuation was seen for the higher weight group within the standard protocol (left) and similar mean attenuation was seen for both weight groups within the individualised protocol (right) 

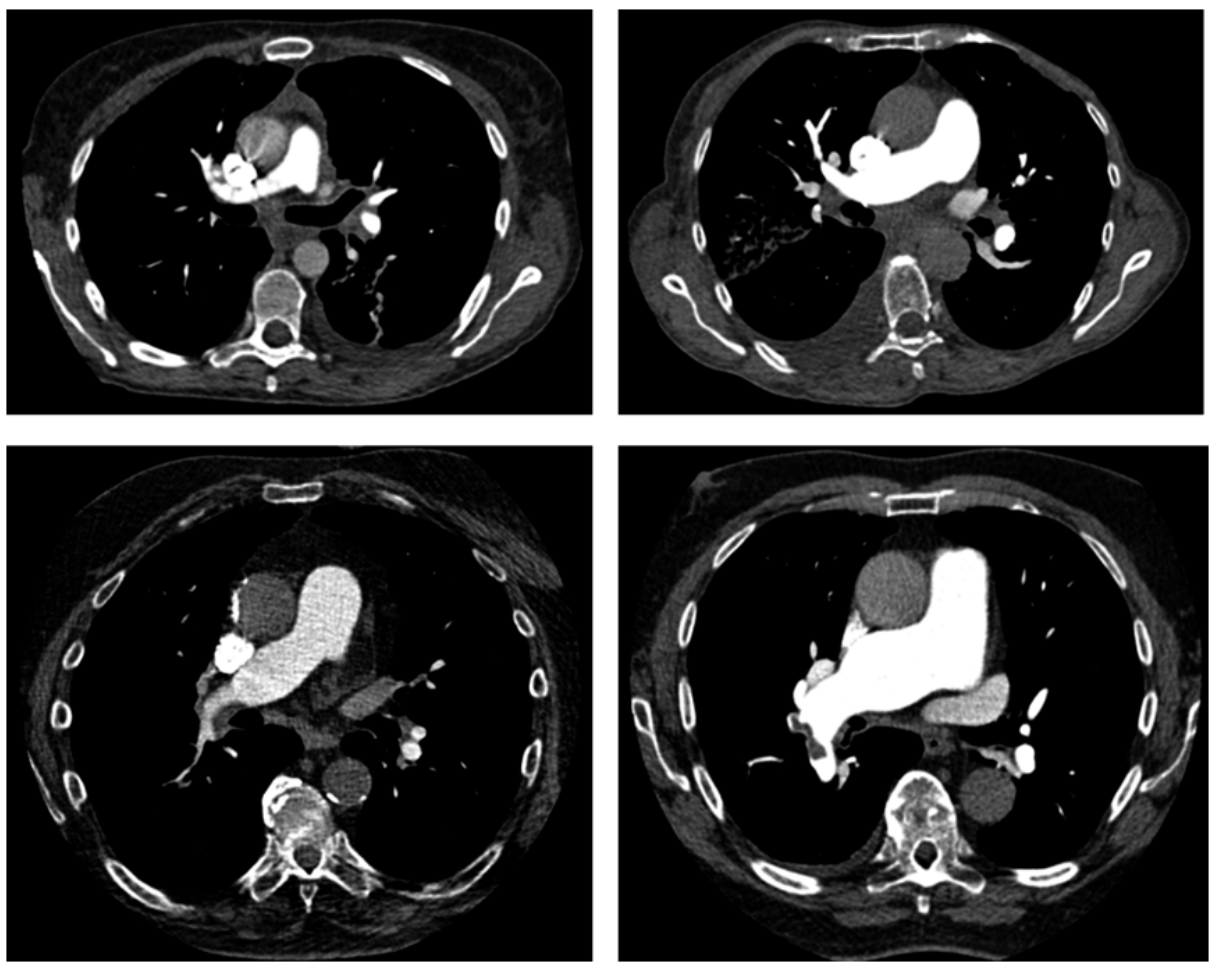

Figure 5.5 Images show contrast enhancement at the level of the pulmonary trunk (W-C levels: 600-125) Left images show two patients from group 1 including low weight (top) and high weight (bottom) with attenuation values of $532 \mathrm{HU}$ and $362 \mathrm{HU}$ respectively. Right images show two patients from group 2 including low weight (top) and high weight (bottom) with attenuation values of $555 \mathrm{HU}$ and $520 \mathrm{HU}$ respectively. Right bottom image also shows right lobar $\mathrm{PE}$

\section{DISCUSSION}

Individualised CM bolus administration in CTPA provided equal to superior enhancement compared to a fixed protocol whilst using less CM volume. Moreover, greater consistency of vascular enhancement values - indicating a more reliable and robust protocol - was observed throughout group 2, whereas the scans for group 1 showed a steady decline in attenuation with increasing body weight. The observed homogeneity of attenuation throughout all patient weights is concordant with other studies using CM individualisation in CTA, however this research shows an additional reduction of $\mathrm{CM}$ volume as well. ${ }^{17,20}$

Some studies on bodyweight adapted CM protocols for CTPA in selective, low weight patient groups have been published: Holmquist et al used an $80 \mathrm{kVp}$ protocol with TIL of around $13 \mathrm{gl}$ in a low weight patient group and Kristiansson et al reduced the TIL in a similar patient group even further to $9.6 \mathrm{gl}$. However, $8-12 \%$ of the examinations were 
regarded as suboptimal. ${ }^{21,22}$ In coronary CTA a smaller SD of intracoronary attenuation was reported when using a body weight adapted injection protocol, indicating a smaller variation in attenuation values between individual patients. ${ }^{17,20}$

In CTPA the lower HU limit is important as CM attenuation is typically even lower in the more peripheral arteries. A CTPA with arterial attenuation below $180 \mathrm{HU}$ may be considered to be of non-diagnostic quality to reliably detect subsegmental emboli as mean $\mathrm{HU}$ values for acute and chronic embolism are around $33 \mathrm{HU}$ and $87 \mathrm{HU}$, respectively. ${ }^{23}$ In this study all patients met this crucial cut-off value of $180 \mathrm{HU}$.

CNR was sufficient in both groups. CNR values above 10 are generally accepted in coronary CTA literature ${ }^{19}$, however there is currently no consensus regarding CNR values in CTPA. In this study, CNR decreased significantly with increasing patient weight in group 1, whereas CNR remained constant in the group with individualised CM injections (group 2). The observed decrease in CNR can be attributed to lower CM attenuation values in heavier patients in combination with higher image noise due to higher body mass. ${ }^{19,24}$ A further improvement in CNR could be achieved by alteration of reconstruction methods, for example with the implementation of iterative reconstruction (IR). ${ }^{25-27}$ However, subjective image quality will not always be experienced as superior due to possible loss of contrast between different densities.

All patients (up to $117 \mathrm{~kg}$ ) from the individualised CM group received less CM compared to standard group patients. The original fixed protocol in this study used a broad $\mathrm{CM}$ bolus (injection over 20s) with a relatively high flow rate (IDR of $1.8 \mathrm{gl} / \mathrm{s}$ ), which had been chosen as a safe option. The problems regarding the realisation of diagnostic quality in CTPA previously called for a safe 'one size fits all' bolus, in order to prevent double scanning and bolus administration. Consequently, part of the CM reduction in the individualised group can be traced back to the comparison with a generous fixed $\mathrm{CM}$ bolus. Nevertheless, even attenuation in patients weighing $76-117 \mathrm{~kg}$ from the individualised group was higher compared to patients of equal body weight in the standard group. The use of relatively smaller CM volumes in combination with higher flow rates indicates an inferior importance of CM volume and TIL compared to flow rate and IDR with respect to arterial enhancement, even under emergency conditions: IDR can be manipulated by adjusting either flow rate or iodine concentration of CM $(I D R[\mathrm{gl} / \mathrm{s}]=$ flow rate $[\mathrm{ml} / \mathrm{s}] \times$ iodine concentration $[\mathrm{gl} / \mathrm{ml}])$. Some authors state that attenuation in CTA could be increased by using higher iodine concentrations of $\mathrm{CM}^{28}$, whereas others state that increasing IDR - by increasing flow rate - is the most influencing factor regarding $\mathrm{CM}$ enhancement. ${ }^{16,29}$ Increasing flow rate might be preferable for optimising CM application for CTA, since increasing iodine concentration of CM simultaneously increases $\mathrm{CM}$ viscosity. A phantom study conducted by Kok et al showed that low concentration, low viscosity and pre-warmed CM are beneficial for achieving low injection pressures. ${ }^{30}$

Nowadays, contrast induced nephropathy (CIN) might not be as much of a concern as previously suspected. ${ }^{31,32}$ However, Lee et al found thyroid dysfunction in $22 \%$ of pa- 
tients after a single iodinated $\mathrm{CM}$ injection, with urinary iodine excretion correlating to the TIL. ${ }^{33}$ According to a recent review contrast-induced thyroid dysfunction mostly appears to be transient, however there is a risk for complications. ${ }^{34}$ The precise relationship between $\mathrm{CM}$ volume and thyroid dysfunction remains unclear to this point, thus administering smaller volumes of CM might prove a safe option and help to avoid delays in scheduling CTPA. Furthermore, smaller bolus volumes in other CTA protocols have been shown to reduce costs in medical clinics. ${ }^{35}$

With the current scan protocol a tube voltage of $100 \mathrm{kVp}$ was used. Already some advancements have been made using lower kVp settings in CTA. ${ }^{25-27,36-38} A$ decrease in $k V p$ increases intra-arterial CM attenuation, because the higher photon energy at lower kVp settings is closer to the iodine k-edge of keV. ${ }^{4,24,39,40}$ Many studies focused on low $\mathrm{kVp}$ protocols, however one must ensure to concordantly increase mAs to avoid excessive image noise. ${ }^{19,41,42}$ For future optimisation it may prove beneficial to further define the optimal IDR values and CM volumes per weight category that ensure a mean attenuation of $180-300 \mathrm{HU}$ for all kVp settings regularly used in the clinics, e.g. $120 \mathrm{kVp}, 100 \mathrm{kVp}$ and $80 \mathrm{kVp}$.

\section{Limitations}

For this study a dedicated scan protocol at $100 \mathrm{kVp}$ was used, only. This resulted in exclusion of patients with body weights requiring higher $\mathrm{kVp}$ protocols, e.g. $150 \mathrm{~kg}$ body weight at $120 \mathrm{kVp}$.

\section{CONCLUSION}

The use of individualised $\mathrm{CM}$ protocols provides diagnostic and robust enhancement in emergency CTPA, as well as a substantial CM volume reduction in lower weight patients, compared to a fixed CM protocol. 


\section{REFERENCES}

1. Cohen AT, Agnelli G, Anderson FA, Arcelus JI, Bergqvist D, Brecht JG, et al. Venous thromboembolism (VTE) in Europe. The number of VTE events and associated morbidity and mortality. Thrombosis and haemostasis. 2007;98(4):756-64.

2. Remy-Jardin M, Pistolesi M, Goodman LR, Gefter WB, Gottschalk A, Mayo JR, et al. Management of suspected acute pulmonary embolism in the era of CT angiography: a statement from the Fleischner Society. Radiology. 2007;245(2):315-29.

3. Konstantinides SV. 2014 ESC Guidelines on the diagnosis and management of acute pulmonary embolism. European heart journal. 2014;35(45):3145-6.

4. Bae KT. Intravenous contrast medium administration and scan timing at CT: considerations and approaches. Radiology. 2010;256(1):32-61.

5. MacDonald SL, Mayo JR, editors. Computed tomography of acute pulmonary embolism. Seminars in Ultrasound, CT and MRI; 2003: Elsevier.

6. Moores LK, Jackson WL, Jr., Shorr AF, Jackson JL. Meta-analysis: outcomes in patients with suspected pulmonary embolism managed with computed tomographic pulmonary angiography. Annals of internal medicine. 2004;141(11):866-74.

7. Mos IC, Klok FA, Kroft L, A DER, Dekkers OM, Huisman MV. Safety of ruling out acute pulmonary embolism by normal computed tomography pulmonary angiography in patients with an indication for computed tomography: systematic review and meta-analysis. Journal of thrombosis and haemostasis : JTH. 2009;7(9):1491-8.

8. Quiroz R, Kucher N, Zou KH, Kipfmueller F, Costello P, Goldhaber SZ, et al. Clinical validity of a negative computed tomography scan in patients with suspected pulmonary embolism: a systematic review. Jama. 2005;293(16):2012-7.

9. Cronin P, Weg JG, Kazerooni EA. The role of multidetector computed tomography angiography for the diagnosis of pulmonary embolism. Seminars in nuclear medicine. 2008;38(6):418-31.

10. Schoepf UJ. Pulmonary artery CTA. Techniques in vascular and interventional radiology. 2006;9(4):180-91.

11. Ozawa $Y$, Hara M, Shibamoto $Y$. The frequency of insufficient contrast enhancement of the pulmonary artery in routine contrast-enhanced chest CT and its improvement with an increased injection rate: a prospective study. Journal of thoracic imaging. 2011;26(1):42-7.

12. He J, Wang F, Dai HJ, Li M, Wang Q, Yao Z, et al. Chinese multi-center study of lung scintigraphy and CT pulmonary angiography for the diagnosis of pulmonary embolism. The international journal of cardiovascular imaging. 2012;28(7):1799-805.

13. Delesalle MA, Pontana F, Duhamel A, Faivre JB, Flohr T, Tacelli N, et al. Spectral optimization of chest $\mathrm{CT}$ angiography with reduced iodine load: experience in 80 patients evaluated with dualsource, dual-energy CT. Radiology. 2013;267(1):256-66.

14. Bae KT, Tao C, Gurel S, Hong C, Zhu F, Gebke TA, et al. Effect of patient weight and scanning duration on contrast enhancement during pulmonary multidetector CT angiography. Radiology. 2007;242(2):582-9.

15. Schoellnast $H$, Deutschmann HA, Berghold A, Fritz GA, Schaffler GJ, Tillich M. MDCT angiography of the pulmonary arteries: influence of body weight, body mass index, and scan length on arterial enhancement at different iodine flow rates. AJR American journal of roentgenology. 2006;187(4):1074-8.

16. Mihl C, Wildberger JE, Jurencak T, Yanniello MJ, Nijssen EC, Kalafut JF, et al. Intravascular enhancement with identical iodine delivery rate using different iodine contrast media in a circulation phantom. Investigative radiology. 2013;48(11):813-8.

17. Seifarth H, Puesken M, Kalafut JF, Wienbeck S, Wessling J, Maintz D, et al. Introduction of an individually optimized protocol for the injection of contrast medium for coronary CT angiography. European Radiol. 2009;19(10):2373-82. 
18. Bae KT, Heiken JP, Brink JA. Aortic and hepatic contrast medium enhancement at CT. Part II. Effect of reduced cardiac output in a porcine model. Radiology. 1998;207(3):657-62.

19. Lee SM, Lee W, Chung JW, Park EA, Park JH. Effect of kVp on image quality and accuracy in coronary $\mathrm{CT}$ angiography according to patient body size: a phantom study. The international journal of cardiovascular imaging. 2013;29 Suppl 2:83-91.

20. Nakaura T, Awai K, Yauaga Y, Nakayama Y, Oda S, Hatemura M, et al. Contrast injection protocols for coronary computed tomography angiography using a 64-detector scanner: comparison between patient weight-adjusted- and fixed iodine-dose protocols. Investigative radiology. 2008;43(7):512-9.

21. Holmquist F, Hansson K, Pasquariello F, Bjork J, Nyman U. Minimizing contrast medium doses to diagnose pulmonary embolism with $80-\mathrm{kVp}$ multidetector computed tomography in azotemic patients. Acta radiologica. 2009;50(2):181-93.

22. Kristiansson M, Holmquist F, Nyman U. Ultralow contrast medium doses at CT to diagnose pulmonary embolism in patients with moderate to severe renal impairment: a feasibility study. European Radiology. 2010;20(6):1321-30.

23. Wittram C, Maher MM, Halpern EF, Shepard J-AO. Attenuation of Acute and Chronic Pulmonary Emboli 1. Radiology. 2005;235(3):1050-4.

24. Nakayama Y, Awai K, Funama Y, Hatemura M, Imuta M, Nakaura T, et al. Abdominal CT with low tube voltage: preliminary observations about radiation dose, contrast enhancement, image quality, and noise. Radiology. 2005;237(3):945-51.

25. Laqmani A, Regier M, Veldhoen S, Backhaus A, Wassenberg F, Sehner S, et al. Improved image quality and low radiation dose with hybrid iterative reconstruction with $80 \mathrm{kV}$ CT pulmonary angiography. European journal of radiology. 2014;83(10):1962-9.

26. Lu GM, Luo S, Meinel FG, McQuiston AD, Zhou CS, Kong X, et al. High-pitch computed tomography pulmonary angiography with iterative reconstruction at $80 \mathrm{kVp}$ and $20 \mathrm{~mL}$ contrast agent volume. European radiology. 2014;24(12):3260-8.

27. Oda S, Utsunomiya D, Yuki H, Kai N, Hatemura M, Funama Y, et al. Low contrast and radiation dose coronary CT angiography using a 320-row system and a refined contrast injection and timing method. Journal of cardiovascular computed tomography. 2015;9(1):19-27.

28. Ramgren B, Bjorkman-Burtscher IM, Holtas S, Siemund R. CT angiography of intracranial arterial vessels: impact of tube voltage and contrast media concentration on image quality. Acta Radiologica. 2012;53(8):929-34.

29. Hansmann J, Fink C, Jost G, Pietsch H, Meyer M, Nance JW, Jr., et al. Impact of iodine delivery rate with varying flow rates on image quality in dual-energy $\mathrm{CT}$ of patients with suspected pulmonary embolism. Academic radiology. 2013;20(8):962-71.

30. Kok M, Mihl C, Mingels AA, Kietselaer BL, Muhlenbruch G, Seehofnerova A, et al. Influence of contrast media viscosity and temperature on injection pressure in computed tomographic angiography: a phantom study. Investigative radiology. 2014;49(4):217-23.

31. Langner S, Stumpe S, Kirsch M, Petrik M, Hosten N. No increased risk for contrast-induced nephropathy after multiple CT perfusion studies of the brain with a nonionic, dimeric, iso-osmolal contrast medium. AJNR American journal of neuroradiology. 2008;29(8):1525-9.

32. McDonald RJ, McDonald JS, Bida JP, Carter RE, Fleming CJ, Misra S, et al. Intravenous contrast material-induced nephropathy: causal or coincident phenomenon? Radiology. 2013;267(1):10618.

33. Lee SY, Chang DL, He X, Pearce EN, Braverman LE, Leung AM. Urinary lodine Excretion and Serum Thyroid Function in Adults After lodinated Contrast Administration. Thyroid : official journal of the American Thyroid Association. 2015.

34. Lee SY, Rhee CM, Leung AM, Braverman LE, Brent GA, Pearce EN. A review: Radiographic iodinated contrast media-induced thyroid dysfunction. J Clin Endocrinol Metab. 2015;100(2):37683. 
35. Arana E, Marti-Bonmati L, Tobarra E, Sierra C. Cost reduction in abdominal CT by weight-adjusted dose. European journal of radiology. 2009;70(3):507-11.

36. Kalender WA, Deak P, Kellermeier M, van Straten M, Vollmar SV. Application-and patient sizedependent optimization of x-ray spectra for CT. Medical physics. 2009;36(3):993-1007.

37. Meinel FG, Canstein C, Schoepf UJ, Sedlmaier M, Schmidt B, Harris BS, et al. Image quality and radiation dose of low tube voltage 3rd generation dual-source coronary CT angiography in obese patients: a phantom study. European radiology. 2014;24(7):1643-50.

38. Schueller-Weidekamm C, Schaefer-Prokop CM, Weber M, Herold CJ, Prokop M. CT angiography of pulmonary arteries to detect pulmonary embolism: improvement of vascular enhancement with low kilovoltage settings. Radiology. 2006;241(3):899-907.

39. Funama Y, Awai K, Nakayama Y, Kakei K, Nagasue N, Shimamura M, et al. Radiation dose reduction without degradation of low-contrast detectability at abdominal multisection CT with a low-tube voltage technique: phantom study. Radiology. 2005;237(3):905-10.

40. Huda W, Scalzetti EM, Levin G. Technique factors and image quality as functions of patient weight at abdominal CT. Radiology. 2000;217(2):430-5.

41. McCollough $\mathrm{CH}$, Primak AN, Braun N, Kofler J, Yu L, Christner J. Strategies for reducing radiation dose in CT. Radiologic Clinics of North America. 2009;47(1):27-40.

42. Szucs-Farkas Z, Verdun FR, von Allmen G, Mini RL, Vock P. Effect of X-ray tube parameters, iodine concentration, and patient size on image quality in pulmonary computed tomography angiography: a chest-phantom-study. Investigative radiology. 2008;43(6):374-81. 



\section{CHAPTER 6}

\section{Low contrast media volume in pre-TAVI CT examinations}

Kok M, Turek J, Mihl C, Reinartz SD, Gohmann RF, Nijssen EC, Kietselaer BLJH, Kats S, van Ommen VG, Wildberger JE, Das M.

Eur Radiol. 2016 Aug;26(8):2426-35. 


\section{ABSTRACT}

Purpose

To evaluate image quality using reduced contrast media (CM) volume in pre-TAVI assessment.

\section{Materials and methods}

47 consecutive patients referred for pre-TAVI examination were evaluated. Patients were divided into two groups: group $1 \mathrm{BMI}<28 \mathrm{~kg} / \mathrm{m}^{2} \quad(\mathrm{n}=29)$; and group 2 $\mathrm{BMI}>28 \mathrm{~kg} / \mathrm{m}^{2}(\mathrm{n}=18)$. Patients received a combined scan protocol: retrospective ECGgated helical CTA of the aortic root $(80 \mathrm{kVp})$ followed by a high-pitch spiral CTA (group 1: 70kVp; group 2: $80 \mathrm{kVp}$ ) from aortic arch to femoral arteries. All patients received one bolus of $\mathrm{CM}(300 \mathrm{mgl} / \mathrm{ml})$ : group 1: volume $=40 \mathrm{ml}$; flow rate $=3 \mathrm{ml} / \mathrm{s}$, group 2 : volume $=53 \mathrm{ml}$; flow rate $=4 \mathrm{ml} / \mathrm{s}$. Attenuation values $[\mathrm{HU}]$ and contrast-to-noise ratio (CNR) were measured at the levels of the aortic root (helical) and peripheral arteries (highpitch). Diagnostic image quality was considered sufficient at attenuation values $\geq 200 \mathrm{HU}$ and CNR $\geq 3$.

\section{Results}

Diagnostic image quality for TAVI measurements was obtained in 46 patients. Mean attenuation values and CNR (HU士SD) at the aortic root (helical) were: group 1: $381 \pm 65 \mathrm{HU}$ and $13 \pm 8$; group 2: $442 \pm 68 \mathrm{HU}$ and $10 \pm 5$. At the peripheral arteries (highpitch), mean values were: group 1: $430 \pm 117 \mathrm{HU}$ and $11 \pm 6$; group 2: $389 \pm 102 \mathrm{HU}$ and $13 \pm 6$.

\section{Conclusion}

$\mathrm{CM}$ volume can be substantially reduced using low $\mathrm{kVp}$ protocols, while maintaining sufficient image quality for the evaluation of aortic root and peripheral access sites. 


\section{INTRODUCTION}

Transcatheter aortic valve implantation (TAVI) is considered an effective treatment option for patients with severe and symptomatic valve stenosis not suitable for conventional valve replacement. ${ }^{1,2}$ Throughout the years, multi detector-row CT (MDCT) has become the standard non-invasive imaging method in pre-TAVI assessment for aortic root dimensions and access site. ${ }^{3,4}$ To ensure technical success and optimal valve-prosthesis sizing, dedicated scan technique including reliable contrast media (CM) injection protocols during pre-operative imaging are of utmost importance. However, the CM required may pose a risk for TAVI candidates, who are frequently suffering from impaired renal function and considered to be at increased risk of contrastinduced nephropathy (CIN). ${ }^{5,6}$ The European Society of Urogenital Radiology (ESUR) guidelines recommend expansion of extracellular volume as one of the measures to prevent CIN. ${ }^{7}$ However, aortic stenosis in TAVI candidates does not allow for fluid expansion due to the increased risk of subsequent heart failure.

Not only pre-existing renal insufficiency is correlated with increased risk of CIN, but also the use of increased $\mathrm{CM}$ volume ${ }^{8}$ as well as the administration of multiple doses of intravascular CM within a short period of time ( $<24$ hours). ${ }^{9,10}$

TAVI protocols - as described in the literature - usually entail the injection of large CM volumes up to $120 \mathrm{ml}$ to ensure optimal filling of the aortic root as well as the peripheral arteries. ${ }^{4,11-13}$ In the combination of ultra-fast data acquisition and use of low kVp protocols, this amount might be substantially reduced, offering patient tailored CT protocols.

Thus, the aim of this study was to evaluate the use of low CM volumes in pre-TAVI CT examinations, using low $k V p$ settings in combination with iterative reconstruction techniques.

\section{MATERIALS AND METHODS}

\section{Ethics}

A waiver of written informed consent was obtained from the local ethical committee (METC, ref. 14-4-165).

\section{Patient population}

Between July 2014 and January 2015, 56 consecutive patients with severe symptomatic aortic stenosis were evaluated. All of them were referred from the cardiology outpatient department for pre-interventional assessment of aortic root dimensions and peripheral arteries. Patients with body mass index $(\mathrm{BMI})>35 \mathrm{~kg} / \mathrm{m}^{2}$ received a diver- 
gent scan protocol and were therefore excluded $(n=9)$. The other 47 patients received a specific scan and injection protocol according their BMI: Group $1 \mathrm{BMI}<28 \mathrm{~kg} / \mathrm{m}^{2}$; $(\mathrm{n}=29)$; Group $2 \mathrm{BMI}>28 \mathrm{~kg} / \mathrm{m}^{2}(\mathrm{n}=18) .{ }^{14,15}$

Other patient characteristics such as age, gender, height and weight were recorded.

\section{MDCT scan protocol}

All examinations were performed on a $2^{\text {nd }}$ generation dual-source CT scanner (Definition Flash; Siemens Healthcare, Forchheim, Germany). Aortic root dimension assessment was carried out using a retrospective ECG-gated helical scan in caudo-cranial direction with parameters as follows: tube voltage $80 \mathrm{kVp}$; effective tube current $370 \mathrm{mAs}_{\text {eff; }}$ rotation time $0.28 \mathrm{~s}$; slice collimation $128 \times 0.6 \mathrm{~mm}$; pitch value 0.23 . Tube current was set to $370 \mathrm{mAs}_{\text {eff, }}$ being the highest possible value for this scan protocol using this type of scanner. Image reconstruction of the entire cardiac cycle was done at the $20 \%$ phase of the cardiac cycle with individually adapted field of view (FOV) at $0.6 \mathrm{~mm}$ slice thickness, an increment of $0.4 \mathrm{~mm}$ using raw-data based iterative reconstruction (kernel I26f, SAFIRE [Sinogram Affirmed Iterative Reconstruction], strength 3).

Directly afterwards, all patients received a non ECG-triggered high-pitch spiral scan (flash) of the aorta in cranio-caudal direction from the aortic arch to the femoral arteries (see figure 6.1). Scan parameters were as follows: reference tube-current-time product $400 \mathrm{mAs}_{\text {ref; }}$; rotation time $0.28 \mathrm{~s}$; slice collimation $128 \times 0.6 \mathrm{~mm}$; pitch value 3.0 . Scan protocol varied for the two groups in tube voltage setting - group 1 at $70 \mathrm{kVp}$, group 2 at $80 \mathrm{kVp}$ - and effective tube current was $90-122 \mathrm{mAs}_{\text {eff }}$ (maximum possible values were 93 and $122 \mathrm{mAs}_{\text {eff }}$ for 70 and $80 \mathrm{kVp}$, respectively). Images were reconstructed with individually adapted FOV at $2 \mathrm{~mm}$ slice thickness with an increment of $1.4 \mathrm{~mm}$ using an I30f kernel (SAFIRE, strength 3 - see figure 6.2). Dose modulation (CAREDose4D, Siemens) was used. In table 6.1 all relevant scan parameters are summarised. Total scan time of the combined acquisition was 13-14s: $6-7 \mathrm{~s}$ for retrospective ECG-gated acquisition, $5 \mathrm{~s}$ gap between acquisitions and $2 \mathrm{~s}$ for the high-pitch acquisition. In order to minimise the gap between acquisitions, the scan direction was adapted accordingly, starting with a caudo-cranial direction for the helical scan, followed by a cranio-caudal direction for the high-pitch spiral scan. 


\begin{tabular}{|c|c|c|}
\hline Protocol & Cardiac & Aorta \\
\hline Mode & Spiral & High pitch \\
\hline Collimation [mm] & 0.6 & 0.6 \\
\hline Acquisition [mm] & $128 * 0.6$ & $128 * 0.6$ \\
\hline Tube voltage [kVp] & 80 & $70 / 80$ (group 1/group 2) \\
\hline Dose modulation & off & on \\
\hline Tube current [mAs] & & \\
\hline $\mathrm{mAs}_{\text {ref }}$ & 370 & 400 \\
\hline $\mathrm{mAs}_{\text {eff }}$ & 370 & $90-122$ \\
\hline Rot.Time [s] & 0.28 & 0.28 \\
\hline Pitch & 0.23 & 3.0 \\
\hline Delay [s] & Test bolus technique & Test bolus technique \\
\hline Scan time $[s]$ & $6-7$ & 2 \\
\hline Direction & Caudo-cranial & Cranio-caudal \\
\hline Reconstruction & Best Systolic-20\% & \\
\hline Slice thickness [mm] & 0.6 & 2.0 \\
\hline Increment [mm] & 0.4 & 1.4 \\
\hline Kernel & $126 \mathrm{f}$ & $130 f$ \\
\hline
\end{tabular}

Table 6.1 Scan protocol parameters of both helical and high-pitch acquisitions

\section{CM injection protocol}

Monomeric, non-ionic, low-osmolar iodinated CM $(300 \mathrm{mgl} / \mathrm{ml}$; lopromide; Bayer Healthcare, Berlin, Germany) was prewarmed to standardised $37^{\circ} \mathrm{C}$ prior to injection in the antecubital vein using catheter sizes between 18-22G (Sterican, Braun, Melsungen, Germany). Group 1 received a CM bolus of $40 \mathrm{ml}$ followed by a saline flush of $36 \mathrm{ml}$, both at injection rate $3 \mathrm{ml} / \mathrm{s}$. Group 2 received a $\mathrm{CM}$ bolus of $53 \mathrm{ml}$ followed by a saline flush of $48 \mathrm{ml}$, both at injection rate $4 \mathrm{ml} / \mathrm{s}$. Injection time of $\mathrm{CM}$ bolus and saline flush was kept constant in both groups (CM bolus: 13.3; saline flush: 12s). Total iodine load (TIL, [gI]) and iodine delivery rate (IDR, [gl/s]) were kept constant at $12 \mathrm{~g}$ and $0.9 \mathrm{gl} / \mathrm{s}$ for group 1; as well as $15.9 \mathrm{~g}$ and $1.2 \mathrm{gl} / \mathrm{s}$ for group 2 . In order to determine time to peak (TTP) for accurate scan delay settings, test-bolus technique was used with $10 \mathrm{ml}$ undiluted CM followed by $30 \mathrm{ml}$ saline, injected at $3 \mathrm{ml} / \mathrm{s}$ or $4 \mathrm{ml} / \mathrm{s}$ for group 1 and 2, respectively. Injection parameters such as injection pressures [psi], flow rates [ml/s] and total amount of $\mathrm{CM}[\mathrm{ml}]$ were continuously monitored by a data acquisition program (Certegra $^{\mathrm{TM}}$ Informatics Solution, Bayer) and read out after each injection. 


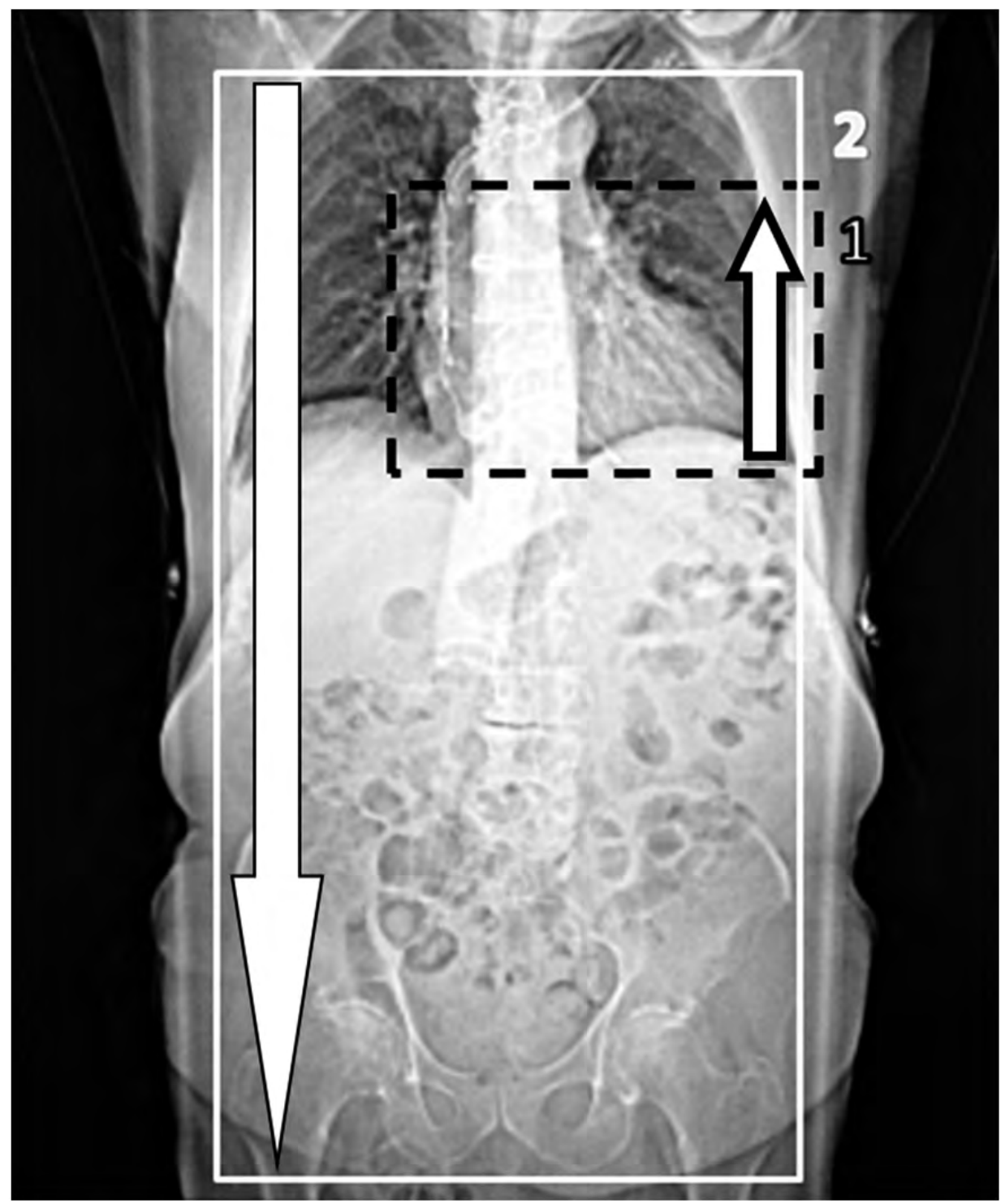

Figure 6.1 This figure shows the scout view with the planned anatomical range

The box with the dashed lines (1) indicates the retrospective ECG-gated acquisition of the heart in caudocranial direction. Box 2 indicates the high-pitch acquisition from the aortic arch to the femoral arteries in cranio-caudal direction 


\section{Quantitative analysis}

\section{Radiation dose}

The dose-length product (DLP) was recorded for each protocol to calculate the effective dose [mSv]. The effective dose (E) was quantified by multiplying the DLP value and the combination of conversion coefficients $(k)$ of chest $(k=0.014 \mathrm{mSv} /[\mathrm{mGy} . \mathrm{cm}])$, abdominal $(\mathrm{k}=0.015 \mathrm{mSv} /[\mathrm{mGy} . \mathrm{cm}])$ and pelvic $(\mathrm{k}=0.017 \mathrm{mSv} /[\mathrm{mGy} . \mathrm{cm}]) .{ }^{16}$ Because of the thoracic-abdominal-pelvic scan range, an average conversion factor $(k=0.015$ $\mathrm{mSv} /[\mathrm{mGy} . \mathrm{cm}])$ was used. ${ }^{16}$

\section{Image quality}

Image analysis was performed of both helical and flash scans. For the helical scan, the $20 \%$ time point of cardiac cycle was used for image quality assessment. ${ }^{17}$ Quality determination was based on the ability of images to provide diagnostically sufficient information of the aortic root (annulus and root diameters, distance from annulus to coronary ostia and length of valve leaflets) and aorto iliofemoral arteries for dimensional measurements (iliofemoral diameter). The latter is as well as tortuosity, calcifications and/or atherosclerosis part of the access assessment. ${ }^{18}$ Image quality was determined from a combination of arterial enhancement, image noise and presence of artefacts.

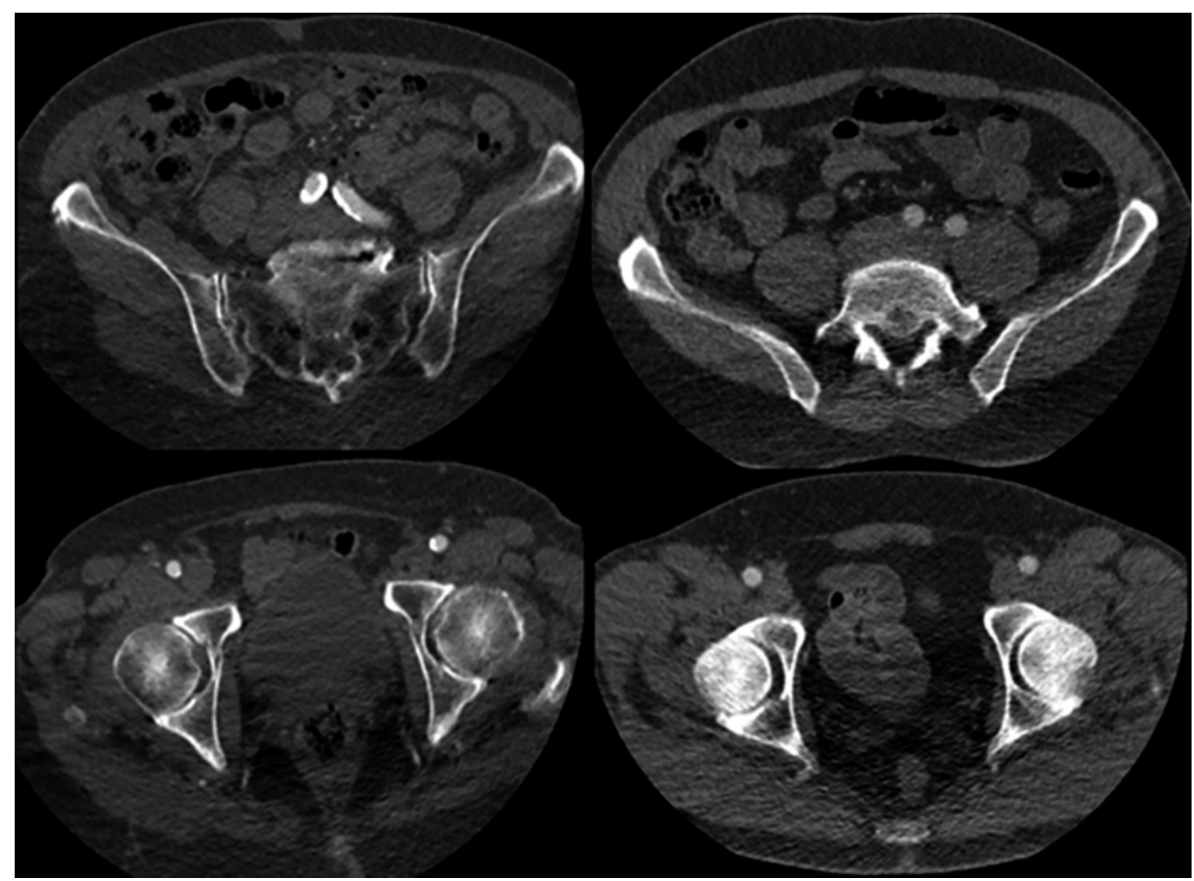

Figure 6.2 Images show the iliofemoral arteries obtained by the high-pitch CTA Images were obtained using $80 \mathrm{kVp}$ (left) and the $70 \mathrm{kVp}$ (right) 
Objective image quality measurements were performed by two experienced observers in consensus: attenuation in the region of interest (ROI), signal-to-noise ratio (SNR), and contrast to noise ratio (CNR). Circular ROls (as large as possible) were placed at six levels of the aorta. The ascending aorta (AA) was evaluated from both the $80 \mathrm{kVp}$ helical scan and the $70 / 80 \mathrm{kVp}$ high-pitch spiral scan. The other five levels of the aorta (aortic arch [arch]; descending aorta [DA]; abdominal aorta [AAo]; right and left common iliac arteries [RCIA and LCIA] and right and left common femoral arteries [RCFA and LCFA]), were evaluated from the 70/80kVp high-pitch spiral scan, only.

SNR was defined as vessel enhancement in Hounsfield Units [HU] divided by vessel enhancement standard deviation (SD). CNR was defined as vessel enhancement $\left(\mathrm{HU}_{\text {vessel }}\right)$ minus adjacent muscle tissue enhancement $\left(\mathrm{HU}_{\text {muscle }}\right)$, divided by adjacent muscle tissue enhancement SD. Diagnostic image quality was considered sufficient at attenuation values $>200 \mathrm{HU}^{19,20}$ and $\mathrm{CNR}>3$. $^{21}$

Subjective image quality (IQ) of both the helical and the high-pitch acquisition was determined by rating the presence of artefacts using a 4-point grading-scale: 1=nondiagnostic image quality; $2=$ significantly reduced image quality due to major artefacts, but still diagnostic for assessment; $3=$ good image quality with minor artefacts and 4=excellent image quality without artefacts.

Images were analysed using multiplanar reformation (MPR) with Syngo-Via ${ }^{\mathrm{TM}}$ software (Siemens).

\section{Renal function}

For the evaluation of renal function of this population, estimated glomerular filtration rate (eGFR; $\left[\mathrm{ml} / \mathrm{min} / 1.73 \mathrm{~m}^{2}\right]$ ) and serum creatinine $[\mu \mathrm{mol} / \mathrm{L}] \leq 12$ months before the pre-TAVI CT scan were recorded according to the current hospital protocol.

Long-term renal function was evaluated by recording eGFR values $\geq 1-2$ months after CTA.

\section{TAVI procedure}

For the evaluation of the placement of the valve prosthesis, the amount of patients treated by TAVI was recorded, as well as the survival rate after one month post TAVI. In addition, the CT measurements from the radiological reports were compared to the actual size of the valve prosthesis. References proposed guidelines show best results when using area derived diameter or mean diameter for valve sizing. ${ }^{42}$ For both balloon-expandable prosthesis and self-expandable prosthesis oversizing was recommended, by $10-15 \%$. 


\section{Statistical analysis}

Data analysis was conducted using SPSS version 20.0 (SPSS Inc, Chicago, IL, USA). Continuous variables were reported as mean $\pm S D$, categorical values as proportions [\%]. The chi-square test was used to measure differences between categorical variables. Continuous variables were compared using independent-samples t-test or ANOVA test. In addition, post hoc comparisons of differences between the vascular segments were performed. All reported p-values are 2-sided, and a p-value of less than 0.05 is considered statistically significant.

\section{RESULTS}

\section{Baseline characteristics}

Baseline characteristics are listed in table 6.2. Group 1 consisted of 16 males and 13 females with average age $76 \pm 9 y$ and BMI $22 \pm 3 \mathrm{~kg} / \mathrm{m}^{2}$. Group 2 consisted of 5 males and 13 females with average age $75 \pm 9 y$ and $B M I 31 \pm 2 \mathrm{~kg} / \mathrm{m}^{2}$.

\begin{tabular}{|l|l|l|l|}
\hline Baseline characteristics & $\begin{array}{l}\text { Group 1 } \\
(\mathrm{n}=29)\end{array}$ & $\begin{array}{l}\text { Group 2 } \\
(\mathrm{n}=18)\end{array}$ & P-value \\
\hline Age [y] & $76 \pm 9$ & $75 \pm 9$ & 0.78 \\
\hline Gender [male] & $16[55 \%]$ & $5[28 \%]$ & 0.07 \\
\hline Height [cm] & $171 \pm 9$ & $166 \pm 10$ & 0.08 \\
\hline Weight [kg] & $67 \pm 11$ & $85 \pm 12$ & $<.001$ \\
\hline BMI [kg/m] & $22 \pm 3$ & $31 \pm 2$ & $<.001$ \\
\hline $\begin{array}{l}\left.\text { eGFR [ml/min } / 1.73 \mathrm{~m}^{2}\right] \\
\text { Before CT } \\
\text { After CT }\end{array}$ & $\begin{array}{l}54 \pm 8(35-60) \\
57 \pm 4(46-60)\end{array}$ & $55 \pm 8(36-60)$ & 0.65 \\
\hline
\end{tabular}

Table 6.2 Baseline characteristics

$\mathrm{BMI}=$ Body mass index; ${ }^{a}<1$ year before $\mathrm{CTA} ;{ }^{b} \geq 1-2$ months after CTA

\section{Radiation dose and CM injection}

Radiation dose- and $\mathrm{CM}$ injection parameters are given in table 6.3. Mean effective radiation dose for the combined scans was lower for group $1(6 \pm 2 \mathrm{mSv})$ as compared to 
group $2(8 \pm 2 \mathrm{mSv}) ; p=0.06$. Effective dose for helical and high-pitch scans were respectively $5 \pm 1 \mathrm{mSv}$ and $0.9 \pm 0.1 \mathrm{mSv}$ for group 1 , and $6 \pm 1 \mathrm{mSv}$ and $1.8 \pm 0.2 \mathrm{mSv}$ for group 2 . Mean volume, flow rate, peak flow rate, and peak pressure for group 1 and group 2 were: $40.0 \pm 0.1 \mathrm{ml}$ and $53.0 \pm 0.1 \mathrm{ml} ; 2.9 \pm 0.0 \mathrm{ml} / \mathrm{s}$ and $3.9 \pm 0.1 \mathrm{ml} / \mathrm{s} ; 3.4 \pm 0.0 \mathrm{ml} / \mathrm{s}$ and $4.2 \pm 0.0 \mathrm{ml} / \mathrm{s} ; 54 \pm 8 \mathrm{psi}$ and $68 \pm 8 \mathrm{psi}$ respectively.

\begin{tabular}{|l|l|l|l|}
\hline Radiation dose parameters & $\begin{array}{l}\text { Group 1 } \\
(\mathrm{n}=29)\end{array}$ & $\begin{array}{l}\text { Group 2 } \\
(\mathrm{n}=18)\end{array}$ & P-value \\
\hline Total CTDI ${ }_{\text {vol }}[\mathrm{mGy}]$ & $40 \pm 9$ & $38 \pm 9$ & 0.38 \\
\hline Total DLP [mGy.cm] & $443 \pm 135$ & $521 \pm 124$ & 0.06 \\
\hline $\begin{array}{l}\text { Total Effective Dose [mSv] } \\
\text { Helical } \\
\text { High-pitch }\end{array}$ & $\begin{array}{l}6 \pm 2 \\
5 \pm 1\end{array}$ & $\begin{array}{l}8 \pm 9 \pm 0.1 \\
6 \pm 1\end{array}$ & 0.06 \\
\hline CM injection parameters & $1.8 \pm 0.2$ & 0.30 \\
\hline Applied volume [ml] & $40.0 \pm 0.1$ & & $<.001$ \\
\hline Applied flow rate [ml/s] & $2.9 \pm 0.0$ & $53.0 \pm 0.1$ & $<.001$ \\
\hline Peak flow rate [ml/s] & $3.4 \pm 0.0$ & $3.9 \pm 0.1$ & $<.001$ \\
\hline Peak pressure [psi] & $54 \pm 8$ & $4.2 \pm 0.0$ & $<.001$ \\
\hline
\end{tabular}

Table 6.3 Radiation dose and injection related parameters Values are expressed as mean \pm SD

\section{Image quality}

Of the image sets obtained from 47 patients, 46 were diagnostically sufficient for aortic root anatomy, cardiac structures, and aorto iliofemoral anatomy. In one patient image quality was insufficient; this was due to streak artefacts caused by bilateral prosthesis material at the level of the hips and therefore at the level of the femoral arteries. Prosthesis material was present in one other patient (right hip) and femoral access could be properly depicted in this patient. 


\section{Group}

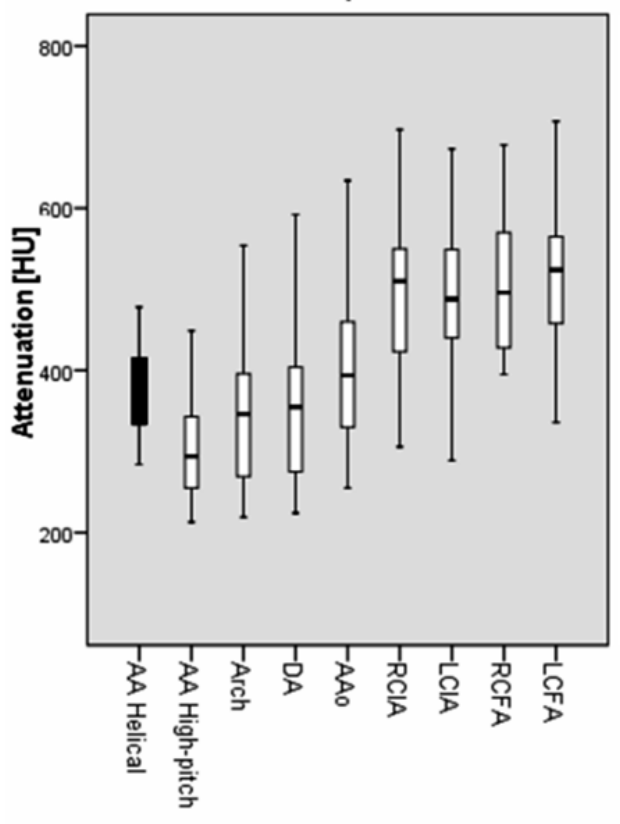

2

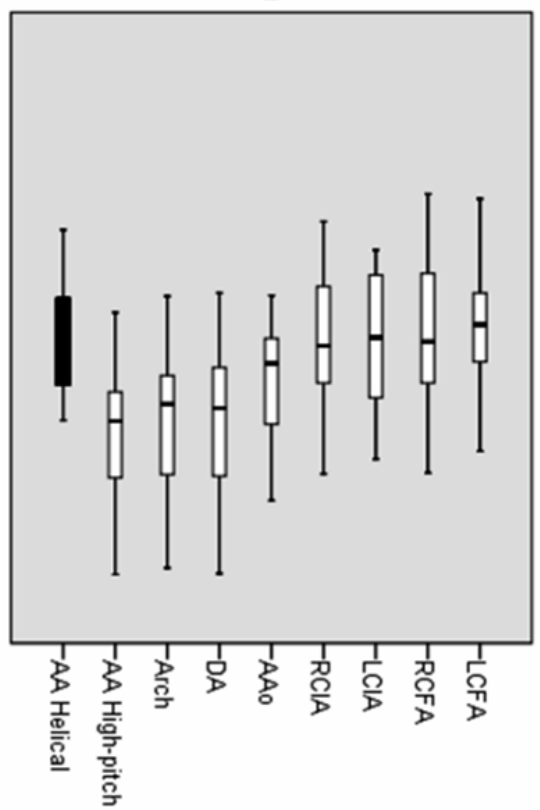

Figure 6.3 Box plots showing attenuation levels of each vascular segment

"AA helical" (black) was measured in the helical cardiac scan. "AA high-pitch" and the other levels (white) were measured in the high-pitch spiral scan of the aorta.

$\mathrm{AA}=$ ascending aorta; $\mathrm{DA}=$ descending aorta; $\mathrm{AAO}=$ abdominal aorta; $\mathrm{RCI} A$ and $\mathrm{LCI} A=$ right and left common femoral artery; RCFA and LCLA= right and left common femoral artery 

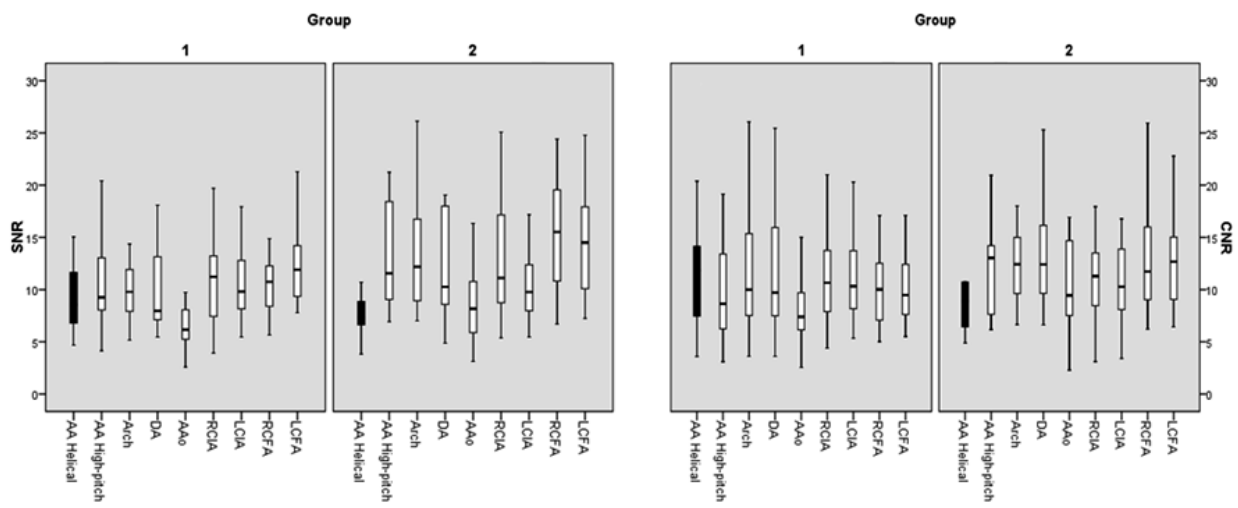

Figure 6.4 Box plots show SNR (left) and CNR (right) levels of each vascular segment

"AA helical" (black) was measured in the helical cardiac scan. "AA high-pitch" and the other levels (white) were measured in the high-pitch spiral scan of the aorta.

$A A=$ ascending aorta; $D A=$ descending aorta; $A A O=$ abdominal aorta; $R C I A$ and $L C I A=$ right and left common femoral artery; RCFA and LCLA= right and left common femoral artery

In helical scan images of the AA, sufficient enhancement levels $(>200 \mathrm{HU})$ were reached for both groups. Significantly higher attenuation values were observed for group 2 (mean attenuation group 1: $381 \pm 65 \mathrm{HU}$; group 2: $442 \pm 68 \mathrm{HU} ; p=0.004$ ), whereas better SNR and CNR was observed for group 1 (SNR group 1 vs. group 2: $10 \pm 5$ vs $8 \pm 2$, $p=0.045$; CNR group 1 vs. group 2: $13 \pm 8,10 \pm 5, p=0.152$.

High-pitch spiral scan images achieved sufficient overall enhancement levels (>200HU) in both groups. A significantly higher mean attenuation was found at all levels of the aorta in group $1(430 \pm 117 \mathrm{HU})$ as compared to group $2(389 \pm 102 \mathrm{HU}) ; p<0.001$. Post hoc comparisons for each vascular segment revealed that the significant difference in attenuation existed at the levels of the RCIA, LCIA, RCFA and LCFA, with corresponding $p$ values $0.045,0.016,0.017$ and 0.026 . In none of the vascular segments the mean attenuation was $<200 \mathrm{HU}$, nor were individual attenuation levels of $<200 \mathrm{HU}$ found at the level of the peripheral arteries (see figure 6.3). Significantly higher SNR and CNR were

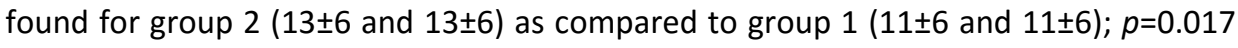
and $p=0.021$, respectively (see figure 6.4). Post hoc comparisons for each vascular segment revealed one mild significant difference between groups in the SNR at the level of the AAo, $p=0.048$. 


\begin{tabular}{|l|l|l|l|}
\hline $\begin{array}{l}\text { IQ score } \\
\text { Helical }\end{array}$ & $\begin{array}{l}\text { Group 1 } \\
\text { [n] }\end{array}$ & $\begin{array}{l}\text { Group 2 } \\
\text { [n] }\end{array}$ & P-value \\
\hline 1 & 0 & 0 & 0.03 \\
2 & 0 & 1 & \\
3 & 12 & 13 & \\
4 & 17 & 4 & \\
\hline IQ score & & & \\
High-pitch & & & 0.07 \\
\hline 1 & 1 & 0 & \\
2 & 5 & 0 & \\
3 & 11 & 4 & 14 \\
\hline 4 & 12 & 0.37 & \\
\hline$P$-value & 0.67 & & \\
\hline
\end{tabular}

Table 6.4 IQ scores of different anatomic levels for group 1 and group 2

IQ score: 1=non-diagnostic; 2=diagnostic; 3=good and 4=excellent

IQ scores of helical and high-pitch spiral acquisitions for both groups are listed in table 6.4. No significant differences were found between IQ scores of both acquisitions, with $p$-values of 0.67 for group 1 and 0.37 for group 2. IQ of each helical acquisition was diagnostic and IQ scores were significantly lower for group 2 compared to group 1 $(p=0.03)$. No significant difference was found in IQ between both groups for the highpitch spiral scans $(p=0.07)$.

\section{Renal function}

The mean eGFR was $54 \pm 8 \mathrm{ml} / \mathrm{min} / 1.73 \mathrm{~m}^{2}$ and $55 \pm 8 \mathrm{ml} / \mathrm{min} / 1.73 \mathrm{~m}^{2}$ for group 1 and group 2 respectively. In 4 patients (9\%) the eGFR was $<45 \mathrm{ml} / \mathrm{min} / 1.73 \mathrm{~m}^{2}$. These values indicate the overall impaired renal function of this population. The mean eGFR $\geq 1-2$ months after CTA was higher compared to the mean eGFR before CTA: $57 \pm 4 \mathrm{ml} / \mathrm{min} / 1.73 \mathrm{~m}^{2}$ and $57 \pm 6 \mathrm{ml} / \mathrm{min} / 1.73 \mathrm{~m}^{2}$ for group 1 and group 2 respectively. $A$ constant eGFR was found in 32 patients, an increased eGFR in 13 patients and a decreased eGFR in two patients. In none of the cases CIN was detected after 1-2 months. 


\begin{tabular}{|c|c|c|c|}
\hline \multirow[t]{2}{*}{ Prosthesis size } & \multirow{2}{*}{$\begin{array}{l}\text { Number } \\
\text { of patients }\end{array}$} & \multicolumn{2}{|l|}{ Measurements } \\
\hline & & Mean diameter [mm] & Area derived diameter $[\mathrm{mm}]$ \\
\hline \multicolumn{4}{|l|}{ Edwards Sapien $3^{A}$} \\
\hline $23 \mathrm{~mm}$ & 5 & 22 & 22 \\
\hline $26 \mathrm{~mm}$ & 15 & 25 & 25 \\
\hline $29 \mathrm{~mm}$ & 2 & 28 & 27 \\
\hline \multicolumn{4}{|l|}{ Edwards Sapien ${ }^{A} X T$} \\
\hline $20 \mathrm{~mm}$ & 1 & 19 & 20 \\
\hline $23 \mathrm{~mm}$ & 1 & 22 & 22 \\
\hline \multicolumn{4}{|l|}{ Medtronic Engager ${ }^{8}$} \\
\hline $26 \mathrm{~mm}$ & 1 & 23 & 24 \\
\hline \multicolumn{4}{|l|}{ Symetis Acuarte ${ }^{8}$} \\
\hline $23 \mathrm{~mm}$ & 1 & 22 & 22 \\
\hline
\end{tabular}

Table 6.5 Number of patients treated by different types of prosthesis as well as the annulus sizes measured by CT

${ }^{A}$ balloon-expandable prosthesis; ${ }^{B}$ self-expandable prosthesis

\section{TAVI procedure}

In total, 26 patients were treated by TAVI and the survival rate after one month was $100 \%$. Other patients underwent either open procedure or conservative treatment. In all patients the CT measurements were comparable to the size of the valve prosthesis implemented (table 6.5).

\section{DISCUSSION}

Vascular enhancement depends on three major factors - CM characteristics (e.g. flow rate), scanner related factors (e.g. tube voltage) and patient related factors (e.g. BMI). Especially use of lower $k V p$ is advantageous in terms of reducing $C M$, as the same amount of iodine will lead to a higher enhancement at lower $k V p^{20}$, enabling substantial reduction in $\mathrm{CM}$ volume. ${ }^{23-25}$ New scanner technologies facilitate lower kVp settings in a broader range of patients. ${ }^{26}$ In addition, new reconstruction technologies such as iterative reconstruction (IR) reduce image noise and therefore improve image quality $^{27-30}$ at lower kVp settings as well. Using BMI adapted low volume CM injection protocols in combination with low $\mathrm{kVp}$ scan settings provided diagnostically sufficient image quality in pre-TAVI assessment. Compared to the $80-120 \mathrm{ml} \mathrm{CM}$ mostly used in TAVI protocols ${ }^{13}$, we were able to reduce CM volume to $40 \mathrm{ml}(=12 \mathrm{gl})$ and $53 \mathrm{ml}(=16 \mathrm{gl})$ 
by using $70 \mathrm{kVp}$ and $80 \mathrm{kVp}$ settings, respectively. Further reduction of $(10 \mathrm{ml})$ would have been possible with use of bolus tracking, but a test bolus was chosen as additional information could be retrieved (e.g. cardiac output - beyond scope of this paper) ${ }^{31}$ and which might be used for further adaptation of the injection protocol. ${ }^{32}$

Volume reduction up to $67 \%$ still lead to sufficient attenuation values at all anatomical levels in all patients. In addition, SNR and CNR levels were found to be sufficient for both groups according to Leber et $a l^{21}$ who suggests CNR values $>3$ to be diagnostically acceptable.

Attenuation values, image noise and image quality ratios (SNR/CNR) are most affected by $\mathrm{CM}$ injection parameters, scan technique and patient body $\operatorname{size}^{33}$ : Lowering IDR and TIL might compromise attenuation values and therefore image quality; Lowering radiation dose - by decreasing kVp or tube current settings - increases the amount of image noise; Increased body size decreases attenuation values due to increased circulating blood volume and simultaneously image noise increases due to absorbing tissue. These factors necessitate optimised injection and scan parameters in terms of image quality. However, individual patient characteristics and indication for CTA need to be taken into account. For TAVI candidates, optimal image quality - meaning low image noise and high enhancement - is required at the level of the aortic root for aortic annulus evaluation. For the peripheral access route, higher noise levels are acceptable. In this respect, IQ scores were defined according different criteria for each anatomic level in the current study. Comparisons between IQ at the level of the aortic root and the level of the peripheral arteries showed no significant differences in both groups. However, in one patient, image quality was found to be non-diagnostic at the level of the peripheral arteries due to the presence of prosthesis material. This could easily be picked up on the scout view and scan parameters can be adjusted accordingly (higher $k V p$ settings). On the other hand metallic artefacts do not necessarily hinder full evaluation of the vessels. 

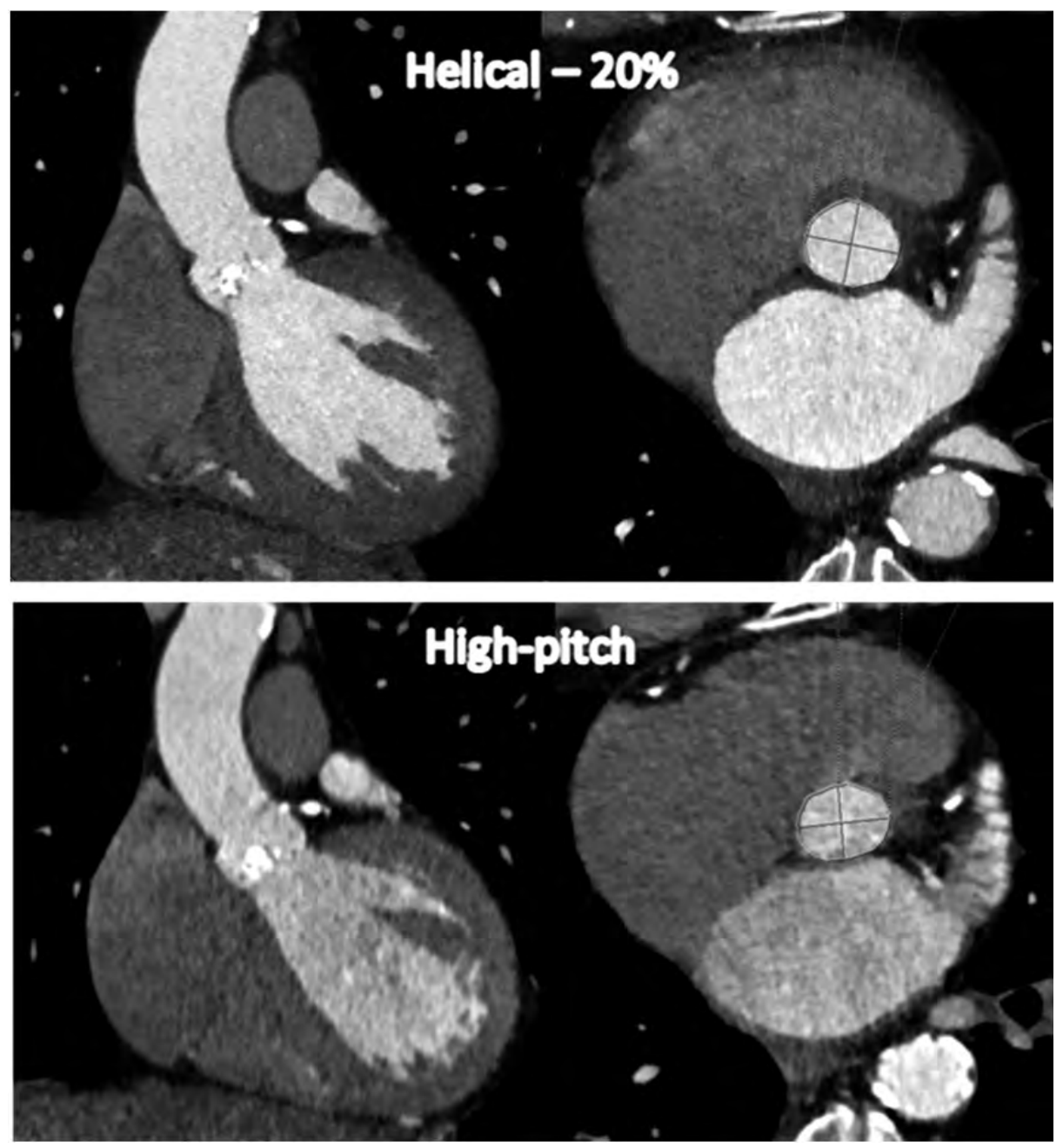

Figure 6.5 Images show the difference in the dimensions of the annulus and valve between reconstructions from different scan acquisitions

Reconstruction at the $20 \%$ phase of the cardiac cycle using retrospective ECG-gated helical acquisition (upper) and reconstruction using the non ECG-gated high-pitch acquisition (bottom). The measurements for short and long diameter as well as perimeter were: $21 \mathrm{~mm}, 25 \mathrm{~mm}$ and $4.2 \mathrm{~cm}^{2}$, respectively for the helical acquisition and $19 \mathrm{~mm}, 24 \mathrm{~mm}$ and $3.8 \mathrm{~cm}^{2}$, respectively for the high-pitch acquisition

Optimising radiation dose is of less importance in this particular patient population, stochastic effects can be regarded as negligible in patients with a mean age of 75/76 years. But the most challenging and important part of protocol optimisation in a TAVI population with an inherent high number of impaired renal function, is to reduce the risk of CIN by means of the most efficient use of $\mathrm{CM}^{34,35}$

The use of reduced TIL in pre-TAVI assessment has been investigated by several other groups. For example, Dubourg et $a l^{36}$ evaluated a combined CM injection protocol for 
an ECG-gated helical scan followed by a non ECG-triggered high-pitch spiral scan. They used a dual energy acquisition with fast kVp switching (80-140kVp) for the second acquisition, and were able to reduce the second bolus CM volume by $50 \%$. Total CM volume was reduced from $125 \mathrm{ml}$ to $95 \mathrm{ml}$, which still results in a relatively high TIL (33gl using $\mathrm{CM}$ concentration of $350 \mathrm{mgl} / \mathrm{ml}$ ).

Wuest et $a l^{37}$ were able to reduce CM volume to $40 \mathrm{ml}$ for CTA in TAVI candidates (14gI with $350 \mathrm{mgl} / \mathrm{ml}$ ). Patients with $\mathrm{BMI}<30$ received a $100 \mathrm{kVp}$ scan protocol, with BMI $>30$ a $120 \mathrm{kVp}$ scan. Image quality (presence of motion artefacts, enhancement, image noise and (NR) for evaluation of aortic root complex was found to be diagnostic in $\mathbf{4 0}$ from 42 patients.

Azzalini et $a l^{38}$ tested the feasibility of an ultralow CM volume injection $(20 \mathrm{ml}=7.4 \mathrm{gl}$ with $370 \mathrm{mg} / \mathrm{ml}$ ), in combination with a high-pitch scan mode in 8 patients. They found acceptable image quality using a 100 or $120 \mathrm{kVp}$ setting (automated tube voltage setting according patient body size). However, in these studies, only one scan - a highpitch spiral acquisition - was performed for the evaluation of both aortic root and iliac dimensions, which compromises the dynamic assessment of the aortic valve and the annulus as retrospectively gated CTA - including a $20 \%$ phase reconstruction - is recommended. ${ }^{17}$ Figure 6.5 demonstrates the difference in dimensions of the annulus and valve between a $20 \%$ phase reconstruction from a retrospective ECG-gated helical acquisition and a reconstruction from a high-pitch acquisition - as the latter provides no $20 \%$ phase reconstruction. ECG-triggered high-pitch CTA is usually acquired during diastolic phase, and should therefore be used exclusively for aorto iliofemoral CTA. ${ }^{2,18,}$ ${ }^{36}$ Although differences between phases of reconstruction might be small, they will lead to different measurements for the diameter and could therefore lead to different prosthesis sizing. ${ }^{17}$

In none of the abovementioned studies a combined scan protocol including a retrospective ECG-gated acquisition was used. Either a high-pitch spiral scan acquisition was used in combination with low volume injections, at the expense of a dynamic study; or a combined scan acquisition was used at the expense of $\mathrm{CM}$ volume reduction. One could argue that the use of only one scan acquisition is most advantageous as this could reduce scan time and therefore radiation dose and $\mathrm{CM}$ volume. However, an ECG-triggered high-pitch scan acquisition is not desirable because of the reconstruction in the diastolic phase, as mentioned above. A complete retrospective ECG-gated acquisition is also not desirable as the scan time will greatly increase because of the decreased pitch factor compared to a high-pitch acquisition (0.23 vs. 3.0). As a result, radiation dose will increase and $\mathrm{CM}$ volume must also be adjusted according a prolonged injection time (see also figure 6.6).

The combined scan protocol as presented will therefore ensure best image quality at the level of the aortic root for dedicated pre-interventional analysis in combination with a full picture of the access options for TAVI, while keeping radiation dose and TIL as low as possible. 
In the current study, the overall renal function was not impaired after 1-2 months from CTA. This is in line with the study of McDonald et $a l^{39}$, which stated that intravenous iodinated CM may not be the causative agent in impaired renal function after CM administration.

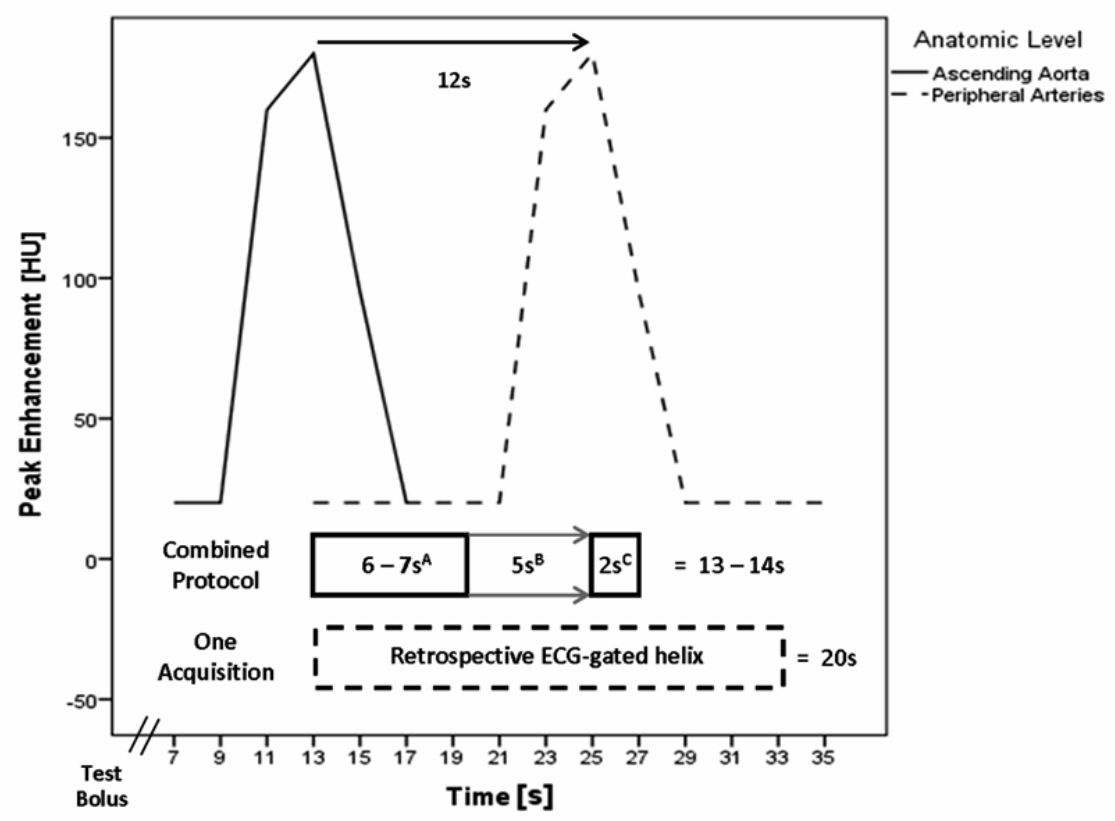

Figure 6.6 This schematic figure shows the time to peak at the level of the ascending aorta as well as at the level of the peripheral arteries

The time in between was 12s. Using the combined scan protocol, the fast second scan acquisition will again catch the bolus in the peripheral arteries. With only the retrospective ECG-gated acquisition scan time will be extended and the bolus will likely overtake the scan.

${ }^{A}$ retrospective ECG-gated helical acquisition of the heart; ${ }^{B}$ gap between acquisitions; ${ }^{C}$ high-pitch acquisition of the aorta from aortic arch to femoral arteries

\section{Limitations}

One limitation is that serum creatinine data from 48-72 hours after CTA could not be retrieved in the majority of patients and therefore acute kidney failure could not be detected. However, the eGFR after 1-2 months showed no relevant changes in renal function compared to the eGFR before CTA. In addition, ultra-low kVp scan protocols as well as the ultra-fast acquisition mode are not available on every type of scanner 
and in the current situation the protocols are not applicable to every patient, due to technical limitations of the dedicated CT scanner used in this study: the maximum tube-current-time product for a high-pitch flash scan was $122 \mathrm{mAs}_{\text {eff }}$ for $80 \mathrm{kVp}$ and only $93 \mathrm{mAs}_{\text {eff }}$ for $70 \mathrm{kVp}$. These low tube-current-time products present a problem because of resulting streak artefacts in the presence of prosthesis materials, or too high noise levels in obese patients.

\section{CONCLUSION}

Low kVp scan protocols allow for substantial reduction in CM volume as compared to common high volume injection protocols for pre-TAVI CT examinations. Sufficient image quality was maintained for the evaluation of the aortic root and peripheral access site despite a CM volume reduction of 34-67\%. This may play an important role in terms of increased patient safety, as lower iodine load is regarded to lower the risk of CIN. 


\section{REFERENCES}

1. Webb JG, Pasupati S, Humphries K, Thompson C, Altwegg L, Moss R, Sinhal A, Carere RG, Munt B, Ricci D, Ye J, Cheung A and Lichtenstein SV. Percutaneous transarterial aortic valve replacement in selected high-risk patients with aortic stenosis. Circulation. 2007;116:755-63.

2. Holmes DR, Jr., Mack MJ, Kaul S, Agnihotri A, Alexander KP, Bailey SR, Calhoon JH, Carabello BA, Desai MY, Edwards FH, Francis GS, Gardner TJ, Kappetein AP, Linderbaum JA, Mukherjee C, Mukherjee D, Otto CM, Ruiz CE, Sacco RL, Smith D, Thomas JD, Harrington RA, Bhatt DL, Ferrari VA, Fisher JD, Garcia MJ, Gardner TJ, Gentile F, Gilson MF, Hernandez AF, Jacobs AK, Kaul S, Linderbaum JA, Moliterno DJ, Weitz HH, American Heart A, American Society of E, European Association for Cardio-Thoracic S, Heart Failure Society of A, Mended H, Society of Cardiovascular A, Society of Cardiovascular Computed T and Society for Cardiovascular Magnetic R. 2012 ACCF/AATS/SCAI/STS expert consensus document on transcatheter aortic valve replacement: developed in collabration with the American Heart Association, American Society of Echocardiography, European Association for Cardio-Thoracic Surgery, Heart Failure Society of America, Mended Hearts, Society of Cardiovascular Anesthesiologists, Society of Cardiovascular Computed Tomography, and Society for Cardiovascular Magnetic Resonance. The Journal of thoracic and cardiovascular surgery. 2012;144:e29-84.

3. Husser O, Holzamer A, Resch M, Endemann DH, Nunez J, Bodi V, Schmid C, Riegger GA, Gossmann H, Hamer O, Stroszczynski C, Luchner A, Hilker M and Hengstenberg C. Prosthesis sizing for transcatheter aortic valve implantation--comparison of three dimensional transesophageal echocardiography with multislice computed tomography. International journal of cardiology. 2013;168:3431-8.

4. Jilaihawi H, Kashif M, Fontana G, Furugen A, Shiota T, Friede G, Makhija R, Doctor N, Leon MB and Makkar RR. Cross-sectional computed tomographic assessment improves accuracy of aortic annular sizing for transcatheter aortic valve replacement and reduces the incidence of paravalvular aortic regurgitation. Journal of the American College of Cardiology. 2012;59:1275-86.

5. Yamamoto M, Hayashida K, Mouillet G, Chevalier B, Meguro K, Watanabe Y, Dubois-Rande JL, Morice MC, Lefevre $T$ and Teiger E. Renal function-based contrast dosing predicts acute kidney injury following transcatheter aortic valve implantation. JACC Cardiovascular interventions. 2013;6:479-86.

6. Becker CR, Davidson C, Lameire N, McCullough PA, Stacul F, Tumlin J, Adam A and Panel CINCW. High-risk situations and procedures. The American journal of cardiology. 2006;98:37K-41K.

7. European Society of Urogenital Radiology web-site. ESUR Contrast Media Safety Committee. ESUR guidelines on contrast media, version 8.1. www.esur.org/guidelines/. Published 2012. Accessed May, 2015

8. Mehran R and Nikolsky E. Contrast-induced nephropathy: definition, epidemiology, and patients at risk. Kidney international Supplement. 2006:S11-5.

9. Abujudeh $\mathrm{HH}$, Gee MS and Kaewlai R. In emergency situations, should serum creatinine be checked in all patients before performing second contrast CT examinations within 24 hours? Journal of the American College of Radiology : JACR. 2009;6:268-73.

10. Trivedi $\mathrm{H}$ and Foley WD. Contrast-induced nephropathy after a second contrast exposure. Renal failure. 2010;32:796-801.

11. Beeres M, Loch M, Schulz B, Kerl M, Al-Butmeh F, Bodelle B, Herrmann E, Gruber-Rouh T, Lee C, Jacobi V, Vogl TJ and Bauer RW. Bolus timing in high-pitch CT angiography of the aorta. European journal of radiology. 2013;82:1028-33.

12. Gurvitch R, Webb JG, Yuan R, Johnson M, Hague C, Willson AB, Toggweiler S, Wood DA, Ye J, Moss R, Thompson CR, Achenbach S, Min JK, Labounty TM, Cury R and Leipsic J. Aortic annulus diameter determination by multidetector computed tomography: reproducibility, applicability, 
and implications for transcatheter aortic valve implantation. JACC Cardiovascular interventions. 2011;4:1235-45.

13. Nguyen $\mathrm{G}$ and Leipsic J. Cardiac computed tomography and computed tomography angiography in the evaluation of patients prior to transcatheter aortic valve implantation. Current opinion in cardiology. 2013;28:497-504.

14. Feuchtner GM, Jodocy D, Klauser A, Haberfellner B, Aglan I, Spoeck A, Hiehs S, Soegner P and Jaschke W. Radiation dose reduction by using 100-kV tube voltage in cardiac 64-slice computed tomography: a comparative study. European journal of radiology. 2010;75:e51-6.

15. Winklehner A, Blume I, Winklhofer S, Eberli D, Gnannt R, Frauenfelder T and Alkadhi H. Iterative reconstructions versus filtered back-projection for urinary stone detection in low-dose CT. Academic radiology. 2013;20:1429-35.

16. Deak PD, Smal Y and Kalender WA. Multisection CT protocols: sex- and age-specific conversion factors used to determine effective dose from dose-length product. Radiology. 2010;257:158-66.

17. Jurencak T, Turek J, Kietselaer BL, Mihl C, Kok M, van Ommen VG, van Garsse LA, Nijssen EC, Wildberger JE and Das M. MDCT evaluation of aortic root and aortic valve prior to TAVI. What is the optimal imaging time point in the cardiac cycle? European radiology. 2015.

18. Achenbach S, Delgado V, Hausleiter J, Schoenhagen P, Min JK and Leipsic JA. SCCT expert consensus document on computed tomography imaging before transcatheter aortic valve implantation (TAVI)/transcatheter aortic valve replacement (TAVR). Journal of cardiovascular computed tomography. 2012;6:366-80.

19. Bae KT. Optimization of contrast enhancement in thoracic MDCT. Radiologic clinics of North America. 2010;48:9-29.

20. Weininger M, Barraza JM, Kemper CA, Kalafut JF, Costello P and Schoepf UJ. Cardiothoracic CT angiography: current contrast medium delivery strategies. AJR American journal of roentgenology. 2011;196:W260-72.

21. Leber AW, Knez A, Becker C, Becker A, White C, Thilo C, Reiser M, Haberl R and Steinbeck G. Noninvasive intravenous coronary angiography using electron beam tomography and multislice computed tomography. Heart (British Cardiac Society). 2003;89:633-9.

22. Bloomfield GS, Gillam LD, Hahn RT, Kapadia S, Leipsic J, Lerakis S, Tuzcu M and Douglas PS. A practical guide to multimodality imaging of transcatheter aortic valve replacement. JACC Cardiovascular imaging. 2012;5:441-55.

23. Vlahos I, Chung R, Nair A and Morgan R. Dual-energy CT: vascular applications. AJR American journal of roentgenology. 2012;199:S87-97.

24. Strocchi S, Vite C, Callegari L and Conte L. Optimisation of multislice computed tomography protocols in angio-CT examinations. La Radiologia medica. 2006;111:238-44.

25. Cao JX, Wang YM, Lu JG, Zhang Y, Wang P and Yang C. Radiation and contrast agent doses reductions by using $80-\mathrm{kV}$ tube voltage in coronary computed tomographic angiography: A comparative study. European journal of radiology. 2014;83:309-14.

26. Xia W, Wu JT, Yin XR, Wang ZJ and Wu HT. CT angiography of the neck: value of contrast medium dose reduction with low tube voltage and high tube current in a 64-detector row CT. Clinical radiology. 2014;69:e183-9.

27. Pontana F, Pagniez J, Duhamel A, Flohr T, Faivre JB, Murphy C, Remy J and Remy-Jardin M. Reduced-dose low-voltage chest CT angiography with Sinogram-affirmed iterative reconstruction versus standard-dose filtered back projection. Radiology. 2013;267:609-18.

28. Wang R, Schoepf UJ, Wu R, Reddy RP, Zhang C, Yu W, Liu Y and Zhang Z. Image quality and radiation dose of low dose coronary $\mathrm{CT}$ angiography in obese patients: sinogram affirmed iterative reconstruction versus filtered back projection. European journal of radiology. 2012;81:3141-5.

29. Korn A, Bender B, Fenchel M, Spira D, Schabel C, Thomas C, Flohr T, Claussen CD, Bhadelia R, Ernemann $U$ and Brodoefel $H$. Sinogram affirmed iterative reconstruction in head $C T$ : 
improvement of objective and subjective image quality with concomitant radiation dose reduction. European journal of radiology. 2013;82:1431-5.

30. Baker ME, Dong F, Primak A, Obuchowski NA, Einstein D, Gandhi N, Herts BR, Purysko A, Remer E and Vachhani N. Contrast-to-noise ratio and low-contrast object resolution on full- and low-dose MDCT: SAFIRE versus filtered back projection in a low-contrast object phantom and in the liver. AJR American journal of roentgenology. 2012;199:8-18.

31. Mahnken AH, Klotz E, Hennemuth A, Jung B, Koos R, Wildberger JE and Gunther RW. Measurement of cardiac output from a test-bolus injection in multislice computed tomography. European radiology. 2003;13:2498-504.

32. Mahnken AH, Rauscher A, Klotz E, Muhlenbruch G, Das M, Gunther RW and Wildberger JE. Quantitative prediction of contrast enhancement from test bolus data in cardiac MSCT. European radiology. 2007;17:1310-9.

33. Bae KT. Intravenous contrast medium administration and scan timing at CT: considerations and approaches. Radiology. 2010;256:32-61.

34. Bruce RJ, Djamali A, Shinki K, Michel SJ, Fine JP and Pozniak MA. Background fluctuation of kidney function versus contrast-induced nephrotoxicity. AJR American journal of roentgenology. 2009;192:711-8.

35. Mack MJ, Brennan JM, Brindis R, Carroll J, Edwards F, Grover F, Shahian D, Tuzcu EM, Peterson ED, Rumsfeld JS, Hewitt K, Shewan C, Michaels J, Christensen B, Christian A, O'Brien S, Holmes D and Registry SAT. Outcomes following transcatheter aortic valve replacement in the United States. Jama. 2013;310:2069-77.

36. Dubourg B, Caudron J, Lestrat JP, Bubenheim M, Lefebvre V, Godin M, Tron C, Eltchaninoff H, Bauer F and Dacher JN. Single-source dual-energy CT angiography with reduced iodine load in patients referred for aortoiliofemoral evaluation before transcatheter aortic valve implantation: impact on image quality and radiation dose. European radiology. 2014;24:2659-68.

37. Wuest W, Anders K, Schuhbaeck A, May MS, Gauss S, Marwan M, Arnold M, Ensminger S, Muschiol G, Daniel WG, Uder M and Achenbach S. Dual source multidetector CT-angiography before Transcatheter Aortic Valve Implantation (TAVI) using a high-pitch spiral acquisition mode. European radiology. 2012;22:51-8.

38. Azzalini L, Abbara S and Ghoshhajra BB. Ultra-low contrast computed tomographic angiography (CTA) with 20-mL total dose for transcatheter aortic valve implantation (TAVI) planning. Journal of computer assisted tomography. 2014;38:105-9.

39. McDonald RJ, McDonald JS, Bida JP, Carter RE, Fleming CJ, Misra S, Williamson EE and Kallmes DF. Intravenous contrast material-induced nephropathy: causal or coincident phenomenon? Radiology. 2013;267:106-18. 




\section{CHAPTER 7}

\section{Individualised CT angiography protocols for the evaluation of the aorta: A feasibility study}

M. Kok, M.W. de Haan, C. Mihl, B.M.F. Hendriks, E.G. Eijsvoogel, K. Derks, R.S. Schnerr, G.W. Schurink, J.E. Wildberger, M. Das.

J Vasc Interv Radiol. 2016 Apr;27(4):531-8. 


\section{ABSTRACT}

\section{Purpose}

lonising radiation and iodinated contrast are potential drawbacks for repetitive followup CT angiography (CTA) in current practice. The aim of this study was to optimise radiation dose and contrast volume by using individualised CTA protocols.

\section{Materials and methods}

Eighty consecutive patients referred for CTA of the whole aorta were prospectively evaluated. Patients were divided into two groups: group 1: body mass index (BMI) $<28 \mathrm{~kg} / \mathrm{m}^{2}(\mathrm{n}=50)$ and group 2: $\mathrm{BMI} \geq 28 \mathrm{~kg} / \mathrm{m}^{2}(\mathrm{n}=30)$. A control group was used and consisted of 50 consecutive patients who were retrospectively evaluated. CTA parameters on a $2^{\text {nd }}$ generation dual-source scanner were: $128 \times 0.6 \mathrm{~mm}$ coll., pitch 0.9 , rot.time $0.33 \mathrm{~s}$, 80/100/120kVp (group 1/group 2/control), 400mAs ref; image reconstruction: $1 \mathrm{~mm} / 0.8 \mathrm{~mm}$ slice thickness (kernel: B30f [control] and I30f, strength 3 [group 1/2]). The control group received $120 \mathrm{ml}$ of contrast $(300 \mathrm{mgl} / \mathrm{ml})$ at $4.8 \mathrm{ml} / \mathrm{s}$; group 1 and group 2: $44 \mathrm{ml}$ and $53 \mathrm{ml}$ at $3.3 \mathrm{ml} / \mathrm{s}$ and $4 \mathrm{ml} / \mathrm{s}$, respectively. Effective dose [mSv] was evaluated for each patient. Image quality was determined by qualitative image analysis at the level of the thoracic, abdominal and pelvic aorta: non-diagnostic/diagnostic/ good/excellent and quantitative image analysis: attenuation values [HU] and contrastto-noise ratio (CNR).

\section{Results:}

Mean effective radiation dose values for a CTA of the aorta were: $3.7 \pm 0.7 \mathrm{mSv}$ (group 1 ); $6.7 \pm 1.4 \mathrm{mSv}$ (group 2) and $8.7 \pm 1.9 \mathrm{mSv}$ (control) with p-values $<0.001$. Mean attenuation values and CNR levels were as follows (mean \pm SD): group 1: $334 \pm 66 \mathrm{HU}$ and $16 \pm 8$; group 2: $277 \pm 56 \mathrm{HU}$ and $14 \pm 5$; control: $305 \pm 77 \mathrm{HU}$ and $11 \pm 4$.

\section{Conclusion:}

Iterative reconstruction algorithms resulted in $23-57 \%$ less radiation in combination with $55-63 \%$ less contrast volume when compared to standard CT protocols. 


\section{INTRODUCTION}

Computed tomographic angiography (CTA) is widely used in current practice to detect aortic aneurysms, to evaluate aortic diameter over time and for follow-up after endovascular aneurysm repair (EVAR). ${ }^{1,2}$ With technical improvements such as multi detector-row CT (MDCT) even more options exist to image anatomical structures, to visualise the aortic wall and lumen, calcifications and thrombus as well as metallic stentgrafts. $^{1,3-7}$ Furthermore, compared to other imaging methods, advantages of CTA include the fast image acquisition and easy post processing, the ability to obtain a threedimensional (3D) reconstruction of the entire aorta, and the widespread availability of this method. ${ }^{1}$ However, use of iodinated contrast and ionising radiation dose are considered potential drawbacks for $\mathrm{CTA}^{1,8}$ - especially when lifelong follow-up imaging is recommended. ${ }^{9-11}$ In order to minimise these risks, using as low as reasonably achievable radiation dose and subsequently lowering contrast volume ${ }^{12}$ seem to be fair options. However, these protocol adaptations should not be at the expense of image quality. Therefore, the use of body weight adapted protocols ${ }^{13,14}$ and new scanner options such as iterative reconstruction allow imaging at lower radiation dose without compromising image quality compared to routine dose filtered back projection (FBP). ${ }^{15-17}$ For example, Lehti et $a l^{18}$ could reduce radiation dose with $12 \%$ and iodine load with $48 \%$ using $80 \mathrm{kVp}$ compared to $120 \mathrm{kVp}$. Chen et al $1^{19}$ reduced radiation dose with $48 \%$ and iodine load with $60 \%$ in aortic CTA using $80 \mathrm{kVp}$ compared to $120 \mathrm{kVp}$, while using iterative reconstruction. In both studies, however, scan protocols were not adapted according to patients' body size (mean body mass index (BMI) in both studies was approximately $27 \mathrm{~kg} / \mathrm{m}^{2}$ ).

Taking all these factors into consideration, individualisation and optimisation of scan protocols as well as contrast administration according to patients' body size in CTA of the aorta, is warranted. Thus, the aim of this study was to evaluate the use of individualised aortic CTA protocols with interative reconstruction and to compare this with the use of standard CTA.

\section{MATERIALS AND METHODS}

\section{Ethics and patient population}

The study design was approved by the local ethical committee and the institutional review board. A waiver of written informed consent was obtained from the local ethical committee (METC, ref. 15-4-015).

Ninety-eight consecutive patients referred from the vascular surgery outpatient department underwent CTA for evaluation of different aortic diseases. The patients were divided into two groups and received an adapted scan and injection protocol based on 
their $\mathrm{BMI}^{20,21}$ : group $1 \mathrm{BMI}<28 \mathrm{~kg} / \mathrm{m}^{2}(\mathrm{n}=50)$; group $2 \mathrm{BMI} \geq 28 \mathrm{~kg} / \mathrm{m}^{2}(\mathrm{n}=30)$. Patients with $\mathrm{BMI} \geq 35 \mathrm{~kg} / \mathrm{m}^{2}$ received a scan protocol without the use of lower $\mathrm{kVp}$ settings and were therefore excluded from the analysis $(n=18)$. In total, 80 patients were prospectively included for this study. The control group was retrospectively included and consisted of 50 consecutive patients who received a standard scan and injection protocol with fixed parameters. Baseline characteristics such as age, gender and BMI of all groups are listed in table 7.1. Included patients received an aortic CTA for different clinical indications regarding the evaluation of the aorta as listed in table 7.2. In patients referred for a follow-up scan post TEVAR (thoracic endovascular aneurysm repair), EVAR or FEVAR (fenestrated endovascular aneurysm repair), the indication consisted of aortic diameter evaluation and stent-graft evaluation including its position and the detection of possible endoleakages.

\begin{tabular}{|l|l|l|l|l|}
\hline Baseline characteristics & $\begin{array}{l}\text { Control } \\
(\mathrm{n}=50)\end{array}$ & $\begin{array}{l}\text { Group 1 } \\
(\mathrm{n}=50)\end{array}$ & $\begin{array}{l}\text { Group 2 } \\
(\mathrm{n}=30)\end{array}$ & -value $^{\wedge}$ \\
\hline Age [y] & $68 \pm 11$ & $67 \pm 12$ & $64 \pm 12$ & 0.3 \\
\hline Gender [male] & $39[78 \%]$ & $30[60 \%]$ & $23[77 \%]$ & 0.2 \\
\hline Height [cm] & $175 \pm 10$ & $174 \pm 10$ & $173 \pm 10$ & 0.2 \\
\hline Weight $[\mathrm{kg}]$ & $82 \pm 16$ & $72 \pm 14$ & $92 \pm 10$ & 0.2 \\
\hline BMI* $\left[\mathrm{kg} / \mathrm{m}^{2}\right]$ & & & & \\
\hline
\end{tabular}

Table 7.1 Baseline characteristics

*BMI = Body mass index

$\wedge$ The $p$-value is based on the difference between the control group and the intervention group (= group 1 and 2 together) 


\begin{tabular}{|c|c|c|c|}
\hline Clinical indication & $\begin{array}{l}\text { Control } \\
(n=50)\end{array}$ & $\begin{array}{l}\text { Group 1 } \\
(n=50)\end{array}$ & $\begin{array}{l}\text { Group 2 } \\
(n=30)\end{array}$ \\
\hline \multicolumn{4}{|l|}{ CTA } \\
\hline Aortic diameter $(n=44)$ & $15[30 \%]$ & $15[30 \%]$ & $14[46 \%]$ \\
\hline Pre intervention $(n=13)$ & $4[8 \%]$ & 7 [14\%] & $2[7 \%]$ \\
\hline \multicolumn{4}{|l|}{ Aneurysm } \\
\hline 1. mesenteric branches/arteries $(n=5)$ & - & $3[6 \%]$ & $2[7 \%]$ \\
\hline 2. iliac/femoral arteries $(n=5)$ & $2[4 \%]$ & $2[4 \%]$ & $1[3 \%]$ \\
\hline \multicolumn{4}{|l|}{ Stenosis } \\
\hline 1. renal arteries $(n=1)$ & - & $1[2 \%]$ & - \\
\hline 2. mesenteric branches/arteries $(n=6)$ & $3[6 \%]$ & $2[4 \%]$ & $1[3 \%]$ \\
\hline 3. iliac/femoral arteries $(n=2)$ & - & $2[4 \%]$ & . \\
\hline \multicolumn{4}{|l|}{$\underline{C T A}+$ additional scans } \\
\hline \multicolumn{4}{|l|}{ Postintervention } \\
\hline 1. TEVAR $(n=14)$ & $6[12 \%]$ & $5[10 \%]$ & $3[10 \%]$ \\
\hline 2. $\operatorname{EVAR}(n=16)$ & $9[18 \%]$ & $5[10 \%]$ & $2[7 \%]$ \\
\hline 3. FEVAR $(n=6)$ & $4[8 \%]$ & - & $2[7 \%]$ \\
\hline Type B dissection (n=17) & $6[12 \%]$ & $8[16 \%]$ & $3[10 \%]$ \\
\hline Bleeding $(n=1)$ & $1[2 \%]$ & - & - \\
\hline
\end{tabular}

Table 7.2 Number of scans for different scan ranges and for different clinical indications among all groups

\section{CTA scan and contrast injection protocols}

All patients received a thoraco-abdominal-pelvic CTA. For the assessment of the aorta, scans were performed using a $2^{\text {nd }}$ generation Dual-source CT scanner (Somatom Definition Flash, Siemens Medical Solutions, Forchheim, Germany) with a $128 \times 0.6 \mathrm{~mm}$ slice collimation; gantry rotation time of $0.33 \mathrm{~s}$ and pitch value 0.9 . The acquisition time for this scan range while using these parameters varies between 8-12 seconds depending on the scan range in the z-direction. Group 1 and group 2 received a scan protocol using a reference tube current of $400 \mathrm{mAs}_{\text {ref }}$ (CareDose $4 \mathrm{D}^{\mathrm{TM}}$, Siemens Medical Solutions) and a tube voltage of $80 \mathrm{kVp}$ and $100 \mathrm{kVp}$, respectively. The control group received a dual energy scan protocol using the following settings: a reference tube current of $136 \mathrm{mAs}_{\text {ref }}$ and $116 \mathrm{mAs}$ ref (CareDose $4 \mathrm{D}^{\mathrm{TM}}$, Siemens Medical Solutions) for tube $A$ and tube $B$, respectively and a tube voltage of $100 \mathrm{kVp}$ and $140 \mathrm{kVp}$ for tube $A$ and tube $B$, respectively (dual energy composition of $0.5[\approx 120 \mathrm{kVp}]$ for the mixed images). lodinated contrast (iopromide @ $300 \mathrm{mgl} / \mathrm{ml}$; Ultravist, Bayer Healthcare, Berlin, Germany) was pre-heated to body temperature $\left(37^{\circ} \mathrm{C} ; 99^{\circ} \mathrm{F}\right)$ and injected using a standard dual-head CT power injector (Stellant, Bayer Healthcare, Berlin, Germany). Patients from group 1 received a main contrast bolus of $44 \mathrm{ml}$ injected at $3.3 \mathrm{ml} / \mathrm{s}$ and patients from group 2 received a main bolus of $53 \mathrm{ml}$ injected at $4 \mathrm{ml} / \mathrm{s}$. Patients from the control group received a main contrast bolus over $25 \mathrm{~s}(120 \mathrm{ml}$ injected at $4.8 \mathrm{ml} / \mathrm{s})$. 
All injections were followed by a saline flush of $40 \mathrm{ml}$ at the same flow rate. Scan delay was determined by bolus tracking technique. Contrast monitoring software (Certegra $^{\mathrm{TM}}$ Informatics Solution, Bayer Healthcare, Berlin, Germany) was used to record the relevant contrast injection parameters (e.g. volume, flow rate, peak flow rate and peak pressure) for each patient.

Image reconstruction was performed using $1 \mathrm{~mm}$ slice thickness with an increment of $0.8 \mathrm{~mm}$ using a B30f kernel (FBP) for the control group and an I30f kernel (Sinogram Affirmed Iterative Reconstruction; [SAFIRE] strength 3) for group 1 and group 2. Scan parameters are summarised in table 7.3. All dose related parameters (e.g. effective tube current $\left[\mathrm{mAs}_{\text {eff }}\right], \mathrm{CTD}$ Ivol, dose-length product [DLP] and effective radiation dose) were recorded for each scan.

\begin{tabular}{|c|c|c|}
\hline Group & Control & Group 1/ Group 2 \\
\hline Protocol & Aorta & Aorta \\
\hline Mode & Spiral & Spiral \\
\hline Collimation [mm] & 0.6 & 0.6 \\
\hline Acquisition [mm] & $128 * 0.6$ & $128 * 0.6$ \\
\hline Tube voltage [kVp] & $100 / 140$ & $80 / 100$ (group 1/group 2) \\
\hline Dose modulation & on & on \\
\hline Tube current $\left[\mathrm{mAs}_{\text {ref }}\right]$ & $136 / 116$ & 400 \\
\hline Rot.Time [s] & 0.33 & 0.33 \\
\hline Pitch & 0.9 & 0.9 \\
\hline Delay [s] & Bolus tracking technique & Bolus tracking technique \\
\hline Direction & Cranio-caudal & Cranio-caudal \\
\hline \multicolumn{3}{|l|}{ Reconstruction 1} \\
\hline Slice thickness [mm] & 1.0 & 1.0 \\
\hline Increment [mm] & 0.8 & 0.8 \\
\hline Kernel & B3of & $130 f$ \\
\hline
\end{tabular}

Table 7.3 Scan protocol parameters

\section{Quantitative analysis - radiation dose and image quality}

Radiation dose monitoring software (Radimetrics $^{\mathrm{TM}}$ Enterprise Platform, Bayer Healthcare, Berlin, Germany) was used to record the CTDIvol [mGy], DLP [mGy.cm] and the effective dose [mSv] from each CTA acquisition. The software calculates the effective dose using age- and sex-averages tissue weighting factors as described by the international commission on radiological protection (ICRP) in publication $103 .{ }^{22}$ 
All CTA images were analysed using multi-planar reconstruction with Syngo-Via ${ }^{\mathrm{TM}}$ software (Siemens Healtcare), figure 7.1. Objective image quality was evaluated by measuring intravascular enhancement in Hounsfield Units [HU] by delineating circular regions of interest (ROI) in eight predefined vascular segments: ascending aorta (AA), aortic arch, descending aorta (DA), abdominal aorta (AAo), right and left common iliac artery (RCIA and LCIA) and right and left common femoral arteries (RCFA and LCFA). Image noise was defined as the standard deviation (SD) of the vessel attenuation. Contrast-to-noise ratio (CNR) was calculated by using adjacent muscle tissue enhancement and SD: CNR is the intraluminal attenuation minus intramuscular attenuation divided by the SD of the intramuscular attenuation. Attenuation values of 200$250 \mathrm{HU}$ are considered diagnostically sufficient for the evaluation of the aorta ${ }^{23,24}$, e.g. general anatomy, calcifications, dissection, aneurysm and in selected cases the extension of disease into the aortic branches.

Quantitative image quality was independently analysed by two experienced readers who were trained for the analysis (MK, KD). Qualitative image analysis was determined by subjectively rating the contrast enhancement, image noise and the presence of artefacts at three anatomic levels (thoracic, abdominal and pelvic) using a 4-point Likert scale: $1=$ non-diagnostic image quality; 2=significantly reduced image quality, but still diagnostic for assessment; 3=good image quality and 4=excellent image quality. Qualitative image quality was independently rated by two experienced observers (MK, $\mathrm{MWH})$. 

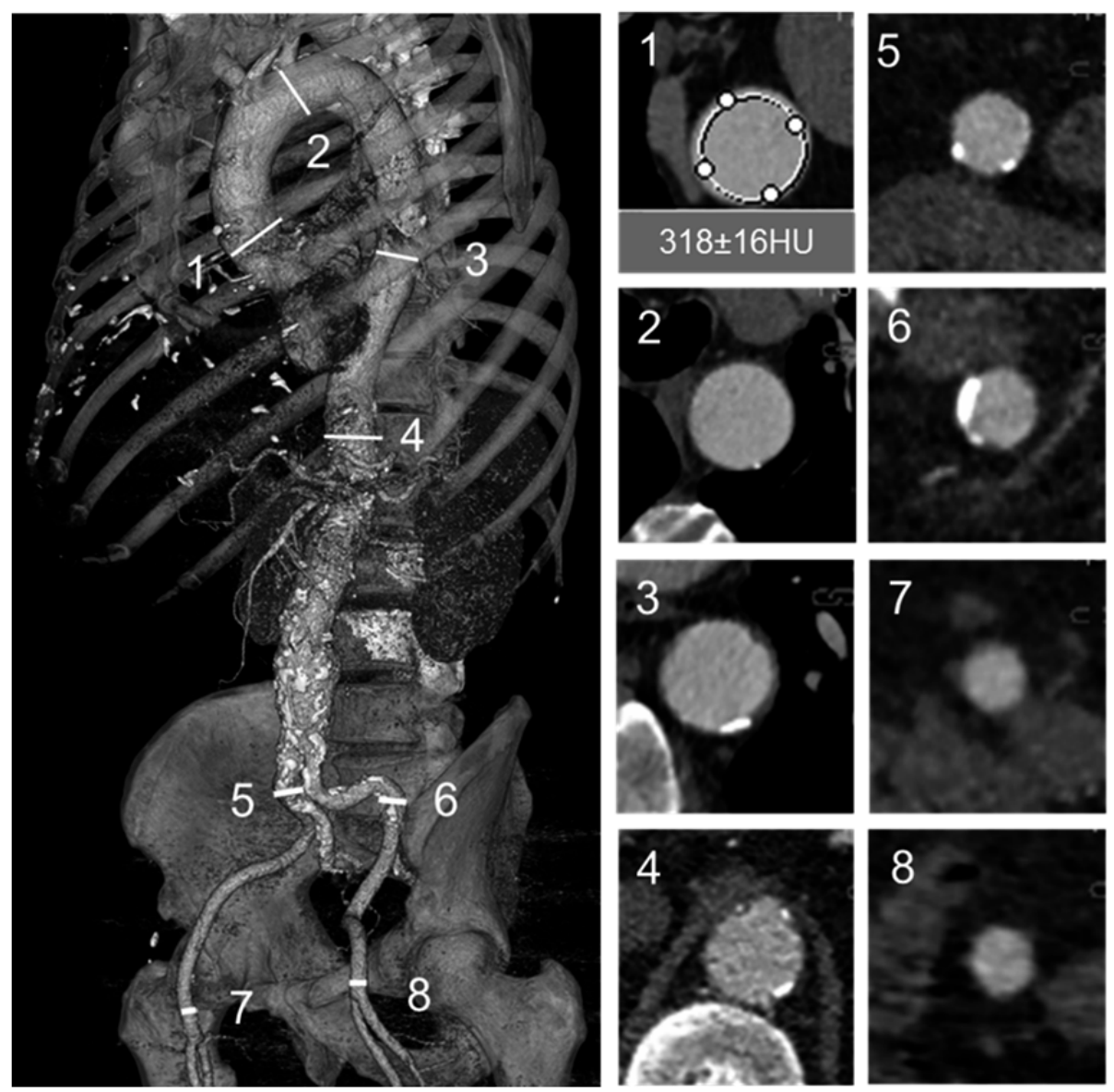

Figure 7.1 Images as reconstructed by Syngo-Via ${ }^{\mathrm{TM}}$ software

3D-reconstruction of the entire aorta (left) with given landmarks (right; 1-8). Landmarks were used for measurements of intravascular attenuation; (1) Ascending aorta; (2) Aortic arch; (3) Descending aorta; (4) Abdominal aorta; $(5,6)$ Right and left common iliac arteries as well as $(7,8)$ Right and left common femoral arteries

\section{Statistical analysis}

Continuous variables were expressed as mean $\pm S D$, categorical variables as absolute numbers [n] and percentages [\%]. Continuous variables were compared using one-way ANOVA test and Tukey test was performed for post hoc comparisons between groups and between different anatomic levels. The chi-square test was used to measure differences between categorical variables. Intra-observer variability for the quantitative image analysis was evaluated by calculating intraclass correlation coefficients (ICC), using a two-way mixed model. ICC can be interpreted as follows: 0-0.2 indicates poor 
agreement; 0.3-0.4 indicates fair agreement; 0.5-0.6 indicates moderate agreement; 0.7-0.8 indicates strong agreement and $>0.8$ indicates almost perfect agreement. Interrater agreement for the qualitative image analysis was evaluated by calculating Cohen's Kappa (K). Data analysis was performed using SPSS version 20.0 software (SPSS, Inc., Chicago, IL). All p-values are 2-sided, and a p-value lower than 0.05 was considered to be statistically significant.

\section{RESULTS}

\section{Patients, radiation dose and contrast volume}

No significant differences in baseline characteristics were found between the control group and the intervention group (group 1 + group 2; table 7.1). Mean CTDIvol [mGy], DLP [mGy.cm] and effective radiation dose [mSv] for each group are listed in table 7.4. Mean effective radiation dose for group 1 was reduced by $57 \%$ compared to the control group, with $p$-value $<0.001$. Mean effective radiation dose for group 2 was reduced by $23 \%$ compared to the control group, with $p$-value $<0.001$. Mean volume, flow rate and peak flow rate for the control group, group 1 and group 2 are listed in table 7.4.

\begin{tabular}{|l|l|l|l|l|}
\hline Radiation dose parameters & $\begin{array}{l}\text { Control } \\
(n=50)\end{array}$ & $\begin{array}{l}\text { Group 1 } \\
(n=50)\end{array}$ & $\begin{array}{l}\text { Group 2 } \\
(n=30)\end{array}$ & P-value \\
\hline Tube current CTA [mAs eff] & $\begin{array}{l}\text { Tube A/Tube B } \\
122 \pm 26 / 101 \pm 23\end{array}$ & $204 \pm 24$ & $205 \pm 18$ & \\
\hline CTDlvol CTA [mGy] & $24 \pm 5$ & $17 \pm 5$ & $19 \pm 3$ & $570 \pm 88$ \\
\hline DLP CTA [mGy.cm] & $650 \pm 113$ & $286 \pm 57$ & $6.7 \pm 1.4$ & $<.001^{*}$ \\
\hline Effective dose CTA [mSv] & $8.7 \pm 1.9$ & $3.7 \pm 0.7$ & & \\
\hline CM injection parameters & & $44 \pm 0$ & $53 \pm 0$ & \\
\hline Applied volume [ml] & $119 \pm 2$ & $3.2 \pm 0.0$ & $3.9 \pm 0.1$ & \\
\hline Applied flow rate [ml/s] & $4.8 \pm 0.1$ & $3.6 \pm 0.2$ & $4.2 \pm 0.0$ & \\
\hline Peak flow rate [ml/s] & $5.1 \pm 0.1$ & $62 \pm 12$ & $72 \pm 16$ & \\
\hline Peak pressure [psi] & $89 \pm 11$ & & & \\
\hline
\end{tabular}

Table 7.4 Radiation dose and injection parameters (mean $\pm S D$ ), recorded from each scan

*Significant difference was found between all groups after post hoc comparisons 


\section{Image quality}

Mean attenuation values (HU $\pm S D$ ) for the control group, group 1 and group 2 were diagnostic $(>200 \mathrm{HU})$ : as shown in figure 7.2. In the control group, non-diagnostic enhancement levels were found in two patients; in one of them the overall enhancement level was $<200 \mathrm{HU}$. In the other patient, a large infra-renal aneurysm caused nondiagnostic enhancement levels in the iliac and femoral arteries. No non-diagnostic enhancement levels were found in patients of group 1 and 2. Corresponding mean CNR values are shown in figure 7.2. Lowest CNR values were found at level of the AAo as well as at the level of the RCIA and LCIA due to the higher amount of image noise in the abdomen caused by surrounding tissues. Qualitative image quality is listed in table 7.5. In groups 1 and 2, all scans were graded 'diagnostic', 'good' or 'excellent' at each anatomic level. In two scans of the control group enhancement levels were $<200 \mathrm{HU}$, however, the indication for CTA in the scan with overall enhancement levels $<200 \mathrm{HU}$ was 'evaluation of aortic diameter' and this could be properly depicted although the low enhancement levels. In the other patient, the indication for CTA was 'aortic anatomy pre intervention' and the enhancement level was not diagnostic for assessment at the level of the peripheral arteries. Therefore, the scan was graded 'non-diagnostic' at this level (table 7.5).

Reproducibility of quantitative image quality measurements proved to be excellent: as the intraclass correlation coefficient was 0.986 and this indicates almost perfect agreement.

Inter-rater agreement of the qualitative image quality analysis was strong at each anatomic level: thoracic $=0.81$; abdominal $=0.79$ and pelvic $=0.78$, respectively.
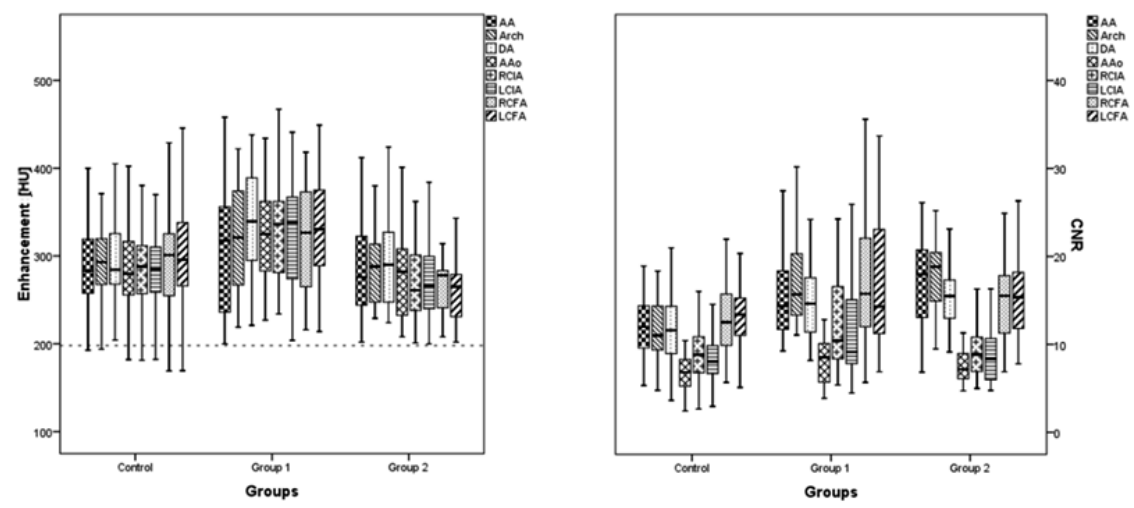

Figure 7.2 Box plots show the intravascular enhancement (left) as well as the CNR values (right) at different anatomic levels for each group 


\begin{tabular}{|l|l|l|l|l|}
\hline $\begin{array}{l}\text { Qualitative image quality } \\
\text { (Likert score) }\end{array}$ & $\begin{array}{l}\text { Control } \\
\text { (n=50) }\end{array}$ & $\begin{array}{l}\text { Group 1 } \\
(n=50)\end{array}$ & $\begin{array}{l}\text { Group 2 } \\
(n=30)\end{array}$ & $P$-value \\
\hline Thoracic aorta & - & & - & \\
1 & $1[2 \%]$ & - & - & 0.77 \\
2 & $4[8 \%]$ & $3[6 \%]$ & - & \\
3 & $45[90 \%]$ & $47[94 \%]$ & $2[7 \%]$ & \\
4 & - & & $28[93 \%]$ & \\
\hline Abdominal aorta & - & - & - & 0.48 \\
1 & $1[2 \%]$ & - & - & \\
2 & $12[24 \%]$ & $7[14 \%]$ & $5[17 \%]$ & \\
3 & $37[74 \%]$ & $43[86 \%]$ & $25[83 \%]$ & \\
4 & & & & 0.45 \\
\hline Pelvic aorta & $1[2 \%]$ & - & - & \\
1 & $1[2 \%]$ & $1[2 \%]$ & $1[3 \%]$ & \\
2 & $8[16 \%]$ & $11[22 \%]$ & $4[14 \%]$ & \\
3 & $40[80 \%]$ & $38[76 \%]$ & $25[83 \%]$ & \\
4 & & & & \\
\hline
\end{tabular}

Table 7.5 Qualitative image qualities at different anatomic levels for the control group, group 1 and group 2 1=non-diagnostic; $2=$ diagnostic; $3=$ good and $4=$ =xcellent

\section{DISCUSSION}

The use of BMI adapted aortic contrast-enhanced protocols (thoraco-abdominalpelvic) resulted in a radiation dose reduction of approximately $57 \%$ for patients with a $\mathrm{BMI}<28 \mathrm{~kg} / \mathrm{m}^{2}$ and approximately $23 \%$ for patients with a BMI $\geq 28 \mathrm{~kg} / \mathrm{m}^{2}$ and $<35 \mathrm{~kg} / \mathrm{m}^{2}$ as well as for a contrast volume reduction of $63 \%$ and $55 \%$, respectively. These reductions were achieved by using lower tube voltages in combination with iterative reconstruction compared to the $120 \mathrm{kVp}$ protocol in combination with FBP which is used in our institution (figure 7.3). These results reveal that an injection time of 13.3 s (groups 1 and 2) already turned out to be robust in providing diagnostic enhancement at each aortic level for an acquisition time of $8-12 \mathrm{~s}$.

Furthermore, the results also show that diagnostic scans were obtained using BMI adapted protocols; all scans being graded as 'diagnostic', 'good' or 'excellent'. 


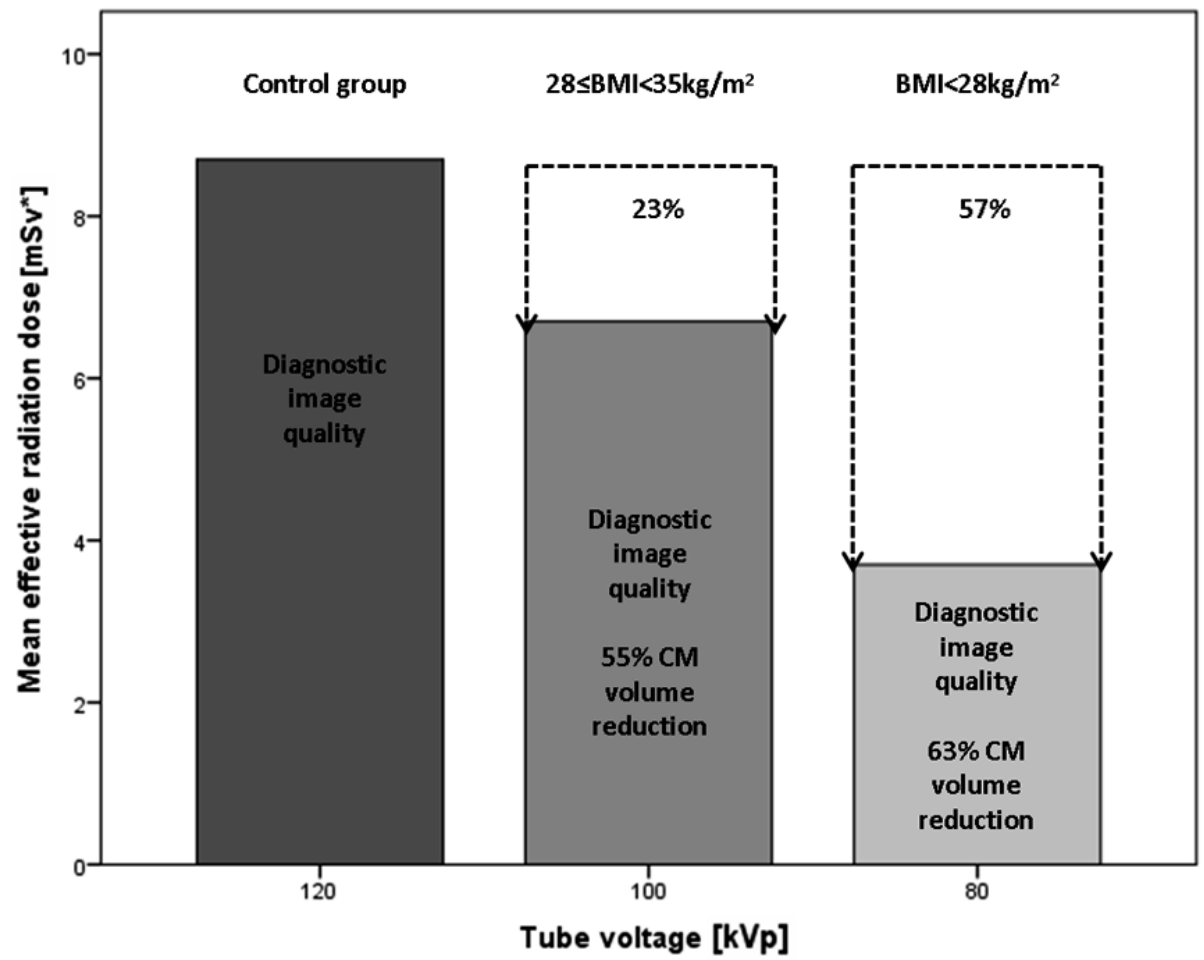

Figure 7.3 Bar graphs and arrows show the achievable reduction of radiation dose exposure and $\mathrm{CM}$ volume for a thoraco-abdominal-pelvic CTA for patients with a BMI<35kg/m²

* Radiation dose [mSv] was calculated by Radimetrics ${ }^{\mathrm{TM}}$ Enterprise Platform (Bayer Healthcare, Berlin, Germany)

Objective image quality was slightly better for group 1 and group 2 compared to the control group. Previous research already found that the application of iterative reconstruction resulted in better quantitative image quality compared to FBP. ${ }^{25,26}$ This means that reduced tube voltage potentially improves CNR because contrast enhancement increases at lower kVp settings and image noise decreases with the use of iterative reconstruction. ${ }^{27}$ However, in the present study, the injection protocol was adapted to the lower $\mathrm{kVp}$ settings and differences in quantitative image quality were therefore limited. Moreover, the scan protocol used for the control group was dual energy, which makes the comparison between iterative reconstruction and FBP unreliable. This comparison, however, was not the primary goal and more important is the fact that diagnostic scans were provided while radiation dose exposure and contrast volume could be reduced in comparison to the standardly used CTA protocol.

With respect to the image quality for different clinical indications and the impact on radiation dose exposure, there are two important influencing factors. First, CTA only will not provide enough image quality for each indication; a non-enhanced CT followed 
by CTA is - for example - particularly recommended for suspected bleeding or dissection $^{1,28}$ and delayed-phase CT in addition to CTA is recommended for suspected bleeding or after EVAR procedure in order to detect endoleakage. ${ }^{1,7}$ These additional scans will provide a significant increase in radiation exposure for these patients but are certainly desirable for diagnosis and follow-up. Second, there are also technical parameters influencing the diagnostic image quality for a specific indication. Image noise and intravascular enhancement are important parameters indicating image quality. High image noise levels and low intravascular enhancement might therefore lead to nondiagnostic scans. For CTA of the aorta there are several different indications. For example: in case of suspected stenosis (renal/mesenteric arteries) optimal image quality is required for the adequate assessment of these smaller vessels, meaning a combination of high intravascular enhancement and low image noise should be pursued. For evaluation of the aortic diameter only, higher image noise levels are acceptable. In this study, none of the CTA's using reduced radiation dose and contrast volume were rated as non-diagnostic, indicating that the current radiation dose and contrast volume reduction is a reliable option for a broad range of indications and even more reduction might be possible for measuring the aortic diameter only.

The current study shows that cumulative radiation dose exposure over the first year including 4 recommended time points ${ }^{2,7}$ - will be approximately $35 \mathrm{mSv}$ (control group; $4 * 8.7 \mathrm{mSv}$ ). As CTA protocols would be adapted to patient body size, the expected cumulative value is $15.8 \mathrm{mSv}$ for patients with a $\mathrm{BMI}<28 \mathrm{~kg} / \mathrm{m}^{2}$ and $27 \mathrm{mSv}$ for patients with a $\mathrm{BMl}>28 \mathrm{~kg} / \mathrm{m}^{2}$. In addition, contrast volume would also be reduced from $480 \mathrm{ml}$ for the control group to $176 \mathrm{ml}$ and $212 \mathrm{ml}$ for group 1 and 2, respectively in the first year.

The current study provides an overview of reducing radiation dose and contrast volume for the individual patient, giving insight into decreasing potential drawbacks for CTA imaging. The range of patients who will benefit from reduced radiation dose and contrast volume is only expected to increase in the future due to ongoing advancements in detector technology of newer scanners - making the use of lower kVp settings, including $70 \mathrm{kVp}$, possible in patients of different sizes. ${ }^{29,30}$

\section{Limitations}

This study has several limitations: it is a single center study performed on limited number of patients, especially for group 2. A larger study population would improve the impact of the results. Furthermore, the control group was retrospectively included and it would have been of additive value for the quality of the methods if the control group was also prospectively included. In addition, adaptation of additional non-enhanced scan acquisitions and delayed-phase scan acquisitions would be desirable as well, as 
they significantly increase the overall radiation dose. However, this was not the goal of present study.

\section{CONCLUSION}

Individualised CTA protocols based on the BMI of the patient are favourable for CTA of the whole aorta in routine clinical practice. Iterative reconstruction algorithms resulted in $23-57 \%$ less radiation in combination with $55-63 \%$ less contrast volume when compared to standard CT protocols. 


\section{REFERENCES}

1. Erbel R, Aboyans V, Boileau C, et al. 2014 ESC Guidelines on the diagnosis and treatment of aortic diseases: Document covering acute and chronic aortic diseases of the thoracic and abdominal aorta of the adult. The Task Force for the Diagnosis and Treatment of Aortic Diseases of the European Society of Cardiology (ESC). European heart journal 2014;35:2873-926.

2. Uthoff H, Pena C, Katzen BT, et al. Current clinical practice in postoperative endovascular aneurysm repair imaging surveillance. Journal of vascular and interventional radiology : JVIR 2012;23:1152-9 e6.

3. Hagan PG, Nienaber CA, Isselbacher EM, et al. The International Registry of Acute Aortic Dissection (IRAD): new insights into an old disease. Jama 2000;283:897-903.

4. Agarwal PP, Chughtai A, Matzinger FR, Kazerooni EA. Multidetector CT of thoracic aortic aneurysms. Radiographics : a review publication of the Radiological Society of North America, Inc 2009;29:537-52.

5. Parker MS, Matheson TL, Rao AV, et al. Making the transition: the role of helical $\mathrm{CT}$ in the evaluation of potentially acute thoracic aortic injuries. AJR American journal of roentgenology 2001;176:1267-72.

6. Mirvis SE, Shanmuganathan K, Buell J, Rodriguez A. Use of spiral computed tomography for the assessment of blunt trauma patients with potential aortic injury. The Journal of trauma 1998;45:922-30.

7. Ueda T, Fleischmann D, Rubin GD, Dake MD, Sze DY. Imaging of the thoracic aorta before and after stent-graft repair of aneurysms and dissections. Seminars in thoracic and cardiovascular surgery 2008;20:348-57.

8. Lameire NH. Contrast-induced nephropathy--prevention and risk reduction. Nephrology, dialysis, transplantation : official publication of the European Dialysis and Transplant Association European Renal Association 2006;21:i11-23.

9. Chaikof EL, Brewster DC, Dalman RL, et al. SVS practice guidelines for the care of patients with an abdominal aortic aneurysm: executive summary. Journal of vascular surgery 2009;50:880-96.

10. Walker TG, Kalva SP, Yeddula K, et al. Clinical practice guidelines for endovascular abdominal aortic aneurysm repair: written by the Standards of Practice Committee for the Society of Interventional Radiology and endorsed by the Cardiovascular and Interventional Radiological Society of Europe and the Canadian Interventional Radiology Association. Journal of vascular and interventional radiology : JVIR 2010;21:1632-55.

11. Moll FL, Powell JT, Fraedrich G, et al. Management of abdominal aortic aneurysms clinical practice guidelines of the European society for vascular surgery. European journal of vascular and endovascular surgery 2011;41 Suppl 1:S1-S58.

12. Mehran R, Nikolsky E. Contrast-induced nephropathy: definition, epidemiology, and patients at risk. Kidney international Supplement 2006:S11-5.

13. Bae KT. Intravenous contrast medium administration and scan timing at CT: considerations and approaches. Radiology 2010;256:32-61.

14. Schoellnast H, Deutschmann HA, Berghold A, Fritz GA, Schaffler GJ, Tillich M. MDCT angiography of the pulmonary arteries: influence of body weight, body mass index, and scan length on arterial enhancement at different iodine flow rates. AJR American journal of roentgenology 2006;187:1074-8.

15. Pontana F, Pagniez J, Duhamel A, et al. Reduced-dose low-voltage chest CT angiography with Sinogram-affirmed iterative reconstruction versus standard-dose filtered back projection. Radiology 2013;267:609-18. 
16. Wang $\mathrm{R}$, Schoepf UJ, Wu R, et al. Image quality and radiation dose of low dose coronary CT angiography in obese patients: sinogram affirmed iterative reconstruction versus filtered back projection. European journal of radiology 2012;81:3141-5.

17. Korn $A$, Bender $B$, Fenchel $M$, et al. Sinogram affirmed iterative reconstruction in head CT: improvement of objective and subjective image quality with concomitant radiation dose reduction. European journal of radiology 2013;82:1431-5.

18. Lehti L, Nyman U, Soderberg M, Bjorses K, Gottsater A, Wasselius J. 80-kVp CT angiography for endovascular aneurysm repair follow-up with halved contrast medium dose and preserved diagnostic . Acta radiologica 2015.

19. Chen CM, Chu SY, Hsu MY, Liao YL, Tsai HY. Low-tube-voltage ( 80 kVp) CT aortography using 320row volume $\mathrm{CT}$ with adaptive iterative reconstruction: lower contrast medium and radiation dose. European radiology 2014;24:460-8.

20. Feuchtner GM, Jodocy D, Klauser A, et al. Radiation dose reduction by using 100-kV tube voltage in cardiac 64-slice computed tomography: a comparative study. European journal of radiology 2010;75:e51-6.

21. Kok M, Turek J, Mihl C, et al. Low contrast media volume in pre-TAVI CT examinations. European radiology 2015.

22. The 2007 Recommendations of the International Commission on Radiological Protection. ICRP publication 103. Annals of the ICRP 2007;37:1-332.

23. Bae KT. Optimization of contrast enhancement in thoracic MDCT. Radiologic clinics of North America 2010;48:9-29.

24. Weininger M, Barraza JM, Kemper CA, Kalafut JF, Costello P, Schoepf UJ. Cardiothoracic CT angiography: current contrast medium delivery strategies. AJR American journal of roentgenology 2011;196:W260-72.

25. Hosch W, Stiller W, Mueller D, et al. Reduction of radiation exposure and improvement of image quality with BMl-adapted prospective cardiac computed tomography and iterative reconstruction. European journal of radiology 2012;81:3568-76.

26. Kordolaimi SD, Argentos S, Stathis G, et al. Radiation dose and image noise evaluation in coronary computed tomography angiography (CCTA) using an iterative reconstruction algorithm. Hellenic journal of cardiology : HJC = Hellenike kardiologike epitheorese 2014;55:184-90.

27. Szucs-Farkas Z, Verdun FR, von Allmen G, Mini RL, Vock P. Effect of X-ray tube parameters, iodine concentration, and patient size on image quality in pulmonary computed tomography angiography: a chest-phantom-study. Investigative radiology 2008;43:374-81.

28. Alexander SA, Rubin GD. Imaging the thoracic aorta: anatomy, technical considerations, and trauma. Seminars in roentgenology 2009;44:8-15.

29. Meinel FG, Canstein C, Schoepf UJ, et al. Image quality and radiation dose of low tube voltage 3(rd) generation dual-source coronary CT angiography in obese patients: a phantom study. European radiology 2014;24:1643-50.

30. Meyer M, Haubenreisser H, Schoepf UJ, et al. Closing in on the K Edge: Coronary CT Angiography at 100, 80, and 70 kV-Initial Comparison of a Second- versus a Third-Generation Dual-Source CT System. Radiology 2014:140244. 


CHAPTER 8

General Discussion 
This thesis showed that CM injection protocols and scanning parameters can be optimised by making use of individualised medicine in routine CTA examinations; CM volume and radiation dose being used more efficiently while maintaining diagnostic image quality.

In order to optimise CTA protocols for the individual patient, broad knowledge about injection and scanning parameters is required. Therefore, this thesis starts with exploring the basics of $\mathrm{CM}$ characteristics and the influence of different $\mathrm{CM}$ injection parameters and scanning parameters on image quality in phantom studies. After that, the clinical application was investigated for different clinical CTA indications.

Based on Chapter 2, we can conclude that the amount iodine per milliliter within CM is directly correlated to the viscosity of $\mathrm{CM}$, although this relationship was not linear. The highest concentration $\mathrm{CM}(400 \mathrm{mgl} / \mathrm{ml})$ was associated with the highest viscosity. Increasing temperature of $\mathrm{CM}$ (to body temperature $\left[37^{\circ} \mathrm{C}\right]$ ) substantially decreased the viscosity of $\mathrm{CM}$, however, the viscosity of the highest $400 \mathrm{mgl} / \mathrm{ml} \mathrm{CM}$ at body temperature was still significantly higher compared to the viscosity of the lower concentrations $(240 \mathrm{mgl} / \mathrm{ml}$ and $300 \mathrm{mgl} / \mathrm{ml})$ at room temperature $\left(20^{\circ} \mathrm{C}\right)$. Consequently, lowest injection pressures were found for $\mathrm{CM}$ of $240 \mathrm{mgl} / \mathrm{ml}$ and $300 \mathrm{mgl} / \mathrm{ml}$ at $37^{\circ} \mathrm{C}$. These findings implicate and stress the positive effect of preheating $\mathrm{CM}$ in order to reduce viscosity and therefore, to reduce injection pressure. Furthermore, due to the decreased injection pressure higher flow rates might be facilitated without increasing the risk of complications whilst using lower concentrations of CM. In that respect, in an ongoing research project we investigate patient comfort during injection of higher flow rates in a large patient population.

In Chapter 3, the influence of different $\mathrm{CM}$ concentrations on radiation dose reduction was investigated. From literature, it is already known that automated kVp-selection is strongly effective in terms of radiation dose reduction. ${ }^{1-4}$ Our investigation showed that radiation dose reduction was independent of the $\mathrm{CM}$ concentration - as long as the IDR and TIL were kept identical.

Switching to lower tube voltage settings using automated $\mathrm{kVp}$-selection is only feasible over the whole scan length. Tube current modulation, however, gives the opportunity to reduce tube-current-time product per slice. ${ }^{5-7}$ Both dose modulation techniques highly depend on the body size of the patient and the anatomical area(s) within the scan range. As this was a phantom study, no patient related factors such as BMI, weight or thoracic/abdominal diameter could be included. Even though dose reduction is independent of the CM concentration used, the performance of both dose modulation techniques should be investigated in a broad range of patients - and, preferably on a scanner with possibilities of a broader range of tube voltage settings.

A logical next step was to investigate how to optimise attenuation values and injection parameters when using different tube voltage settings in a patient experiment.

Chapter 4 first includes a phantom study, which was performed in order to explain how to adapt IDR and TIL while using lower tube voltages. Then, a part of this investi- 
gation was performed in 60 patients referred for CCTA. We could conclude that TIL and therefore $\mathrm{CM}$ volume could be reduced up to $56 \%$ at $70 \mathrm{kVp}$ - whilst maintaining diagnostically sufficient attenuation values within the target vessels. Initial results in patients confirmed this finding at $100 \mathrm{kVp}$ using $12 \%$ reduction of $\mathrm{CM}$ volume in CCTA compared to the $\mathrm{CM}$ volume used at $120 \mathrm{kVp}$. These results may promote understanding of how to apply lower tube voltages on an individual basis, how to directly link contrast parameters such as IDR and TIL to tube voltage, and how to subsequently optimise contrast and dose settings.

Empirically dose reduction of $\mathrm{CM}$ has been reported by other groups as well ${ }^{8-10}$ - they used $100 \mathrm{kVp}$ with $10-20 \% \mathrm{CM}$ reduction in patients with a $\mathrm{BMl}<25 \mathrm{~kg} / \mathrm{m}^{2}$, or they used $80 \mathrm{kVp}$ with $30 \% \mathrm{CM}$ reduction in patients with a mean weight of $58-60 \mathrm{~kg}$. However, no systematic approach to reduce CM volume at different kVp settings was used in these studies.

Lell et $a l^{11}$ performed a systematic approach for the thoraco-abdominal aorta. They concluded that adjusting IDR to a specific $\mathrm{kVp}$ setting indeed provided comparable arterial enhancement levels. Therefore, our systematic approach might serve as a profound basis for the imaging of other vascular territories.

The idea of applying $\mathrm{CM}$ injection parameters according to patients' body size and the specific clinical indication is presented in Chapter 5. In this study, patients suspected of pulmonary embolism (PE) and therefore referred for CTPA received CM injections individually adapted according to their body weight and scan duration. For this emergency indication, the scan protocol should be expected to deliver robust and reliable results twenty four hours a day, seven days a week. This study shows a greater consistency of vascular enhancement - indicating a more reliable protocol - using individualised injections compared to injections with fixed parameters. Even under emergency conditions it was feasible to adapt the most important injection parameters (e.g. flow rate, IDR) to the individual patient.

Some studies on body weight adapted CM protocols for CTPA in selective, low weight patient groups have been published: Holmquist et al ${ }^{12}$ used an $80 \mathrm{kV}$ protocol with TIL of around $13 \mathrm{~g}$ in a low weight patient group and Kristiansson et $a l^{13}$ reduced the TIL in a similar patient group even further to $9.6 \mathrm{~g}$. However, $8-12 \%$ of the examinations were regarded as suboptimal. A CTPA with arterial attenuation below $180 \mathrm{HU}$ may be considered to be of non-diagnostic quality to reliably detect subsegmental emboli as mean $\mathrm{HU}$ values for acute and chronic embolism are around $33 \mathrm{HU}$ and $87 \mathrm{HU}$, respectively. ${ }^{14}$ In our study, all patients met this crucial cut-off value of $180 \mathrm{HU}$.

Using the current approach; patient related factors (e.g. body weight) and the clinical indication (e.g. specific scan acquisition and duration) have been already taken into account. However, since tube voltage is an important influencing factor regarding contrast enhancement as well, future research should focus more on a complete individual adaptation of $\mathrm{CM}$ injections using a similar approach with the addition of the 
factor tube voltage - for example by using the automated-kVp selection tool in combination with the reduction percentages for injection parameters as elaborated in Chapter 4.

The next step was to combine individualised injection protocols with individualised scan protocols in a broader range of CTA examinations; the use of iodinated CM and ionising radiation dose being an intrinsic matter of concern in general CTA. ${ }^{15}$

Chapter 6 mainly focused on the most efficient use of CM as TAVI candidates are frequently suffering from impaired renal function and are considered to be at increased risk of CIN. ${ }^{16,17}$ Especially use of lower tube voltages enables substantial reduction of $\mathrm{CM}$ volume ${ }^{9,18,19}$, as the same amount of iodine will lead to a higher enhancement at lower tube voltage. ${ }^{20}$ However, image noise increases at lower kVp settings, mainly due to higher absorption of low-energy photons by the patient. ${ }^{21}$ Nowadays, new reconstruction technologies such as IR improve image quality in comparison to routinely used FBP, as IR reduces image noise. ${ }^{22-25}$ Therefore, IR was used in order to maintain diagnostic image quality whilst using reduced radiation dose. We could conclude that despite a CM volume reduction up to $67 \%$ - compared to the generally used volumes for pre-TAVI CT examinations ${ }^{26}$ - diagnostic image quality could be provided by performing $80 \mathrm{kVp}$ and $70 \mathrm{kVp}$ scans while using IR. In addition, the overall renal function was not impaired after 1-2 months post CTA. However, the prevalence of CIN could not be evaluated as data from 48-72 hours after CTA was inconsistent in the majority of patients. One method could be to set up a large cohort study referred for pre-TAVI CT examination and to structural test renal function right before CTA and after 24-72 hours from CTA in order to quantify the incidence of CIN in this patient population.

The potential drawbacks of CTA will be even more pronounced when frequent imaging over time is recommended due to the related high cumulative radiation dose and repetitive administration of iodinated $\mathrm{CM}$ - especially in patients for follow-up of EVAR. ${ }^{27,28}$ Based on Chapter 7, we could conclude that $23-57 \%$ radiation dose in combination with $55-63 \%$ CM volume might be saved compared to standard CTA aorta protocols. These reductions were achieved by using lower tube voltages $[\mathrm{kVp}]$ in combination with IR. A few studies investigated the influence of using IR on CTA of the aorta: For example, Lehti et $\left.a\right|^{29}$ reduced radiation dose with $12 \%$ and iodine load with $48 \%$ using $80 \mathrm{kVp}$ compared to $120 \mathrm{kVp}$. Chen et a ${ }^{30}$ reduced radiation dose with $48 \%$ and iodine load with $60 \%$ in aortic CTA using $80 \mathrm{kVp}$ compared to $120 \mathrm{kVp}$, while using IR. In both studies, however, scan protocols were not adapted according to patients' body size (mean BMI in both studies was approximately $27 \mathrm{~kg} / \mathrm{m}^{2}$ ).

As non-enhanced CT scans followed by CTA are particularly recommended for suspected bleeding or dissection ${ }^{15,31}$ and delayed-phase CT scans in addition to CTA are recommended for suspected bleeding or after EVAR procedure in order to detect endoleakage ${ }^{15,27}$, adaptation of these additional acquisitions in the future would be desirable as well, as they significantly increase the overall radiation dose. 


\section{Future perspectives}

Currently, the demanding need for imaging is still growing. Therefore, the range of patients who will benefit from individually adapted use of radiation dose and CM volume is only expected to increase in the future. In addition, due to the advancements in detector technology of newest scanners - and especially in adaptation of tube-currenttime product - the use of lower tube voltage settings, including $70 \mathrm{kVp}$, might be possible in patients from all different sizes, as dose settings (e.g. CTDlvolume, [mGy]) may remain equal at each $\mathrm{kVp}$ setting. ${ }^{32-34}$

Furthermore, the content of this thesis mainly focused on the individual optimisation of different $\mathrm{CM}$ injection and scan protocols in order to maintain diagnostic image quality for the assessment of CTA images. The basis of achieving diagnostic image quality while using individualised protocols - and in particular diagnostic arterial enhancement - was already investigated and confirmed by the different manuscripts within this thesis. ${ }^{35}$ However, when combining individualised injection and scan parameters, knowledge should be acquired regarding cut-off values for clinically used image quality parameters such as SNR and CNR. In order to understand these ratios and make it possible to actually provide specific cut-off values, the amount of image noise achieved by particular dose related parameters should be investigated in the future. Most important is to understand the underlying principles of the relation between image noise and diagnostic image quality for the specific indication and vascular structure, as well as the relation between dose related parameters used by the scanner (e.g. tube voltage, tube-current-time product) and image noise. Figure $\mathbf{8 . 1}$ shows an example of a stepwise approach regarding the requirement of image quality for different CTA indications. The question is, how much image noise we may accept for the assessment of each vascular structure in combination with the clinical indication, and, which tube voltage and tube-current-time product settings do we need to use in order to achieve these image noise values. In addition, what is the exact influence of different reconstruction methods such as FBP and IR. With respect to these parameters, we want to investigate this at different types of scanners as well as in patients from different sizes. 


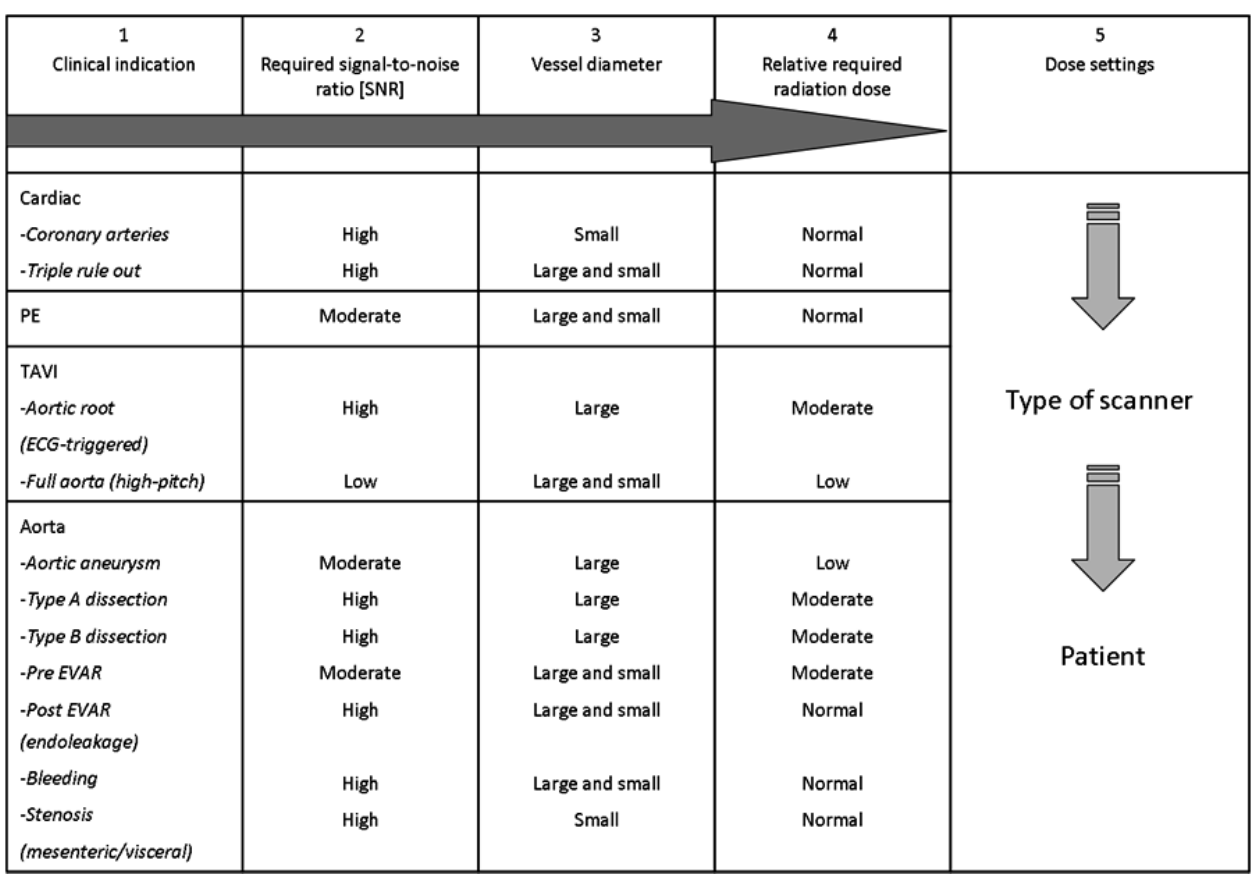

Figure 8.1 Example of a stepwise approach

\section{CONCLUSION}

In conclusion, individualised scan and injection protocols allow for a more efficient use of radiation dose and $\mathrm{CM}$ volume whilst diagnostic image quality could be maintained. Newest CT technologies allow even faster scanning as well as use of low tube voltages (e.g. 80 and $70 \mathrm{kVp}$ ) in a broader range of patients. Further research should focus on how to efficiently apply radiation dose and CM volume in routine CTA in the future using these newest $\mathrm{CT}$ technologies. 


\section{REFERENCES}

1. Heyer CM, Mohr PS, Lemburg SP, Peters SA, Nicolas V. Image quality and radiation exposure at pulmonary CT angiography with $100-$ or $120-\mathrm{kVp}$ protocol: prospective randomized study. Radiology 2007;245:577-83.

2. Bischoff B, Hein F, Meyer T, et al. Impact of a reduced tube voltage on $\mathrm{CT}$ angiography and radiation dose: results of the PROTECTION I study. JACC Cardiovascular imaging 2009;2:940-6.

3. Siegel MJ, Schmidt B, Bradley D, Suess C, Hildebolt C. Radiation dose and image quality in pediatric CT: effect of technical factors and phantom size and shape. Radiology 2004;233:515-22.

4. $\mathrm{Yu}$ L, Fletcher JG, Grant KL, et al. Automatic selection of tube potential for radiation dose reduction in vascular and contrast-enhanced abdominopelvic CT. AJR American journal of roentgenology 2013;201:W297-306.

5. Angel E, Yaghmai N, Jude CM, et al. Dose to radiosensitive organs during routine chest CT: effects of tube current modulation. AJR American journal of roentgenology 2009;193:1340-5.

6. Graser A, Wintersperger BJ, Suess C, Reiser MF, Becker CR. Dose reduction and image quality in MDCT colonography using tube current modulation. AJR American journal of roentgenology 2006;187:695-701.

7. Winklehner A, Goetti R, Baumueller S, et al. Automated attenuation-based tube potential selection for thoracoabdominal computed tomography angiography: improved dose effectiveness. Investigative radiology 2011;46:767-73.

8. Zhang C, Zhang Z, Yan Z, Xu L, Yu W, Wang R. 320-row CT coronary angiography: effect of 100-kV tube voltages on image quality, contrast volume, and radiation dose. The international journal of cardiovascular imaging 2011;27:1059-68.

9. Cao JX, Wang YM, Lu JG, Zhang Y, Wang P, Yang C. Radiation and contrast agent doses reductions by using $80-\mathrm{kV}$ tube voltage in coronary computed tomographic angiography: a comparative study. European journal of radiology 2014;83:309-14.

10. Kidoh M, Nakaura T, Nakamura $\mathrm{S}$, et al. Contrast material and radiation dose reduction strategy for triple-rule-out cardiac CT angiography: feasibility study of non-ECG-gated low kVp scan of the whole chest following coronary CT angiography. Acta radiologica 2013.

11. Lell MM, Jost G, Korporaal JG, et al. Optimizing contrast media injection protocols in state-of-the art computed tomographic angiography. Investigative radiology 2015;50:161-7.

12. Holmquist F, Hansson K, Pasquariello F, Bjork J, Nyman U. Minimizing contrast medium doses to diagnose pulmonary embolism with $80-\mathrm{kVp}$ multidetector computed tomography in azotemic patients. Acta radiologica 2009;50:181-93.

13. Kristiansson $\mathrm{M}$, Holmquist $\mathrm{F}$, Nyman $\mathrm{U}$. Ultralow contrast medium doses at $\mathrm{CT}$ to diagnose pulmonary embolism in patients with moderate to severe renal impairment: a feasibility study. European Radiology 2010;20:1321-30.

14. Wittram C, Maher MM, Halpern EF, Shepard J-AO. Attenuation of acute and chronic pulmonary emboli. Radiology 2005;235:1050-4.

15. Erbel R, Aboyans V, Boileau C, et al. 2014 ESC Guidelines on the diagnosis and treatment of aortic diseases: Document covering acute and chronic aortic diseases of the thoracic and abdominal aorta of the adult. The Task Force for the Diagnosis and Treatment of Aortic Diseases of the European Society of Cardiology (ESC). European heart journal 2014;35:2873-926.

16. Yamamoto M, Hayashida K, Mouillet G, et al. Renal function-based contrast dosing predicts acute kidney injury following transcatheter aortic valve implantation. JACC Cardiovascular interventions 2013;6:479-86.

17. Becker CR, Davidson C, Lameire N, et al. High-risk situations and procedures. The American journal of cardiology 2006;98:37K-41K.

18. Vlahos I, Chung R, Nair A, Morgan R. Dual-energy CT: vascular applications. AJR American journal of roentgenology 2012;199:S87-97. 
19. Strocchi S, Vite C, Callegari L, Conte L. Optimisation of multislice computed tomography protocols in angio-CT examinations. La Radiologia medica 2006;111:238-44.

20. Weininger M, Barraza JM, Kemper CA, Kalafut JF, Costello P, Schoepf UJ. Cardiothoracic CT angiography: current contrast medium delivery strategies. AJR American journal of roentgenology 2011;196:W260-72.

21. McCollough $\mathrm{CH}$, Primak AN, Braun N, Kofler J, Yu L, Christner J. Strategies for reducing radiation dose in CT. Radiologic clinics of North America 2009;47:27-40.

22. Pontana F, Pagniez J, Duhamel A, et al. Reduced-dose low-voltage chest CT angiography with Sinogram-affirmed iterative reconstruction versus standard-dose filtered back projection. Radiology 2013;267:609-18.

23. Wang R, Schoepf UJ, Wu R, et al. Image quality and radiation dose of low dose coronary CT angiography in obese patients: sinogram affirmed iterative reconstruction versus filtered back projection. European journal of radiology 2012;81:3141-5.

24. Korn $A$, Bender $B$, Fenchel $M$, et al. Sinogram affirmed iterative reconstruction in head CT: improvement of objective and subjective image quality with concomitant radiation dose reduction. European journal of radiology 2013;82:1431-5.

25. Baker ME, Dong F, Primak A, et al. Contrast-to-noise ratio and low-contrast object resolution on full- and low-dose MDCT: SAFIRE versus filtered back projection in a low-contrast object phantom and in the liver. AJR American journal of roentgenology 2012;199:8-18.

26. Nguyen G, Leipsic J. Cardiac computed tomography and computed tomography angiography in the evaluation of patients prior to transcatheter aortic valve implantation. Current opinion in cardiology 2013;28:497-504.

27. Ueda T, Fleischmann D, Rubin GD, Dake MD, Sze DY. Imaging of the thoracic aorta before and after stent-graft repair of aneurysms and dissections. Seminars in thoracic and cardiovascular surgery 2008;20:348-57.

28. Uthoff H, Pena C, Katzen BT, et al. Current clinical practice in postoperative endovascular aneurysm repair imaging surveillance. Journal of vascular and interventional radiology : JVIR 2012;23:1152-9.

29. Lehti L, Nyman U, Soderberg M, Bjorses K, Gottsater A, Wasselius J. 80-kVp CT angiography for endovascular aneurysm repair follow-up with halved contrast medium dose and preserved diagnostic quality. Acta radiologica 2015.

30. Chen CM, Chu SY, Hsu MY, Liao YL, Tsai HY. Low-tube-voltage (80 kVp) CT aortography using 320row volume $\mathrm{CT}$ with adaptive iterative reconstruction: lower contrast medium and radiation dose. European radiology 2014;24:460-8.

31. Alexander SA, Rubin GD. Imaging the thoracic aorta: anatomy, technical considerations, and trauma. Seminars in roentgenology 2009;44:8-15.

32. Meinel FG, Canstein C, Schoepf UJ, et al. Image quality and radiation dose of low tube voltage $3($ rd) generation dual-source coronary CT angiography in obese patients: a phantom study. European radiology 2014;24:1643-50.

33. Meyer $\mathrm{M}$, Haubenreisser $\mathrm{H}$, Schoepf $\mathrm{UJ}$, et al. Closing in on the $\mathrm{K}$ edge: coronary $\mathrm{CT}$ angiography at 100,80 , and $70 \mathrm{kV}$-initial comparison of a second- versus a third-generation dual-source CT system. Radiology 2014;273:373-82.

34. Hell MM, Bittner D, Schuhbaeck A, et al. Prospectively ECG-triggered high-pitch coronary angiography with third-generation dual-source $\mathrm{CT}$ at $70 \mathrm{kVp}$ tube voltage: feasibility, image quality, radiation dose, and effect of iterative reconstruction. Journal of cardiovascular computed tomography 2014;8:418-25.

35. Kok M, Turek J, Mihl C, et al. Low contrast media volume in pre-TAVI CT examinations. European radiology 2015. 




\section{CHAPTER 9}

Summary

Valorisation

Dankwoord

Curriculum vitae

List of publications 

9.1

Summary 
This thesis addressed several topics on individual optimisation of contrast media (CM) volume and radiation dose for different CT angiography (CTA) examinations. The overall focus of this research was to maintain diagnostic image quality in CTA while using iodinated $\mathrm{CM}$ and radiation dose in a more efficient way for the individual patient.

In Chapter 2 the relationship between CM concentration and viscosity was described. The results show that the viscosity of $\mathrm{CM}$ lower with lower concentrations of iodine $(240 \mathrm{mgl} / \mathrm{ml}$ and $300 \mathrm{mgl} / \mathrm{ml}$ ) was significantly lower compared to $\mathrm{CM}$ with higher concentrations of iodine $(370 \mathrm{mgl} / \mathrm{ml}$ and $400 \mathrm{mgl} / \mathrm{ml})$. Furthermore, pre-heating $\mathrm{CM}$ to body temperature drastically decreased the viscosity of $\mathrm{CM}$. In addition, the influence of different viscosity levels was investigated in circulation phantom, where CM was injection at different temperatures $\left(20-37^{\circ} \mathrm{C}\right)$. From these experiments, we could conclude that the injection pressure significantly decreased while using lower concentrated $\mathrm{CM}$ and, moreover, when injecting these concentrations at body temperature. Therefore, standardised pre-heating should be a prerequisite for clinical CM administration.

In Chapter 3 the potential for automated $k V p$-selection to reduce the radiation dose during CTA using different concentrated CM - normalised to an identical iodine delivery rate (IDR; $[\mathrm{gl} / \mathrm{s}]$ ) - was explored using a circulation phantom. The results showed that automated tube current modulation can result in radiation dose reduction up to $53 \%$ and automated tube voltage selection up to $77 \%$, if human subjects approximate the dimensions and therefore the attenuation values of the phantom used in the experiment. Furthermore, Dose reduction was - as expected - independent of the CM concentration applied at normalised IDR.

In Chapter 4 the influence of scan parameters - especially tube voltage [kVp] settings on intravascular enhancement in coronary CTA (CCTA) was investigated. A circulation phantom was used to systematically investigate how IDR and CM volume could be adapted to a particular kVp setting in order to remain optimal enhancement levels in the coronary arteries. These primary results were then also tested in sixty patients referred for CCTA. In a circulation phantom, lower kVp settings allowed a substantial reduction in $\mathrm{CM}$ volume - up to $56 \%$ at $70 \mathrm{kVp}$ - whilst maintaining diagnostically sufficient attenuation within the target vessels. Furthermore, initial results in patients confirmed this finding at $100 \mathrm{kVp}$ using $12 \%$ reduction of CM volume in CCTA.

In Chapter $\mathbf{5}$ the effect on image quality when using body weight adapted injections was studied in patients referred for CT pulmonary angiography (CTPA). The use of individualised $\mathrm{CM}$ protocols provided diagnostic and robust enhancement in emergency CTPA, as well as a substantial CM volume reduction in lower weight patients compared to a fixed CM protocol. Moreover, greater consistency of vascular enhancement 
values - indicating a more reliable protocol - was observed throughout the patients who received body weight adapted injections, whereas the scans for patients who received fixed injections showed a steady decline in attenuation with increasing body weight.

In Chapter 6 the role of individual adaptation of both injection and scan protocols based on patient's body mass index (BMI) was elaborated in patients referred for preTAVI CT examination. As these patients frequently suffer from an impaired renal function, the possibility of reducing CM volume while using lower kVp settings was investigated. The use of low $k V p(80 k V p$ and $70 k V p)$ scan protocols allowed for substantial reduction in $\mathrm{CM}$ volume as compared to common high volume injection protocols for pre-TAVI CT examinations. Sufficient image quality was maintained for the evaluation of the aortic root and peripheral access site despite a CM volume reduction of $34-67 \%$.

In Chapter $\mathbf{7}$ the possibility of reducing radiation dose exposure and CM volume was studied in patients referred for the evaluation of the aorta, as aortic CTA is associated with frequent follow-up over time, which implies high cumulative radiation dose and iodinated CM volume for these patients. It turned out that individualised CTA protocols based on the BMI of the patient are favourable for CTA of the whole aorta in routine clinical practice. Iterative reconstruction algorithms resulted in $23-57 \%$ less radiation in combination with $55-63 \%$ less contrast volume when compared to standard CT protocols. 

9.2

Valorisation 


\section{INTRODUCTION}

Computed tomographic angiography (CTA) is an imaging method which is widely used as a diagnostic tool for the visualisation and evaluation of various vascular structures. CTA has several advantages over other image modalities, for example because of its widespread availability and the short time required for image acquisition and processing. Furthermore, technology of CT imaging has undergone many changes in the past two decades; especially the advent of multidetector-row CT with high spatial and temporal resolution, wider detector coverage, increased rotation speed and iterative reconstruction improved image quality, resulting in improved visualisation of these various vascular structures. However, there are also potential drawbacks for CTA, including the administration of iodinated contrast media (CM) - which may cause allergic reactions or contrast induced nephropathy $(\mathrm{CIN})$ - as well as the use of ionising radiation dose due to the risk of stochastic effects.

Consequently, it is important to select CTA protocols where patients will benefit from individualised application of iodinated $\mathrm{CM}$ and radiation dose in order to use iodinated $\mathrm{CM}$ and radiation dose in a more efficient way and to reduce the general drawbacks for CTA.

\section{RELEVANCE OF SCIENTIFIC RESULTS}

This thesis addressed several topics on individual optimisation of $\mathrm{CM}$ volume and radiation dose for different CTA examinations. For a long time the injection and scan protocols were standardised, in order to ensure diagnostic image quality in all patients, on the basis of the vascular structure that needed to be scanned. This resulted in so-called "one size fits all" protocols, which means that every patient received the exact same amount of radiation dose and iodine. One can imagine that not every patient needs this amount of iodine and radiation dose, whereas other patients may need some more in order to maintain diagnostic image quality. It has already been described in literature that body weight and body mass index (BMI) significantly correlate with image quality; higher body weight and BMI will decrease intravascular enhancement and increase image noise, resulting in deterioration of image quality.

The results from this thesis showed that CM volume and radiation dose in CTA could be significantly reduced by individual adaptation of protocols with respect to body size of the patient and clinical indication for the scan. Therefore, we would advise to use individualised CTA protocols in current routine practice; minimising the possible adverse effects of iodine and radiation dose in patients. 


\section{TARGET GROUPS}

The results of this thesis are relevant for radiologists, and in particular, vascular radiologists as well as for the treating physicians in this case such as cardiologists, vascular surgeons and internists. For the treating physicians it could be important for decision making in the referral for CTA. Furthermore, patients who are referred for CTA and especially the relatively young patients and patients suffering from an impaired renal function can benefit from the individualised protocols.

\section{INNOVATION AND REALISATION}

This thesis first shows a standardised way of applying lower radiation dose on an individual basis, directly linking contrast parameters to radiation dose, and subsequently optimising contrast and dose settings. Eventually, there will be a lot of costs that can be saved because of the fact that the amount of CM can be drastically reduced in many cases.

It must be very clear that "one size fits all" protocols are outdated now. Obtaining diagnostic attenuation values using reduced $\mathrm{CM}$ volumes and radiation dose will play an important role in the future - especially due to the ongoing advancements in detector technologies. Newest CT technologies allow for even faster scanning as well as for the use of low tube voltages (e.g. 80 and $70 \mathrm{kVp}$ ) in a broader range of patients. Further research should focus on how to efficiently apply radiation dose and $\mathrm{CM}$ volume in all different routine CTA protocols using these newest CT technologies. 

9.3

Dankwoord 
Met heel veel plezier heb ik gewerkt aan dit proefschrift op de afdeling radiologie van het MUMC. Ik zou daarom graag iedereen willen bedanken voor de fijne samenwerking en daarnaast zijn er natuurlijk een aantal personen die ik in het bijzonder zou willen bedanken.

Prof. Wildberger, beste Joachim, ik kan me onze eerste echte afspraak nog goed herinneren; Ik was net klaar met mijn studie en stond op het punt om bij jullie van start te gaan met mijn promotieonderzoek, maar vlak daarvoor moesten we nog even grondig de revisions doorlopen van, bleek later, mijn eerste publicatie. Uiteraard hebben dit soort afspraken nog meerdere malen gevolgd en ben ik blij dat jij, met jouw kritische blik en tot in detail gegeven correcties, mijn promotor bent. Dank voor je steun in de afgelopen jaren en alle mogelijkheden die je me geboden hebt. Ik hoop in de toekomst onze research samenwerking voort te kunnen zetten.

Herr Dr. Das, beste Marco, jij bent toch wel echt mijn voorbeeld op het gebied van research, als ik dat zo mag noemen - een onuitputtelijke bron van ideeën, pragmatisch en bovenal efficiënt. Alhoewel ik me niet kan voorstellen dat ik ooit dezelfde hoeveelheid taken op me zou kunnen nemen als jij - dat multitasken heb je me (helaas) niet bij kunnen brengen - zijn er een hele hoop dingen die je me geleerd hebt en waar ik je ontzettend dankbaar voor ben. Buiten het vertrouwen dat je me hebt gegeven om onderzoek zelfstandig uit te voeren en jouw ideeën over hoe snel je "theoretisch" een artikel kunt schrijven, heb je me ook geleerd hoe je dit over kunt brengen op de volgende generatie onderzoekers. Niets was voor jou te veel, elk moment van de dag kon ik je aan je jas trekken en je lastigvallen met e-mails en vragen, zonder jouw intensieve begeleiding had ik het nooit gered in die twee jaar. Maar gelukkig ben jij van mening dat er na hard werken ook tijd is voor bier (+ Jägermeister, Ramazzotti und so weiter), dus ook zeker dank voor alle gezelligheid en je gastvrijheid in de afgelopen jaren.

Dr. Kietselaer, beste Bas, dank voor je begeleiding als imaging cardioloog. Je wist altijd onze radiologische blik weer even in de context te zetten van de klinische relevantie. Ondanks je drukte en begeleiding van andere promovendi wist je altijd snelle feedback te geven op onze manuscripten. Dank voor jouw kritische maar ook zeker positieve blik!

Sibel, mijn collega van cardiologie, kamer-buddy en paranimf. Met jou heb ik mogen samenwerken, koffiedrinken, lunchen en spuien over echt álles! Heel erg bedankt dat je mij op je kamer wilde hebben, ik heb het echt ervaren als een hele leuke tijd. We hebben heel veel gelachen, af en toe gejankt uit frustratie maar vooral veel lol gehad! Jij staat altijd klaar voor iedereen, of het nu werk gerelateerd is of niet. Ik wens je heel veel succes met het afronden van je promotie en de start van je opleiding tot cardio- 
loog, maar ik ben ervan overtuigd dat dat helemaal goed komt. Dank ook dat je mijn paranimf wil zijn en weet dat ik altijd voor je klaar sta!

Casper, jij bent degene die mij uiteindelijk in het onderzoek 'geluld' heeft, om het zo maar eens even uit te drukken. Ik kan me nog goed herinneren dat jij aan de coassistenten vroeg wie er naast radiologie ook geïnteresseerd was in cardiologie, waarop ik een volmondig "ja" antwoordde. Nog geen maand later zat ik met Marco om de tafel en was het plan voor mijn WESP-stage rond. In die tijd hebben een super leuk project gedaan met het fantoom, waarna er nog meerdere mochten volgen. Dank dat je mij enthousiast hebt gemaakt voor dit onderzoekstraject, anders was ik er waarschijnlijk nooit op gekomen. En dank voor de gezelligheid op ons kantoor, in de kroeg, op feestjes en je eeuwige urge om Sibel en mij te betrekken in je aandelen en hoe het allemaal werkt (ik snap er nog steeds niks van);-)

Babs, ik had geen beter persoon kunnen treffen om als eerste te begeleiden, dat ging eigenlijk gewoon vanzelf. Al snel lagen we op één lijn op meer gebieden dan alleen werk, dank voor je gezelligheid en vriendschap! Ik heb echt ontzettend leuke tijden gehad met jou, zowel hardlopend als spuiend over van alles en nog wat met een wijntje op de bank en niet te vergeten onze congressen in Wenen waarbij we het voor elkaar kregen om bijna het vliegtuig van $3 u$ 's middags te missen na een avondje stappen. Heel veel succes met het doorzetten van je promotie. Je bent een keiharde werker dus ik heb er alle vertrouwen in!

Nienke, wat vond ik het leuk om te zien hoe enthousiast jij raakte voor het vak tijdens je GEZP-stage. We kennen elkaar natuurlijk al ruim 6 jaar dus dat samenwerken ging eigenlijk meteen al van een leien dakje, maar ik ben blij dat je alles zo snel hebt opgepakt en het ook leuk vindt! Dank ook dat je in de laatste maanden mijn huisgenoot wilde zijn en voor alle gezellige avonden op de bank en in de kroeg. Ik wens je heel veel succes met je verdere promotie en ik blijf natuurlijk graag betrokken, dus ik zal zeker proberen regelmatig langs te komen.

De CT-laboranten en in het bijzonder Jeroen en Ralf. Jullie hebben het meeste geduld moeten hebben met mij. Avonden, zaterdagen, zondagen, niets was voor jullie te gek. Honderd+ scans maakten we op een dag, totdat we intussen zo op elkaar ingewerkt waren dat alleen de reconstructietijd en het afkoelen van de scanner nog de vertragende factoren waren. Dank voor jullie onuitputtelijke geduld en fijne samenwerking, ik ga jullie zeker missen! 
Alle coauteurs

Ik wil graag alle coauteurs bedanken voor alle moeite die jullie hebben genomen om een kritische blik te werpen op de manuscripten en de bijdrage die jullie geleverd hebben.

De dames van het secretariaat: Elfie, Monique, Christianne, Monique en Peggy. Dank dat jullie altijd weer bereid waren om administratieve zaken voor ons te regelen. $\mathrm{k}$ weet niet hoe vaak ik jullie pasjes heb moeten lenen om iets in te kunnen scannen. Maar dank ook voor jullie eeuwige vrolijkheid, gezellige intermezzo's op het secretariaat en de altijd gevulde snoeppot;-)

Angela, Bart en Tim, oftewel mijn semi-maatjes. Tijdens onze tijd als semiarts hebben we zeker een half jaar in één hok gezeten en dat was echt een mooie tijd. Ik ben er nog steeds verbaasd over dat we ondanks onze veelvoudige bezoekjes aan het bestuursgebouw - voor goede koffie, Youtube - voor hilarische filmpjes, en de ontelbare hoeveelheden Gouden Carolus tripel in de Falstaff, toch allemaal aan opleiding of promotie zijn begonnen ;-) Dank voor de leuke begintijd, jullie waren top collega's en ik zal jullie vast nog vaker tegenkomen.

Betina, ook jou heb ik leren kennen in het "cohok", jij schrijvend aan je eindscriptie en ik net startend met mijn eerste onderzoek. Na een aantal eindeloze avonden in café Zondag werden we elkaars eerste huisgenoten :) Daar hebben we supermooie avonden gehad en feestjes gevierd. Dank daarvoor en dank voor je vriendschap en het feit dat jouw deur altijd openstaat.

Anne, Mirjam, Moll, Muriël en Poodt. Ik denk dat niemand van jullie had gedacht dat deze altijd-met-jullie-aan-de-bar-hangende student ooit echt enthousiast zou raken over een vak, laat staan over het starten van een promotieonderzoek. We hebben de afgelopen jaren niet echt bij elkaar in de buurt gewoond en elkaar daardoor een stuk minder gezien, maar toch waren de schaarse vrijdagavonden altijd geniaal, met name als we weer eens in de Blender/Reinders of zelfs de Alla eindigden. Thanks dat jullie altijd hebben willen luisteren naar de beslommeringen rondom mijn veel te technische onderzoek, waar jullie waarschijnlijk niet echt iets van begrepen, maar waarin jullie toch altijd geïnteresseerd waren. Maar natuurlijk het meest bedankt voor jullie jarenlange vriendschap, ik woon intussen gelukkig weer wat dichterbij, dus ik stel voor dat we weer wat vaker aan de bar gaan hangen!

Tom, eerst vond ik jou de "Nerdie", later jij mij. Desalniettemin was jij meteen al mijn telefonische hulplijn bij het bouwen van die extreme Excel sheet, inclusief allerlei formules, voor mijn eerste project. Dank voor je steun, het meedenken en je altijd slimme 
oplossingen voor alles. Dank ook voor je eeuwige gastvrijheid in Amsterdam, de weekendjes Frankrijk en de winterportvakanties, je bent een top schoonbroer!

Claudia, Sis en vandaag ook mijn paranimf. Altijd heb jij over mij gewaakt als grote zus, ik was de wildebras en jij de verstandige. Toch zijn we altijd twee handen op een buik geweest en sinds jij het huis uit ging, hebben we tot op de dag van vandaag nog steeds dagelijks contact. Maar gelukkig kunnen we vanaf nu ook gewoon weer bij elkaar thuis aankloppen (:)

Jij bent in alle opzichten een enorme steun en kort gezegd ben ik gewoon ongelofelijk trots dat jij mijn zus en vandaag ook mijn paranimf bent!

Pap en mam, dank voor jullie onvoorwaardelijke vertrouwen in mij. Jullie hebben me echt ontzettend gesteund bij het maken van al mijn keuzes in de afgelopen jaren, waarbij jullie mij steeds de ruimte gaven om net zo lang van me af te praten totdat ik zelf tot de conclusie kwam dat ik mijn keuze eigenlijk al gemaakt had...Tja, jullie kennen me immers langer dan vandaag. Nu heb ik ook het zonnige zuiden verlaten, maar ik hoop dat jullie langzaam weer meer bij ons in de buurt komen wonen!

Lieve Joshua, jij bent de rust zelve, altijd in staat om te relativeren en daardoor mijn ultieme held! Altijd weer sta je voor mij klaar, van het paniekmoment - in een van mijn eerste maanden - waarin ik jou een rekenmachine in je hand duwde om alle waardes opnieuw uit te rekenen tot de laatste maanden van mijn promotie waarin ik je vroeg al mijn hoofdstukken eens even kritisch te beoordelen. Dank voor alles wat je voor mij gedaan hebt, ik hoop dat ik hetzelfde nog een keer voor jou kan betekenen in de toekomst! 

9.4

Curriculum vitae 
Madeleine Kok was born the 30th of April 1988 in Amsterdam, the Netherlands. She grew up in Beek and finished her secondary school in Geleen. After secondary school, she started her medical training at Maastricht University in 2006. In her final year as a student she became involved with Dr. Das and Prof. dr. Wildberger's research regarding the use of contrast media in computed tomographic angiography. After obtaining her medical degree in October 2013 she became a PhD fellow under supervision of Prof. dr. Wildberger, Dr. Das and Dr. Kietselaer, focusing on the optimisation of contrast media and radiation dose for the individual patient. She presented her work at several national and international conferences. The most important results are described in this thesis. While completing her PhD, she assisted and trained new students who became members of the research team. From February 2016 Madeleine is working as a resident in Radiology at the University Medical Centre in Utrecht under supervision of Dr. R.A.J. Nievelstein. 


9.5

List of publications 


\section{THIS THESIS}

Kok M, Turek J, Mihl C, Reinartz SD, Gohmann RF, Nijssen EC, Kats S, van Ommen VG, Kietselaer BLJ, Wildberger JE, Das M. Low contrast media volume in pre-TAVI CT examinations. Eur Radiol. 2016 Aug;26(8):2426-35.

Kok M, Mihl C, Hendriks BMF, Altintas S, Kietselaer BLH, Wildberger JE, Das M. Optimizing contrast media application in CT angiography at lower tube voltage: evaluation in a circulation phantom and sixty patients. Eur J Radiol. 2016 Jun;85(6):1068-74.

Hendriks BMF, Kok M, Mihl C, Bekkers SC, Wildberger JE, Das M. Individually tailored contrast enhancement in CT pulmonary angiography. Br J Radiol. 2016 May;89(1061).

Kok M, de Haan MW, Mihl C, Eijsvoogel NG, Hendriks BMF, Sailer AM, Derks K, Schnerr RS, Schurink GW, Wildberger JE, Das M. Individualized CT angiography protocols for the evaluation of the aorta: A feasibility study. J Vasc Interv Radiol. 2016 Apr;27(4):531-8.

Kok M, Mihl C, Seehofnerová A, Turek J, Jost G, Pietsch H, Haberland U, Wildberger JE, Das M. Automated Tube Voltage Selection for Radiation Dose Reduction in CT Angiography Using Different Contrast Media Concentrations and a Constant lodine Delivery Rate. AJR Am J Roentgenol. 2015 Dec;205(6):1332-8.

Kok M, Mihl C, Mingels AM, Kietselaer BLJH, Mühlenbruch G, Seehofnerová A, Wildberger JE, Das $M$. Influence of contrast media viscosity and temperature on injection pressure in computed tomographic angiography: a phantom study. Invest Radiol. 2014 Apr;49(4):217-23. 


\section{OTHER}

Kok M, Mihl C, Hendriks BMF, Altintas S, Eijsvoogel NG, Kietselaer BLJH, Wildberger JE, Das M. Patient comfort during contrast media injection in coronary CT angiography using varying contrast media concentrations and flow rates - results from the EICAR trial. Invest Radiol. 2016 May 10. Epub ahead of print.

Mihl C, Kok M, Altintas S, Kietselaer BL, Turek J, Wildberger JE, Das M. Comparison of individual contrast application versus fixed volume injection and its effects on image quality in coronary CT-angiography. Eur J Radiol. 2016 Apr;85(4):830-6.

Mihl C, Kok M, Wildberger JE, Altintas S, Labus D, Nijssen EC, Hendriks BM, Kietselaer $\mathrm{BL}$, Das M. Coronary CT angiography using low concentrated contrast media injected with high flow rates: Feasible in clinical practice. Eur J Radiol. 2015 Nov; 84(11):215560 .

Kok M, Kietselaer BL, Mihl C, Altintas S, Nijssen EC, Wildberger JE, Das M. Contrast Enhancement of the Right Ventricle during Coronary CT Angiography--Is It Necessary? PLoS One. 2015 Jun 1;10(6):e0128625

Mihl C, Kok M, Wildberger JE, Turek J, Muehlenbruch G, Das M. Computed Tomography Angiography With High Flow Rates: An In Vitro and In Vivo Feasibility Study. Invest Radiol. 2015 Jul;50(7):464-9

Jurencak T, Turek J, Kietselaer BL, Mihl C, Kok M, van Ommen VG, van Garsse LA, Nijssen EC, Wildberger JE, Das M. MDCT evaluation of aortic root and aortic valve prior to TAVI. What is the optimal imaging time point in the cardiac cycle? Eur Radiol. 2015 Jul;25(7):1975-83.

Seehofnerová A, Kok M, Mihl C, Douwes D, Sailer AM, Nijssen EC, de Haan MW, Wildberger JE, Das M. Feasibility of low contrast media volume in $\mathrm{CT}$ angiography of the aorta. Eur J Radiol Open. 2015;2:58-65 
